\title{
Heterogenisation of polyoxometalates and other metal-based complexes in metal-organic frameworks: from synthesis to characterisations and applications in catalysis
}

\author{
P. Mialane, ${ }^{a}$ C. Mellot-Draznieks, ${ }^{b}$ P. Gairola, ${ }^{a}$ M. Duguet, ${ }^{a, b}$ Y. Benseghir, ${ }^{a, b}$ O. Oms ${ }^{a}$ and A. \\ Dolbecq*a
}

\begin{abstract}
These last years have seen a huge growing interest in the heterogenisation of molecular catalysts since it allows combining the advantages of homogeneous and heterogeneous catalysis. Besides bringing recyclability, the immobilisation of the catalyst may increase its stability while allowing tuning its selectivity. In this respect, Metal-Organic Frameworks (MOFs) attract an evergrowing interest as a platform for their confinement within their pores or channels. In this review, Cat@MOF composites whereby molecular catalysts (Cats) are immobilised in MOFs through non-covalent interactions with their host, are reviewed thoroughly. Polyoxometalates (POMs) and other metal-based complexes as immobilised molecular species are covered. In the first part, the different synthetic methods and analytical tools are described. A critical analysis of the various physico-chemical methods available to characterise the Cat@MOF composites is provided - a particular attention being paid toward their pertinence for the investigation of the content, the position and the stability of the catalyst within the MOF. Besides, focus is made on non-conventional techniques such as Pair Distribution Function (PDF) and a section is dedicated to the contribution of DFT calculations. In the second part, the applications of these materials in the fields of catalysis, including oxidation and reduction reactions, acid-base catalysis, photo- and electrocatalysis are detailed.
\end{abstract}

\section{Introduction}

Metal-containing molecular species continue to be tremendously studied as homogeneous catalysts. Although most-efficient molecular catalysts are based on noble metals (Pt, Re, Ru, Ir), several classes of noble metal-free catalysts, such as simple earth-abundant coordination metal complexes or polyoxometalates (POMs), covering a large range of catalysis fields, have also been reported. POMs are discrete soluble anionic metal oxide clusters of $d$-block transition metals in high oxidation states (usually $\mathrm{W}^{\mathrm{VI}}, \mathrm{Mo}^{\mathrm{V}, \mathrm{VI}}, \mathrm{V}^{\mathrm{I}, \mathrm{V}} \mathrm{V}$ ) which can be described as metal complexes with oxo ligands with a large domain of applications. ${ }^{1.2}$ In homogenous catalysis, one major drawback of molecular catalysts is their low stability under catalytic conditions as well as their small surface areas. Furthermore, both the recovery and reuse of these molecular catalysts are generally difficult due to their high solubility in polar solvents, associated with the difficulty of their separation from the products. Their immobilization in rigid matrices such as Metal-Organic Frameworks (MOFs) has thus emerged in the recent years as an attractive strategy to address these drawbacks and develop heterogenous catalytic composites. MOFs are a vast class of porous hybrid organic-inorganic crystalline solids built from the connection of metallic ions or clusters by polydentate organic linkers. They have recently proved to be an extremely attractive platform for catalysis, ${ }^{3}$ with a number of key advantages: i) their modular porosity allows the diffusion of reactants and products, ii) their versatile chemical functionalization allows 'design' strategies, iii) they offer improved stability and recyclability unreached so far with homogeneous catalysts and iv) their crystalline structures facilitate computational and theoretical approaches. In this review, we will give an overview of the composite materials obtained by the immobilisation of known molecular catalysts in the cavities of known MOFs, denominated Cat@MOFs. The vast majority of such Cat@MOFs composites reported so far involves mainly POMs but also organometallic and coordination complexes. The present review thus covers these different types of guests, excluding the immobilisation of organic molecules or nanoparticles. We have also excluded hybrid frameworks that do not exist in the absence of their Cat guests, since they may not be considered as genuine heterogenisation platforms. We will also not review catalytic species covalently grafted to the MOF host, either to its linkers or to its inorganic nodes. ${ }^{4-7}$ Here, we will rather focus on pore-functionalized MOF composites, thus involving non-covalent interactions between the hosted moieties and the MOF. One of the first reviews on this subject was written in 2012 by Juan-Alcañiz et al. and covered all the composite materials possessing encapsulated active species ranging from nanoparticles to organometallic species and POMs. ${ }^{8}$ Since then the literature on the subject has greatly increased and some recent reviews have been published on the specific sub-family of POM@MOFs as heterogeneous catalysts. ${ }^{9,10}$ We can also mention reviews on POMs and MOFbased electrocatalysts, ${ }^{11}$ on POM-based MOF materials ${ }^{12}$ and on POM-functionalized architectures ${ }^{13}$ which have devoted a section to POM@MOFs. A number of reviews on MOFs also propose a section dedicated to the immobilisation of molecular catalysts. ${ }^{14,15,16}$ Nonetheless, none of these reviews proposes an exhaustive state of the art of Cat@MOFs materials as defined above neither a critical analysis of all the characterisation tools available ranging from routine solid state techniques to the 
more sophisticated ones. After a comprehensive list of the Cat@MOF compounds reported in the literature in the form of two tables, one for POM@MOFs and the other for Complex@MOFs and a description of the various synthetic methods, we will deliver a critical discussion on the physicochemical methods available to characterize these composites and of their pertinence for investigating the content, the structural features (including the positioning of the catalyst in the MOF) and the stability of the catalyst within the MOF or of the MOF itself. We will focus on growingly used methods such as pair distribution function (PDF) and difference envelope density (DED) analysis and we will give a perspective on how DFT calculations can bring valuable information. Finally, we will present the applications of these materials in the field of catalysis, including oxidation and reduction reactions, acid-base catalysis, photo- and electrocatalysis.

\section{Synthesis of Cat@MOF composites}

A list of the various Cat@MOFs systems synthesized is gathered in two distinct Tables. The POM@MOF composites are listed in Table 1 with the formula of the POM, the weight \% in catalyst when indicated in the related article, the synthetic method used, including the nature of the solvent, the temperature and the catalytic application considered. Table 2 is dedicated to other types of Complex@MOFs materials. In both tables, the composites are listed according to the MOF-host family. We have also included some references on POM@MOFs and Complex@MOFs with no reported applications when they were useful for the discussion on synthesis or characterization.

\subsection{Presentation of the host and guest components}

MOFs can offer many advantages such as thermal and chemical stability, high surface areas with hierarchical porosity and the possibility to accommodate catalytic guests into their cages or channels. Analysing Tables 1 and 2, it is apparent that MIL$101(\mathrm{Cr})$ MOF has been by far the most studied porous hybrid solid for hosting Cat species. This may be explained by its facile and effective synthesis in water, its high stability and extra-large cavities (see below). However, the presence of chromium ions - considered as one of the most toxic metal ions - is a significant drawback. MIL-100(Fe) and $\mathrm{NH}_{2}-\mathrm{MIL}-101$ (Al) have thus also been largely investigated as alternative hosts. Furthermore, $\mathrm{Zr}$ based MOFs appear more eco-friendly and among them, UiO66 and 67 are the most commonly represented in literature along with MOF-545 and NU-1000. Finally, HKUST-1 (mostly Cubased) and Zn-based ZIF-8 are also highly popular host. Representation of the main MOFs presented in this review with their formulas and the dimensions of their cavities is given in Fig. 1, followed below by a short description of their structure and stability. Obviously, both the MOF's structure and stability are key parameters to take into account when selecting a MOF as a platform to target the immobilization of catalytic species.

$\left(\mathrm{NH}_{2-}\right)$ MIL-101(M) (M = Cr'III, Fe $\left.{ }^{\mathrm{III}}, \mathrm{Al}^{\prime \prime \prime}\right)^{17}$ is built of $\mathrm{M}^{\prime \prime \prime}$ trimers made of corner-sharing octahedra connected by benzenedicarboxylate (BDC) linkers, leading to the general formula $\mathrm{M}_{3} \mathrm{O}(\mathrm{BDC})_{3}\left(\mathrm{H}_{2} \mathrm{O}\right)_{2} \mathrm{X}\left(\mathrm{X}=\mathrm{F}, \mathrm{Cl}, \mathrm{NO}_{3}, \mathrm{OH}, \ldots\right) .{ }^{18}$ Four metal trimers are linked together by $\mathrm{BDC}$ forming supertetrahedra (ST) interconnected in a corner-sharing fashion to form a hybrid framework with the MTN zeotype topology. ${ }^{19,20}$ The resulting crystal structure displays two types of mesoporous spherical cages. The smallest ones (20 ST) have an internal free diameter of $\sim 29 \AA$ and are delimited by 12 pentagonal windows of $\sim 12 \AA$ free aperture. The largest cages (28 ST) have an internal free diameter of $34 \AA$ and both pentagonal and hexagonal windows, the latter having an aperture of $14.7 \AA ̊ .16 \AA .{ }^{17} \mathrm{MIL}-101$ (M) has a gigantic cell volume of $702000 \AA^{3}$ and a BET surface area up to $4500 \mathrm{~m}^{2} \cdot \mathrm{g}^{-1}$ upon solvent removal allowing the hosting of large molecules. Moreover, functionalized MIL-101(M) may be easily obtained via direct use in the synthesis of BDC linkers bearing functional groups $\left(-\mathrm{NH}_{2},-\mathrm{NO}_{2},-\mathrm{SO}_{3}\right.$ or other functions), ${ }^{21}$ or via post-synthetic ligand modifications. ${ }^{22}$ MIL$101(\mathrm{M})$ 's stability is highly correlated to the nature of its metal centres and of the BDC's functional groups. While MIL-101(Cr) is highly resistant to water (as solvent, moisture or even steam) and can last several days in boiling water without any structural degradation, MIL-101(Fe) and (Al) homologues show much lower stabilities toward hydrolysis, with for example $\mathrm{NH}_{2}-\mathrm{MIL}-$ 101 (Al) transforming into the more thermodynamically stable $\mathrm{NH}_{2}$-MIL-53(Al) after only 5 min exposure to water. ${ }^{23}$ MIL$101(\mathrm{Cr})$ is also stable to acidic and basic conditions for several weeks and resilient to oxidative conditions $\left(5 \% \mathrm{H}_{2} \mathrm{O}_{2}\right)$ for a few days. Again, the Al homologue shows in contrast a poor stability toward acidic or basic conditions, with partial transformation into MIL-53 and high loss of porosity. ${ }^{24}$

MIL-100,25,26 formulated as $\mathrm{M}_{3} \mathrm{O}(\mathrm{BTC})_{2}\left(\mathrm{H}_{2} \mathrm{O}\right)_{2} \mathrm{X}(\mathrm{X}=\mathrm{F}, \mathrm{Cl}$, $\mathrm{OH}, \ldots ; \mathrm{M}=\mathrm{Al}, \mathrm{Fe}, \mathrm{Cr}$ ) possesses the same topology than MIL-101 with a smaller cell volume of $\sim 380000 \AA^{3}$, i.e. built of trimers of conner-sharing metal octahedra connected by benzenetricarboxylate (BTC) linkers (rather than BDC in MIL101). The smallest cages have an internal diameter of $25 \AA$ and pentagonal windows of ca. $5 \AA$. The largest cages display an internal diameter of $29 \AA$ and hexagonal windows with a free aperture of $8.6 \AA$. Those two types of cages allow a large surface area of $3100 \mathrm{~m}^{2} \cdot \mathrm{g}^{-1}$. MIL-100 displays high water stability and no degradation after $24 \mathrm{~h}$ at $323 \mathrm{~K} .{ }^{27} \mathrm{It}$ is stable in most solvents. Still, its thermal stability is highly linked to the metal node's nature, the solid being stable up to 270,325 and $370^{\circ} \mathrm{C}$ for MIL100(Fe), MIL-100(Cr) and MIL-100(Al), respectively. ${ }^{28}$ However, Bezverkhyy et al. have shown that MIL-100(Fe) is stable mainly in acidic $\mathrm{pH}$ and starts degrading at $\mathrm{pH} 7 .{ }^{29}$

UiO-66 $\left(\mathrm{Zr}_{6} \mathrm{O}_{4}(\mathrm{OH})_{4}(\mathrm{BDC})_{6}\right)$ is one of the most studied $\mathrm{Zr}$ based MOF, attracting also much interest due to its tunable defective structure. First synthetized in $2008,{ }^{24}$ it consists in $\mathrm{Zr}_{6}$ oxoclusters connected by BDC linkers, forming octahedral mesoporous cages with a diameter of $11 \AA$ and tetrahedral cages of 8 $\AA$ internal diameter. The BET surface area is 1200 $\mathrm{m}^{2}$. $\mathrm{g}^{-1}$. Similarly to MIL-101, the functionalization of the BDC 


\section{ARTICLE}

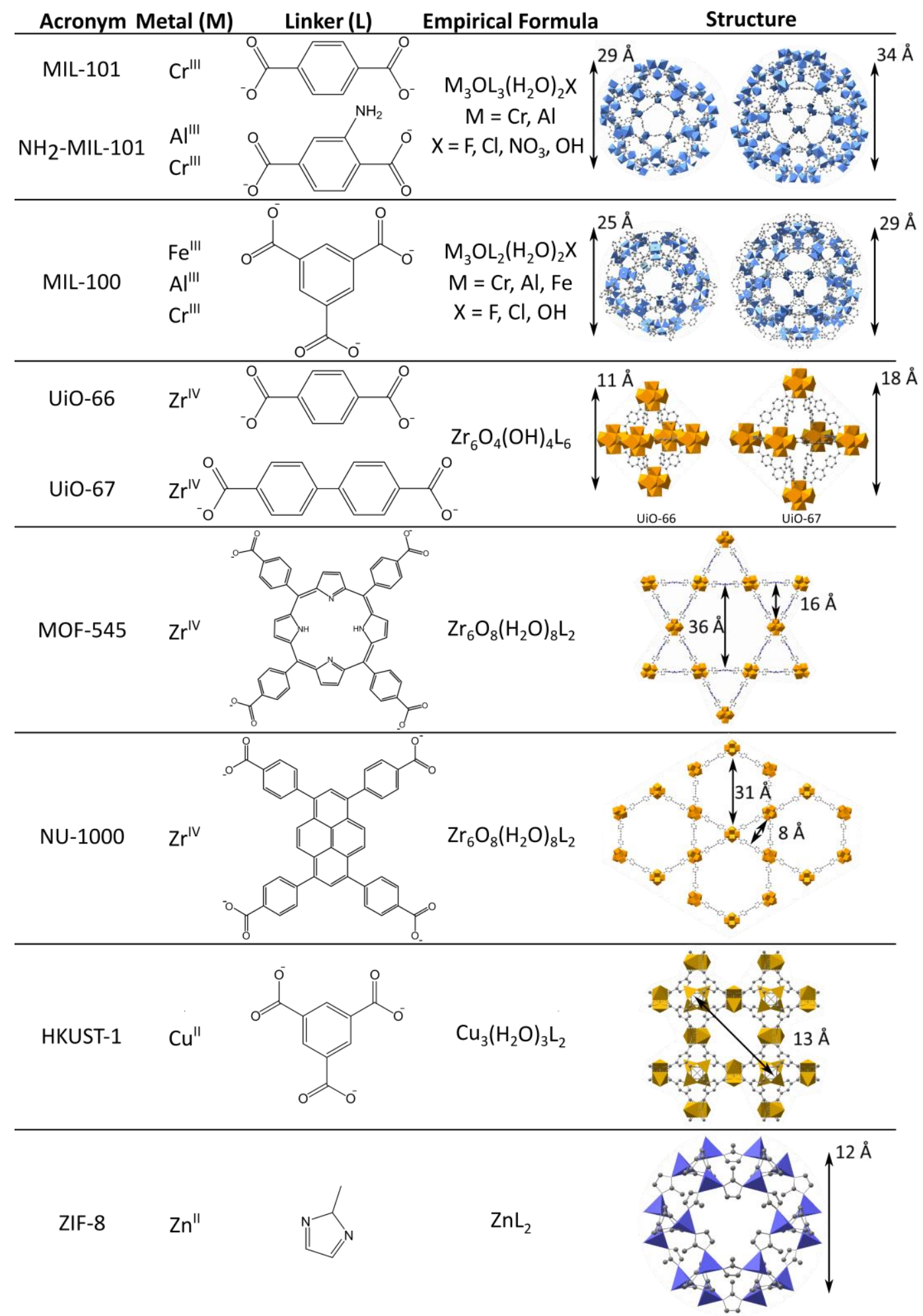

Fig. 1 Representation of the structures of the main MOF hosts reported in this review with the dimensions of the cavities, the linker's and MOF's formulas. 


\section{ARTICLE}

Table 1. Overview of reported POM@MOF composites.

\begin{tabular}{|c|c|c|c|c|c|c|c|}
\hline MOF & POM precursor & $\mathrm{wt} \%$ & $\begin{array}{l}\text { Synthetic } \\
\text { method }^{a}\end{array}$ & Solvent, $\mathrm{T}$, time & Applications & $\begin{array}{l}\text { Reactants, solvent, } \mathrm{T} \text { for the } \\
\text { catalytic reaction }\end{array}$ & $\begin{array}{l}\text { Corresponding authors, } \\
\text { year, ref. }\end{array}$ \\
\hline \multirow[t]{17}{*}{ MIL-101(Cr) } & $\mathrm{H}_{3} \mathrm{PW}_{4} \mathrm{O}_{24}$ & $5-14$ & $\operatorname{Imp}$ & $\mathrm{H}_{2} \mathrm{O} / \mathrm{H}_{2} \mathrm{O}_{2}, \mathrm{RT}, 3 \mathrm{~h}$ & Alkene epoxidation & $\mathrm{H}_{2} \mathrm{O}_{2}, \mathrm{CH}_{3} \mathrm{CN}, 50^{\circ} \mathrm{C}$ & Kholdeeva, 2010, ${ }^{30}$ \\
\hline & $(\mathrm{BTBA})_{4} \mathrm{H}\left[\mathrm{BW}_{4} \mathrm{O}_{24}\right]$ & & Imp & $\mathrm{CH}_{3} \mathrm{CN}, \mathrm{RT}, 24 \mathrm{~h}$ & Geraniol oxidation & $\mathrm{H}_{2} \mathrm{O}_{2}, \mathrm{CH}_{3} \mathrm{CN}, \mathrm{RT}$ & Santos, $2013,{ }^{31}$ \\
\hline & $\mathrm{Na} 9\left[\mathrm{PW}_{9} \mathrm{O}_{34}\right]$ & & $\operatorname{Imp}$ & $\mathrm{H}_{2} \mathrm{O}, \mathrm{RT}, 24 \mathrm{~h}$ & $\begin{array}{l}\text { Oxidation of monoterpenes } \\
\text { ODS }\end{array}$ & $\begin{array}{l}\mathrm{H}_{2} \mathrm{O}_{2}, \mathrm{CH}_{3} \mathrm{CN}, 80^{\circ} \mathrm{C} \\
\text { Model oil } / \mathrm{CH}_{3} \mathrm{CN}, 50^{\circ} \mathrm{C}\end{array}$ & $\begin{array}{l}\text { Cunha-Silva, Balula, } \\
2014,{ }^{32}\end{array}$ \\
\hline & $\mathrm{TBA}_{5}\left[\mathrm{PZnMo}_{2} \mathrm{~W}_{9} \mathrm{O}_{39}\right]$ & & $\operatorname{Imp}$ & $\mathrm{CH}_{3} \mathrm{CN}, \mathrm{RT}, 6 \mathrm{~h}$ & Alkene oxidation & $\mathrm{H}_{2} \mathrm{O}_{2}, \mathrm{CH}_{3} \mathrm{CN}, 70^{\circ} \mathrm{C}$ & $\begin{array}{l}\text { Tangestaninejad, } \\
\text { Moghadam, 2012, }\end{array}$ \\
\hline & $\mathrm{K}_{7}\left[\mathrm{PW}_{11} \mathrm{O}_{39}\right]$ & $\sim 35$ & Imp & $\mathrm{H}_{2} \mathrm{O}, \mathrm{RT}, 2 \mathrm{~h}$ & - & - & Ferey, $2005,{ }^{17}$ \\
\hline & $\mathrm{K}_{7}\left[\mathrm{PW}_{11} \mathrm{O}_{39}\right], \mathrm{K}_{8}\left[\mathrm{SiW}_{11} \mathrm{O}_{39}\right]$ & $15-20$ & $\operatorname{Imp}$ & $\mathrm{H}_{2} \mathrm{O}, \mathrm{RT}, 24 \mathrm{~h}$ & Alkene epoxidation & $\mathrm{H}_{2} \mathrm{O}_{2}, \mathrm{CH}_{3} \mathrm{CN}, 75^{\circ} \mathrm{C}$ & $\begin{array}{l}\text { Cunha-Silva, Balula, } \\
2013^{34}\end{array}$ \\
\hline & $(\mathrm{TBA})_{4} \mathrm{H}\left[\mathrm{PW}{ }_{11} \mathrm{CoO}_{39}\left(\mathrm{H}_{2} \mathrm{O}\right)\right]$ & 7 & Imp & $\mathrm{CH}_{3} \mathrm{CN}, \mathrm{RT}, 12 \mathrm{~h}$ & Alkene epoxidation & $\mathrm{O}_{2}, \mathrm{CH}_{3} \mathrm{CN}, 50^{\circ} \mathrm{C}$ & Kholdeeva, 2008, ${ }^{36}$ \\
\hline & $\mathrm{NaH}_{4}\left[\mathrm{PW}_{11} \mathrm{TiO}_{40}\right]$ & 10 & Imp & $\mathrm{CH}_{3} \mathrm{CN}, \mathrm{RT}, 12 \mathrm{~h}$ & Alkene epoxidation & $\mathrm{H}_{2} \mathrm{O}_{2}, \mathrm{CH}_{3} \mathrm{CN}, 70^{\circ} \mathrm{C}, 50^{\circ} \mathrm{C}, 30^{\circ} \mathrm{C}$ & Kholdeeva, 2008, ${ }^{36}$ \\
\hline & $(\mathrm{TBA})_{4} \mathrm{H}\left[\mathrm{SiW}_{11} \mathrm{FeO}_{39}\left(\mathrm{H}_{2} \mathrm{O}\right)\right]$ & & $\operatorname{Imp}$ & $\mathrm{CH}_{3} \mathrm{CN}, \mathrm{RT}, 24 \mathrm{~h}$ & $\begin{array}{l}\text { Electrocatalytic nitrite and iodate } \\
\text { reduction, ascorbic acid oxidation }\end{array}$ & $\mathrm{H}_{2} \mathrm{SO}_{4} / \mathrm{Na}_{2} \mathrm{SO}_{4}$ buffer ( $\left.\mathrm{pH} 2.5\right), \mathrm{RT}$ & $\begin{array}{l}\text { Fernandes, Balula, Freire, } \\
2014,{ }^{37}\end{array}$ \\
\hline & $\mathrm{Cs}_{5}\left[\mathrm{PW}_{11} \mathrm{CoO}_{39}\left(\mathrm{H}_{2} \mathrm{O}\right)\right]$ & & $\operatorname{Imp}$ & $\mathrm{H}_{2} \mathrm{O}, \mathrm{RT}, 24 \mathrm{~h}$ & - & - & $\begin{array}{l}\text { Roch-Marchal, Dolbecq, } \\
2014,43^{38}\end{array}$ \\
\hline & 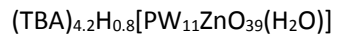 & & Imp & $\mathrm{CH}_{3} \mathrm{CN}, \mathrm{RT}, 72 \mathrm{~h}$ & ODS (DBT, 1-BT, 4,6-DMDBT) & $\mathrm{H}_{2} \mathrm{O}_{2}, \mathrm{BMIMPF}_{6} / \mathrm{CH}_{3} \mathrm{CN}, 50^{\circ} \mathrm{C}$ & Balula, 2015, ${ }^{39}$ \\
\hline & $\begin{array}{l}\mathrm{K}_{4} \mathrm{PW}_{11} \mathrm{VO}_{40}, \mathrm{H}_{3} \mathrm{PW}_{12} \mathrm{O}_{40} \\
\mathrm{~K}_{4} \mathrm{SiW}_{12} \mathrm{O}_{40}\end{array}$ & & SE & $\mathrm{H}_{2} \mathrm{O}, 180^{\circ} \mathrm{C}, 72 \mathrm{~h}$ & Dye adsorption & & Yao, Zhang, Wang, 2014, ${ }^{40}$ \\
\hline & $\mathrm{H}_{3} \mathrm{PW}_{12} \mathrm{O}_{40}$ & $\begin{array}{l}10,20 \\
50\end{array}$ & $\begin{array}{l}\text { SE } \\
\text { Imp }\end{array}$ & $\begin{array}{l}\mathrm{H}_{2} \mathrm{O}, 200-210^{\circ} \mathrm{C}, 8 \\
h\end{array}$ & $\begin{array}{l}\text { Knoevenagel condensation of } \\
\text { benzaledhyde with }\end{array}$ & $\mathrm{DMF}$, toluene, $\mathrm{EtOH}, 40^{\circ} \mathrm{C}$ & Gascon, 2010, ${ }^{41}$ \\
\hline & & & & $\mathrm{H}_{2} \mathrm{O}, \mathrm{RT}, 12 \mathrm{~h}$ & $\begin{array}{l}\text { ethylcyanoacetate, } \\
\text { Esterification of acetic acid, } \\
\text { dehydration of } \mathrm{MeOH}\end{array}$ & No solvent, $110^{\circ} \mathrm{C}$ & \\
\hline & & & & & $\begin{array}{l}\text { Dehydration of } \mathrm{MeOH} \text { with } \\
\text { ethylcyanoacetate }\end{array}$ & Vapour phase & \\
\hline & $\mathrm{H}_{3} \mathrm{PW}_{12} \mathrm{O}_{40}$ & $10-30$ & SE & $\mathrm{H}_{2} \mathrm{O}, 220^{\circ} \mathrm{C}, 8 \mathrm{~h}$ & $\begin{array}{l}\text { Selective dehydration of fructose } \\
\text { and glucose }\end{array}$ & $\begin{array}{l}\text { 1-ethyl-3-methylimidazolium } \\
\text { chloride, } 80^{\circ} \mathrm{C} \text { and } 100^{\circ} \mathrm{C}\end{array}$ & Li, Hensen, 2011, ${ }^{42}$ \\
\hline & $\mathrm{H}_{3} \mathrm{PW}_{12} \mathrm{O}_{40}$ & & $\begin{array}{l}\text { SE } \\
\text { Imp }\end{array}$ & $\begin{array}{l}\mathrm{H}_{2} \mathrm{O}, 218^{\circ} \mathrm{C}, 18 \mathrm{~h} \\
\mathrm{H}_{2} \mathrm{O}, \mathrm{RT} 48 \mathrm{~h}\end{array}$ & Aldehyde-alcohol condensation & THF-d8, $25-55^{\circ} \mathrm{C}$ & Hatton, $2011{ }^{43}$ \\
\hline
\end{tabular}


$\mathrm{H}_{3} \mathrm{PW}_{12} \mathrm{O}_{40}$

$\mathrm{H}_{3} \mathrm{PW}_{12} \mathrm{O}_{40}$

(TBA) ${ }_{3} \mathrm{PW}_{12} \mathrm{O}_{4}$

$\mathrm{H}_{3} \mathrm{PW}_{12} \mathrm{O}_{40}$

$\mathrm{H}_{3} \mathrm{PW}_{12} \mathrm{O}_{40}$

$\mathrm{H}_{3} \mathrm{PW}_{12} \mathrm{O}_{40}$

$\mathrm{H}_{3} \mathrm{PW}_{12} \mathrm{O}_{40}$

$\mathrm{H}_{3} \mathrm{PW}_{12} \mathrm{O}_{40}+\mathrm{RhH}(\mathrm{CO})\left(\mathrm{PPh}_{3}\right)_{3}$

$\mathrm{H}_{3} \mathrm{PW}_{12} \mathrm{O}_{40}$

$\mathrm{H}_{3} \mathrm{PW}_{12} \mathrm{O}_{40}+\mathrm{ILS}$

$\mathrm{H}_{3} \mathrm{PW}_{12} \mathrm{O}_{40}$

$\mathrm{H}_{3} \mathrm{PW}_{12} \mathrm{O}_{40}+$ diatomite

$\mathrm{K}_{6} \mathrm{CoW}_{12} \mathrm{O}_{40}, \mathrm{Na}_{6} \mathrm{H}_{2} \mathrm{~W}_{12} \mathrm{O}_{40}$

$\mathrm{K}_{5} \mathrm{CoW}_{12} \mathrm{O}_{40}$

$\mathrm{K}_{6} \mathrm{CoW}_{12} \mathrm{O}_{40}$

$\mathrm{K}_{8} \mathrm{H}\left[\mathrm{P}_{2} \mathrm{~W}_{15} \mathrm{~V}_{3} \mathrm{O}_{62}\right]$,

$\mathrm{K}_{8}\left[\mathrm{P}_{2} \mathrm{~W}_{17} \mathrm{Ni}_{2}\left(\mathrm{H}_{2} \mathrm{O}\right) \mathrm{O}_{61}\right]$

$\mathrm{K}_{8}\left[\mathrm{P}_{2} \mathrm{~W}_{17} \mathrm{Co}\left(\mathrm{H}_{2} \mathrm{O}\right) \mathrm{O}_{61}\right]+$

$\mathrm{Ru}(\mathrm{bpy})_{3} \mathrm{Cl}_{2}$

$\mathrm{K}_{6} \mathrm{P}_{2} \mathrm{~W}_{18} \mathrm{O}_{62}+\mathrm{Fe}_{3} \mathrm{O}_{4}$

$\mathrm{K}_{11} \mathrm{H}\left[\left(\mathrm{PW}_{9} \mathrm{O}_{34}\right)_{2}\left(\mathrm{HOSn}{ }^{\mathrm{V}} \mathrm{OH}\right)_{3}\right]$

$\mathrm{K}_{9}\left(\mathrm{NH}_{4}\right)_{2}\left[\left(\mathrm{PW}_{9} \mathrm{O}_{34}\right)_{2}\left(\mathrm{OCe}^{\mathrm{lV}} \mathrm{O}\right)_{3}\right.$

(TBA $)_{7} \mathrm{H}_{3}\left[\left(\mathrm{PW}_{9} \mathrm{O}_{34}\right)_{2} \mathrm{CO}_{4}\left(\mathrm{H}_{2} \mathrm{O}\right)_{2}\right]$

$\mathrm{K}_{10}\left[\left(\mathrm{PW}_{9} \mathrm{O}_{34}\right)_{2} \mathrm{CO}_{4}\left(\mathrm{H}_{2} \mathrm{O}\right)_{2}\right]$

$\mathrm{Na}_{10}\left[\left(\mathrm{PW}_{9} \mathrm{O}_{34}\right)_{2} \mathrm{CO}_{4}\left(\mathrm{H}_{2} \mathrm{O}\right)_{2}\right]$

$\mathrm{K}_{11}\left[\mathrm{Ln}\left(\mathrm{PW}_{11} \mathrm{O}_{39}\right)_{2}\right](\mathrm{Ln}=\mathrm{Eu}$,
$\mathrm{H}_{2} \mathrm{O}, 218^{\circ} \mathrm{C}, 18 \mathrm{~h} \quad$ Baeyer condensation of

$\mathrm{H}_{2} \mathrm{O}, \mathrm{RT}, 48 \mathrm{~h}$

benzaldehyde and 2-naphtol,

Epoxidation of caryophyllene

$\mathrm{H}_{2} \mathrm{O}, 220^{\circ} \mathrm{C}, 8 \mathrm{~h}$

$\mathrm{CH}_{3} \mathrm{CN}, \mathrm{RT}, 24 \mathrm{~h}$

$\mathrm{H}_{2} \mathrm{O}, \mathrm{RT}, 24 \mathrm{~h}$

$\mathrm{H}_{2} \mathrm{O}, 220^{\circ} \mathrm{C}, 8 \mathrm{~h}$

$\mathrm{H}_{2} \mathrm{O}, 220^{\circ} \mathrm{C}, 8 \mathrm{~h}$

$\mathrm{H}_{2} \mathrm{O}, \mathrm{RT}, 48 \mathrm{~h}$

$\mathrm{H}_{2} \mathrm{O}, 220^{\circ} \mathrm{C}, 8 \mathrm{~h}$

$\mathrm{H}_{2} \mathrm{O}, \mathrm{RT}, 48 \mathrm{~h}$

$\mathrm{H}_{2} \mathrm{O}, 180^{\circ} \mathrm{C}, 20 \mathrm{~h}$

$\mathrm{CH}_{3} \mathrm{CN}, \mathrm{RT}, 24 \mathrm{~h}$

$\mathrm{H}_{2} \mathrm{O}, 210^{\circ} \mathrm{C}, 40$

min (microwave)

$\mathrm{H}_{2} \mathrm{O}, 180^{\circ} \mathrm{C}, 72 \mathrm{~h}$

$\mathrm{H}_{2} \mathrm{O}, 180^{\circ} \mathrm{C}, 72 \mathrm{~h}$

$\mathrm{H}_{2} \mathrm{O}, 218^{\circ} \mathrm{C}, 18 \mathrm{~h}$

$\mathrm{H}_{2} \mathrm{O}, 218^{\circ} \mathrm{C}, 18 \mathrm{~h}$

DDS (DBT, 1-BT, 4,6-DMDBT)

ODS (DBT, 1-BT, 4,6-DMDBT)

Pechmann, esterification and

Friedel-Crafts acylation

Aldol self-condensation of cyclic

ketones

Hydroxyalkylation of phenol with

formaldehyde to bisphenol $\mathrm{F}$

Biginelli condensation reaction

Hydroformylation of octene

Proton conductivity

Oxidation of benzyl alcohol

Reaction of $\mathrm{CO}_{2}$ with styrene oxide

ODS (DBT)

Quantum dots solar cell

Methanolysis of epoxides

Cycloaddition of $\mathrm{CO}_{2}$ with epoxides, esterification of $\mathrm{CH}_{3} \mathrm{COOH}$
$\mathrm{H}_{2} \mathrm{O}, 180^{\circ} \mathrm{C}, 72 \mathrm{~h}$

Photocatalytic $\mathrm{H}_{2}$ production

$\mathrm{H}_{2} \mathrm{O}, 200^{\circ} \mathrm{C}, 18 \mathrm{~h} \quad$ Dye adsorptio

$\mathrm{H}_{2} \mathrm{O}, \mathrm{RT}, 24 \mathrm{~h}$

$\mathrm{CH}_{3} \mathrm{CN}, \mathrm{RT}, 24 \mathrm{~h}$

Alkene oxidation

Geraniol oxidation

$\mathrm{H}_{2} \mathrm{O}, \mathrm{RT}, 24 \mathrm{~h}$

$\mathrm{H}_{2} \mathrm{O}, 100^{\circ} \mathrm{C}, 12 \mathrm{~h}$

Electro/photocatalytic water oxidation

$\mathrm{H}_{2} \mathrm{O}, \mathrm{RT}, 24 \mathrm{~h}$

Oxidation of styrene
Oxidation of sulfides
No solvent, $60-90^{\circ} \mathrm{C}$, microwaves

(300 $\mathrm{mW}$ power)

$\mathrm{H}_{2} \mathrm{O}_{2}, \mathrm{CH}_{3} \mathrm{CN}, 55^{\circ} \mathrm{C}$, microwaves

(300 $\mathrm{mW}$ power)

$\mathrm{H}_{2} \mathrm{O}_{2}$, n-heptane/DMF, $40-50^{\circ} \mathrm{C}$

$\mathrm{H}_{2} \mathrm{O}_{2}$, n-octane $/ \mathrm{BMIPF}_{6}, 50^{\circ} \mathrm{C}$

No solvent, $120^{\circ} \mathrm{C}$

No solvent, $130^{\circ} \mathrm{C}$ (under $\mathrm{N}_{2}$ )

No solvent, $60-120^{\circ} \mathrm{C}$

Ethylacetoacetate/Aldehyde/Urea, no solvent, $100^{\circ} \mathrm{C}$

$\mathrm{H}_{2} / \mathrm{CO}$, toluene, $70^{\circ} \mathrm{C}$

$\mathrm{TBHP}, \mathrm{CHCl}_{3}, 100^{\circ} \mathrm{C}$

No solvent $60^{\circ} \mathrm{C}$

$\mathrm{H}_{2} \mathrm{O}_{2}$, n-heptane $/ \mathrm{CH}_{3} \mathrm{CN}, 60^{\circ} \mathrm{C}$

No solvent, RT

No solvent $90^{\circ} \mathrm{C}$

No solvent, $70^{\circ} \mathrm{C}$

$\left.\mathrm{Ru}(\mathrm{bpy})_{3}\right] \mathrm{Cl}_{2}, \mathrm{TEOA}, \mathrm{H}_{2} \mathrm{O}(\mathrm{pH} 2.0)$ $\mathrm{DMF} / \mathrm{CH}_{3} \mathrm{CN}$ (7/3), RT, $300 \mathrm{~W} \mathrm{Xe}$ light $(\lambda>420 \mathrm{~nm})$

$\mathrm{H}_{2} \mathrm{O}_{2}, \mathrm{CH}_{3} \mathrm{CN}, \mathrm{H}_{2} \mathrm{O}$, EtOH, DMF,

$\mathrm{H}_{2} \mathrm{O} / \mathrm{PEG}, \mathrm{RT}$

$\mathrm{H}_{2} \mathrm{O}_{2}, \mathrm{CH}_{3} \mathrm{CN}, 80^{\circ} \mathrm{C}$

$\mathrm{H}_{2} \mathrm{O}_{2}, \mathrm{CH}_{3} \mathrm{CN}, \mathrm{RT}$

$\mathrm{Ru}\left(\right.$ bpy) ${ }_{3} \mathrm{Cl}_{2}, \mathrm{Na}_{2} \mathrm{~S}_{2} \mathrm{O}_{8}$, sodium

borate buffer (pH 9), RT, $300 \mathrm{~W} X$

lamp $(\lambda>420 \mathrm{~nm})$

$\mathrm{CH}_{3} \mathrm{CN}, 75^{\circ} \mathrm{C}$ (with or without

microwaves $70 \mathrm{~mW}$ powder)
Hatton, 2012,44

iu, 2013,45

Balula, 2013,4

Khder, El-Shall, 2014, ${ }^{47}$

Zou, $2015,{ }^{48}$

Li, Liu, 2015, 49

Saikia, 2015,

Sartipi, Gascon, 2015, ${ }^{51}$

Liu, 2017, ${ }^{52}$

Van der Voort, 2017,

Pescarmona, 2017, ${ }^{54}$

Zhao, Su, 2018,

Chen, Li, Wang, 2015,, 56

Tangestaninejad, 2018,57

Tangestaninejad,

Moghadam, Mirkhani

$2019,{ }^{58}$

Zhang, Lin,2018, 59

Farhadi, 2018,60

Khoshnavazi, 2018, ${ }^{61}$

Balula, Cunha-Silva,

2013,62

Roch-Marchal, Dolbecq

2014

$x_{u, 2016,63}$

Cunha-Silva, Balula

$2013{ }^{64}$ 


\begin{tabular}{|c|c|c|c|c|c|c|c|}
\hline & $\mathrm{K}_{11}\left[\mathrm{~Tb}\left(\mathrm{PW}_{11} \mathrm{O}_{39}\right)_{2}\right]$ & & $\operatorname{Imp}$ & $\mathrm{H}_{2} \mathrm{O}, \mathrm{RT}, 24 \mathrm{~h}$ & ODS (DBT, 1-BT, 4,6-DMDBT) & $\begin{array}{l}\mathrm{H}_{2} \mathrm{O}_{2}, \mathrm{n} \text {-octane } / \mathrm{CH}_{3} \mathrm{CN} \text {, } \\
\text { isopropanol, DMF, } \mathrm{CH} \mathrm{H}_{3} \mathrm{CN} / \mathrm{H}_{2} \mathrm{O} \\
\text { (1/1), RT }\end{array}$ & Balula, 2013, ${ }^{65}$ \\
\hline & $\mathrm{K}_{11}\left[\mathrm{Eu}\left(\mathrm{PW}_{11} \mathrm{O}_{39}\right)_{2}\right]$ & & Imp & $\mathrm{H}_{2} \mathrm{O}, \mathrm{RT}, 24 \mathrm{~h}$ & $\begin{array}{l}\text { ODS (T, DBT, 1-BT, 4-MDBT, 4- } \\
\text { 6DMDBT) }\end{array}$ & $\mathrm{H}_{2} \mathrm{O}_{2}, \mathrm{n}$-octane $/ \mathrm{CH}_{3} \mathrm{CN}, 70^{\circ} \mathrm{C}$ & $\begin{array}{l}\text { Balula, Cunha-Silva, } \\
2016,66\end{array}$ \\
\hline & $(\mathrm{TBA})_{4} \mathrm{H}\left[\mathrm{PMO}_{10} \mathrm{~V}_{2} \mathrm{O}_{40}\right]$ & $\sim 40$ & Imp & $\mathrm{CH}_{3} \mathrm{CN}, \mathrm{RT}, 96 \mathrm{~h}$ & $\begin{array}{l}\text { Electrocatalytic ascorbic acid } \\
\text { oxidation }\end{array}$ & $\begin{array}{l}\mathrm{H}_{2} \mathrm{SO}_{4} / \mathrm{Na}_{2} \mathrm{SO}_{4} \text { buffer solution (pH } \\
\text { 2.5), RT }\end{array}$ & $\begin{array}{l}\text { Cunha-Silva, Freire, } \\
2013,67\end{array}$ \\
\hline & $\mathrm{H}_{5} \mathrm{PMO}_{10} \mathrm{~V}_{2} \mathrm{O}_{40}$ & $17-33$ & Imp & $\mathrm{H}_{2} \mathrm{O}, \mathrm{RT}, 4 \mathrm{~h}$ & $\begin{array}{l}\text { Oxidation of 2-chloroethyl ethyl } \\
\text { sulfide }\end{array}$ & $\mathrm{CH}_{2} \mathrm{Cl}_{2}, \mathrm{RT}$ & Zhou, Zhong, 2018, ${ }^{68}$ \\
\hline & $\mathrm{H}_{3} \mathrm{PMo}_{12} \mathrm{O}_{40}$ & & SE & $\mathrm{H}_{2} \mathrm{O}, 220^{\circ} \mathrm{C}, 9 \mathrm{~h}$ & $\begin{array}{l}\text { In situ formation of Au NPs, optical } \\
\text { contrast agent }\end{array}$ & - & $\begin{array}{l}\text { Roch-Marchal, Horcajada, } \\
2016,69\end{array}$ \\
\hline \multirow[t]{2}{*}{$\begin{array}{l}\mathrm{NH}_{2}-\mathrm{MIL}- \\
101(\mathrm{Cr})\end{array}$} & $\mathrm{H}_{3} \mathrm{PW}_{12} \mathrm{O}_{40}$ & & $\operatorname{Imp}$ & $\mathrm{H}_{2} \mathrm{O}, \mathrm{RT}, 10 \mathrm{~h}$ & ODS (DBT, BT, 4,6-DMDBT) & $\begin{array}{l}\mathrm{H}_{2} \mathrm{O}_{2}, \mathrm{n} \text {-heptane } / \mathrm{CH}_{3} \mathrm{CN}, \mathrm{DMF}, 30- \\
60^{\circ} \mathrm{C}\end{array}$ & Huang, Cao, 2014,70 \\
\hline & $\mathrm{H}_{3} \mathrm{PMo}_{12} \mathrm{O}_{40}$ & & $\operatorname{Imp}$ & $\mathrm{H}_{2} \mathrm{O}, \mathrm{RT}, 10 \mathrm{~h}$ & $\begin{array}{l}\text { ODS (DBT, BT, 4-MDBT, 4,6- } \\
\text { DMDBT) }\end{array}$ & $\begin{array}{l}\mathrm{H}_{2} \mathrm{O}_{2}, \text { n-octane/BMIMPF } \\
\text { diesel/BMIMPF } 6,50^{\circ} \mathrm{C}\end{array}$ & Balula, 2018,71 \\
\hline \multirow[t]{5}{*}{$\begin{array}{l}\mathrm{NH}_{2}-\mathrm{MIL-} \\
101(\mathrm{Al})\end{array}$} & $(\mathrm{TBA})_{4.2} \mathrm{H}_{0.8}\left[\mathrm{PW}_{11} \mathrm{ZnO}_{39}\left(\mathrm{H}_{2} \mathrm{O}\right)\right]$ & & $\begin{array}{l}\operatorname{Imp} \\
\mathrm{SE}\end{array}$ & $\begin{array}{l}\mathrm{CH}_{3} \mathrm{CN}, \mathrm{RT}, 48 \mathrm{~h} \\
\mathrm{DMF}, 130^{\circ} \mathrm{C}, 5 \mathrm{~h} \\
\text { (microwave) }\end{array}$ & ODS (DBT, 1-BT, 4,6-DMDBT) & $\begin{array}{l}\mathrm{H}_{2} \mathrm{O}_{2}, \mathrm{n} \text {-octane } / \mathrm{BMIMPF}_{6} \\
\text { diesel } / \mathrm{CH}_{3} \mathrm{CN}, 50^{\circ} \mathrm{C}\end{array}$ & $\begin{array}{l}\text { Cuhna Silva, Balula, } \\
2016,^{72}\end{array}$ \\
\hline & $\mathrm{K}_{6}\left[\mathrm{AgPW}_{11} \mathrm{O}_{39}\right]$ & & $\operatorname{Imp}$ & $\begin{array}{l}\mathrm{MeOH} / \mathrm{H}_{2} \mathrm{O} 1 / 1 \\
\mathrm{RT}, 24 \mathrm{~h}\end{array}$ & $\begin{array}{l}\text { Formation of Ag NPs, } \\
\text { Reduction of 4-nitrophenol, } \\
\text { Photocatalytic degradation of } \\
\text { Rhodamine B }\end{array}$ & $\begin{array}{l}\mathrm{NaBH}_{4} \text {, no solvent, } \mathrm{RT} \\
\mathrm{H}_{2} \mathrm{O}, \mathrm{RT}, 300 \mathrm{~W} \text { Xe lamp }(\lambda>400 \\
\mathrm{nm})\end{array}$ & Wang, Li, 2016,73 \\
\hline & $\mathrm{H}_{3} \mathrm{PW}_{12} \mathrm{O}_{40}+\mathrm{Pt} \mathrm{NPs}$ & & SE & $\begin{array}{l}\mathrm{DMF}, 130^{\circ} \mathrm{C}, 1 \mathrm{~h} \\
\text { (microwave) }\end{array}$ & $\begin{array}{l}\text { Oxidation of } \mathrm{CO} \\
\text { Hydrogenation of toluene }\end{array}$ & $\begin{array}{l}\text { No solvent, } 1 \% \mathrm{O}_{2}, 0.5 \% \mathrm{CO} \text { in } \mathrm{He} \\
\text { Toluene in a flowing } \mathrm{H}_{2}-\mathrm{N}_{2} \text { mixture }\end{array}$ & $\begin{array}{l}\text { Ramos-Fernandez, } \\
\text { Gascon, 2012,74 }\end{array}$ \\
\hline & $\mathrm{H}_{3} \mathrm{PW}_{12} \mathrm{O}_{40}$ & & SE & $\mathrm{DMF}, 130^{\circ} \mathrm{C}$ & - & - & Gascon, 2011,75 \\
\hline & $\mathrm{H}_{3} \mathrm{PW}_{12} \mathrm{O}_{40}$ & 29-32 & $\begin{array}{l}\mathrm{Imp} \\
\mathrm{SE}\end{array}$ & $\begin{array}{l}\mathrm{H}_{2} \mathrm{O} / \mathrm{MeOH} 1 / 1, \\
\mathrm{RT}, 8 \mathrm{~h}\end{array}$ & $\begin{array}{l}\text { Aldehyde condensation and } \\
\text { polymerization }\end{array}$ & $\mathrm{H}_{2} \mathrm{O} / \mathrm{CH}_{3} \mathrm{CN}, 25^{\circ} \mathrm{C}$ & Hatton, 2013,76 \\
\hline \multirow[t]{7}{*}{ MIL-100(Fe) } & $\mathrm{H}_{3} \mathrm{PW}_{4} \mathrm{O}_{24}+\mathrm{ILS}$ & & $\operatorname{Imp}$ & $\begin{array}{l}\mathrm{H}_{2} \mathrm{O} / \mathrm{H}_{2} \mathrm{O}_{2}, \mathrm{RT}, 24 \\
h\end{array}$ & Oxidation of benzyl alcohol & $\mathrm{TBHP}, \mathrm{CHCl}_{3}, 100^{\circ} \mathrm{C}$ & Abbasi, 2017, ${ }^{77}$ \\
\hline & $\mathrm{H}_{3} \mathrm{PW}_{12} \mathrm{O}_{40}$ & & $\operatorname{Imp}$ & $\begin{array}{l}\text { Absolute EtOH, } \\
\text { RT, } 6 \mathrm{~h}\end{array}$ & $\begin{array}{l}\text { Ethanol conversion to diethylether } \\
\text { and ethylene }\end{array}$ & Vapour phase, $90-210^{\circ} \mathrm{C}$ & Gil, 2012, ${ }^{78}$ \\
\hline & $\mathrm{H}_{3} \mathrm{PW}_{12} \mathrm{O}_{40}$ & & SE & $\mathrm{H}_{2} \mathrm{O}, 95^{\circ} \mathrm{C}, 12 \mathrm{~h}$ & $\begin{array}{l}\text { Acetalization of benzaldehyde and } \\
\text { ethanediol }\end{array}$ & Cyclohexane, $80^{\circ} \mathrm{C}$ & Zhang, El-Shall, 2015,79 \\
\hline & $\mathrm{H}_{3} \mathrm{PW}_{12} \mathrm{O}_{40}$ & & SE & $\mathrm{H}_{2} \mathrm{O}, 160^{\circ} \mathrm{C}, 12 \mathrm{~h}$ & $\begin{array}{l}\text { Hydroxyalkylation of phenol with } \\
\text { formaldehyde to bisphenol F }\end{array}$ & No solvent, $60-120^{\circ} \mathrm{C}$ & Li, Liu, 2015,,$^{49}$ \\
\hline & $\mathrm{H}_{3} \mathrm{PW}_{12} \mathrm{O}_{40}$ & $7-35$ & SE & $\mathrm{H}_{2} \mathrm{O}, 160^{\circ} \mathrm{C}, 24 \mathrm{~h}$ & ODS (DBT, 1-BT, 4,6-DMDBT) & $\begin{array}{l}\mathrm{H}_{2} \mathrm{O}_{2}, \mathrm{n} \text {-heptane } / \mathrm{CH}_{3} \mathrm{CN} \text {, } \\
\text { gasoline/ } \mathrm{CH}_{3} \mathrm{CN}\end{array}$ & Cao, Huang, 2017, ${ }^{80}$ \\
\hline & $\mathrm{H}_{3} \mathrm{PW}_{12} \mathrm{O}_{40}+$ lipase & & SE & $\mathrm{H}_{2} \mathrm{O}, 130^{\circ} \mathrm{C}, 72 \mathrm{~h}$ & Esterification of cinnamic acid & Benzyl alcohol, isooctane, $45^{\circ} \mathrm{C}$ & Rafiee, $2018,{ }^{81}$ \\
\hline & $\mathrm{H}_{3} \mathrm{PW}_{12} \mathrm{O}_{40}+\mathrm{ILS}$ & & SE & $\mathrm{H}_{2} \mathrm{O}, 130^{\circ} \mathrm{C}, 72 \mathrm{~h}$ & Esterification of oleic acid & EtOH, $111^{\circ} \mathrm{C}$ & Guan, 2015,82 \\
\hline
\end{tabular}

61 
$\mathrm{Na}_{10}\left[\left(\mathrm{PW}_{9} \mathrm{O}_{34}\right)_{2} \mathrm{CO}_{4}\left(\mathrm{H}_{2} \mathrm{O}\right)_{2}\right]$

$\mathrm{K}_{7}\left[\mathrm{CO}_{2} \mathrm{~W}_{11} \mathrm{O}_{39}\left(\mathrm{H}_{2} \mathrm{O}\right)\right]$

$\mathrm{H}_{5} \mathrm{PMO}_{10} \mathrm{~V}_{2} \mathrm{O}_{40}, \mathrm{H}_{4} \mathrm{PMO}_{11} \mathrm{VO}_{40}$,

$\mathrm{H}_{3} \mathrm{PMO}_{12} \mathrm{O}_{40}$

$\mathrm{H}_{5} \mathrm{PMO}_{10} \mathrm{~V}_{2} \mathrm{O}_{40}$

(TBA) ${ }_{4} \mathrm{H}\left[\mathrm{PMO}_{11} \mathrm{MnO}_{39}\left(\mathrm{H}_{2} \mathrm{O}\right)\right]$

$\mathrm{H}_{3} \mathrm{PMO}_{12} \mathrm{O}_{40}$

$\mathrm{H}_{3} \mathrm{PMO}_{12} \mathrm{O}_{40}$

MIL-100(Cr)

$\mathrm{H}_{3} \mathrm{PW}_{12} \mathrm{O}_{40}+\mathrm{RuCl}_{3}$

$\mathrm{H}_{3} \mathrm{PW}_{12} \mathrm{O}_{40}$

$\mathrm{NH}_{2}-\mathrm{MIL}-$
$53(\mathrm{Al})$

$\mathrm{H}_{3} \mathrm{PW}_{12} \mathrm{O}_{40}$

53(Al)

$\mathrm{K}_{11} \mathrm{Eu}\left(\mathrm{PW}_{11} \mathrm{O}_{39}\right)_{2}$

Zr-MOF

UiO-66

$\mathrm{H}_{3} \mathrm{PW}_{12} \mathrm{O}_{40}$

25-40 S

$10 \quad \mathrm{SE}$

$\mathrm{Cs}_{2.5} \mathrm{H}_{0.5} \mathrm{PW}_{12} \mathrm{O}_{40}$

20-50 SE

$\mathrm{H}_{3} \mathrm{PW}_{12} \mathrm{O}_{40}$

$\mathrm{H}_{4} \mathrm{SiW}_{12} \mathrm{O}_{40}$

$\mathrm{H}_{2} \mathrm{O}, 130^{\circ} \mathrm{C}, 72 \mathrm{~h}$

Photocatalytic water oxidation

Oxidation of cyclohexene

Anode material

Reduction of $\mathrm{p}$-nitrophenol into $\mathrm{p}$ aminophenol

$130^{\circ} \mathrm{C}, 72 \mathrm{~h}$

$\mathrm{H}_{2} \mathrm{O}, 130^{\circ} \mathrm{C}, 72 \mathrm{~h}$

$\mathrm{H}_{2} \mathrm{O}, 130^{\circ} \mathrm{C}, 72 \mathrm{~h}$

Photocatalytic oxidation of benzylic alcohols

Reduction of $\mathrm{Cr}(\mathrm{VI})$

$\mathrm{H}_{2} \mathrm{O}$ or $\mathrm{H}_{2} \mathrm{O} / \mathrm{DMF}$,

$220^{\circ} \mathrm{C}, 96 \mathrm{~h}$

or $180^{\circ} \mathrm{C}, 3 \mathrm{~h}$

(microwave)

$\mathrm{H}_{2} \mathrm{O}, 220^{\circ} \mathrm{C}, 96 \mathrm{~h}$

$\mathrm{H}_{2} \mathrm{O}, 220^{\circ} \mathrm{C}, 96 \mathrm{~h}$

Conversion of cellobiose and

cellulose into sorbitol

Hydroxyalkylation of phenol with

formaldehyde to bisphenol $F$

$\mathrm{H}_{2} \mathrm{O} / \mathrm{EtOH} 1 / 1, \mathrm{RT}, \quad$ Aldehyde condensation and

$8 \mathrm{~h}$

polymerization

(microwave)

Imp $\quad \mathrm{H}_{2} \mathrm{O}, \mathrm{RT}, 120 \mathrm{~h}$

ODS (T, DBT, 1-BT, 4-DMDBT, 46DMDBT)

$\mathrm{DMF}, 120^{\circ} \mathrm{C}, 24 \mathrm{~h}$

Oxidation of cyclopentene to glutaraldehyd

DMF, $120^{\circ} \mathrm{C}, 24 \mathrm{~h} \quad \mathrm{ODS}$ (DBT, 1-BT, 4,6-DMDBT)

DMF, $120^{\circ} \mathrm{C}, 30 \mathrm{~h}$

Acidolysis of soybean oil

DMF, $120^{\circ} \mathrm{C}, 24 \mathrm{~h}$

Oxidation of cyclohexanone to

adipic acid

Esterification of lauric acid with

methanol
$\mathrm{Ru}(\mathrm{bpy})_{3} \mathrm{Cl}_{2}, \mathrm{Na}_{2} \mathrm{~S}_{2} \mathrm{O}_{8}$, sodium

orate buffer ( $\mathrm{pH}$ 9), RT, $300 \mathrm{~W} \times$

lamp $(\lambda>420 \mathrm{~nm})$

$\mathrm{H}_{2} \mathrm{O}_{2}, \mathrm{CH}_{3} \mathrm{CN}, 70^{\circ} \mathrm{C}$

$\mathrm{H}_{2} \mathrm{O}, 20-45^{\circ} \mathrm{C}$

Benzotrifluoride saturated with pure $\mathrm{O}_{2}, \mathrm{RT}, 300 \mathrm{~W}$ Xe lamp $(\lambda \geq$

$420 \mathrm{~nm}$ )

Ammonium oxalate, $\mathrm{H}_{2} \mathrm{O}, \mathrm{RT}, 400$

$W$ Xe lamp $(420 \leq \lambda<760 \mathrm{~nm})$

Juan-Alcañiz, Gascon $2012,^{89}$

$\mathrm{H}_{2}, \mathrm{H}_{2} \mathrm{O}, 150^{\circ} \mathrm{C}$ and $190^{\circ} \mathrm{C}$

Chen, Chen, 2013,90

No solvent, $60-120^{\circ} \mathrm{C}$

$\mathrm{H}_{2} \mathrm{O} / \mathrm{CH}_{3} \mathrm{CN}, 25^{\circ} \mathrm{C}$

Li, Liu, 2015,49

Hatton, 2013,76

$\mathrm{H}_{2} \mathrm{O}_{2}$, n-octane $/ \mathrm{CH}_{3} \mathrm{CN}, 70^{\circ} \mathrm{C}$

$\mathrm{H}_{2} \mathrm{O}_{2}$, tert-butylalcohol, $35^{\circ} \mathrm{C}$

$\mathrm{H}_{2} \mathrm{O}_{2}$, n-heptane $/ \mathrm{CH}_{3} \mathrm{CN}$,

gasoline $/ \mathrm{CH}_{3} \mathrm{CN}$

Capric acid, caprylic acid, no

solvent, $100-170^{\circ} \mathrm{C}$

$\mathrm{H}_{2} \mathrm{O}_{2}$, no solvent $90^{\circ} \mathrm{C}$

No solvent, $160^{\circ} \mathrm{C}$

2016, ${ }^{66}$

Yang, Dai, 2015, ${ }^{91}$

Cao, Huang, 2017, ${ }^{80}$

$\mathrm{Hu}, 2017,92$

Feng, 2019, ${ }^{93}$

Zhang, Zhang, 2019,94 


\begin{tabular}{|c|c|c|c|c|c|c|c|}
\hline & Zr-doped $\mathrm{H}_{4} \mathrm{SiW}_{12} \mathrm{O}_{40}$ & & SE & $\mathrm{DMF}, 120^{\circ} \mathrm{C}, 6 \mathrm{~h}$ & $\begin{array}{l}\text { Esterification of oleic acid with } \\
\text { methanol }\end{array}$ & No solvent, $140-160^{\circ} \mathrm{C}$ & Zhang, Zhang, 2020,95 \\
\hline & $\mathrm{H}_{3} \mathrm{PMO}_{12} \mathrm{O}_{40}$ & $2-20$ & SE & $\begin{array}{l}\mathrm{DMF} / \mathrm{HAC} \\
(30 / 3.6), 120^{\circ} \mathrm{C}, 24 \\
\mathrm{~h} \text { and calcinations } \\
200-500^{\circ} \mathrm{C}\end{array}$ & ODS (DBT) & TBHP, decalin, $80^{\circ} \mathrm{C}$ & Wang, Zhang, 2019,96 \\
\hline & $\begin{array}{l}\mathrm{H}_{3} \mathrm{PMO}_{12} \mathrm{O}_{40} \\
{[\mathrm{Bmim}]_{3} \mathrm{PMo}_{12} \mathrm{O}_{40}}\end{array}$ & & SE & $\mathrm{DMF}, 120^{\circ} \mathrm{C}, 24 \mathrm{~h}$ & ODS (DBT, 4,6-DMDBT) & TBHP, n-octane, $80^{\circ} \mathrm{C}$ & Wang, Bu, 2020, ${ }^{97}$ \\
\hline \multirow[t]{2}{*}{$\begin{array}{l}\text { Zr-MOF } \\
\text { UiO-66-NH2 }\end{array}$} & $\mathrm{H}_{3} \mathrm{PW}_{12} \mathrm{O}_{40}$ & & SE & $\mathrm{DMF}, 120^{\circ} \mathrm{C}, 72 \mathrm{~h}$ & Photocatalytic $\mathrm{H}_{2}$ production, & $\begin{array}{l}\mathrm{H}_{2} \mathrm{O} / \mathrm{CH}_{3} \mathrm{OH}(3 / 1), \mathrm{RT}, 500 \mathrm{~W} \mathrm{Xe} \\
\text { lamp } \\
\mathrm{H}_{2} \mathrm{O}, \mathrm{RT} \text {, visible-light irradiation }\end{array}$ & $\mathrm{Li}, 2018,^{98}$ \\
\hline & & & & & Degradation of RhB & & \\
\hline $\begin{array}{l}\mathrm{Zr}-\mathrm{MOF} \\
\text { UiO-66-2 } \mathrm{CO}_{2} \mathrm{H}\end{array}$ & $\mathrm{H}_{3} \mathrm{PW}_{12} \mathrm{O}_{40}+\mathrm{ILS}$ & 10 & SE & $\mathrm{H}_{2} \mathrm{O}, 100^{\circ} \mathrm{C}, 24 \mathrm{~h}$ & $\begin{array}{l}\text { Transesterification of soybean oil } \\
\text { with methanol }\end{array}$ & $\begin{array}{l}\text { With and without oleic acid, no } \\
\text { solvent, } 110^{\circ} \mathrm{C}\end{array}$ & Xie, 2019,,$^{99}$ \\
\hline \multirow[t]{8}{*}{$\begin{array}{l}\text { Zr-MOF } \\
\text { UiO-67 }\end{array}$} & $(\mathrm{DODA})_{9}\left[\mathrm{EuW}_{10} \mathrm{O}_{36}\right]$ & & SE & $\mathrm{DMF}, 120^{\circ} \mathrm{C}, 24 \mathrm{~h}$ & $\begin{array}{l}\text { Chemical probe, temperature } \\
\text { sensor }\end{array}$ & - & $\begin{array}{l}\text { Mialane, Serier-Brault, } \\
2018,{ }^{100}\end{array}$ \\
\hline & $\begin{array}{l}\mathrm{H}_{3} \mathrm{PW}_{12} \mathrm{O}_{40} \\
(\mathrm{TBA})_{4} \mathrm{H}_{3}\left[\mathrm{PW}_{11} \mathrm{O}_{39}\right] \\
(\mathrm{TBA})_{6}\left[\mathrm{P}_{2} \mathrm{~W}_{18} \mathrm{O}_{62}\right]\end{array}$ & & SE & $\mathrm{DMF}, 120^{\circ} \mathrm{C}, 24 \mathrm{~h}$ & - & - & $\begin{array}{l}\text { Roch-Marchal, Dolbecq, } \\
2015,{ }^{101}\end{array}$ \\
\hline & $\mathrm{H}_{3} \mathrm{PW}_{12} \mathrm{O}_{40}$ & & SE & $\mathrm{DMF}, 120^{\circ} \mathrm{C}, 12 \mathrm{~h}$ & ODS (DBT, 1-BT, 4,6-DMDBT) & $\mathrm{H}_{2} \mathrm{O}_{2}$, n-heptane $/ \mathrm{CH}_{3} \mathrm{CN}, 40-90^{\circ} \mathrm{C}$ & $\mathrm{Li}, 2018,^{102}$ \\
\hline & $\mathrm{H}_{3} \mathrm{PW}_{12} \mathrm{O}_{40}+\mathrm{Cp} * \mathrm{Rh}\left(\right.$ bpydc) $\mathrm{Cl}_{2}$ & & SE & $\mathrm{DMF}, 120^{\circ} \mathrm{C}, 12 \mathrm{~h}$ & $\begin{array}{l}\text { Photocatalytic } \mathrm{CO}_{2} \text { reduction to } \\
\text { formate and } \mathrm{H}_{2}\end{array}$ & $\begin{array}{l}\mathrm{Ru}(\mathrm{bpy})_{3} \mathrm{Cl}_{2}, \mathrm{CH}_{3} \mathrm{CN} / \mathrm{TEOA}(5 / 1), \mathrm{RT}, \\
280 \mathrm{~W} \text { lamp }(\lambda>415 \mathrm{~nm})\end{array}$ & $\begin{array}{l}\text { Dolbecq, Sassoye, Mellot- } \\
\text { Draznieks, 2020,103 }\end{array}$ \\
\hline & $\mathrm{H}_{4} \mathrm{SiW}_{12} \mathrm{O}_{40}$ & & SE & $\mathrm{DMF}, 120^{\circ} \mathrm{C}, 24 \mathrm{~h}$ & Photocatalytic $\mathrm{H}_{2}$ production & $\begin{array}{l}30 \text { vol\% lactic acid aqueous } \\
\text { solution, RT, } 300 \text { W Xe lamp ( } \lambda> \\
400 \mathrm{~nm} \text { ) }\end{array}$ & $\mathrm{Li}, \mathrm{Xu}, 2016,{ }^{104}$ \\
\hline & $(\mathrm{TBA})_{6}\left[\mathrm{P}_{2} \mathrm{~W}_{18} \mathrm{O}_{62}\right]$ & & SE & $\mathrm{DMF}, 100^{\circ} \mathrm{C}, 96 \mathrm{~h}$ & Photocatalytic $\mathrm{H}_{2}$ production & $\begin{array}{l}{\left[\mathrm{Ru}(\mathrm{bpy})_{3}\right]^{2+} \text { covalently grafted as }} \\
\mathrm{PS}, \mathrm{CH} \mathrm{H}_{3} \mathrm{OH} \text { aqueous solution }(10 \% \text {, } \\
\text { pH } 1.8), \mathrm{RT}, 230 \mathrm{~W} \text { solid state light } \\
\text { source }(\lambda>400 \mathrm{~nm})\end{array}$ & Lin, 2015,105 \\
\hline & $(\mathrm{TBA})_{10}\left[\left(\mathrm{PW} \mathrm{O}_{34}\right)_{2} \mathrm{Ni}_{4}\left(\mathrm{H}_{2} \mathrm{O}\right)_{2}\right]$ & & SE & $\mathrm{DMF}, 100^{\circ} \mathrm{C}, 72 \mathrm{~h}$ & Photocatalytic $\mathrm{H}_{2}$ production & $\begin{array}{l}{\left[\mathrm{Ir}(\mathrm{ppy})_{2}(\mathrm{bpy})\right]^{+} \text {or }\left[\mathrm{Ru}(\mathrm{bpy})_{3}\right]^{2+}} \\
\text { covalently grafted as } \mathrm{PS}, \mathrm{CH}_{3} \mathrm{OH} \\
\text { aqueous solution }(10 \%, \mathrm{pH} 1.2), \\
230 \mathrm{~W} \text { solid state light source }(\lambda> \\
400 \mathrm{~nm})\end{array}$ & Lin, 2016,106 \\
\hline & $\mathrm{H}_{3} \mathrm{PMo}_{12} \mathrm{O}_{40}, \mathrm{CoHPMo}_{12} \mathrm{O}_{40}$ & & SE & $\mathrm{DMF}, 120^{\circ} \mathrm{C}, 24 \mathrm{~h}$ & Olefins epoxidation & $\begin{array}{l}\mathrm{H}_{2} \mathrm{O}_{2}, \mathrm{CH}_{3} \mathrm{CN}, 70^{\circ} \mathrm{C} \\
\mathrm{O}_{2}, \mathrm{TBHP} \text {, no solvent, } 80^{\circ} \mathrm{C}\end{array}$ & Jia, Yu, 2019, ${ }^{107}$ \\
\hline
\end{tabular}

$8 \mid$ 


\begin{tabular}{|c|c|}
\hline $\begin{array}{l}\text { Zr-MOF } \\
\text { MOF-545 }\end{array}$ & $\mathrm{Na}_{10}\left[\left(\mathrm{PW}_{9} \mathrm{O}_{34}\right)_{2} \mathrm{CO}_{4}\left(\mathrm{H}_{2} \mathrm{O}\right)_{2}\right]$ \\
\hline $\begin{array}{l}\text { Zr-MOF } \\
\text { MOF- } \\
525(\mathrm{Fe}) / \mathrm{PCN}- \\
224(\mathrm{Fe})\end{array}$ & $(\mathrm{TBA})_{3} \mathrm{PW}_{12} \mathrm{O}_{40}$ \\
\hline \multirow[t]{4}{*}{$\begin{array}{l}\text { Zr-MOF } \\
\text { NU-1000 }\end{array}$} & $\mathrm{H}_{3} \mathrm{PW}_{12} \mathrm{O}_{40}$ \\
\hline & $\mathrm{H}_{3} \mathrm{PW}_{12} \mathrm{O}_{40}$ \\
\hline & $\mathrm{H}_{3} \mathrm{PW}_{12} \mathrm{O}_{40}$ \\
\hline & $\mathrm{H}_{5} \mathrm{PMO}_{10} \mathrm{~V}_{2} \mathrm{O}_{40}$ \\
\hline $\begin{array}{l}\text { NU-1000-NDC } \\
\text { NU-1008 }\end{array}$ & $\mathrm{H}_{3} \mathrm{PW}_{12} \mathrm{O}_{40}$ \\
\hline $\begin{array}{l}\text { Zr-MOF } \\
\text { MOF-808 }\end{array}$ & $\mathrm{H}_{3} \mathrm{PW}_{12} \mathrm{O}_{40}$ \\
\hline $\begin{array}{l}\text { HKUST-1 } \\
\text { (Cu-BTC) }\end{array}$ & $\begin{array}{l}\mathrm{H}_{3} \mathrm{PW}_{4} \mathrm{O}_{12}, \mathrm{H}_{3} \mathrm{PMO}_{12} \mathrm{O}_{40}, \\
\mathrm{H}_{5} \mathrm{PMO}_{10} \mathrm{VO}_{40}, \mathrm{H}_{5} \mathrm{PMo}_{10} \mathrm{~V}_{2} \mathrm{O}_{40}, \\
\mathrm{H}_{6} \mathrm{PMO}_{9} \mathrm{~V}_{3} \mathrm{O}_{40}\end{array}$ \\
\hline & $\begin{array}{l}\mathrm{H}_{3} \mathrm{PW}_{12} \mathrm{O}_{40}, \mathrm{H}_{3} \mathrm{PMO}_{12} \mathrm{O}_{40}, \\
\mathrm{H}_{5} \mathrm{PMO}_{10} \mathrm{VO}_{40}, \mathrm{H}_{5} \mathrm{PMO}_{10} \mathrm{~V}_{2} \mathrm{O}_{40}, \\
\mathrm{H}_{6} \mathrm{PMO}_{9} \mathrm{~V}_{3} \mathrm{O}_{40}\end{array}$ \\
\hline
\end{tabular}

Photocatalytic water oxidation

$\mathrm{K}_{7} \mathrm{PW}_{10} \mathrm{Ti}_{2} \mathrm{O}_{40}+\mathrm{Au} \mathrm{NP}$

\section{$\mathrm{K}_{5} \mathrm{PW}_{11} \mathrm{CuO}_{39}$}

$\left(\mathrm{NMe}_{4}\right)\left[\mathrm{SiW}_{11} \mathrm{Mo}^{\vee} \mathrm{O}_{40}\right]$

$\mathrm{H}_{\mathrm{n}} \mathrm{XM}_{12} \mathrm{O}_{40}(\mathrm{X}=$
1) $\mathrm{DMF}, 130^{\circ} \mathrm{C}, 2 \mathrm{~h}$ Photocatalytic $\mathrm{CO}_{2}$ reduction 2) $\mathrm{DMF}, 120^{\circ} \mathrm{C}, 1 \mathrm{~h}$

$\mathrm{H}_{2} \mathrm{O}, \mathrm{RT}, 72 \mathrm{~h}$

$\mathrm{H}_{2} \mathrm{O}, \mathrm{RT}, 72 \mathrm{~h}$

$\mathrm{H}_{2} \mathrm{O}, \mathrm{RT}, 72 \mathrm{~h}$

$\mathrm{H}_{2} \mathrm{O}, \mathrm{RT}, 72 \mathrm{~h}$

$\mathrm{H}_{2} \mathrm{O}, \mathrm{RT}, 72 \mathrm{~h}$

DMF, $130^{\circ} \mathrm{C}, 48 \mathrm{~h}$

SE

\section{$\mathrm{H}_{2} \mathrm{O} / \mathrm{EtOH}(3 / 4)$, \\ Oxidation of benzylic alcohol}

$$
\text { RT, } 120 \mathrm{~h}
$$

$\mathrm{H}_{2} \mathrm{O} / \mathrm{EtOH}(3 / 4)$ RT, $120 \mathrm{~h}$

$\mathrm{H}_{2} \mathrm{O}, 180^{\circ} \mathrm{C}, 24 \mathrm{~h}$ $\mathrm{H}_{2} \mathrm{O} /$ ethylene

glycol $(4 / 3), 80^{\circ} \mathrm{C}$,

$30 \mathrm{~min}$

$\mathrm{H}_{2} \mathrm{O}, 200^{\circ} \mathrm{C}, 16 \mathrm{~h}$,

$100^{\circ} \mathrm{C}, 4 \mathrm{~h}$

$\mathrm{H}_{2} \mathrm{O}, 180^{\circ} \mathrm{C}, 72 \mathrm{~h}$

$\mathrm{H}_{2} \mathrm{O}, 180^{\circ} \mathrm{C}, 24 \mathrm{~h}$

Esterification of glycerol

Oxidation of thiols

Magnetic properties, proton

conductivity

Hydrolysis of esters
Oxidation of 2-chloroethyl ethyl
sulfide after activation at $120^{\circ} \mathrm{C}$

Oxidation of 2-chloroethyl ethyl

sulfide

O-xylene isomerization

Aerobic oxidation of 2-chloroethyl ethyl sulfide

Oxidation of 2-chloroethyl ethyl sulfide

ODS (DBT, 1-BT, 4,6-DMDBT)

Photocatalytic $\mathrm{CO}_{2}$ reduction to $\mathrm{CO}$
$\mathrm{Ru}(\text { bpy })_{3} \mathrm{Cl}_{2}, \mathrm{Na}_{2} \mathrm{~S}_{2} \mathrm{O}_{8}$, borate buffer Dolbecq, Mellotsolution (pH 8), RT, 280 W Xe lamp Draznieks, 2018, ${ }^{108}$

$(\lambda>420 \mathrm{~nm})$

$\mathrm{Ru}(\mathrm{bpy})_{3} \mathrm{Cl}_{2}, \mathrm{CH}_{3} \mathrm{CN} / \mathrm{TEOA}(5 / 1)$ $280 \mathrm{~W}$ Xe lamp $(\lambda>415 \mathrm{~nm})$

Mellot-Draznieks, Sassoye, Dolbecq, 2020, ${ }^{109}$

$\mathrm{H}_{2} \mathrm{O}_{2}, \mathrm{CH}_{3} \mathrm{CN}, 45^{\circ} \mathrm{C}$

$\mathrm{H}_{2} \mathrm{O}_{2}, \mathrm{CH}_{3} \mathrm{CN}, 45^{\circ} \mathrm{C}$

Farha, 2018, ${ }^{111}$

$\mathrm{H}_{2}$, vapour phase, $250^{\circ} \mathrm{C}$ (under $\mathrm{Ar}$ )

$\mathrm{O}_{2}$, isobutyraldehyde,

cyclohexane, $70^{\circ} \mathrm{C}$

$\mathrm{H}_{2} \mathrm{O}_{2}, \mathrm{CH}_{3} \mathrm{CN}, 45^{\circ} \mathrm{C}$

$\mathrm{H}_{2} \mathrm{O}_{2}$, n-dodecane $/ \mathrm{n}$ heptane $/ \mathrm{CH}_{3} \mathrm{CN}, 60^{\circ} \mathrm{C}$

$\mathrm{H}_{2} \mathrm{O}_{2}, \mathrm{H}_{2} \mathrm{O}$ (CTAB micellar

solution), $80^{\circ} \mathrm{C}$

Farha, Notestein, $2018,{ }^{112}$

Farha, 2020, ${ }^{113}$

Farha, 2019,114

Lin, Cao, 2018,

Lu, 2014, ${ }^{116}$

$\mathrm{H}_{2} \mathrm{O}_{2}$, glycerol, $\mathrm{H}_{2} \mathrm{O}, 40^{\circ} \mathrm{C}$

Wang, Lu, 2015, ${ }^{117}$

$\mathrm{H}_{2} \mathrm{O}$ vapor, $40^{\circ} \mathrm{C}, 300 \mathrm{~W}$ Xe lamp

Liu, Liu, 2018, ${ }^{118}$ $(\lambda>420 \mathrm{~nm})$

$\mathrm{O}_{2} /$ air, dichlorobenzene, $45^{\circ} \mathrm{C}$

Hill, 2011,199

$\mathrm{Xu}, 2016,{ }^{120}$

$\mathrm{H}_{2} \mathrm{O} / \mathrm{CH}_{3} \mathrm{CN}, 60-80^{\circ} \mathrm{C}$ 
$\mathrm{Si}, \mathrm{Ge}, \mathrm{P}, \mathrm{As} ; \mathrm{M}=\mathrm{W}, \mathrm{Mo} ; \mathrm{n}=$

$3,4)$

$\mathrm{H}_{3} \mathrm{PW}_{12} \mathrm{O}_{10} \mathrm{H}_{4} \mathrm{SiMO}_{12} \mathrm{O}_{10}$

$\mathrm{H}_{3} \mathrm{PMO}_{6} \mathrm{~W}_{6} \mathrm{O}_{40}$

$\mathrm{Na}_{3} \mathrm{PW}_{12} \mathrm{O}_{40}$

$\mathrm{H}_{3} \mathrm{PW}_{12} \mathrm{O}_{40}$

$\mathrm{H}_{3} \mathrm{PW}_{12} \mathrm{O}_{40}$

$\mathrm{H}_{3} \mathrm{PW}_{12} \mathrm{O}_{40}$

$\mathrm{H}_{3} \mathrm{PW}_{12} \mathrm{O}_{40}, \mathrm{H}_{3} \mathrm{PMO}_{12} \mathrm{O}_{40}$,

$\mathrm{H}_{4} \mathrm{SiW}_{12} \mathrm{O}_{40}$

$\mathrm{H}_{3} \mathrm{PW}_{12} \mathrm{O}_{40}$

$\mathrm{H}_{3} \mathrm{PW}_{12} \mathrm{O}_{40}$

$\mathrm{H}_{4} \mathrm{SiW}_{12} \mathrm{O}_{40}$

$\mathrm{K}_{4} \mathrm{SiW}_{12} \mathrm{O}_{40}$

$\mathrm{H}_{4} \mathrm{PMo}_{10} \mathrm{~V}_{2} \mathrm{O}_{40}$

$\mathrm{H}_{5} \mathrm{PMO}_{10} \mathrm{~V}_{2} \mathrm{O}_{40}$

Fe-BTC $\quad \mathrm{H}_{5} \mathrm{PMO}_{10} \mathrm{~V}_{2} \mathrm{O}_{40}, \mathrm{H}_{6} \mathrm{PMo}_{9} \mathrm{~V}_{3} \mathrm{O}_{40}$, $\mathrm{H}_{4} \mathrm{PMo}_{11} \mathrm{VO}_{40}, \mathrm{H}_{5} \mathrm{SiMo}_{11} \mathrm{VO}_{40}$

$\mathrm{H}_{4} \mathrm{SiMo}_{12} \mathrm{O}_{40}, \mathrm{H}_{3} \mathrm{PMO}_{12} \mathrm{O}_{40}$

$\mathrm{H}_{3} \mathrm{PMO}_{12} \mathrm{O}_{40}$

Cu-MOF

rht-MOF-1

$\mathrm{H}_{3} \mathrm{PMo}_{12} \mathrm{O}_{40}, \mathrm{H}_{3} \mathrm{PW}_{12} \mathrm{O}_{40}$,

$\mathrm{H}_{4} \mathrm{SiMo}_{12} \mathrm{O}_{40}$
$\mathrm{H}_{2} \mathrm{O}, 230^{\circ} \mathrm{C}, 1 \mathrm{~h}$,

$180^{\circ} \mathrm{C}, 24 \mathrm{~h}$

$\mathrm{H}_{2} \mathrm{O}, 180^{\circ} \mathrm{C}, 72 \mathrm{~h}$

$\mathrm{H}_{2} \mathrm{O} / \mathrm{EtOH} 1 / 1$,

lyophilization, 18

$\mathrm{H}_{2} \mathrm{O} /$ EtOH $1 / 1$,

lyophilization, 18

$\mathrm{H}_{2} \mathrm{O} / \mathrm{EtOH} 12 / 16$,

$120^{\circ} \mathrm{C}, 12 \mathrm{~h}$

$\mathrm{H}_{2} \mathrm{O} / \mathrm{EtOH} 12 / 16$,

RT, 48-96 h

Anhydrous EtOH,

$50-80^{\circ} \mathrm{C}, 1.5 \mathrm{~h}$

Mechanochemica

synthesis, liquid

assisted grinding

method

$\mathrm{H}_{2} \mathrm{O}, 180^{\circ} \mathrm{C}, 6-72$

$\mathrm{H}_{2} \mathrm{O}, 180^{\circ} \mathrm{C}, 72 \mathrm{~h}$

$\mathrm{H}_{2} \mathrm{O}, 180^{\circ} \mathrm{C}, 24 \mathrm{~h}$

(single crystals)

$\mathrm{H}_{2} \mathrm{O} / \mathrm{EtOH}(1 / 1)$,

RT (nanocrystals)

Mechanochemical

synthesis

Anhydrous EtOH

$75^{\circ} \mathrm{C}, 12 \mathrm{~h}$,

distillation and

freeze-drying

$\mathrm{H}_{2} \mathrm{O} / \mathrm{EtOH} 1 / 4, \mathrm{Cu}$

foil, $100^{\circ} \mathrm{C}, 1 \mathrm{~h}$

$\mathrm{H}_{2} \mathrm{O} / \mathrm{EtOH} 1 / 1, \mathrm{RT}, \quad$ Conversion of 5 -

$12 \mathrm{~h} \quad$ hydroxymethylfurfural

$\mathrm{H}_{2} \mathrm{O} / \mathrm{DMF} 1 / 1, \quad$ Oxidation of alkylbenzenes

$85^{\circ} \mathrm{C}, 12 \mathrm{~h}$
Hydrolysis of dimethyl

methylphosphonate

Esterification of acetic acid

Esterification of acetic acid

Oxidation of cyclopentene to

glutaraldehyde

ODS (MPS, DBT, T)

Conversion of long-chain fatty acids

into monoalkyl esters

Phenol oxidation with $\mathrm{H}_{2} \mathrm{O}_{2}$

Methanol dehydration

NO adsorption and decomposition

ODS (DBT)

Oxidation of alcohols

Degradation of RhB
$\mathrm{H}_{2} \mathrm{O}, 50^{\circ} \mathrm{C}$

1-propanol, $60^{\circ} \mathrm{C}$

1-propanol, $60^{\circ} \mathrm{C}$

TBHP, $\mathrm{CH}_{3} \mathrm{CN}, 30^{\circ} \mathrm{C}$

$\mathrm{H}_{2} \mathrm{O}_{2}, \mathrm{H}_{2} \mathrm{O}, \mathrm{H}_{2} \mathrm{O} / \mathrm{EtOH}$, n-hexane, $25-65^{\circ} \mathrm{C}$

$\mathrm{MeOH}, 65^{\circ} \mathrm{C}$

$\mathrm{H}_{2} \mathrm{O}_{2}$, no solvent, $35^{\circ} \mathrm{C}$

Vapour phase, $240-300^{\circ} \mathrm{C}$ (under $\mathrm{N}_{2}$ )

$\mathrm{O}_{2}$, isobutyraldehyde, decalin, $80^{\circ} \mathrm{C}$

TBHP, toluene, $100^{\circ} \mathrm{C}$

EtOH, $100^{\circ} \mathrm{C}$

TBHP, no solvent, $80^{\circ} \mathrm{C}$
Liu, $2018,{ }^{133}$

Lu, Liu, 2020, ${ }^{134}$

Chen, 2016, ${ }^{135}$

Naruke, 2003, ${ }^{122}$

Liu, Su, 2011, ${ }^{123}$

Martens, 2010, ${ }^{124}$

Martens, 2011, ${ }^{125}$

Dai, 2015, ${ }^{126}$

Rafiee, 2015, ${ }^{127}$

Liu, 2015,

Lu, Liu, 2018, 129

Liu, 2011, ${ }^{130}$

Liu, 2012, 131

Liu, Zheng, 2013,132

Yan, Li, Yang, 2016, ${ }^{136}$

$10 \mid$ 
$\mathrm{H}_{3+\mathrm{n}} \mathrm{PMO}_{12-\mathrm{n}} \mathrm{V}_{\mathrm{n}} \mathrm{O}_{40}$

Zn-MOF $\quad \mathrm{H}_{3} \mathrm{PW}_{12} \mathrm{O}_{40}, \mathrm{H}_{4} \mathrm{SiW}_{12} \mathrm{O}_{40}$

ZIF-8 $\quad \mathrm{H}_{3} \mathrm{PMO}_{12} \mathrm{O}_{40}$

$\mathrm{H}_{3} \mathrm{PW}_{12} \mathrm{O}_{40}$

$\mathrm{K}_{6} \mathrm{CoW}_{12} \mathrm{O}_{40}$

$\mathrm{K}_{3} \mathrm{Na}_{3} \mathrm{H}_{4}\left[\mathrm{SiW}_{9} \mathrm{CO}_{3}\left(\mathrm{H}_{2} \mathrm{O}\right)_{3} \mathrm{O}_{37}\right]$

$\mathrm{H}_{4} \mathrm{SiW}_{12} \mathrm{O}_{40}+$ Fe-salen

$\begin{array}{ll}\text { Zn-MOF } & \mathrm{H}_{6} \mathrm{PMO}_{9} \mathrm{~V}_{3} \mathrm{O}_{40}, \mathrm{H}_{5} \mathrm{PMO}_{10} \mathrm{~V}_{2} \mathrm{O}_{40}, \\ \text { Rho-ZIF } & \mathrm{H}_{4} \mathrm{PMO}_{11} \mathrm{VO}_{40} \\ \begin{array}{l}\text { Co-MOF } \\ \text { ZIF-67 }\end{array} & \mathrm{H}_{3} \mathrm{PW}_{12} \mathrm{O}_{40}\end{array}$

$\mathrm{K}_{3} \mathrm{Na}_{3} \mathrm{H}_{4}\left[\mathrm{SiW}_{9} \mathrm{Co}_{3}\left(\mathrm{H}_{2} \mathrm{O}\right)_{3} \mathrm{O}_{37}\right]$
$\mathrm{H}_{2} \mathrm{O} / \mathrm{DMF} 1 / 1$ $75^{\circ} \mathrm{C}, 3 \mathrm{~h}$

10

SE

SE

SE

SE

SE

SE

SE

\section{Mechanochemical} synthesis

$\mathrm{MeOH}, \mathrm{RT}, 24 \mathrm{~h}$

$\mathrm{MeOH} / \mathrm{H}_{2} \mathrm{O} 50 / 3$,

RT, $24 \mathrm{~h}$

$\mathrm{MeOH} / \mathrm{H}$

$\mathrm{RT}, 3.5 \mathrm{~h}$

$\mathrm{MeOH}, \mathrm{RT}, 2 \mathrm{~h}$

Mechanochemical

synthesis

$\mathrm{H}_{2} \mathrm{O}, \mathrm{RT}, 6 \mathrm{~h}$

(1)

$\mathrm{MeOH} / \mathrm{H}_{2} \mathrm{O} 50 / 10$ $\mathrm{RT}, 24 \mathrm{~h}$
ODS (DBT, 1-BT, 4,6-DMDBT)

Adsorption of dyes

Controlled release of 5-FU

ODS (DBT, 1-BT, 4,6-DMDBT)

Electrocatalytic OER

Electrocatalytic OER

Electrocatalytic OER

Oxidation of sulfides to sulfoxides

Photocatalytic OER and HER after calcination treatment

Electrocatalytic OER
$\mathrm{H}_{2} \mathrm{O}_{2}$, n-octane $/ \mathrm{CH}_{3} \mathrm{CN}, 40-90^{\circ} \mathrm{C}$

Li, 2020,137

Wang, 2014, ${ }^{138}$

$\mathrm{H}_{2} \mathrm{O}_{2}$, n-heptane $/ \mathrm{CH}_{3} \mathrm{CN}$,

gasoline $/ \mathrm{CH}_{3} \mathrm{CN}, 70^{\circ} \mathrm{C}$

$\mathrm{Na}_{2} \mathrm{SO}_{4}$ solution ( $\left.\mathrm{pH} 1.9\right)$ RT

$\mathrm{KOH}$ electrolyte $(\mathrm{pH}=13.0), \mathrm{RT}$

$\mathrm{KCl}$ solution (neutral $\mathrm{pH}$ ), RT

$\mathrm{H}_{2} \mathrm{O}_{2}, \mathrm{CH}_{3} \mathrm{OH}, \mathrm{RT}$

$\mathrm{Ru}(\mathrm{bpy})_{3} \mathrm{Cl}_{2}, \mathrm{Na}_{2} \mathrm{~S}_{2} \mathrm{O}_{8}$

$\mathrm{Na}_{2} \mathrm{SiF}_{6} / \mathrm{NaHCO}_{3}$ buffer solution

$(\mathrm{pH} 6), \mathrm{RT}, 300 \mathrm{~W}$ Xe lamp $(\lambda>420$

$\mathrm{nm})$

$\mathrm{KOH}$ solution $(\mathrm{pH}=13.0), \mathrm{RT}$
Cao, Huang, 2017, ${ }^{80}$

Das, $2018,{ }^{139}$

Abdelkader-Fernández, Cunha-Silva, 2020, ${ }^{140}$ Das, 2020, ${ }^{139}$

Wei, Xu, 2017, ${ }^{14}$

Li, Wang, 2016,142

Abdelkader-Fernández, Cunha-Silva 2020, ${ }^{140}$

${ }^{\text {a }} \mathrm{SE}=$ synthetic encapsulation; $\operatorname{Imp}=$ impregnetion; $\mathrm{SB}=$ ship in a bottle.

Table 2. Overview of reported Complex@MOF composites

\begin{tabular}{|c|c|c|c|c|c|c|c|c|}
\hline MOF & Catalyst precursor & Charge & $\mathrm{wt} \%$ & $\begin{array}{l}\text { Synthetic } \\
\text { method }^{a}\end{array}$ & Solvent, $\mathrm{T}$, time & Applications & Solvent, $\mathrm{T}$, reactants & Ref \\
\hline \multirow[t]{2}{*}{ MIL-101(Cr) } & $\begin{array}{l}{\left[\left(\mathrm{H}_{2} \mathrm{O}\right)(\text { terpy }) \mathrm{Mn}(\mu-\right.} \\
\left.\mathrm{O})_{2} \mathrm{Mn}(\text { terpy })\left(\mathrm{H}_{2} \mathrm{O}\right)\right]\left(\mathrm{NO}_{3}\right)_{3}\end{array}$ & $3+$ & 10 & SB & $\begin{array}{l}\text { 1) } \mathrm{H}_{2} \mathrm{O}, \mathrm{RT}, 2 \mathrm{~h} \\
\text { 2) } \mathrm{H}_{2} \mathrm{O}, \mathrm{RT}, 2 \mathrm{~h}\end{array}$ & Water oxidation & K-oxone, acetate buffer, RT & Das, $2013,{ }^{143}$ \\
\hline & $\begin{array}{l}\mathrm{MPcF}_{16}(\mathrm{M}=\mathrm{Fe}, \mathrm{Ru}),(\mathrm{FePctBu})_{2} \mathrm{~N} \\
\text { phthalocyanine }\end{array}$ & 0 & $\begin{array}{l}2.1, \\
3.6, \\
5.2\end{array}$ & $\operatorname{Imp}$ & $\begin{array}{l}\text { Acetone for } \mathrm{MPcF}_{16} \text {, } \\
\mathrm{CH}_{2} \mathrm{Cl}_{2} \text { for } \\
\left(\mathrm{FePctBu}_{4}\right)_{2} \mathrm{~N}, \mathrm{RT}, 72 \\
\text { h }\end{array}$ & Oxidation of tetralin & $\mathrm{O}_{2}$, no solvent, $90^{\circ} \mathrm{C}$ & Farrusseng, 2011, ${ }^{144}$ \\
\hline
\end{tabular}




\begin{tabular}{|c|c|c|c|c|c|c|c|c|}
\hline & FePcS phthalocyanine & 0 & $5-22$ & Imp & $\mathrm{H}_{2} \mathrm{O}, 25^{\circ} \mathrm{C}, 3 \mathrm{~h}$ & $\begin{array}{l}\text { Oxidation of benzyl alcohol, 2,3,6- } \\
\text { trimethylphenol and 8- } \\
\text { hydroxyquinoline }\end{array}$ & $\begin{array}{l}\text { TBHP, } \mathrm{CH}_{3} \mathrm{CN}, \mathrm{CH}_{2} \mathrm{Cl}_{2} \text {, acetone, } \\
30-60^{\circ} \mathrm{C}\end{array}$ & Kholdeeva, 2011, ${ }^{145}$ \\
\hline & $\left.\mathrm{Na}\left[\mathrm{Co}(\mathrm{CO})_{4}\right)\right]$ & $1-$ & & Imp & $\mathrm{MeOH}, \mathrm{RT}, 12 \mathrm{~h}$ & $\begin{array}{l}\text { Ring-expansion carbonylation of } \\
\text { epoxides }\end{array}$ & $\mathrm{CO}$, no solvent, $60^{\circ} \mathrm{C}$ & $\begin{array}{l}\text { Dincă, Román-Leshkov, } \\
\text { 2017, }{ }^{146}\end{array}$ \\
\hline & Cu-salen & 0 & & SB & EtOH, reflux, $30 \mathrm{~min}$ & $\begin{array}{l}\text { Oxidation of styrene to } \\
\text { benzaldehyde }\end{array}$ & $\mathrm{H}_{2} \mathrm{O}_{2}$, tris- $\mathrm{HCl}$ buffer, $30^{\circ} \mathrm{C}$ & $\mathrm{Wu}, 2019,147$ \\
\hline & $\mathrm{Cu}(\mathrm{II})$ phthalocyanine & 0 & 18 & SB & $\begin{array}{l}\text { 1) } \mathrm{EtOH}, 1 \mathrm{~h} \\
\text { 2) }[\mathrm{Bmim}] \mathrm{Br} 180^{\circ} \mathrm{C} \text {, } \\
\text { 1h }\end{array}$ & $\begin{array}{l}\text { Oxidative amidation of } \\
\text { benzaldehyde }\end{array}$ & $\mathrm{TBHP}, \mathrm{CH}_{3} \mathrm{CN}, \mathrm{RT}$ & Shaabani, Amini, 2017, ${ }^{148}$ \\
\hline & $\mathrm{Cu}(\mathrm{II})$ phthalocyanine & 0 & 17.5 & SB & $\begin{array}{l}\text { 1) } \mathrm{EtOH}, 1 \mathrm{~h} \\
\text { 2) } \mathrm{DES}, 150^{\circ} \mathrm{C}, 30 \mathrm{~min}\end{array}$ & Epoxidation of styrene & $\mathrm{O} 2, \mathrm{TBHP}, \mathrm{CH}_{3} \mathrm{CN}, 60-80^{\circ} \mathrm{C}$ & Amini, 2019, ${ }^{149}$ \\
\hline & $\mathrm{RhH}(\mathrm{CO})\left(\mathrm{PPh}_{3}\right)_{3}+\mathrm{H}_{3} \mathrm{PW}_{12} \mathrm{O}_{40}$ & 0 & $\begin{array}{l}0.25 \\
0.88 \\
1.10\end{array}$ & $\operatorname{Imp}$ & Toluene, $70^{\circ} \mathrm{C}, 18 \mathrm{~h}$ & Hydroformylation of octene & $\mathrm{H}_{2} / \mathrm{CO}$, toluene, $70^{\circ} \mathrm{C}$ & Sartipi, Gascon, 2015,51 \\
\hline \multirow[t]{4}{*}{$\begin{array}{l}\mathrm{NH}_{2}-\mathrm{MIL}- \\
101(\mathrm{Al})\end{array}$} & Mn-salen & 0 & & SE & $\mathrm{DMF}, 110^{\circ} \mathrm{C}, 16 \mathrm{~h}$ & Epoxidation of dihydronaphtalene & $\begin{array}{l}\text { MCPBA/N-methylmorpholine, } \\
\mathrm{CH}_{2} \mathrm{Cl}_{2} \text {, RT }\end{array}$ & $\begin{array}{l}\text { Speybroeck, Van Der } \\
\text { Voort, 2013,150 }\end{array}$ \\
\hline & Fe-containing porphyrin (Hemin) & 0 & & $\operatorname{Imp}$ & $\mathrm{DMF}, \mathrm{RT}, 12 \mathrm{~h}$ & $\begin{array}{l}\text { Oxidation of 3,3,5,5- } \\
\text { tetramethylbenzidine }\end{array}$ & $\mathrm{H}_{2} \mathrm{O}_{2}$, citrate buffer, $50^{\circ} \mathrm{C}$ & Liu, 2013, ${ }^{151}$ \\
\hline & Ru alkylidene & $1+$ & & Imp & $\begin{array}{l}\text { Toluene or DCM, RT, } \\
1 \mathrm{~h}\end{array}$ & Olefin metathesis & $\begin{array}{l}\text { Toluene, } \mathrm{CH}_{2} \mathrm{Cl}_{2} \text { or } \\
\text { ethylacetate, } \mathrm{RT}\end{array}$ & $\begin{array}{l}\text { Grela, Chmielewski, } \\
2016,152\end{array}$ \\
\hline & $\begin{array}{l}{\left[\mathrm{Cp} * \mathrm{Rh}\left(4,4^{\prime}-\mathrm{bpydc}\right) \mathrm{Cl}\right] \mathrm{Cl}+} \\
{\left[\mathrm{Ru}(\mathrm{bpy})_{2}\left(4,4^{\prime}-\mathrm{bpydc}\right)\right]\left(\mathrm{PF}_{6}\right)_{2}}\end{array}$ & $1+$ & & Imp & $\mathrm{CH}_{3} \mathrm{CN}, \mathrm{RT}, 24 \mathrm{~h}$ & $\begin{array}{l}\text { Photocatalytic } \mathrm{CO}_{2} \text { reduction to } \\
\text { formate }\end{array}$ & $\begin{array}{l}\mathrm{CH}_{3} \mathrm{CN} / \mathrm{TEOA}(20 / 1), \mathrm{RT}, 300 \mathrm{~W} \\
\text { Xe lamp }(\lambda>415 \mathrm{~nm})\end{array}$ & $\begin{array}{l}\text { Fontecave, Mellot- } \\
\text { Draznieks, 2018, }{ }^{153}\end{array}$ \\
\hline \multirow[t]{2}{*}{$\begin{array}{l}\mathrm{HSO}_{3}-\mathrm{MIL}- \\
101(\mathrm{Cr})\end{array}$} & $\begin{array}{l}{[\mathrm{Rh}(\mathrm{COD})(\mathrm{dppe})] \mathrm{BF}_{4}} \\
{\left[\mathrm{Rh}(\mathrm{COD})\left(\mathrm{CH}_{3} \mathrm{CN}\right)_{2}\right] \mathrm{BF}_{4}}\end{array}$ & $1+$ & & Imp & DMF, RT, $72 \mathrm{~h}$ & Hydrogenation of alkenes & $\begin{array}{l}\mathrm{H}_{2}, \mathrm{DMF} \text {, acetone or } \mathrm{C}_{6} \mathrm{D}_{6}, 25- \\
100^{\circ} \mathrm{C}\end{array}$ & Sanford, 2016,154 \\
\hline & {$\left[\operatorname{Ir}(\mathrm{COD})\left(\mathrm{PC} \mathrm{y}_{3}\right)(\mathrm{py})\right] \mathrm{PF}_{6}$} & $1+$ & 2.28 & $\operatorname{Imp}$ & Acetone, RT, $20 \mathrm{~h}$ & Hydrogenation of alkenes & $\mathrm{CH}_{2} \mathrm{Cl}_{2}, \mathrm{RT}$ & $\begin{array}{l}\text { Weller, Rosseinsky, } \\
2018,{ }^{155}\end{array}$ \\
\hline MIL-100(Al) & Cu-Phen & & & SB & EtOH, RT, $24 \mathrm{~h}$ & Cyclohexane oxidation & $\mathrm{H}_{2} \mathrm{O}_{2}, \mathrm{CH}_{3} \mathrm{CN}, 30-80^{\circ} \mathrm{C}$ & Fan, Li, 2015, ${ }^{156}$ \\
\hline MIL-100(Cr) & Co-salen & 0 & & SB & $\begin{array}{l}\text { 1) Ethyl alcohol, RT, } \\
\text { 12h } \\
\text { 2) Acetone, } 80^{\circ} \mathrm{C}, 24 \\
\text { h }\end{array}$ & Electrocatalytic ORR & Phosphate buffer ( $\mathrm{pH}=6.8$ ) & $L i, 2014,{ }^{157}$ \\
\hline MIL-100(Fe) & Cu-phthalocyanine & 0 & 10.1 & SB & $\begin{array}{l}\text { 1) } \mathrm{EtOH}, 1 \mathrm{~h} \\
\text { 2) } \mathrm{DES}, 150^{\circ} \mathrm{C}, 30 \mathrm{~min}\end{array}$ & Epoxidation of styrene & $\mathrm{TBHP}, \mathrm{CH}_{3} \mathrm{CN}, 80^{\circ} \mathrm{C}$ & Amini, $2019,{ }^{149}$ \\
\hline MIL-125(Ti) & {$\left[\mathrm{Ru}(\mathrm{bpy})_{3}\right] \mathrm{Cl}_{2}$} & $2+$ & & SE & $\begin{array}{l}\mathrm{DMF} / \mathrm{MeOH}(9 / 1.2) \\
130^{\circ} \mathrm{C}, 15 \mathrm{~h}\end{array}$ & $\begin{array}{l}\text { Photocatalytic oxidative coupling } \\
\text { of benzylamine }\end{array}$ & $\begin{array}{l}\mathrm{CH}_{3} \mathrm{CN}, \mathrm{RT}, 300 \mathrm{~W} \text { Xe lamp } \\
(\lambda>440 \mathrm{~nm})\end{array}$ & Gao, Cao, 2019, ${ }^{158}$ \\
\hline
\end{tabular}




\begin{tabular}{|c|c|c|c|c|c|c|c|c|}
\hline \multirow[t]{4}{*}{$\begin{array}{l}\mathrm{NH}_{2}-\mathrm{MIL}- \\
125(\mathrm{Ti})\end{array}$} & Co'll-dioxime-diimine & 0 & $1.1-2.7$ & SB & $\begin{array}{l}\text { 1) Acetone, RT, } 12 \mathrm{~h} \\
\text { 2) Acetone, RT, } 3 \mathrm{~h}\end{array}$ & Photocatalytic HER & $\begin{array}{l}\mathrm{CH}_{3} \mathrm{CN} / \mathrm{TEA} / \mathrm{H}_{2} \mathrm{O}(5 / 1 / 0.1), \mathrm{RT}, \\
500 \mathrm{~W} \text { Xe/Hg lamp }(\lambda>408 \\
\mathrm{nm})\end{array}$ & $\begin{array}{l}\text { Reek, van der Vlugt, } \\
\text { Gascon, 2015, } 159\end{array}$ \\
\hline & [Co"(TPA)Cl]Cl & $1+$ & & SB & $\begin{array}{l}\text { 1) } \mathrm{MeOH}, \mathrm{RT}, 12 \mathrm{~h} \\
\text { 2) } \mathrm{MeOH}, \mathrm{RT}, 12 \mathrm{~h}\end{array}$ & Photocatalytic HER & $\begin{array}{l}\mathrm{CH}_{3} \mathrm{CN} / \mathrm{TEOA} / \mathrm{H}_{2} \mathrm{O}, \mathrm{RT}, 500 \mathrm{~W} \\
\text { Xe lamp }(\lambda>380 \mathrm{~nm})\end{array}$ & Jiang, 2016,160 \\
\hline & {$\left[\mathrm{Ru}(\mathrm{bpy})_{3}\right] \mathrm{Cl}_{2}$} & $2+$ & & SE & $\begin{array}{l}\mathrm{DMF} / \mathrm{MeOH}(9 / 1) \\
150^{\circ} \mathrm{C}, 48 \mathrm{~h}\end{array}$ & $\begin{array}{l}\text { Photocatalytic aerobic oxidation } \\
\text { of benzyl alcohol }\end{array}$ & $\begin{array}{l}\mathrm{CH}_{3} \mathrm{CN}, \mathrm{RT}, 500 \text { W Xe lamp }(\lambda> \\
450 \mathrm{~nm})\end{array}$ & Yamashita, 2019, ${ }^{161}$ \\
\hline & {$\left[\mathrm{Ru}(\mathrm{bpy})_{3}\right] \mathrm{Cl}_{2}$} & $2+$ & 5 & SE & $\mathrm{DMF}, 120^{\circ} \mathrm{C}, 24 \mathrm{~h}$ & $\begin{array}{l}\text { Photophysical properties of } \\
\operatorname{Ru}(\text { bpy })_{3}{ }^{2+}\end{array}$ & - & Larsen, 2017, ${ }^{162}$ \\
\hline \multirow[t]{2}{*}{$\begin{array}{l}\text { Zr-MOF } \\
\text { UiO-67 }\end{array}$} & {$\left[\mathrm{Nil}(\right.$ bpet $\left.)\left(\mathrm{H}_{2} \mathrm{O}\right)_{2}\right]\left(\mathrm{ClO}_{4}\right)_{2}$} & $2+$ & $\begin{array}{l}0.15 \\
0.23 \\
0.31\end{array}$ & SB & $\begin{array}{l}\text { 1) } \mathrm{CH}_{3} \mathrm{CN}, \mathrm{RT} \\
\text { 2) Acetone/ } \mathrm{H}_{2} \mathrm{O} \\
\text { (20/1), } \mathrm{RT}, 24 \mathrm{~h}\end{array}$ & $\begin{array}{l}\text { Photocatalytic } \mathrm{CO}_{2} \text { reduction to } \\
\text { CO }\end{array}$ & $\begin{array}{l}\mathrm{DMF} / \mathrm{H}_{2} \mathrm{O} / \mathrm{BIH} / \mathrm{TEOA}, 15^{\circ} \mathrm{C}, 82 \\
\mathrm{~W} \operatorname{LED}(\lambda=450 \mathrm{~nm})\end{array}$ & Jin, Kong, 2019, 163 \\
\hline & {$\left[\mathrm{Ru}(\mathrm{bpy})_{3}\right]\left(\mathrm{PF}_{6}\right)_{2}$} & $2+$ & & Imp & $\mathrm{DMF}, 90^{\circ} \mathrm{C}, 12 \mathrm{~h}$ & Singlet oxygen generation & & Lee, $2017,{ }^{164}$ \\
\hline $\begin{array}{l}\text { Zr-MOF } \\
\text { MOF-545(Zn) }\end{array}$ & {$\left[\left(1^{\prime}-\mathrm{SCH}_{2}\right)_{2} \mathrm{NC}(\mathrm{O}) \mathrm{C}_{5} \mathrm{H}_{4} \mathrm{~N}\right]\left[\mathrm{Fe}_{2}(\mathrm{CO})_{6}\right]$} & 0 & & $\operatorname{Imp}$ & $\mathrm{CH}_{2} \mathrm{Cl}_{2}, 48 \mathrm{~h}$ & Photocatalytic HER & $\begin{array}{l}\text { Ascorbic acid, acetate buffer } \\
(\mathrm{pH} \mathrm{5)}, \mathrm{RT}, 300 \mathrm{~W} \text { Xe lamp }(\lambda> \\
420 \mathrm{~nm})\end{array}$ & Feng, 2014, ${ }^{165}$ \\
\hline MOF-545(Co) & $\mathrm{MCp}_{2}(\mathrm{M}=\mathrm{Fe}, \mathrm{Co}, \mathrm{Ni})$ & 0 & & CVD & $40^{\circ} \mathrm{C}, 2 \mathrm{~h}$ & $\begin{array}{l}\text { Electrocatalytic } \mathrm{CO}_{2} \text { reduction to } \\
\mathrm{CO}\end{array}$ & $\mathrm{KHCO}_{3}$ solution, $\mathrm{RT}$ & Chen, Lan, 2020,166 \\
\hline $\begin{array}{l}\text { Zr-MOF } \\
\text { PCN-224 }\end{array}$ & $\left.\left[Z n^{\prime \prime}-\mathrm{TMPyP}\right]\right]_{4}$ & $4+$ & 4.93 & Imp & $\mathrm{DMF}, 60^{\circ} \mathrm{C}, 24 \mathrm{~h}$ & $\begin{array}{l}\text { Cycloaddition of } \mathrm{CO}_{2} \text { with } \\
\text { epoxides } \\
\text { Acid/base catalysis }\end{array}$ & No solvent, RT & Nagaraja, 2019, ${ }^{167}$ \\
\hline \multirow{2}{*}{$\begin{array}{l}\text { Zn-MOF } \\
\text { ZIF-8 }\end{array}$} & Mn-TAPP porphyrin & 0 & 3.8 & SE & $\mathrm{DMF}, 135^{\circ} \mathrm{C}, 36 \mathrm{~h}$ & Epoxidation of olefin substrates & $\mathrm{TBHP}, \mathrm{CH}_{3} \mathrm{CN}, 80^{\circ} \mathrm{C}$ & Jiang, 2016, ${ }^{168}$ \\
\hline & {$[\mathrm{Fe}($ salen $) \mathrm{Cl}]+\mathrm{H}_{4} \mathrm{SiW}_{12} \mathrm{O}_{40}$} & & & SE & $\mathrm{MeOH}, \mathrm{RT}, 2 \mathrm{~h}$ & Electrocatalytic OER & $\mathrm{KCl}$ solution (neutral $\mathrm{pH}$ ), $\mathrm{RT}$ & Das, 2020,139 \\
\hline $\begin{array}{l}\text { Zn-MOF } \\
\text { IRMOF-3 }\end{array}$ & $(\mathrm{R}, \mathrm{R})$-salen(Co(III)) & 0 & & $\operatorname{Imp}$ & $\mathrm{CHCl}_{3}, 55^{\circ} \mathrm{C}, 12 \mathrm{~h}$ & Racemic epoxides $/ \mathrm{CO}_{2}$ coupling & No solvent, RT & Chen, Zhang, 2017, ${ }^{169}$ \\
\hline $\begin{array}{l}\text { Cu- and Zn- } \\
\text { MOF } \\
\text { HKUST-1 }\end{array}$ & $\mathrm{Fe}_{4} \mathrm{SP}, \mathrm{Mn}_{4} \mathrm{SP}$ porphyrin & 0 & & SE & $\begin{array}{l}\mathrm{EtOH} / \mathrm{DMF} / \mathrm{H}_{2} \mathrm{O} \\
(1 / 1 / 1), 60^{\circ} \mathrm{C}, 7 \mathrm{~h}\end{array}$ & Peroxidase $\mathrm{H}_{2} \mathrm{O}_{2}$ degradation & $\mathrm{EtOH} / \mathrm{H}_{2} \mathrm{O}, \mathrm{RT}$ & Larsen, 2011, ${ }^{170}$ \\
\hline $\begin{array}{l}\text { In-MOF } \\
\text { ZJU-28 }\end{array}$ & {$[\mathrm{Rh}(\mathrm{COD})(\mathrm{dppe})] \mathrm{BF}_{4}$} & $1+$ & 3.5 & $\operatorname{Imp}$ & $\mathrm{DMF}, \mathrm{RT}, 72 \mathrm{~h}$ & Hydrogenation of 1-octene & $\mathrm{H}_{2}$, acetone, $35-75^{\circ} \mathrm{C}$ & Sanford, $2013,{ }^{171}$ \\
\hline $\begin{array}{l}{\left[\mathrm{Et}_{4} \mathrm{~N}\right]_{3}\left[\mathrm{In}_{3}(\mathrm{BTC}\right.} \\
\left.)_{4}\right]\end{array}$ & $\begin{array}{l}{[\mathrm{Rh}(\mathrm{COD})(\mathrm{dppe})] \mathrm{BF}_{4}} \\
{\left[\mathrm{Rh}(\mathrm{COD})\left(\mathrm{CH}_{3} \mathrm{CN}\right)\right] \mathrm{BF}_{4}}\end{array}$ & $1+$ & & $\operatorname{Imp}$ & $\mathrm{DMF}, \mathrm{RT}, 72 \mathrm{~h}$ & Hydrogenation of alkenes & $\begin{array}{l}\mathrm{H}_{2}, \mathrm{DMF} \text {, acetone or } \mathrm{C}_{6} \mathrm{D}_{6}, 25- \\
100^{\circ} \mathrm{C}\end{array}$ & Sanford, 2016, ${ }^{154}$ \\
\hline
\end{tabular}




\begin{tabular}{|c|c|c|c|c|c|c|c|c|}
\hline & $\begin{array}{l}{\left[\mathrm{CpFe}(\mathrm{CO})_{2}(\mathrm{~L})\right]^{+}, \mathrm{L}=\text { weakly bound }} \\
\text { solvent }\end{array}$ & $1+$ & & & $\begin{array}{l}\text { Dry acetone, RT, } 48 \mathrm{~h} \\
\text { DMF, } 120^{\circ} \mathrm{C}, 24 \mathrm{~h}\end{array}$ & $\begin{array}{l}\text { Diels-Alder reaction between } \\
\text { isoprene and methyl vinyl ketone }\end{array}$ & $\mathrm{CH}_{2} \mathrm{Cl}_{2}, \mathrm{RT}$ & $\begin{array}{l}\text { Weller, Rosseinsky, } \\
2016,{ }^{172}\end{array}$ \\
\hline $\begin{array}{l}\text { In-MOF } \\
\text { PCN-99 }\end{array}$ & {$\left[\mathrm{Ru}(\mathrm{bpy})_{3}\right] \mathrm{Cl}_{2}$} & $2+$ & & $\operatorname{Imp}$ & $\mathrm{DMF}, \mathrm{RT}, 40 \mathrm{~min}$ & $\begin{array}{l}\text { Photocatalytic aerobic oxidative } \\
\text { hydroxylation of aryl-boronic acid }\end{array}$ & $\begin{array}{l}\mathrm{DMF} / \mathrm{Pr}_{2} \mathrm{EtN}, \mathrm{RT}, 36 \mathrm{~W} \\
\text { fluorescence lamp }\end{array}$ & Zhou, 2016, ${ }^{173}$ \\
\hline \multirow[t]{2}{*}{$\begin{array}{l}\text { In-MOF } \\
\text { Rho-ZMOF } \\
{\left[\begin{array}{l}{\left[\ln _{48}(\mathrm{HImDC})_{96}\right]} \\
48-\end{array}\right.}\end{array}$} & {$\left[\mathrm{H}_{2} \mathrm{TMPyP}\right][p \text {-tosyl }]_{4}$ porphyrin } & $4+$ & 2.5 & SE & $\begin{array}{l}\mathrm{DMF} / \mathrm{CH}_{3} \mathrm{CN}(1 / 1), \\
85^{\circ} \mathrm{C}, 12 \mathrm{~h}, 105^{\circ} \mathrm{C}, 24 \\
\mathrm{~h}\end{array}$ & Cyclohexane oxidation & TBHP, no solvent, $65^{\circ} \mathrm{C}$ & Eddaoudi, 2008, ${ }^{174}$ \\
\hline & {$\left[\mathrm{Pt}^{\prime \prime}-\mathrm{TMPyP}\right] \mathrm{Cl}_{4}$ porphryin } & $4+$ & & SE & $\begin{array}{l}\text { EtOH/DMF (1/1), } \\
85^{\circ} \mathrm{C}, 12 \mathrm{~h}, \\
105^{\circ} \mathrm{C}, 48-72 \mathrm{~h}\end{array}$ & Anion selective sensing & - & Eddaoudi, 2018, ${ }^{175}$ \\
\hline
\end{tabular}

${ }^{\mathrm{a}} \mathrm{SE}=$ synthetic encapsulation; $\mathrm{Imp}=$ impregnetion; $\mathrm{SB}=$ ship in a bottle . 


\section{ARTICLE}

ligand leads to a variety of UiO-66's derivatives. The high connectivity (12 linkers per $\mathrm{Zr}_{6}$ unit in the defect-free structure) allows preserving its crystallinity even up to $25 \%$ linkers defect. ${ }^{176}$ UiO-66 is stable to water and organic solvents for several weeks and can withstand long exposure to acidic or basic $\mathrm{pH}$ at least in the 4 to 12 range. Although it does not show any XRD or BET changes after several weeks in oxidative conditions $\left(5 \% \mathrm{H}_{2} \mathrm{O}_{2}\right)$, the material lacks stability when exposed to air, leading to its partial destruction after 3 days. ${ }^{177}$ Stability tests performed on UiO-66- $\mathrm{NH}_{2}$ have shown that the linker functionalization somehow reduces its stability in water but increases its stability in air.

UiO-6724 $\left(\mathrm{Zr}_{6} \mathrm{O}_{4}(\mathrm{OH})_{4}(\mathrm{bpdc})_{2}\right)$ derives from UiO-66, as it incorporates 4,4'-diphenyldicarboxylate (BPDC) linkers instead of BDC. This induces an increase in the distances between $\mathrm{Zr}_{6}$ nodes as well as in the sizes of pores and windows. UiO-67 is thus composed of octahedral and tetrahedral cages of $18 \AA$ and $11.5 \AA$ internal diameter, respectively, ${ }^{101}$ while exhibiting a $3000 \mathrm{~m}^{2} \cdot \mathrm{g}^{-1}$ BET surface area. ${ }^{24}$ UiO-67 is notably less stable than UiO-66, with a decrease in porosity after 3 days in a $\mathrm{pH} 4-$ 12 aqueous solution and even in air/moisture, and a total destruction in $5 \% \mathrm{H}_{2} \mathrm{O}_{2} .{ }^{177}$

MOF-545 $\left(\mathrm{Zr}_{6} \mathrm{O}_{8}\left(\mathrm{H}_{2} \mathrm{O}\right)_{8}(\mathrm{TCPP})_{2}\right),{ }^{178}$ also known as PCN$222,{ }^{179}$ is also a $\mathrm{Zr}$-MOF which incorporates tetrakis(4-carboxyphenyl)porphyrin (TCPP) ligands. In MOF-545, the TCPP linkers are bound to four distinct $\mathrm{Zr}_{6}$ clusters located on two different layers, creating two distinct types of channels, large hexagonal ones of $36 \AA$ diameter and smaller triangular channels, providing a total BET surface area of $\sim 2300 \mathrm{~m}^{2}$. $\mathrm{g}^{-1}$. The large size of hexagonal channels allows easy post synthetic impregnation of various molecules. Moreover, the photosensitivity of TCPP and its possible metalation award this hybrid solid interesting properties for photocatalytic reactions such as $\mathrm{CO}_{2}$ reduction or water splitting (see below). ${ }^{108,180}$ MOF-545 is stable to organic solvents, highly stable in water even in very acidic conditions (concentrated $\mathrm{HCl}$ solution) but decomposes at $\mathrm{pH}$ above $10 .{ }^{179}$

Another $\mathrm{Zr}$-based MOF we will focus on in this review is NU$1000 .{ }^{181}$ It is synthesized by reaction of a $\mathrm{Zr}$ precursor with 1,3,6,8-tetrakis(p-benzoic-acid)pyrene ( $\left.\mathrm{H}_{4} \mathrm{TBAPy}\right)$ under solvothermal conditions. In $\mathrm{Zr}_{6} \mathrm{O}_{8}\left(\mathrm{H}_{2} \mathrm{O}\right)_{8}(\mathrm{TBAPY})_{2}$, the $\mathrm{Zr}_{6}$ oxoclusters are linked via TBAPy ligands located on eight of the twelve octahedron edges, the remaining edges being occupied by bridging hydroxo ligands, leading to a porous material with two kinds of tunnels. The largest tunnel is hexagonally shaped with a diameter of $31 \AA$ and the smallest tunnel has a triangular shape with a diameter of $8 \AA$. The overall structure is highly porous with a BET surface area of $2320 \mathrm{~m}^{2} \cdot \mathrm{g}^{-1}$. Moreover, NU1000 is stable in water in a large $\mathrm{pH}$ range (1-10). ${ }^{182}$

HKUST-1 (or Cu-BTC) is one of the oldest MOF, having been synthetized in 1999 by Chui et al.. ${ }^{183}$ HKUST-1, which can be formulated as $\mathrm{Cu}_{3}\left(\mathrm{H}_{2} \mathrm{O}\right)_{3}(\mathrm{BTC})_{2}$, is composed of dimeric cupric tetracarboxylate units, the 12 oxygens from the carboxylate groups of the BTC linkers binding four coordination sites for each of the three copper ions of the formula unit. Each metal completes its pseudooctahedral coordination sphere with an axial aqua ligand pointing towards the nanopore. This leads to a paddle-wheeled framework exhibiting $18.6 \AA$ diameter hexagonal cages and $13 \AA$ diameter square pore windows. ${ }^{183}$ This MOF exhibits a relatively low surface area of $690 \mathrm{~m}^{2} . \mathrm{g}^{-1}$. It must be noted that Cu-BTC is moderaterly stable to water and air. ${ }^{177}$

Lastly, ZIF- $8^{184}$ belongs to the sub-family of zeolitic imidazolate frameworks whereby individual zinc tetrahedra are connected to each other via the organic ligands to form a sodalite-type network. ZIF-8 has a unique porous structure made of sodalite-type hybrid cages of $12 \AA$ internal diameter communicating through 6-ring windows of $3.4 \AA$ free aperture, allowing a BET surface area of $1630 \mathrm{~m}^{2} \cdot \mathrm{g}^{-1}$. ZIF-8 is highly stable to air, water and steam, showing no degradation after a few days in harsh conditions. It can withstand acid and basic media (in the $\mathrm{pH}$ 4-12 range) for several days and oxidative conditions for the same duration. ${ }^{177}$

Concerning now the catalytic guests, we consider here successively the whole variety of POMs and organometallic and coordination complexes that have been successfully immobilized in one of the MOF mentioned above. Polyoxometalates are anionic metal oxide clusters built by the connection of $\mathrm{MO}_{\mathrm{n}}\left(\mathrm{M}=\mathrm{W}^{\mathrm{VI} / \mathrm{V}}, \mathrm{Mo}^{\mathrm{VI} / \mathrm{V}}, \mathrm{V}^{\mathrm{V} / \mathrm{IV}}\right.$...) polyhedra. They can be divided into two families, isopolyoxometalates and heteropolyoxometalates, these last incorporating additional $\mathrm{XO}_{\mathrm{n}}$ groups $\left(\mathrm{X}=\mathrm{P}^{\mathrm{V}}, \mathrm{Si}^{\mathrm{l}}, \mathrm{Ge}^{\mathrm{lV}}, \mathrm{As}^{\mathrm{V}} \ldots\right)$. To date, only heteropolyoxometalates have been immobilized in MOFs (see Table 1). More precisely, $\left[\mathrm{XM}_{12} \mathrm{O}_{40}\right]^{\mathrm{n}-\mathrm{K}}$ Keggin and $\left[\mathrm{X}_{2} \mathrm{M}_{18} \mathrm{O}_{62}\right]^{\mathrm{n}-}$ Dawson species as well as dimeric sandwich-type Keggin POMs have been considered (Fig. 2). The structure of the Keggin POM $\mathrm{XM}_{12}$ can be seen as the assembly of four trimetallic subunits $\mathrm{M}_{3} \mathrm{O}_{13}$ around a $\mathrm{XO}_{4}$ tetrahedron. ${ }^{185} \mathrm{By}$ controlled hydrolysis under basic conditions of the saturated species $X_{12}$, lacunary (also called vacant) species can be selectively obtained. Monovacant $\left[\mathrm{XM}_{11} \mathrm{O}_{39}\right]^{\mathrm{n}-}$, divacant $\left[\mathrm{XM}_{10} \mathrm{O}_{36}\right]^{\mathrm{n}-}$ or trivacant $\left[\mathrm{XM}_{9} \mathrm{O}_{34}\right]^{\text {n- }}$ derivatives were thus isolated. ${ }^{186}$ Knowing how lacunary species are formed, POMs are known to be highly sensitive to $\mathrm{pH}$. The reaction of lacunary Keggin anions with transition metals $\mathrm{M}^{\prime}$ can lead to the formation of substituted Keggin such as the monomeric $\left[\mathrm{SiW}_{9} \mathrm{Co}_{3}\left(\mathrm{H}_{2} \mathrm{O}\right)_{3} \mathrm{O}_{37}\right]^{10-}$ and $\left[\mathrm{XW}_{11} \mathrm{M}^{\prime} \mathrm{O}_{39}\left(\mathrm{H}_{2} \mathrm{O}\right)\right]^{\mathrm{n}-}\left(\mathrm{M}^{\prime}=\mathrm{Ti}, \mathrm{Fe}, \mathrm{Co}, \mathrm{Cu}, \mathrm{Zn}\right)$ compounds represented in Fig. 2. The dimeric sandwich-type POMs $\left[\left(\mathrm{XW}_{9} \mathrm{O}_{34}\right)_{2} \mathrm{M}_{4}{ }_{4}\left(\mathrm{H}_{2} \mathrm{O}\right)_{2}\right]^{\mathrm{n}-}\left(\mathrm{M}^{\prime}=\mathrm{Co}, \mathrm{Ni}\right)$ can also be isolated by reaction of tri-vacant $X W_{9}$ Keggin units with $3 d$ ions. ${ }^{187}$ 


\section{ARTICLE}
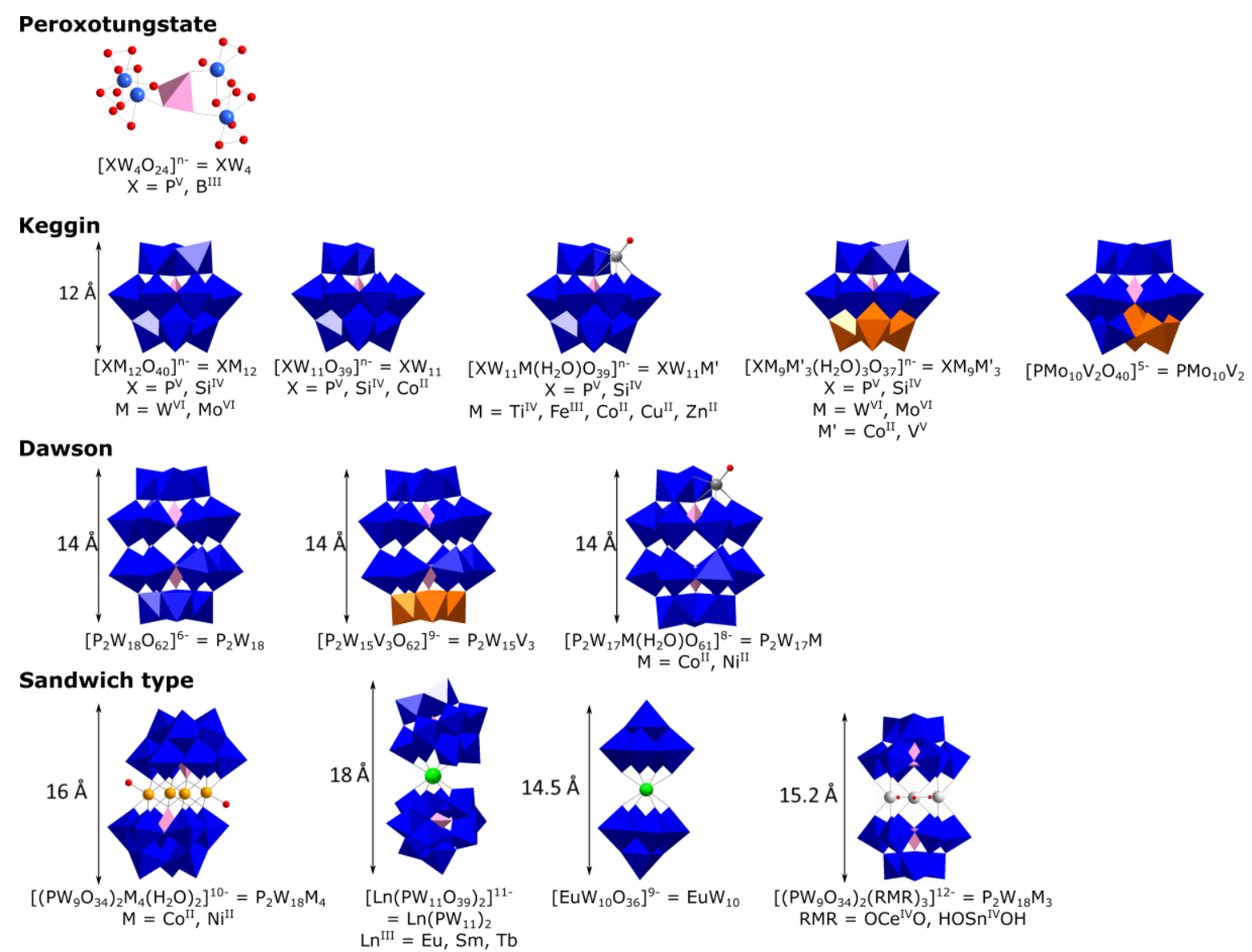

Fig. 2 Representation of the POM guests mentioned in this review with their dimensions, formulas and abbreviations.

Finally, $\mathrm{X}_{2} \mathrm{M}_{18}$ Dawson-type POMs, which may be regarded as two $X M_{9}$ tri-vacant Keggin units connected via six oxygen atoms, have been also incorporated in MOF matrices. Still, looking at Table 1, it is apparent that $\mathrm{PW}_{12}$ stands for $35 \%$ of the studies of POMs immobilized into MOF. This can be explained considering i) its widely recognized catalytic activity, in particular as an acid catalyst, ${ }^{2}$ ii) its stability in most conditions used for its incorporation into MOF, iii) its charge and size among the smallest ones within the POMs family allowing to reach high $\mathrm{POM}$ loadings, i.e. minimizing charge balance issues upon immobilization into MOF iv) its commercially availability at low cost and $v$ ) its characteristic IR and ${ }^{31} \mathrm{P}$ NMR signatures highly useful to check its integrity upon immobilization and before/after the catalytic events.

Concerning the organometallic and coordination complexes, the main species successfully immobilized in MOFs are represented in Fig. 3. Metallated phthalocyanine ${ }^{188}$ and porphyrin ${ }^{189}$ molecules have been particularly studied, these species obviously playing an important role in (photo)catalysis ${ }^{190-193}$ including fundamental reactions such as $\mathrm{CO}_{2}$ reduction. ${ }^{194}$ Bipyridine transition metal complexes (typically $\mathrm{M}(\mathrm{bpy})_{3}(\mathrm{M}=\mathrm{Ru}, \mathrm{Ir})$ species) have also been selected for their photosensitive ${ }^{195}$ and catalytic properties. ${ }^{196}$ Importantly, all these complexes present a good chemical stability. Finally, catalytically active salen complexes have also been considered. ${ }^{197,198}$

\subsection{Synthetic strategies}

The synthesis of the Cat@MOF composites may be performed using various strategies according to the nature of the catalyst, its size compared to the size of the cavity windows and its stability (Fig. 4).

2.2.1 Synthetic encapsulation. Molecular catalysts may be encapsulated within the cavities of MOF by a direct synthesis strategy called 'bottle around the ship' or 'synthetic encapsulation' (Fig. 4a) whereby the catalyst is added as a reactant during the MOF synthesis. This method thus requires that the catalyst is both soluble and stable in the conditions of the MOF's synthesis. For example, hydrothermal conditions, with temperatures equal to $180^{\circ} \mathrm{C}$ (during $72 \mathrm{~h}$ ) or $220^{\circ} \mathrm{C}$ (during $8 \mathrm{~h})$ are usually described for the synthesis of MIL-101(Cr) 
composites (Table 1). Note that microwave conditions have also been reported for example for the synthesis of PW $12 @ M I L-$ 101(Cr), ${ }^{54} \mathrm{PW}_{11} \mathrm{Zn} @ \mathrm{NH}_{2}-\mathrm{MIL}-101(\mathrm{Al})^{72}$ and

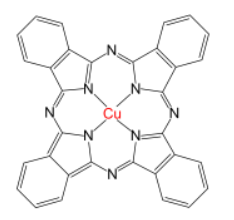

Cu-phthalocyanine

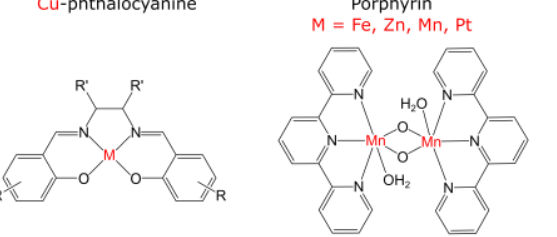

M-salen
$\mathrm{M}=\mathrm{Cu}, \mathrm{Mn}, \mathrm{Co}, \mathrm{Fe}$

$\left[\left(\mathrm{H}_{2} \mathrm{O}\right)(\operatorname{terpy}) \mathrm{Mn}(\mu-\mathrm{O})_{2} \mathrm{Mn}\left(\operatorname{terpy}\left(\mathrm{H}_{2} \mathrm{O}\right)\right]^{3+}\right.$
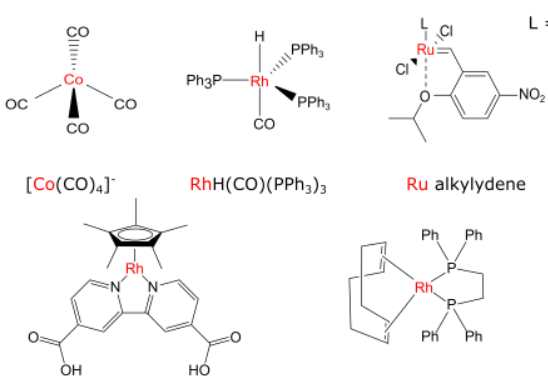

$\left[\mathrm{Cp} * \mathrm{Rh}\left(4,4^{\prime}-\mathrm{bpydc}\right) \mathrm{Cl}\right]^{+}$

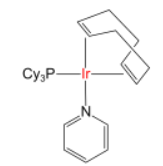

$\left[\operatorname{Ir}(\mathrm{COD})\left(\mathrm{PCy}_{3}\right)(\mathrm{py})\right]^{+}$

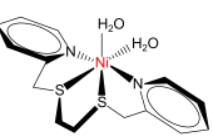

$\left[\mathrm{Ni}(\text { bpet })\left(\mathrm{H}_{2} \mathrm{O}\right)_{2}\right]^{2+}$

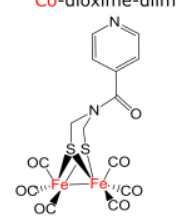

Ru alkylydene

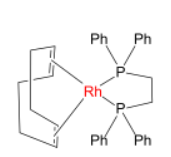

$[\mathrm{Rh}(\mathrm{COD})(\mathrm{dppe})]^{+}$

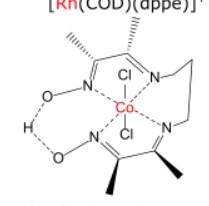

$$
\text { Co-dioxime-diimine }
$$

$\left[\mathrm{Rh}(\mathrm{COD})\left(\mathrm{CH}_{3} \mathrm{CN}\right)_{2}\right]^{+}$

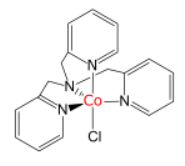

$[\mathrm{Co}(\mathrm{TPA}) \mathrm{CI}]^{+}$

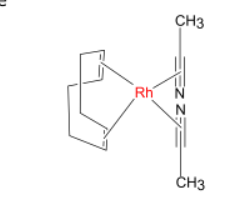

Fig. 3 Representation of the organometallic and coordination complex guests mentionned in this review.

a) Synthetic encapsulation

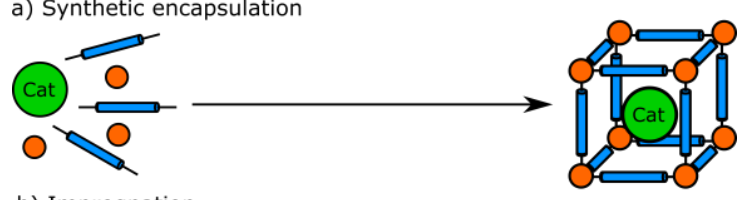

b) Impregnation

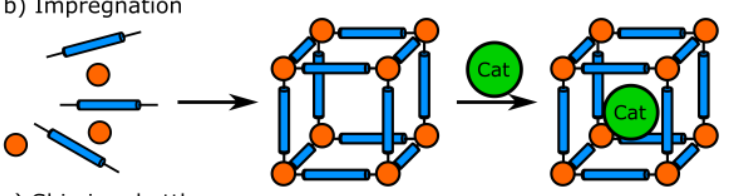

c) Ship in a bottle
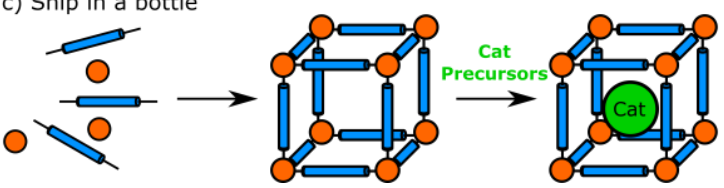

Fig. 4 Schematic representation of the various synthetic pathways used for the synthesis of pore-functionalized Cat@MOFs.
PW $12 @ N_{2}-$ MIL-53(Al) ${ }^{76}$ composites. Zr-based MOFs composites are usually synthesized under solvothermal conditions in DMF at $120^{\circ} \mathrm{C}$ for 6 to $24 \mathrm{~h}$ while HKUST derivatives are isolated by heating the reactants in water at $180^{\circ} \mathrm{C}$ for 6 to $72 \mathrm{~h}$ or in mixed $\mathrm{H}_{2} \mathrm{O} / \mathrm{EtOH}$ solvents, at lower temperature to even room temperature (RT). The mechanochemical synthesis is an original method attracting a growing interest. ${ }^{199,200}$ This method consists in grinding the solid precursors in an agate mortar or using a ball-milling grinder. Fast and easy, it does not consume any solvent nor requires any heating. It has been described for $\mathrm{PMO}_{10} \mathrm{~V}_{2} @ H K U S T-1,{ }^{132}$ PW $_{12} @ H K U S T-1,129$ $\mathrm{XM}_{12} @ Z I F-8(\mathrm{X}=\mathrm{P}, \mathrm{M}=\mathrm{W}, \mathrm{Mo} ; \mathrm{X}=\mathrm{Si}, \mathrm{M}=\mathrm{W})^{138}$ and $\mathrm{PMo}_{12}$ ${ }_{x} V_{x} @ r h o-Z I F(x=0-3) .{ }^{141}$ In their first attempts to synthesize POM@HKUST-1, ${ }^{132}$ Liu et al. showed that the nanocrystals were not well-faceted and improved their protocol by using liquidassisted grinding. ${ }^{129}$ They thus used small volumes of $\mathrm{MeOH}$ and $\mathrm{EtOH}$ ( 1 to $2 \mu \mathrm{L}$ per $\mathrm{mg}$ of solid reactants) as grinding liquids to increase the crystallinity of the products.

The synthetic encapsulation method is mostly used when the targeted molecular catalyst has dimensions greater than those of the MOF's accessible windows, prohibiting their diffusion and any post-synthetic impregnation approach. In this case, one key advantage of the resulting Cat@MOF composite is that the catalyst, provided it is stable in the catalytic conditions, cannot leach. However, the pores may be blocked, hindering the diffusion of reactants.

2.2.2 Impregnation. When the targeted catalyst is not stable in the conditions required for the MOF's synthesis (acidic medium, high temperature, etc...), an impregnation strategy may be sufficient in order to perform its immobilization in the MOF's pores or channels. This synthetic method requires however that such catalysts are small enough to diffuse through the MOF's windows (Fig. 4b). In this milder synthetic method, the catalyst is dissolved in a solvent ensuring its stability, usually water or $\mathrm{CH}_{3} \mathrm{CN}$ for POM catalysts with protons/alkaline or TBA countercations, respectively (Table 1 ). Regarding organometallic and coordination complexes, various organic solvents (acetone, $\mathrm{CH}_{2} \mathrm{Cl}_{2}, \mathrm{CHCl}_{3}, \mathrm{MeOH}$, toluene, DMF) are used (Table 2). The MOFs' crystallites are added and the resulting suspension is then stirred for a determined amount of time ranging from 2 hours to 4 days, usually at RT. Note that the stability of the catalyst in the impregnation solution is not sufficient to ensure its integrity upon its immobilisation. As an illustrative example, ${ }^{31} \mathrm{P}$ NMR together with IR spectroscopy (see below) have shown that the hybrid sandwich-type POM $\left[\left(\mathrm{PW}_{9} \mathrm{O}_{34}\right)_{2} \mathrm{CO}_{7}(\mathrm{OH})_{2}\left(\mathrm{H}_{2} \mathrm{O}\right)_{4}\left(\mathrm{O}_{3} \mathrm{PC}(\mathrm{O})\left(\mathrm{C}_{3} \mathrm{H}_{6} \mathrm{NH}_{3}\right) \mathrm{PO}_{3}\right)_{2}\right]^{14-}$ (noted $\mathrm{P}_{2} \mathrm{~W}_{18} \mathrm{Co}_{7}(\mathrm{Ale})_{2}$ ) evolves into $\mathrm{P}_{2} \mathrm{~W}_{18} \mathrm{Co}_{4}$ when immobilized inside the cavities of the mesoporous MIL-101(Cr) material. ${ }^{38}$ Two explanations have been proposed to account for the instability of this hybrid POM under the impregnation conditions. The first one is the presence of acid sites inside the MOF, considering that $\mathrm{P}_{2} \mathrm{~W}_{18} \mathrm{Co}_{7}(\mathrm{Ale})_{2}$ decomposes in aqueous solution at $\mathrm{pH}$ lower than ca. 6 . Knowing that the stability of the POM depends on the nature of its counter-cations, the second one hypothesises that the loss of its sodium or tetramethylammonium counter-ions upon impregnation in 
MIL-101(Cr) could affect the stability of $\mathrm{P}_{2} \mathrm{~W}_{18} \mathrm{Co}_{7}(\mathrm{Ale})_{2}$. These observations might explain why there are no examples of hybrid organic-inorganic POM immobilized in MOF so far, this type of POM being generally less stable than the fully inorganic ones.

Lai et al. have compared both synthetic methods for preparing $\mathrm{PW}_{12} @ \mathrm{MIL}-101(\mathrm{Cr}) .^{52}$ Using impregnation, the $\mathrm{PW}_{12}$ POM was immobilized in the largest cages of MIL-101 exclusively because the size of the smaller cages' windows prevents the diffusion of the POM into these cavities. By contrast, the direct synthetic encapsulation of $\mathrm{PW}_{12}$ allows its immobilization in both types of cavities. In this latter case, the leaching of $\mathrm{PW}_{12}$ from the large cages of MIL-101 was performed by soaking the composite in distilled water, this process being monitored by UV-vis absorption spectroscopy until no more POM is detected in the lixivium.

A few strategies have been reported to prevent leaching of the catalyst in composites synthesized by impregnation strategies. For example, Rh and Ru complexes functionalized carboxylate groups were co-immobilized in $\mathrm{NH}_{2}-\mathrm{MIL}-101(\mathrm{Cr}) .{ }^{153}$ The authors proposed that hydrogen bond interactions between the carboxylate groups of these pyridine-based complexes and the MOF host allows avoiding their leaching. In the same way, Chen et al. described the post-synthetic modification (PSM) of the linkers of the MOF after the catalyst's encapsulation in order to block the apertures of the MOF cavities and avoid any leaching. ${ }^{169}$ In the first step, the chiral $\mathrm{Co}(\mathrm{III})$-salen catalyst was first immobilized in the cavities of the Zn-MOF IRMOF-3. In a second step, the free-amino groups of the $\mathrm{BDC}-\mathrm{NH}_{2}$ linkers were acylated by reaction with acetic anhydride, the resulting acylamide groups thus blocking the windows as a fence. ICP analyses indicated that the leaching of the catalyst was important after soaking the material in $\mathrm{CHCl}_{3}$ before PSM treatment, while it was not the case after PSM treatment.

Finally, it is worth mentionning that dissociative linker exchange reactions can afford the encapsulation of molecular guests larger than the aperture size of a MOF host. For example, $\mathrm{Li}$ et al. have described the encapsulation of the Ru catalyst $\left({ }^{\text {tBuPNP}}\right) \mathrm{Ru}(\mathrm{CO}) \mathrm{HCl} \quad$ (tBupNP $=2,6$-bis $($ (di-tert-butylphosphino)methyl)pyridine) in the pores of UiO-66 by exposing MOF crystallites to a solution of the catalyst in $\mathrm{MeOH}$ for 5 days (Fig. 5). ${ }^{201}$ The authors thus show that this aperture-opening process involving the de-coordination/re-coordination of linkers may exist even in a robust MOF and is highly dependent on the nature of the solvent used. Protic solvents such as $\mathrm{MeOH}$ are typically adapted to this process. On the contrary, aprotic solvents do not favour dissociative linker exchange reactions and are rather required for the catalysis reaction, preventing linker decoordination and leaching.

On a final note, the main advantage of the impregnation method is that it is performed under milder conditions than the synthetic encapsulation method, which are more compatible with the usual fragility of molecular catalysts. Its drawbacks are i) a limited amount of catalyst's loading for MOFs in which the immobilization of POMs is based on an ionic exchange (see below, section 3.2), ii) possible leaching (depending on the strength of the host/guest interactions) and iii) relative spatial heterogeneity (see for example Fig. 9, section 3.1) when compared to the homogeneity reached with synthetic encapsulation.

2.2.3 Ship in a bottle. This method consists in adding the catalyst's precursors in a suspension of the MOF and in performing its subsequent synthesis within the cavities of the MOF (Fig. 4c). It is particularly used for catalysts possessing large dimensions and/or low solubilities, which thus prevent their immobilisation using impregnation and synthetic encapsulation methods. The 'ship in a bottle' method is poorly represented in POM@MOF composites (Table 1), since POMs rarely have solubility problems and their synthetic conditions are often not compatible with the stability of the MOF hosts. For example, attempts to synthesise the Keggin-type $\mathrm{PMo}_{12}$ POM in situ by adding its precursors, $\mathrm{Na}_{2} \mathrm{MoO}_{4}$ and $\mathrm{H}_{3} \mathrm{PO}_{4}$, into a suspension of MIL-100(Fe) (pH being adjusted to 1.8 ) have failed due to the degradation of the MOF under the acidic conditions needed for the in situ formation of the POM. ${ }^{87}$ To our knowledge, as a unique case in the above classification, only one example of a one-pot synthesis of both the POM and the MOF using a mixture of their precursors has been reported. Yang et al. have thus described the synthesis of the $\mathrm{SiMo}_{12} @ \mathrm{HKUST}-1$ composite by mixing in water/TMAOH, the POM's $\left(\mathrm{Na}_{2} \mathrm{MoO}_{4}, \mathrm{Na}_{2} \mathrm{SiO}_{3}\right)$ and the MOF's $\left(\mathrm{Cu}\left(\mathrm{NO}_{3}\right)_{2}\right.$ and $\left.\mathrm{BTC}\right)$ precursors in a precise order and by heating the mixture. ${ }^{122}$ The successful synthesis of the composite was demonstrated by single crystal X-ray diffraction studies along with ${ }^{29} \mathrm{Si} \mathrm{NMR}$ spectroscopy.

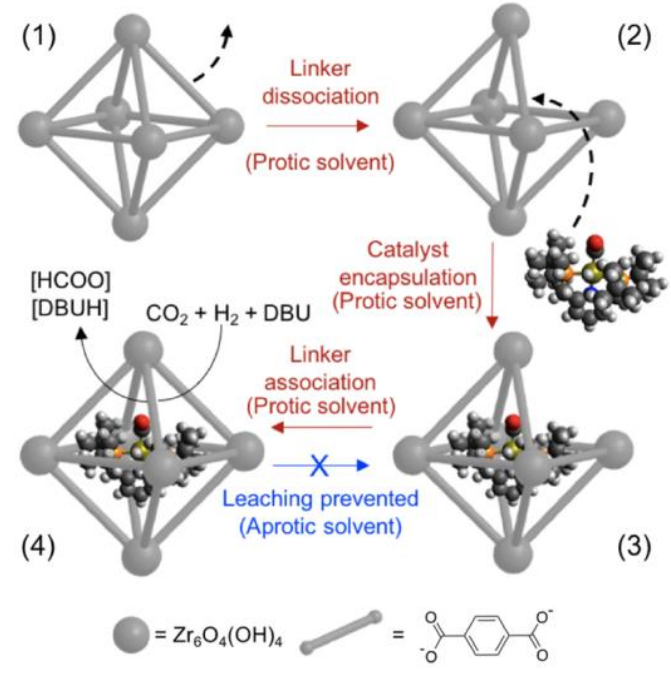

Fig. 5 Schematic representation of the aperture-opening process allowing the encapsulation of a Ru complex in the cavities of UiO-66 for the hydrogenation of $\mathrm{CO}_{2}$ to formate in DMF/1,8-diazabicyclo(5.4.0)undec-7-ene (DBU) mixtures,. Reprinted with permission from ref. ${ }^{201}$. Copyright 2018 American Chemical Society.

By contrast, there have been several successful examples of Complex@MOF composites synthesised by a 'ship in a bottle' strategy (Table 2). This is the case of $\left[\mathrm{Ni}(\right.$ bpet $\left.)\left(\mathrm{H}_{2} \mathrm{O}\right)_{2}\right] @ \mathrm{Ru}-U i \mathrm{O}-$ 67 (bpet = 1,2-bis ((pyridin-2-ylmethyl)thio)ethane; Ru-UiO-67 = UiO-67 where $5 \%$ of the linkers are 2,2'-bipyridine-4,4'dicarboxylic ligands coordinated to $\mathrm{Ru}) .{ }^{163}$ This composite was 
obtained by first adding bpet to a suspension of the MOF in $\mathrm{CH}_{3} \mathrm{CN}$ and, after centrifugation and washing, adding $\mathrm{Ni}\left(\mathrm{ClO}_{4}\right)_{2}$ to a suspension of the bpet/MOF in an acetone/ $\mathrm{H}_{2} \mathrm{O}(20 / 1)$ mixture (Fig. 6). Similarly, Co dioxime-diimine or Co-TPA complexes have been synthesised in situ within the cages of the visible-light photoactive $\mathrm{NH}_{2}-\mathrm{MIL}-125$ (Ti) MOF by first adding the flexible ligands and then the Co ions. ${ }^{159,160}$ After synthesis, the full metalated complex is well entrapped inside the MOF. In the case of the Co-salen@MIL-100(Cr) composite, the order of addition of the complex precursors is different, whereby the Co acetate was added before the $\mathrm{H}_{2}$ salen ligand. ${ }^{157}$ Finally, phthalocyanines metal complexes were also immobilised in MIL-101(Cr $)^{148,149}$ and MIL-100(Fe) ${ }^{149}$ by 'ship in a bottle' synthetic methods.

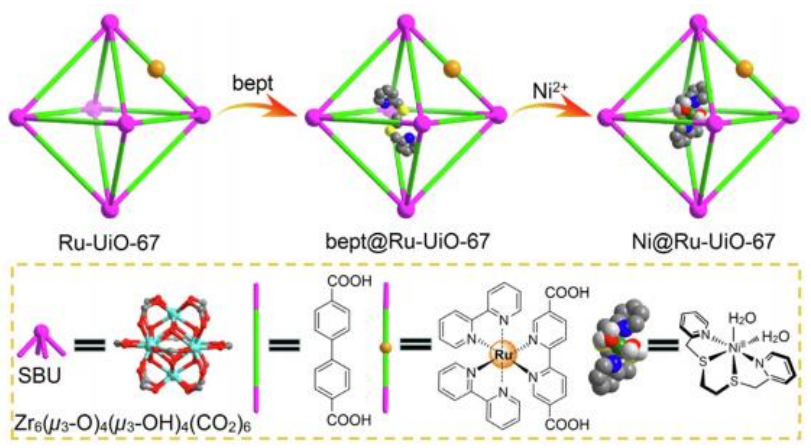

Fig. 6 Schematic illustration for the 'ship in a bottle' synthetic strategy to prepare [Ni(bpet) $\left.\left(\mathrm{H}_{2} \mathrm{O}\right)_{2}\right] @$ Ru-UiO-67. Reprinted with permission from ref. ${ }^{163}$. Copyright 2019 Science China Press. Published by Elsevier B.V. and Science China Press.

The advantages of the ship in a bottle strategy are similar to that of the synthetic encapsulation method. Catalyst leaching is prevented by the large dimensions of the catalyst compared to those of the cavities windows. Catalyst loading must however be controlled in order to leave some porosity available and allow the diffusion of reactants and products within the MOF.

Overall, it can be noticed that since the first syntheses of PW $12 @ H K U S T-1$ in 2003 and PW $11 @ M I L-101(C r)$ in 2005, an increasing number of Cat@MOF combinations has been explored these last years, using the appropriate synthetic technique (synthetic encapsulation, impregnation or ship in a bottle) leaving room however for a larger diversity of compositions, considering the huge number of molecular catalysts and of MOFs available. The synthetic method used for the immobilisation of the molecular catalysts plays an important role in the crystallinity, the loading, the localisation of the catalytic species in the cavities and finally on the catalytic properties, as detailed in the following sections.

\section{Characterisations of Cat@MOF composites}

\subsection{Determination of the composition (ICP, solution NMR, UV-vis,} TGA, EDS)

Combining several techniques is usually required to determine the composition of Cat@MOF materials and give access to the Cat loading, having in mind that controlling the loading is of utmost importance in view of catalytic applications. On the one hand, a material loaded with only a small amount of immobilised catalyst may have low performances. On the other hand, an overloading could block the cages or windows and thus limit the accessibility of the reactants to the catalytic species. This has been typically described for $\mathrm{PW}_{12} @ M O F-808 \mathrm{X}(\mathrm{X}=\mathrm{F}, \mathrm{A}$, and $P$ where the coordinated monocarboxylate ligand is formate, acetate or propioniate, respectively). ${ }^{115}$ Precise knowledge of the Cat@MOF's chemical composition is also needed for the determination of turn over numbers (TONs) in catalytic studies. The most common and precise techniques are ICP analysis of digested solutions of Cat@MOFs for determining the metal content and $\mathrm{C}, \mathrm{H}, \mathrm{N}$ elemental analysis for the organic content. For example, the $\mathrm{Co} / \mathrm{In}$ ratio in $\left[\mathrm{Cp}_{2} \mathrm{Co}\right] @\left[\mathrm{R}_{4} \mathrm{~N}\right]_{3}\left[\mathrm{In}_{3}(\mathrm{BTC})_{4}\right](\mathrm{R}=\mathrm{Et}, n \mathrm{Pr}, n \mathrm{Bu})$ digested in diluted $\mathrm{HNO}_{3}(1 / 10 \mathrm{v} / \mathrm{v})$ was measured by ICP-OES and allowed to quantify the amount of immobilised complex. ${ }^{172}$ Note that ICP is also a powerful technique to monitor the uptake of catalysts upon impregnation by analysing the supernatant solutions as reported for $\mathrm{PW}_{12} @ \mathrm{NU}-1000$, for example.110 This analytic method was also used to follow the leaching of the POM in this material when dispersed in acidic aqueous solutions. Also, solution NMR spectroscopy may be successfully used to determine the relative amounts of immobilised species. For example, ${ }^{1} \mathrm{H}$ NMR spectroscopy allowed to establish the extent of cation exchange via the integration of the relative peaks' areas of the benzene ring of $\mathrm{BTC}$, of the $\mathrm{Cp}^{\prime}$ 's protons in $\left[\mathrm{Cp}_{2} \mathrm{Co}\right]^{+}$ and of tetraethylammonium after the digestion of $\left[\mathrm{Cp}_{2} \mathrm{Co}\right] @[\mathrm{TEA}]_{3}\left[\ln _{3}(\mathrm{BTC})_{4}\right]$ in ${ }^{2} \mathrm{DCl} / \mathrm{d}^{6}-\mathrm{dmso}(1 / 5 \mathrm{v} / \mathrm{v}) .{ }^{172}$

Several other techniques may be used to apprehend the chemical composition. UV-vis spectroscopy can monitor the incorporation of the catalyst into the MOF during the impregnation and estimate the amount of Cat immobilised in the MOF. The decrease of the bands of the POM in solution around $250 \mathrm{~nm}$ (assigned to the charge transfer from the bridging $\mathrm{O}$-atoms to $\mathrm{W}$-atoms) thus allowed to follow the immobilisation of $\mathrm{PW}_{9},{ }^{32} \mathrm{PW}_{11},{ }^{34} \mathrm{SiW}_{11},{ }^{34} \mathrm{PW}_{11} \mathrm{Ti}^{36}$ and $\mathrm{PW}_{11} \mathrm{Co}^{36}$ in MIL-101(Cr) in a qualitative fashion. A detailed UV-vis study was also performed to measure the catalyst's concentration in the supernatant after the impregnation experiment of various Ru catalysts in $\mathrm{NH}_{2}-\mathrm{MIL}-101(\mathrm{Al})$ and MIL-101(Cr) MOFs ${ }^{152}$ and of a $\mathrm{Rh}$ catalyst and a $\mathrm{Ru}$ photosensitiser (PS) in $\mathrm{NH}_{2}-\mathrm{MIL}-$ 101(Al). ${ }^{153}$ This study allowed determining the loadings in catalysts and identifying the best solvent for their immobilisation. However, the analysis of digested solutions of the Cat@MOF composite itself rather than that of the supernatant solutions should allow a more accurate determination of the catalyst's loading. Indeed, it has been reported that the amounts of immobilised catalyst may be overestimated using the analysis of the supernatant solutions owing to adsorption of Cat species at the surface of the MOF crystallites, which should be eliminated with a careful washing. ${ }^{108}$ For example, the amount of di- $\mu$-oxo dimanganese catalytic complex, $\left[\left(\text { terpy) } \mathrm{Mn}(\mu-\mathrm{O}){ }_{2} \mathrm{Mn}(\text { terpy })\right]^{3+}\right.$ (denoted as MnTD, terpy $=2,2^{\prime} ; 6^{\prime}, 2^{\prime \prime}$-terpyridine), immobilised in MIL$101(\mathrm{Cr})$ was determined by measuring the intensity of the absorption band at $328 \mathrm{~nm}$ (arising from the terpy ligand of the 
complex) of a solution of MnTD@MIL-101(Cr) digested in concentrated sulfuric acid. ${ }^{143}$

Thermogravimetric analysis (TGA) may be a useful complement to confirm the chemical composition of a Cat@MOF. A typical example of TGA is represented in Fig. 7 for the PW 11 Zn@MIL-101(Cr) composite. ${ }^{39}$ The first weight loss is assigned to the loss of solvent molecules, the second one to the decomposition of the hybrid framework. The total weight loss of the POM@MOF composite is lower than that of the parent MOF due to the presence of POM guests which decompose into oxides. Hence, the comparison of the weights calculated from the results of elemental analysis with the experimental TGA weight losses allows confirming the molecular formula of the composite and in particular the guest loading. Note that one of the main purposes of TGA is also to study the thermal stability of the composites. In that respect, the temperature of decomposition of a POM@MOF composite is usually very close to that of the MOF host, as exemplified in Fig. 7, which indicates that the insertion of the POM only slightly affects the thermal stability. This seems also the case for the few examples of TGA curves reported for Complex@MOFs. There are however some exceptions to this rule. For example, SiW $12 @ H K U S T-1$ (also named NENU-1), after a thermal treatment at $180^{\circ} \mathrm{C}$ under vacuum to remove $\mathrm{TMA}^{+}$cations and $\mathrm{H}_{2} \mathrm{O}$ molecules (NENU-1a material), is stable up to $300^{\circ} \mathrm{C}$ while the POM-free MOF is stable up to $240^{\circ} \mathrm{C}$ only..$^{130}$ The authors attributed this difference to physicochemical interactions between the POM and the MOF framework. Similarly, the thermal stability of the composite obtained by immobilisation of the MnTD complex in MIL-101(Cr) was reported to be improved by $40^{\circ} \mathrm{C} .{ }^{143}$

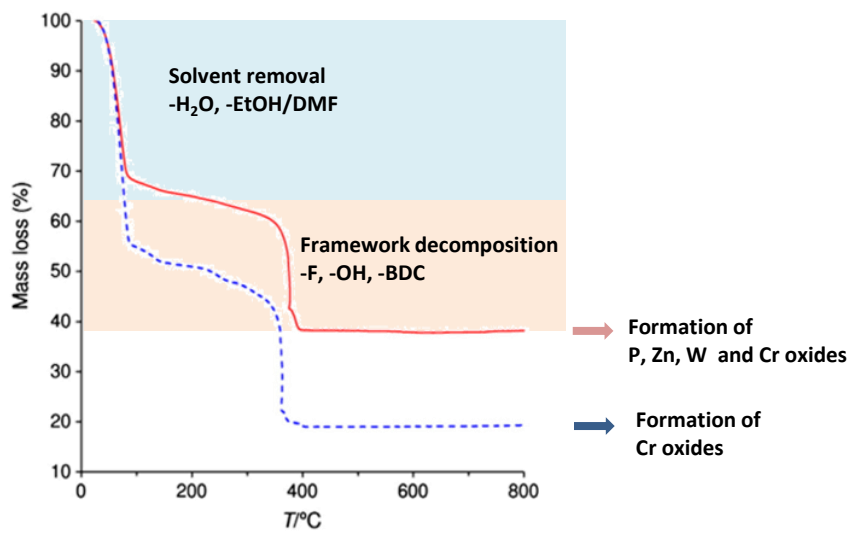

Fig. 7 Typical TGA curve of a Cat@MOF composite: TGA curves under air of the $\mathrm{PW}_{11} \mathrm{Zn} @ \mathrm{MIL}-101(\mathrm{Cr})$ composite (red curve) and of the parent MIL-101(Cr) (dashed blue line) with the attribution of the weight losses. Adapted with permission from ref. ${ }^{39}$. Copyright 2014 Elsevier B.V.

Scanning electron microscopy (SEM) and energy-dispersive X-ray spectroscopy (EDS) are largely used techniques to characterise the morphology and composition of materials, often employed after synthesis, however less often after the catalytic event. SEM images can confirm the degree of the crystallinity of the Cat@MOF composite while EDS analysis may map the distribution of the chemical elements of interest. In most reported cases, SEM-EDS analysis suggests a uniform distribution of immobilized species.
However, one has to be cautious for composites prepared by impregnation since SEM-EDS mapping may not be sufficient to prove a homogeneous distribution. For example, SEM images of $\mathrm{P}_{2} \mathrm{~W}_{18} \mathrm{Co}_{4} @ \mathrm{MOF}-545$ pointed towards an homogeneous distribution of the Co, W and P elements of the POMs while HRTEM revealed higher concentrations of those elements at both extremities of MOF545 crystal rods (Fig. 8). ${ }^{108}$ This observation is consistent with the alignment of the channels of MOF-545 along the $c$ axis, i.e. the longest dimension of the rods, and an accumulation of POMs at the channels' extremities upon impregnation. Along the same line, JuanAlcañiz et al. concluded from the analysis of the HRTEM images that stirring the reaction mixture during the POM@MOF synthesis improved dramatically the distribution of $\mathrm{PW}_{12}$ in the MIL-101 matrix and the resulting catalytic performances. ${ }^{41}$ Also, EDS analysis may be useful to follow anion exchange reactions during impregnation steps. In the two-step procedure leading to the $\left[\mathrm{Co}(\mathrm{CO})_{4}\right] @ \mathrm{MIL}-101(\mathrm{Cr})$ composite, it first showed the $\mathrm{F}^{-} \rightarrow \mathrm{Cl}^{-}$exchange (absence of the $\mathrm{F} \mathrm{K} \alpha$ peak, presence of the $\mathrm{Cl} \mathrm{K} \alpha$ peak) and then the $\mathrm{Cl}^{-} \rightarrow\left[\mathrm{Co}(\mathrm{CO})_{4}\right]^{-}$ exchange (absence of the $\mathrm{Cl} \mathrm{K} \alpha$ peak and presence of the $\mathrm{Co} \mathrm{K} \alpha$ and L $\alpha$ peaks). ${ }^{146}$

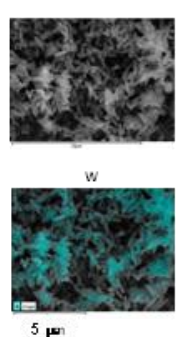

a)

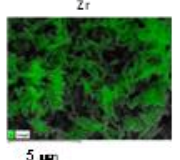

$5 \boldsymbol{\omega n}$

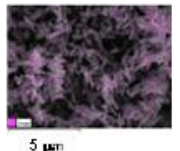

$5 \boldsymbol{m i n}$
Fig. 8 Comparison of a) SEM images and EDS elemental mapping and b) STEM-HAADF images and EDS mapping of $\mathrm{P}_{2} \mathrm{~W}_{18} \mathrm{CO}_{4} @ M O F-545$. Adapted with permission from ref. ${ }^{108}$ Copyright 2018, American Chemical Society.

The crystallites of a Cat@MOF composite usually exhibit a morphology similar to that of the parent MOF. Still, there are a few reports of altered morphologies. For example, PW $12 @ U i O-$ 66 crystallites obtained by synthetic encapsulation do not exhibit regular shapes typical of UiO-66 but rather look like agglomerated small particles with irregular inter-grown microcrystalline poly-octahedra morphologies. ${ }^{91}$ SEM images of (Fe-salen,SiW 12 )@ZIF-8 showed the uneven surface of the nanocrystals, which contrasts with their rather smooth surface in the absence of POM. ${ }^{139}$ This provides strong evidence in support of the growth of POMs on the surface of ZIF-8 crystallites, which was also suggested by the very large amount of POM determined from ICP-OES analysis. Similar SEM images were observed for the yolk/shell ZIF-67/PW 12 composite prepared by stirring a suspension of ZIF-67 nanocrystals in a solution of $\mathrm{H}_{3} \mathrm{PW}_{12}$ and supported the hypothesis of the presence of the POMs on the surface of the MOF crystals. ${ }^{205}$

3.2 Presence of counter-ions. In most cases, the molecular catalyst is charged, bearing a negative charge in case of POMs and most often a positive charge for organometallic and coordination complexes (Table 2). The question thus arises of the charge compensation of the catalysts upon their 
immobilization into the MOF host. Discussions on the matter are quite rare in articles. For composites prepared by impregnation or in situ synthetic methods, the catalysts may be immobilised with their native counter-ions, thus inducing no modification of the composition of the MOF. This is the case of POM@HKUST-1 composites (also called NENU- $n$ ), where the Cu-based MOF framework is neutral and the negative charge of the encapsulated Keggin ions is compensated by their associated TMA cations and/or protons. The proposed formula for these composites is $\left[\mathrm{Cu}_{12}(\mathrm{BTC})_{8}\left(\mathrm{H}_{2} \mathrm{O}\right)_{12}\right]\left[(\mathrm{TMA})_{2} \mathrm{H}_{\mathrm{n}} \mathrm{XM}_{12} \mathrm{O}_{40}\right]$ $(X=\mathrm{Si}, \mathrm{Ge}, \mathrm{P}, \mathrm{As} ; \mathrm{M}=\mathrm{W}, \mathrm{Mo} ; \mathrm{n}=1,2)^{121,122}$ or $\left[\mathrm{Cu}_{12}(\mathrm{BTC})_{8}\left(\mathrm{H}_{2} \mathrm{O}\right)_{12}\right]\left[\mathrm{H}_{3} \mathrm{PW}_{12} \mathrm{O}_{40}\right]^{128}$ for non-metalated Keggin ions, with protons located on the Keggin ions, $\left[\mathrm{Cu}_{12}(\mathrm{BTC})_{8}\left(\mathrm{H}_{2} \mathrm{O}\right)_{12}\right]\left[(\mathrm{TMA})_{4} \mathrm{PW}_{11} \mathrm{CuO}_{40}\right]^{119}$ for the $\mathrm{Cu}$ substituted POM and $\left[\mathrm{Cu}_{12}(\mathrm{BTC})_{8}\left(\mathrm{H}_{2} \mathrm{O}\right)_{12}\right]\left[(\mathrm{TMA})_{2} \mathrm{H}_{5} \mathrm{PW}_{10} \mathrm{Ti}_{2} \mathrm{O}_{40}\right]$ 118 for the Ti-substituted POM. Interestingly, TMA cations may be exchanged with $\mathrm{K}^{+}$ions in $\left[\mathrm{Cu}_{12}(\mathrm{BTC})_{8}\left(\mathrm{H}_{2} \mathrm{O}\right)_{12}\right]\left[(\mathrm{TMA})_{2} \mathrm{HPW}_{12} \mathrm{O}_{40}\right]$ without loss of crystallinity ${ }^{202}$ or eliminated by thermal treatment $\left(180^{\circ} \mathrm{C}\right.$ under vacuum). ${ }^{130}$ The cationic $\mathrm{Zn}(\mathrm{II})$ porphyrin complex [Zn"NMeTPyP $^{4+} \quad$ (NMeTPyP $=5,10,15,20$-tetrakis(1methylpyridinium-4'-yl)porphyrin) was also immobilised in the Zr porphyrinic MOF PCN-224 together with its iodide counterions as shown by EDS analysis.167 In the CoW ${ }_{12} @ Z I F-8$ composite prepared by synthetic encapsulation, the absence of $\mathrm{K}^{+}$counterions (although present in the POM precursor) is evidenced by elemental analysis and the authors propose that charge compensation of the $\left[\mathrm{CoW}_{12} \mathrm{O}_{40}\right]^{6-} \mathrm{POM}$ is ensured by solution protons trapped by the composite. ${ }^{203}$ The localisation of the protons is however not discussed.

By contrast, the immobilisation of anionic catalysts in MIL$101(\mathrm{Cr})$ by impregnation involves ion exchange reactions. It is important to note that, if the solvent is water, the value of the $\mathrm{pH}$ determines the charge of the MOF. Zeta potential can be measured to determine surface charge characteristics of MOFs in aqueous solution as a function of $\mathrm{pH}$. For example, zeta potential measurements showed that MIL-101(Cr) particles are positively charged for $\mathrm{pH}$ values lower than 7.204 This favours the encapsulation of anionic species like POM. MIL-101(Cr) also possesses negatively charged counter-ions (mostly $\mathrm{F}^{-}$or $\mathrm{NO}_{3}$ counter-ions coordinated to the metal nodes) which can be exchanged with negatively charged Cats. This anion exchange reaction implies a limitation in the catalyst's loading that may be reached upon impregnation. Indeed, the total charge carried by the catalysts cannot exceed the maximum initial negative charge of the counter-ions present in the targeted MOF. For example, with the formula of MIL-101(Cr) synthesised with $\mathrm{Cr}\left(\mathrm{NO}_{3}\right)_{3}$ as a precursor without $\mathrm{HF}$ being $\left[\mathrm{Cr}^{\prime \prime \prime}{ }_{3}\left(\mathrm{H}_{2} \mathrm{O}\right)_{3} \mathrm{O}\left(\mathrm{O}_{2} \mathrm{CC}_{6} \mathrm{H}_{4} \mathrm{CO}_{2}\right)_{3}\right] \mathrm{NO}_{3}$, the maximum number of POMs that be loaded depends on their charge, $n$, and amounts to 1 POM for $n$ formula units of MIL-101(Cr). Consistently, the immobilisation of the Co-POMs, $\left[\mathrm{PW}_{11} \mathrm{CoO}_{39}\left(\mathrm{H}_{2} \mathrm{O}\right)\right]^{5-}\left(\mathrm{PW}_{11} \mathrm{Co}\right)$ or $\left[\left(\mathrm{PW}_{9} \mathrm{O}_{34}\right)_{2} \mathrm{CO}_{4}\left(\mathrm{H}_{2} \mathrm{O}\right)_{2}\right]^{10-}\left(\mathrm{P}_{2} \mathrm{~W}_{18} \mathrm{CO}_{4}\right)$, in $\mathrm{MIL}-101(\mathrm{Cr})$ by impregnation in a solution containing a large excess of POMs thus led to composites with the following formula, $\left[\mathrm{Cr}_{3}\left(\mathrm{H}_{2} \mathrm{O}\right)_{3} \mathrm{O}\left(\mathrm{O}_{2} \mathrm{CC}_{6} \mathrm{H}_{4} \mathrm{CO}_{2}\right)_{3}\right]\left[\mathrm{PW}_{11} \mathrm{O}_{39} \mathrm{Co}\left(\mathrm{H}_{2} \mathrm{O}\right)\right]_{0.2}\left(\mathrm{PW}_{11} \mathrm{Co} @ \mathrm{MIL}-\right.$ $101(\mathrm{Cr}))$ and $\left[\mathrm{Cr}_{3}\left(\mathrm{H}_{2} \mathrm{O}\right)_{3} \mathrm{O}\left(\mathrm{O}_{2} \mathrm{CC}_{6} \mathrm{H}_{4} \mathrm{CO}_{2}\right)_{3}\right]\left[\mathrm{P}_{2} \mathrm{~W}_{18} \mathrm{O}_{68} \mathrm{Co}_{4}\left(\mathrm{H}_{2} \mathrm{O}\right)_{2}\right]_{0.1}$
$\left(\mathrm{P}_{2} \mathrm{~W}_{18} \mathrm{Co}_{4} @ \mathrm{MIL}-101(\mathrm{Cr})\right)$, which both correspond to the highest possible POM loading on the basis of charge balance. ${ }^{38}$ Similarly, the immobilisation of the anionic $\left[\mathrm{Co}(\mathrm{CO})_{4}\right]^{-}$complex in MIL$101(\mathrm{Cr})$ is based on an ion-exchange process following two steps: first, the charge-balancing $\mathrm{F}^{-}$anions - directly coordinated to the $\mathrm{Cr}(\mathrm{III})$ sites in the as-synthesised MIL-101(Cr) - are exchanged by $\mathrm{Cl}^{-}$anions (by reaction with $\mathrm{AlCl}_{3}$ ). Second, the labile $\mathrm{Cl}^{-}$ions are exchanged by the negatively charged complex by reaction with $\mathrm{Na}\left[\mathrm{Co}(\mathrm{CO})_{4}\right] .{ }^{146}$

In a similar fashion, the immobilisation of the sandwich-type $\mathrm{P}_{2} \mathrm{~W}_{18} \mathrm{CO}_{4} \mathrm{POM}$ by impregnation of MOF-545 in an aqueous solution of the POM is also based on an ionic exchange reaction. ${ }^{108}$ The MOF-545 framework is positively charged due to the protonation of the $\mathrm{Zr}_{6}$ oxoclusters compensated by $\mathrm{Cl}^{-}$ counter-anions. The latter can be exchanged by POMs, leading to a composite formulated $\left[\mathrm{Zr}_{6} \mathrm{O}_{16} \mathrm{H}_{18}\right]\left[\mathrm{TCPPH}_{2}\right]_{2}\left[\mathrm{P}_{2} \mathrm{~W}_{18} \mathrm{CO}_{4}\right]_{0.2}$. Likewise, in $\mathrm{PW}_{12} @ \mathrm{NU}-1000$, the charge compensation of the POM is claimed to result from hydrogens which protonate the hydroxyl groups on the $\mathrm{Zr}_{6}$ nodes. The synthesis of the composite is performed in acidic $\mathrm{pH}(\mathrm{pH} 2.5)$ to favour this protonation. ${ }^{110}$

In POM@UiO-67 composites recently synthesised by synthetic encapsulation methods, it has been proposed that the negative charge of the POM guests is compensated by the positively charged framework. However, this does not result from the protonation of the MOF but rather from linkers defects. ${ }^{101}$ For example, three POM@UiO-67 composites have been synthesised with the proposed formula: $\left[\mathrm{Zr}_{6} \mathrm{O}_{4}(\mathrm{OH})_{4}\right]\left[\mathrm{C}_{14} \mathrm{H}_{8} \mathrm{O}_{4}\right]_{5.37}\left[\mathrm{PW}_{12} \mathrm{O}_{40}\right]_{0.42} \quad\left(\mathrm{PW}_{12} @ \mathrm{UiO}-67\right)$ $\left[\mathrm{Zr}_{6} \mathrm{O}_{4}(\mathrm{OH})_{4}\right]\left[\mathrm{C}_{14} \mathrm{H}_{8} \mathrm{O}_{4}\right]_{5.73}\left[\mathrm{PW}_{11} \mathrm{O}_{39} \mathrm{Zr}\right]_{0.18}$ (PW $11 \mathrm{Zr@UiO-67)} \mathrm{and}$ $\left[\mathrm{Zr}_{6} \mathrm{O}_{4}(\mathrm{OH})_{4.30}\right]\left[\mathrm{C}_{14} \mathrm{H}_{8} \mathrm{O}_{4}\right]_{5.10}\left[\mathrm{P}_{2} \mathrm{~W}_{18} \mathrm{O}_{62}\right]_{0.25} \quad\left(\mathrm{P}_{2} \mathrm{~W}_{18} @ U i \mathrm{O}-67\right)$ where the percentage of missing linkers is equal to 10.5, 4.5 and $15 \%$ respectively. The correlation between the POM's charge and its loading appears less clear than for MIL-101(Cr) and MOF545. Indeed, $\mathrm{PW}_{12} \mathrm{O}_{40}{ }^{3-}$ allows a higher loading than $\mathrm{P}_{2} \mathrm{~W}_{18} \mathrm{O}_{62}{ }^{6-}$, but $\mathrm{PW}_{11} \mathrm{O}_{39} \mathrm{Zr}^{3-}$ yields a much lower loading than $\mathrm{PW}_{12} \mathrm{O}_{40^{3-}}$ although it has the same charge.

The encapsulation of cationic coordination complexes in anionic MOFs has been rarely reported. The encapsulation of $\left[\mathrm{Ru}(\mathrm{bpy})_{3}\right]^{2+}$ was performed in the In-based anionic PCN-99 MOF by impregnation. ${ }^{173}$ The sulfonated $\mathrm{HSO}_{3}-\mathrm{MIL}-101(\mathrm{Cr})$ is another example of anionic MOF host, which can be isolated using a $\mathrm{Na}^{+}$salt with sodium ions counterbalancing the negative charge of the deprotonated sulfonate groups of the linkers. The encapsulation of cationic $\mathrm{Rh}^{154}$ and Ir $^{155}$ complexes has thus been described as a cation exchange with some of the sodium ions. The heterogenizations of the same Rh complex in the anionic In-MOF ZJU-28 ${ }^{171}$ and of the cationic $\mathrm{Fe}$ and Co complexes in the related $\left[\mathrm{R}_{4} \mathrm{~N}\right]_{3}\left[\mathrm{In}_{3}(\mathrm{BTC})_{4}\right](\mathrm{R}=\mathrm{Et}, n \mathrm{Pr}, n \mathrm{Bu})$ $\mathrm{MOFs}^{172}$ were also performed by partial exchange with the MOF's cations, $\mathrm{NH}_{2} \mathrm{Me}^{2+}$ and $\mathrm{R}_{4} \mathrm{~N}^{+}$, respectively (Fig. 9). The exchange of $\mathrm{R}_{4} \mathrm{~N}^{+}$cations with the cationic $\left[\mathrm{Cp}_{2} \mathrm{Co}\right]^{+}$complexes has been thoroughly studied by the authors showing that the rate of cation exchange depends on i) the duration of the impregnation experiment, ii) the starting $\left[\mathrm{Cp}_{2} \mathrm{Co}\right]^{+} /\left[\mathrm{R}_{4} \mathrm{~N}\right]^{+}$ratio, and $\mathrm{iii)}$ the size of the organic cation. ${ }^{172} \mathrm{~A}$ maximum $82 \%$ exchange rate is reached for $72 \mathrm{~h}$ impregnation experiments, a 
$\left[\mathrm{Cp}_{2} \mathrm{Co}\right]^{+} /\left[\mathrm{R}_{4} \mathrm{~N}\right]^{+}$ratio of $3 / 1$ and for tetraethyl ammonium, the smallest cation.

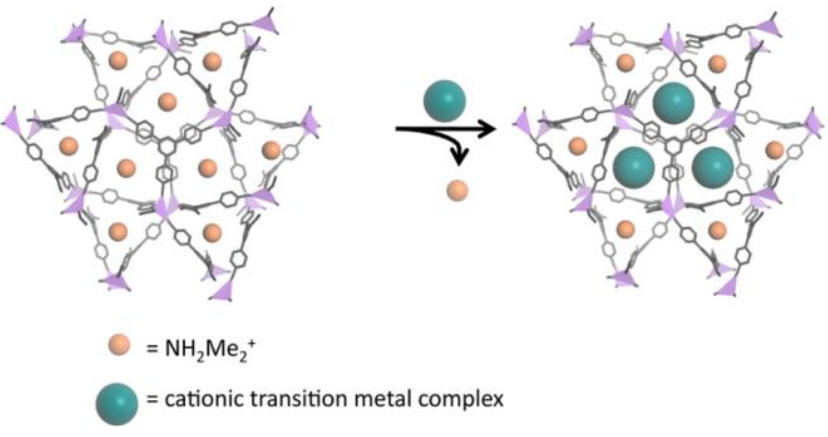

Fig. 9 Proposed immobilisation of a cationic transition metal complex in the anionic ZJU $28 \mathrm{MOF}$ via cation exchange reaction. Reprinted with permission from ref. ${ }^{171}$. Copyright 2013, American Chemical Society.

3.3 Extraction of immobilised catalysts. In some cases, extraction of the immobilized catalyst can be performed, taking advantage of a reversible ion-exchange process. The extraction of the encapsulated species has been studied in POM@MIL$101(\mathrm{Cr})$ following their synthesis by impregnation methods. The extraction was performed by stirring a suspension of POM@MIL-101(Cr) in a solution of $5 \mathrm{M} \mathrm{LiCl}$. It was followed by studying the supernatant composition using UV-vis, EDS analyses, and ${ }^{31} \mathrm{P}$ NMR spectroscopy for POMs containing $P$ atoms. For example, $\mathrm{PW}_{11}$ Co could be quantitatively extracted from MIL-101(Cr) while $\mathrm{P}_{2} \mathrm{~W}_{18} \mathrm{Co}_{4}$ was more tightly bound to the MOF host, allowing only a partial extraction. ${ }^{38}$ The same experiments performed in $5 \mathrm{M} \mathrm{LiNO}_{3}$ did not afford the extraction of the POM, indicating an affinity of the anions for the $\mathrm{MOF}$ in the following order: $\mathrm{Cl}>\mathrm{POM}>\mathrm{NO}_{3}{ }^{-} . \mathrm{PW}_{12},{ }^{30} \mathrm{PW}_{11} \mathrm{Ti}^{36}$ and $\mathrm{PW}_{11} \mathrm{Co}^{36}$ immobilised in $\mathrm{MIL}-101(\mathrm{Cr})$ were also extracted using a $1 \mathrm{M}$ solution of $\mathrm{Bu}_{4} \mathrm{NClO}_{4}$ in $\mathrm{MeCN}$. Similarly, cationic guests can be reversibly exchanged, such as $\left[\mathrm{Ru}(\mathrm{bpy})_{3}\right]^{2+}$ in $\mathrm{Ru}(\mathrm{bpy})_{3} @ \mathrm{PCN}-99 .{ }^{173}$ The release of $\left[\mathrm{Ru}(\mathrm{bpy})_{3}\right]^{2+}$ is triggered by adding saturated $\mathrm{NaNO}_{3}$, the sodium ions replacing the $\left[\mathrm{Ru}(\mathrm{bpy})_{3}\right]^{2+}$ complexes within the composite. These extraction experiments have been used to have a direct proof of the structural integrity of the catalyst upon its immobilisation into the MOF. For example, CuPc phthalocyanines were extracted from MIL-101(Cr) and MIL-100(Fe); UV-vis spectroscopy of the supernatant showed their characteristic absorption bands which demonstrated that the CuPc remained intact after encapsulation into the MOF. ${ }^{149}$ In contrast to Keggin type POMs and CuPc phthalocyanines, the iron tetrasulfophthalocyanine FePcS could not be extracted from MIL-101(Cr) neither using a solution of $\mathrm{NaClO}_{4}$ in $\mathrm{H}_{2} \mathrm{O}$ nor a solution of $\mathrm{Bu}_{4} \mathrm{NClO}_{4}$ in $\mathrm{MeCN} .{ }^{145}$ This pointed towards strong interactions between the complex and the MOF, such as $\pi-\pi$ interactions between the aromatic groups of the MOF's linkers and the complex.

\subsection{IR and Raman spectroscopies}

In all reported Cat@MOF studies, IR spectra are systematically recorded to check whether the catalyst and MOF structures are preserved. This technique is also routinely used to investigate their stability after the catalytic event. For example, for the $\mathrm{PW}_{12}$ catalyst, characteristic $\mathrm{P}-\mathrm{O}, \mathrm{W}=\mathrm{O}$ and $\mathrm{W}$ O-W bands are observed around 1000, 980 and between 800 and $900 \mathrm{~cm}^{-1}$, respectively. Red shifts may be observed when comparing the IR bands of the isolated POM precursor to those of the encapsulated POM. A $\sim 30 \mathrm{~cm}^{-1}$ red shift was reported for the $\mathrm{P}-\mathrm{O}$ and $\mathrm{W}=\mathrm{O}$ bands of $\mathrm{PW}_{12}$ immobilised in MOF-808X.115 The $\mathrm{P}-\mathrm{O}$ vibration was also shifted from 1030 to $1048 \mathrm{~cm}^{-1}$ upon immobilization of $\mathrm{P}_{2} \mathrm{~W}_{18} \mathrm{Co}_{4}$ into $\mathrm{MIL}-101\left(\mathrm{Cr}\right.$ ) (Fig. 10a). ${ }^{38} \mathrm{~A}$ red shift of the W-O-W vibration was similarly observed between the POM $\left(802 \mathrm{~cm}^{-1}\right)$ and the PW $12 @ M I L-100(\mathrm{Fe})^{80}$ or $\mathrm{PW}_{12} @ \mathrm{MIL}-100(\mathrm{Cr})^{89}$ composites $\left(825 \mathrm{~cm}^{-1}\right)$. The four characteristic bands of $\mathrm{PW}_{12}$ were also reported as shifted to higher wavenumbers in $\mathrm{PW}_{12} @$ UiO-66.91 Overall, these shifts are interpretated as a result of significant interactions between the POM and its MOF host. IR spectroscopy may also evidence the catalyst's transformation after its immobilisation into the MOF. For instance, the modification of the $\mathrm{W}-\mathrm{O}$ and $\mathrm{P}-\mathrm{O}$ vibrations in $\mathrm{PW}_{12} @ \mathrm{MIL}-101(\mathrm{Cr})$ (splitting of the band at 1080 $\mathrm{cm}^{-1}$ and shift of the band at $982 \mathrm{~cm}^{-1}$ to $963 \mathrm{~cm}^{-1}$ ) prepared by direct synthesis suggested a partial substitution of tungsten by $\mathrm{Cr}^{3+}$ ions. ${ }^{41}$

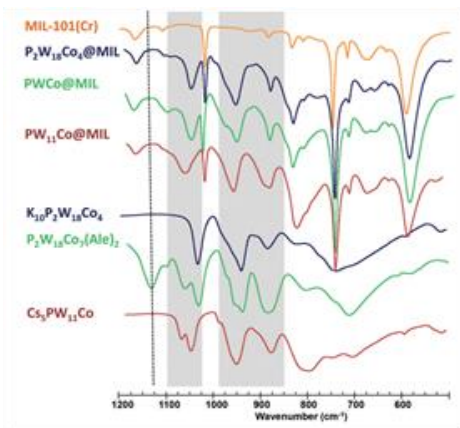

a)

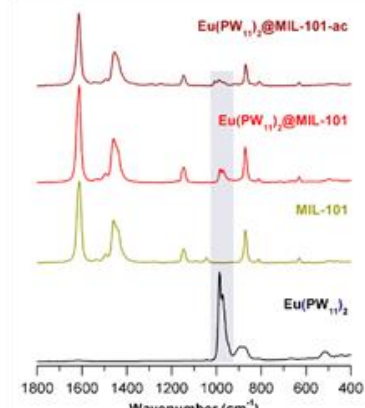

b)
Fig. 10 a) IR spectra of composites synthesised by immobilising Co-substituted POMs in MIL-101(Cr); the composite named PWCo@MIL results from the immobilisation of the hybrid $\mathrm{P}_{2} \mathrm{~W}_{18} \mathrm{Co}_{7}(\mathrm{Ale})_{2}$ POM. b) Raman spectra of Eu(PW $\left.\mathrm{PW}_{11}\right)_{2} @ \mathrm{MIL}-101(\mathrm{Cr})$ before $\left(\mathrm{Eu}\left(\mathrm{PW}_{11}\right)_{2} @ \mathrm{MIL}-101\right)$ and after $\left(\mathrm{Eu}\left(\mathrm{PW}_{11}\right)_{2} @ \mathrm{MIL}-101-\mathrm{ac}\right)$ catalysis compared to that of the POM and MOF precursors. Reprinted from refs. ${ }^{38}$ with permission from RSC and ${ }^{64}$ (Copyright 2013 Elsevier B.V.) respectively.

The modification of $\mathrm{P}_{2} \mathrm{~W}_{18} \mathrm{Co}_{7}(\mathrm{Ale})_{2}$ 's IR bands upon its immobilisation in MIL-101, in particular the disappearance of the vibration at $1117 \mathrm{~cm}^{-1}$ - characteristic of the $\mathrm{P}-\mathrm{O}$ groups of the bisphosphonate ligand - also confirmed its evolution into $\mathrm{P}_{2} \mathrm{~W}_{18} \mathrm{Co}_{4}$ (Fig. 10a). ${ }^{38}$ This observation was alleged by ${ }^{31} \mathrm{P}$ NMR studies (see below). Similarly, IR spectroscopy was used to follow the immobilisation of $\left[\mathrm{CpFe}(\mathrm{CO})_{2}(\mathrm{THF})\right]^{+}$cations in the pores of the anionic $\left[\mathrm{Et}_{4} \mathrm{~N}\right]_{3}\left[\mathrm{In}_{3}(\mathrm{BTC})_{4}\right]$ MOF by impregnation in acetone at room temperature for 24 h. ${ }^{172}$ The presence of three bands instead of two in the $v(C O)$ region $(2123,2065$ and 2016 $\mathrm{cm}^{-1}$ ) in the IR spectrum of the composite indicated the partial decomposition of the catalyst and the formation of undesired $\left[\mathrm{CpFe}(\mathrm{CO})_{3}\right]^{+}$species. The reaction was further performed by simply soaking (and not agitating) the MOF in a solution of the catalyst at low temperature $\left(5^{\circ} \mathrm{C}\right)$ in order to avoid this decomposition. Moreover, the presence of bands at 1711 and 
$1221 \mathrm{~cm}^{-1}$ also suggested that acetone replaces coordinated THF in the complex.

Semi-quantitative analysis may be also performed using the IR spectra of Cat@MOFs. For example, the relative intensities of the bands characteristic of the Keggin ion (P-O vibration at 1077 $\mathrm{cm}^{-1}$ ) and of the MOF's porphyrinic linker ( $\mathrm{C}-\mathrm{C}$ and $\mathrm{C}-\mathrm{N}$ vibrations at $1180 \mathrm{~cm}^{-1}$ ) were followed for $\mathrm{PW}_{12} @ \mathrm{Zr}_{6}-\mathrm{TCPP}-\mathrm{Fe}$, revealing the maximum amount of POM that could be immobilised into the MOF by synthetic encapsulation experiments. ${ }^{109}$ It can be noted however that in some rare cases, the IR bands of the guest cannot be observed, for example in $\mathrm{P}_{2} \mathrm{~W}_{18} \mathrm{Co}_{4} @ M O F-545,108 \mathrm{PMo}_{12} @ U i O-67,107$ and CoW $12 @ Z I F-8,203$ likely because of the low loadings involved.

Raman spectroscopy may complement the characterization of Cat@MOF materials, in particular when the catalyst's bands cannot be clearly identified by IR spectroscopy. However, in the case of POM@MOFs, the intensities of these bands are also often quite weak. For example, the Raman spectrum of SiW11@MIL-101(Cr) exhibits a small band at $\sim 978 \mathrm{~cm}^{-1}$ assigned to a $\mathrm{W}=\mathrm{O}$ stretching mode of $\mathrm{SiW}_{11} \cdot{ }^{37} \mathrm{In} \mathrm{P}_{2} \mathrm{~W}_{18} \mathrm{Co}_{4} @ \mathrm{MIL}-$ $101(\mathrm{Cr})$, the $\mathrm{W}=\mathrm{O}$ band of the POM at $982 \mathrm{~cm}^{-1}$ is clearly visible in the Raman spectrum of the composite, although with a rather weak intensity. ${ }^{62}$ In rare examples, the characteristic Raman bands of the catalyst are intense. This is the case for $\mathrm{Eu}\left(\mathrm{PW}_{11}\right)_{2} @ \mathrm{MIL}-101(\mathrm{Cr})^{64}$ and $\mathrm{P}_{2} \mathrm{~W}_{18} @ \mathrm{MIL}-101(\mathrm{Cr}){ }^{60}$ In the latter, the $\mathrm{W}=\mathrm{O}$ band is shifted to lower frequency as a result of POM/MOF interactions (Fig. 10b). Raman spectroscopy was also used to characterise Complex@MOFs. For example, the bands of the iron tetrasulfophthalocyanine, FePcS, are clearly visible in the Raman spectrum of FePcS@MIL-101(Cr) at the same position than in the bulk FePcS precursor and with no additional band, indicating the integrity of the complex upon its immobilisation. ${ }^{145}$

\section{$3.5 \mathrm{~N}_{2}$ adsorption}

$\mathrm{N}_{2}$ porosimetry is a largely used technique to characterise MOFbased materials. The significant reduction of the amount of $\mathrm{N}_{2}$ adsorbed in Cat@MOF compared with that in the pristine MOF is considered as an indication of the successful immobilisation of the catalyst - provided that the MOF remains intact upon the catalyst's incorporation. The Brunauer-Emmett-Teller (BET) specific surface area and total pore volume of Cat@MOF composites are expected to be lower when compared to thoses of the guest-free MOF, as a result of both the mass increase due to the incorporation of the catalyst and the pore space occupied by the guests. For example, it was shown that the surface area of PW $12 @ M I L-100(F e)$ depends on the amount of immobilized POM where PW $_{12} @ M I L-100(F e)$ exhibits a high BET surface area $\left(1046 \mathrm{~m}^{2} \mathrm{~g}^{-1}\right.$ ) even for high loadings (35 wt \%) when compared to that of the POM-free MOF $\left(2055 \mathrm{~m}^{2} \mathrm{~g}^{-1}\right.$ ) (Fig. 11). ${ }^{80}$ The mesoporous and microporous windows are also retained, which ensures that substrates can enter into the pores and come into contact with the POM.
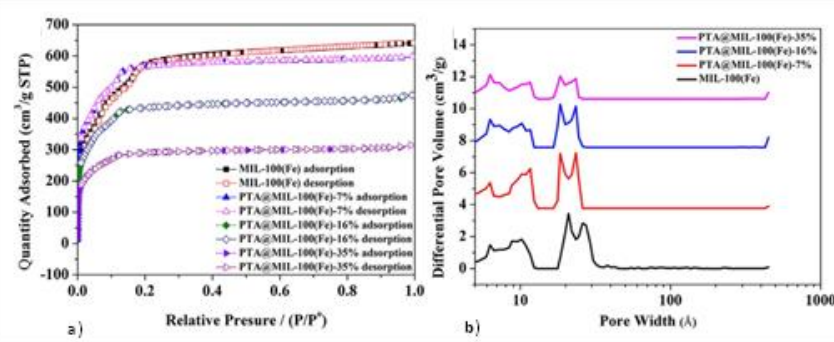

Fig. 11 a) $\mathrm{N}_{2}$ adsorption-desorption isotherms at $77 \mathrm{~K}$ and b) pore size distribution of MIL100(Fe) and PW $12 @ M I L-100(F e)$ with various POM loadings, i.e. PW $12 @ M I L-100(F e)-7 \%$, PW $12 @ M I L-100(\mathrm{Fe})-16 \%$ and $\mathrm{PW}_{12} @ \mathrm{MIL}-100(\mathrm{Fe})-35 \%$. Reprinted with permission from ref. ${ }^{80}$ Copyright 2017 Wiley-VCH Verlag GmbH \& Co. KGaA, Weinheim.

Juan-Alcañiz et al. deduced from the comparison of $\mathrm{N}_{2}$ isotherms of various samples of PW $12 @ M I L-101(C r)$ that for those prepared by synthetic encapsulation, the dispersion of the POMs in the MOF matrix was better than for those obtained by post-synthetic impregnation. ${ }^{41}$ Indeed, the encapsulated samples with high POM loadings show an adsorptive behaviour similar to that of the POM-free MOF, i.e. with two steps corresponding to the filling of the two types of cages. This strongly suggests that the filling of the pores by the POMs is quite homogeneous, with no indication of blocking of the cavities. In contrast, for the impregnated samples, BET measurements suggest that only a fraction of the large cavities is occupied (since the POMs are too large to diffuse through the pentagonal windows) and most of these cavities are blocked. Besides, $\mathrm{N}_{2}$ adsorption/desorption isotherms of the $\left(\mathrm{FePc}^{\mathrm{t} B u 4}\right)_{2} \mathrm{~N} @ \mathrm{MIL}-101$ composite reveal that its total pore volume decreases by only $5 \%$, which corresponds to the weight gain of $5.2 \mathrm{wt} \%$ after loading. ${ }^{144}$ This shows that the bulky

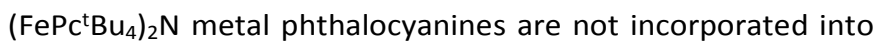
the mesoporous structure of MIL-101(Cr) as they are too large to enter its hexagonal pore windows but that they are rather adsorbed at the surface of the crystallites.

\subsection{Cyclic voltammetry}

Cyclic voltammetry is more rarely used to characterise Cat@MOF composites as it requires that the catalyst itself exhibits characteristic electrochemical signals. It may give useful information not only on the integrity of the catalyst within the composite but also on the strength of its interactions with the MOF. For example, PW $11 @ M I L-101(\mathrm{Cr})$ and $\mathrm{SiW}_{11} @ M I L-101(\mathrm{Cr})$ composites were deposited on a pyrolytic graphite (PG) surface for analyzing their electrochemical behaviour at $\mathrm{pH}$ 2.2.35 The authors showed that the encapsulation of the POMs into the hybrid framework does not affect their redox potentials although the quality of the signals was not as good as that of the precursors. Interestingly, they concluded from the linear variation of both cathodic and anodic peak current intensities with the square root of the scan rate that the $W$ redox processes were diffusion-controlled, indicating that $\mathrm{PW}_{11}$ and $\mathrm{SiW}_{11}$ exhibit some degree of mobility when immobilized into the MOF. The same group studied the electrochemical properties of $\mathrm{SiW}_{11} \mathrm{Fe} @ \mathrm{MIL}-101(\mathrm{Cr})$ on PG and identified - in addition to a peak assigned to the $\mathrm{Cr}$ centres of 
MIL-101(Cr) - the characteristic peaks of the POM which are almost unchanged compared to those of the POM precursor (Fig. 12). ${ }^{37}$ In a similar fashion than for $\mathrm{PW}_{11}$ and $\mathrm{SiW}_{11}$, the incorporation of $\mathrm{SiW}_{11} \mathrm{Fe}$ into MIL-101 leads to a change in its diffusion regime from surface-confined to solution-type behaviour. By contrast, both the anodic and cathodic peak current intensities of $\mathrm{PMo}_{10} \mathrm{~V}_{2} @ \mathrm{MIL}-101(\mathrm{Cr})$ were directly proportional to the scan rate, which indicated processes confined to the surface and a tighter interaction of the POM with its MOF host. ${ }^{67}$ Moreover, electrochemical surface coverage values were four times and ten times higher for $\mathrm{SiW}_{11} \mathrm{Fe} @ \mathrm{MIL}-101(\mathrm{Cr})$ and $\mathrm{PMo}_{10} \mathrm{~V}_{2} @ \mathrm{MIL}-101(\mathrm{Cr})$, respectively, than for the pure POM modified electrodes. This shows that the immobilisation of the POM into the porous structure of MIL101(Cr) increases the quantity of active POM available at the electrode surface.

Cyclic voltammetry was also performed on $\mathrm{PW}_{12} @ \mathrm{NU}$ 1000,110 PW $12 @ U i O-67,101$ PW 11 Zr@UiO-67101 and P2 $W_{18} @ U i O-$ 67,101 showing that the redox activity of the POM is systematically maintained when immobilized into the MOF. Considering Complex@MOFs, their characterisation by cyclic voltammetry is scarcely reported. We can cite a study of the electrochemical properties of a $\mathrm{Ni}(\mathrm{II})$ complex immobilised in UiO-67 functionalised with Ru ions. ${ }^{163}$ In this composite, two irreversible reductive waves are attributed to a step-by-step reduction and change of octahedral $\mathrm{Ni}^{\prime \prime}$ to tetrahedral $\mathrm{Ni}^{\circ}$.

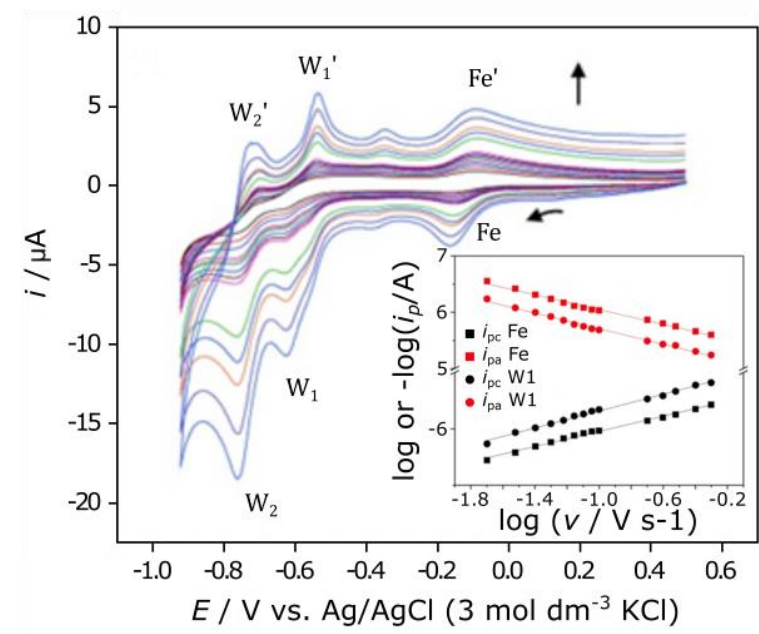

Fig. $12 \mathrm{CVs}$ of SiW 11 Fe@MIL-101(Cr) immobilised on a PG electrode in a pH 2.5 $\mathrm{H}_{2} \mathrm{SO}_{4} / \mathrm{Na}_{2} \mathrm{SO}_{4}$ buffer solution at different scan rates from 0.04 to $0.5 \mathrm{Vs}^{-1}$ showing oxidation and reduction waves of both the POM and the MOF. Inset: Plots of $\log i_{\mathrm{pc}}$ and $\log i_{\text {pa }}$ versus $\log v$ for the $F e$ and $W_{1}$ peaks. Reprinted with permission from ref. ${ }^{37}$. Copyright 2014 Wiley-VCH Verlag GmbH \& Co. KGaA, Weinheim.

\subsection{Solid-State NMR}

For the POMs which contain $\mathrm{P}$ atoms, and in particular for the most frequently studied $\mathrm{PW}_{12},{ }^{31} \mathrm{P}\left\{{ }^{1} \mathrm{H}\right\}$ Cross-Polarisation Magic Angle Spinning (CP MAS) NMR has proved a valuable tool to study their stability in the composite materials upon immobilisation, before and after catalysis. For PW $11 @$ MIL$101(\mathrm{Cr})$, the signal at $-12.2 \mathrm{ppm}$ thus confirmed the integrity of the POM. ${ }^{17}$ Similarly the presence of a single peak around 15.5 ppm $\left(-16.3,{ }^{42}-15.3,{ }^{45}-15.4,{ }^{50}-16.0^{46} \mathrm{ppm}\right)$ in samples of PW $12 @ M I L-101(\mathrm{Cr})$ prepared by either direct synthesis or impregnation suggests that the POM remains intact upon incorporation into the MOF. A single broad peak was also observed for PW PW $_{12} @$ HKUST-1 with however a slightly different chemical shift (-21.4 ppm). ${ }^{124}$

Nevertheless, a few studies have reported the presence of several ${ }^{31} \mathrm{P}$ NMR peaks after the immobilisation of $\mathrm{PW}_{12}$. For example, Maksimchuk et al. reported three main peaks at -16.4, -14.8 and -11.8 ppm in the spectrum of PW $12 @ M I L-101(\mathrm{Cr}) \cdot{ }^{30} \mathrm{As}$ IR spectra did not indicate any noticeable change and thus any degradation of the POM, they proposed that these peaks might correspond to different modes of interaction between the POM and the MOF surface. A similar observation was reported for PW12@NU-1000 where two signals were observed at -15 and $16 \mathrm{ppm}$ and attributed to a different hydration degree of the POM and to interactions of the POM with $\mathrm{Zr}_{6}$ oxoclusters. ${ }^{112}$ In another composite, namely $\mathrm{PW}_{12} @$ MOF-808A with 42 wt \% POM loading, the ${ }^{31} \mathrm{P}$ MAS NMR spectrum exhibited three resonances at $-15.1,-16.2$, and $-17.6 \mathrm{ppm}$, much broader than that of the pure POM. These three distinct signals were attributed as a result of either different protonation states of $\mathrm{PW}_{12}$ or of POM distortion emanating from strong interactions with the host framework. ${ }^{115}$

2D CP MAS NMR ${ }^{31} \mathrm{P}^{-1} \mathrm{H}$ heteronuclear correlation (HETCOR) experiments were performed to go further in the investigation of the localisation of three different POMs $\left(\mathrm{PW}_{12}, \mathrm{P}_{2} \mathrm{~W}_{18}\right.$ and $\mathrm{PW}_{11} \mathrm{Zr}$ ) immobilised into UiO-67. ${ }^{101}$ The observation of dipolar contacts between the phosphorous atom of the POMs and the protons of the MOF's aromatic linkers as well as $\mathrm{Zr}-\mathrm{OH}$ hydroxyl groups indicated the close proximity of the POM to the surface of the MOF's pores. Furthermore, it was shown that $\mathrm{PW}_{12}$ and $\mathrm{P}_{2} \mathrm{~W}_{18}$ developed preferred interactions with the linkers while $P W_{11} Z r$ was closer to the $Z r_{6}$ oxoclusters. 2D NMR ${ }^{31} \mathrm{P}_{-}{ }^{1} \mathrm{H}$ HETCOR experiments provide also valuable information about the interactions between co-immobilised POMs and Cp*Rh complexes in the (PW $12, \mathrm{Cp} * \mathrm{Rh}) @ U i \mathrm{U}-67$ composite. ${ }^{103}$ While a single ${ }^{31} \mathrm{P}$ NMR peak at $-15.1 \mathrm{ppm}$ was observed in PW $12 @ U i O-67,101$ two main resonances at -15.2 and 14.4 ppm were distinguished in ( $\left.\mathrm{PW}_{12}, \mathrm{Cp} * \mathrm{Rh}\right) @ U i \mathrm{O}-67$, suggesting two different POM environments in the latter composite. HETCOR experiments further showed that the ${ }^{31} \mathrm{p}$ signal at $-15.2 \mathrm{ppm}$ correlates with the ${ }^{1} \mathrm{H}$ signal at $8.3 \mathrm{ppm}$ of aromatic protons while the second signal at $-14.4 \mathrm{ppm}$ correlates with that at $1.6 \mathrm{ppm}$ of the Cp* moiety (Fig. 13). DFT calculations were also performed (see below), providing results in full agreement with these experiments, with two possible positions for the POM: one centered in a UiO-67 cavity (with the $\mathrm{Cp} * \mathrm{Rh}$ complex pointing toward a POM-free pore) and one off-centered position with the $\mathrm{Cp}^{*} \mathrm{Rh}$ pointing toward the POM.

${ }^{31} \mathrm{P}$ NMR studies have also proved to be very useful for the characterisation of the paramagnetic Co-substituted POMs in MIL$101(\mathrm{Cr}) .^{38}$ The spectra were recorded for the solid composites as well as for the solutions obtained after stirring a suspension of the composite in $5 \mathrm{M} \mathrm{LiCl}$. These experiments indicated that the monosubstituted Keggin anion, $\mathrm{PW}_{11} \mathrm{Co}$, and the sandwich-type anion, $\mathrm{P}_{2} \mathrm{~W}_{18} \mathrm{CO}_{4}$, can be encapsulated and extracted without degradation, while the hybrid sandwich-type $\mathrm{POM}, \mathrm{P}_{2} \mathrm{~W}_{18} \mathrm{Co}_{7}(\mathrm{Ale})_{2}$, 
evolves into $\mathrm{P}_{2} \mathrm{~W}_{18} \mathrm{Co}_{4}$ once in the cavities of the mesoporous material. Furthermore, the broadness of the ${ }^{31} \mathrm{P}$ NMR signal in $\mathrm{P}_{2} \mathrm{~W}_{18} \mathrm{CO}_{4} @ \mathrm{MIL}-101(\mathrm{Cr})$ under MAS compared to that in PW 11 Co@MIL-101(Cr) tends to indicate that $\mathrm{P}_{2} \mathrm{~W}_{18} \mathrm{CO}_{4}$ POMs are strongly anchored to the MIL framework while $\mathrm{PW}_{11} \mathrm{Co}$ POMs are more mobile. In another study, the broadening of the ${ }^{31} \mathrm{P}$ NMR signal in $\mathrm{PW}_{12} @ \mathrm{NU}-1000$ heated at $120^{\circ} \mathrm{C}$ was attributed to a loss of symmetry around the phosphorous and strong POM/MOF interactions. ${ }^{111}$

Solid-state NMR has also been used to characterise Complex@MOFs. ${ }^{13} \mathrm{C}$ CP-MAS NMR of CuPhen@MIL-100(Al) exhibits signals assigned to the aromatic carbons and carboxylate groups of the MOF's linkers and Phen ligand. ${ }^{156}$ The single broad peak observed at $\sim 15 \mathrm{ppm}$ in the ${ }^{31} \mathrm{P}\left\{{ }^{1} \mathrm{H}\right\}$ MAS NMR spectrum of $\left[\mathrm{Ir}(\mathrm{cod})\left(\mathrm{PCy}_{3}\right)(\mathrm{py})\right] @ \mathrm{NaSO}_{3}-\mathrm{MIL}-101(\mathrm{Cr})$ is assigned to $\mathrm{PCy}_{3}$ ligands. ${ }^{155}$ The absence of peak characteristic of $\mathrm{PF}_{6}$ anions (around $-146 \mathrm{ppm}$ ) suggests that the cation exchange is indeed complete.

Solution NMR is also useful to investigate the formation of composites. 31P solution NMR was used to study the interactions between $\mathrm{Cu}^{2+}$ and $\mathrm{PMo}_{12}$ ions during the synthetic process of $\mathrm{PMO}_{12} @ H K H U S T-1$. A shift in the phosphorus resonance was observed from $3.72 \mathrm{ppm}$ for a solution of $\mathrm{PMo}_{12}$ to $3.00 \mathrm{ppm}$ after the addition of $\mathrm{Cu}^{2+}$ and to $3.09 \mathrm{ppm}$ after subsequent addition of BTC. Shifts in the ${ }^{183} \mathrm{~W}$ NMR spectra of a solution of $\mathrm{PW}_{12}$ also support the occurence of strong interactions between the copper ions and the POM during the synthesis of PW $12 @$ HKHUST-1, while confirming the integrity of the POM. ${ }^{206}$

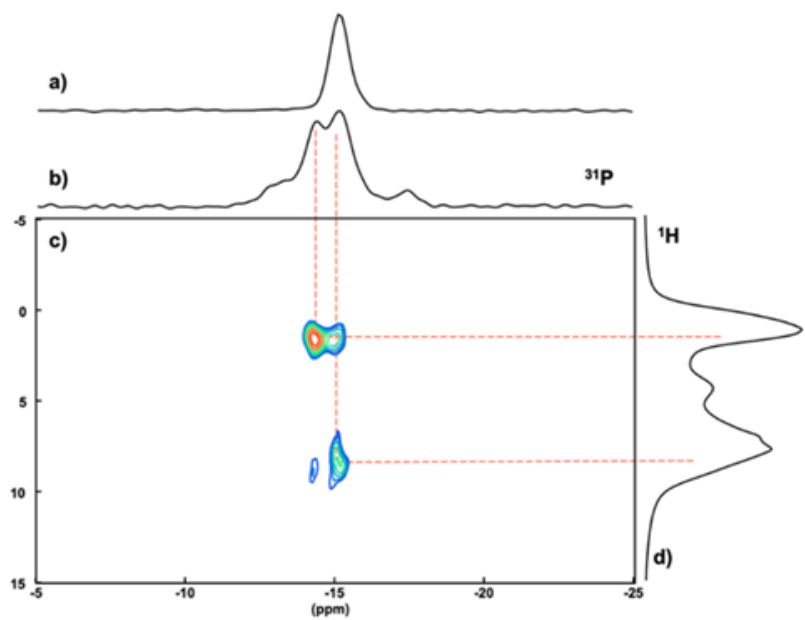

Fig. $13{ }^{31} \mathrm{P}\left\{{ }^{1} \mathrm{H}\right\}$ CP-MAS NMR spectra of a) PW $\left.12 @ U i O-67, b\right)\left(P W_{12}, \mathrm{Cp}^{*} \mathrm{Rh}\right) @ U i \mathrm{U}-67$ and c) ${ }^{31} \mathrm{P}_{-}{ }^{1} \mathrm{H}$ HETCOR and d) ${ }^{1} \mathrm{H}$ MAS NMR spectra of $\left(\mathrm{PW}_{12}, \mathrm{Cp} * \mathrm{Rh}\right) @$ UiO-67. Reprinted with permission from ref. ${ }^{103}$ Copyright 2020, American Chemical Society.

\subsection{X-ray diffraction patterns}

Single crystal X-ray diffraction (XRD) has only been possible on a limited number of Cat@MOF materials, mostly for Cubased MOFs. The single crystal structure of a POM@HKHUST-1 composite $(\mathrm{POM}=$ Keggin-type polyoxomolybdate or polyoxotungstate) was first reported in 2003.122 The composite crystallises in the cubic space group $F m-3 m(a \approx 26 \AA$ ) , with the
POM guests entrapped into half of the cavities of the MOF. This MOF possesses two types of pores ( $A$ and $B$ ), with diameters of ca. $13 \AA$ and $10 \AA$. Both display cuboctahedral shapes but only the A-type pores can accommodate the Keggin anions (Fig. 14a). ${ }^{121}$ Water molecules coordinated to the copper ions point towards the centre of the B-type pores, preventing the incorporation of guest species. The Keggin ion is disordered over two positions due to the $\mathrm{O}_{\mathrm{h}}$ symmetry of pores $\mathrm{A}$ while the Keggin ion has a tetrahedral symmetry. Since then, several structural studies have been performed on POM@HKUST-1 materials (Table 1 ). An original synthesis was recently described by Li et al. who used the ability of POMs to oxidise metals to cations: the reaction of $\mathrm{Cu}$ foils with aqueous solutions of polyoxomolybdates and BTC linkers led to the nucleation of crystals of POM@HKUST-1 on the metal surface. ${ }^{134}$ The authors evidence an effect of the POM's charge on the morphology of the resulting crystals: cubic for $\mathrm{SiMo}_{11} \mathrm{~V}^{5-}, \mathrm{PMo}_{9} \mathrm{~V}_{3}{ }^{6-}$ and $\mathrm{PMo}_{10} \mathrm{~V}_{2}{ }^{5-}$ or octahedral for $\mathrm{PMo}_{11} \mathrm{~V}^{4-}, \mathrm{SiMo}_{12}{ }^{4-}$ and $\mathrm{PMo}_{12}{ }^{3-}$. This was confirmed later by the synthesis of cubic crystals of $\mathrm{PW}_{10} \mathrm{Ti}_{2}{ }^{7-}$ encapsulated in HKUST-1 while octahedral crystals were obtained with $\mathrm{PW}_{12^{3-}}$ when using the same synthetic conditions. ${ }^{118}$ The authors correlated this difference of crystal shape to the difference in electrostatic interactions between $\mathrm{Cu}^{2+}$ ions and the oxygen atoms of the POM during the synthetic process, thus confirming the templating role of the POMs.

rht-MOF-1 is also a Cu-based MOF which crystallises in the cubic Fm-3m space group ( $a \approx 44 \AA$ ). It contains four types of cages: cuboid ( $5.9 \AA$ A), rhombitruncated cuboctahedral ( 11.6 ̊̊), $\beta$-cage like ( $12.1 \AA)$, and $\alpha$-cage like $(\sim 20.2 \AA)$. The size of the Keggin-type anions is perfectly adapted to the size and the symmetry of the $\beta$-cages which are the only occupied cavities of the MOF (Fig. 14b). ${ }^{137,136}$

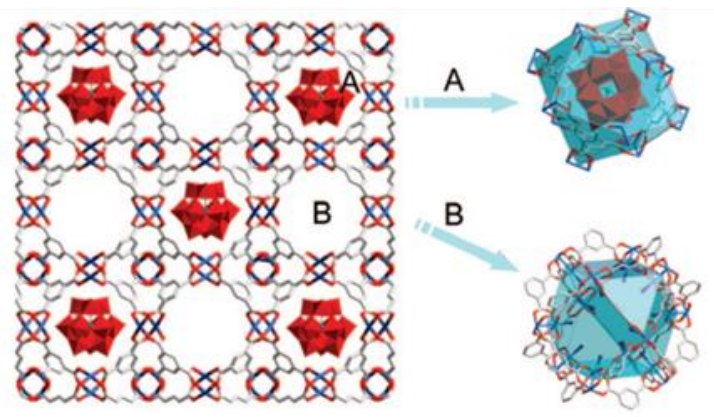

a)

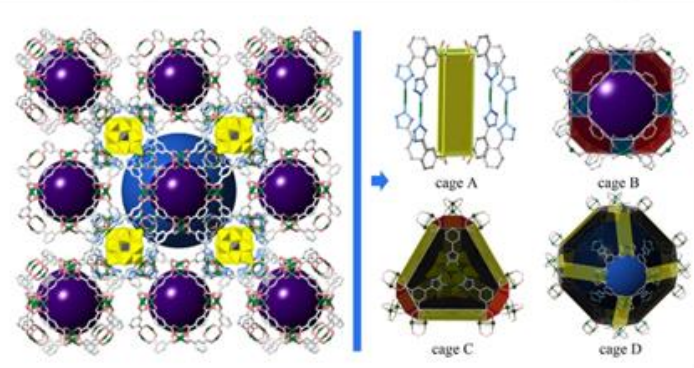

Fig. 14 Crystal structure of a) XM $\mathrm{XM}_{12} @ H K U S T-1$ (NENU- $n$ with $n=1-6$ ) and b) $\mathrm{XM}_{12} @ r h t$ MOF-1 with their different type of cages. Adapted with permissions from refs. ${ }^{121}$ (Copyright 2009 American Chemical Society) and ${ }^{136}$ (Copyright 2016 Springer Nature) respectively. 
Single crystal $\mathrm{X}$-ray diffraction also allowed to locate the cationic guest $\left[\mathrm{Cp}_{2} \mathrm{Co}\right]^{+}$in the cavities of the anionic $\left[\mathrm{Et}_{4} \mathrm{~N}\right]_{3}\left[\ln _{3}(\mathrm{BTC})_{4}\right] \mathrm{MOF} .{ }^{172}$ The impregnation of crystals of MOFs with solutions of the cations lead to crystals with disordered guests. For the crystallographic studies, the composite material was isolated by direct synthetic encapsulation using $\left[\mathrm{Cp}_{2} \mathrm{Co}\right]^{+}$as a template. $\left[\mathrm{Cp}_{2} \mathrm{Co}\right]_{3}\left[\mathrm{In}_{3}(\mathrm{BTC})_{4}\right]$ crystallises in the 1-43d space group. The disordered cations are localised in the channels and are slightly offset from the -4 axes in the centre of the pores. They interact weakly with the framework via hydrogen bonding between the $\mathrm{H}$ atoms of the $\mathrm{Cp}$ rings and the $\mathrm{O}$ atoms of the MOF framework. The remaining space in the channels is occupied by disordered DMF and $\mathrm{H}_{2} \mathrm{O}$ solvent molecules.

Powder X-ray diffraction (PXRD) is routinely used to check the crystallinity and especially confirm the phase purity and integrity of the MOF host after the immobilisation of the guests. In almost all cases, modifications in the intensities of the XRD peaks are observed for POM@MOF composites when compared to those of the pristine MOF. However, both the positions and widths of the $\mathrm{X}$-ray reflections have to remain unchanged to indicate that the MOF does not lose its crystallinity upon the immobilisation of the catalyst. A detailed study on the influence of the catalyst's loading on the relative intensity of the PXRD peaks of the composite was reported for CuPhen@MIL-100(Al), isolated by a ship in a bottle mehod. ${ }^{156}$ The authors showed that the intensity of the Bragg peak at $2 \theta=$ $4.0^{\circ}$ gradually decreases when the amount of immobilized CuPhen increases (Fig. 15). Such variation was not observed when the sample was prepared by impregnating the MOF with a solution of the CuPhen complex. In this latter case, it was hypothesized that the complex could access the external surface of MIL-100(Al) crystallites only, due to its large size when compared to that of MIL-100 hexagonal windows.

In some rare cases of Cat@MOFs obtained by synthetic encapsulation, it has been observed that the crystallinity of the MOF depends on the number of encapsulated guests. For example, in PW $12 @$ MOF-808X, the crystallinity was improved compared to that of the pristine MOF using POM loadings lower than $32 \%$. The authors hypothesized that the POMs may play the role of a modulator at relatively low loadings while they may rather induce defects at higher loadings - by inhibiting the coordination between zirconium ions and ligands - thus leading to a decrease in crystallinity. ${ }^{115}$ Some authors have also reported an increase of the intensity of some peaks. It is the case for the peaks around $5^{\circ}$ in the PXRD of $\mathrm{P}_{2} \mathrm{~W}_{18} \mathrm{Co}_{4} @ \mathrm{MIL}-$ $101(\mathrm{Cr}){ }^{62}$ The occurrence of new diffraction peaks in the PXRD patterns of PW $12 @ M I L-101(\mathrm{Cr})^{44}$ and PW $12 @ \mathrm{NH}_{2}-\mathrm{MIL}-101(\mathrm{Cr})^{70}$ has been observed. Although absent in the PXRD of the POMfree MOF, the positions of the new peaks are consistent with the unit cell of MIL-101 and Rietveld refinements were attempted to propose possible locations of the POM in $\mathrm{PW}_{12} @ \mathrm{MIL}-101(\mathrm{Cr}){ }^{44}$ The authors proposed that the incorporation of the $\mathrm{PW}_{12} \mathrm{POM}$ adds electron density to the crystal structure of the MOF thus creating the observed diffracted intensity at these peak positions.

An interesting study was performed on PW $_{12} @ N U-1000$ composites which had undergone various treatments. ${ }^{111}$ The PXRD pattern of PW $_{12} @ N U-1000$ is different from that of the parent NU-1000 while that of $\mathrm{PW}_{12} @ \mathrm{NU}-1000-120^{\circ} \mathrm{C}$ activated at $120^{\circ} \mathrm{C}$ is more similar (Fig. 16). Furthermore, the PXRD pattern of $\mathrm{PW}_{12} @ \mathrm{NU}-1000-\mathrm{scCO}_{2}$ activated with supercritical $\mathrm{CO}_{2}$ exhibits peaks at similar d-spacing than PW $12 @ \mathrm{NU}-1000-$ $120^{\circ} \mathrm{C}$ but with very different intensities. Upon heating, there is an irreversible evolution of the PXRD pattern of PW $12 @ N U$ $1000-\mathrm{scCO}_{2}$ to that of $\mathrm{PW}_{12} @ \mathrm{NU}-1000-120^{\circ} \mathrm{C}$. The authors proposed that, assuming no preferred orientation of composite crystallites and retention of MOF structure, the variations in peak intensities indicate major differences in the location of the guest. These discrepancies, corroborated by difference envelope density analyses (see section 3.7) were thus attributed to the POM residing either in the mesoporous channels of $\mathrm{NU}$ 1000 (before treatment at $120^{\circ} \mathrm{C}$ ) or in the microporous ones (after treatment at $120^{\circ} \mathrm{C}$ ). These hypotheses were further confirmed with a study on PW $12 @ N U-1000-N D C$ and PW $12 @ N U-1008$, where NU-1000-NDC and NU-1008 have similar structures to NU-1000. ${ }^{114}$ PXRD also allowed to show the transformation of $\mathrm{NH}_{2}-\mathrm{MIL}-101$ (Al) to $\mathrm{NH}_{2}-\mathrm{MIL}-53$ (Al) during the immobilisation of an hemin catalyst, a consequence of the instability of $\mathrm{NH}_{2}-\mathrm{MIL}-101$ (Al) in DMF. ${ }^{151}$

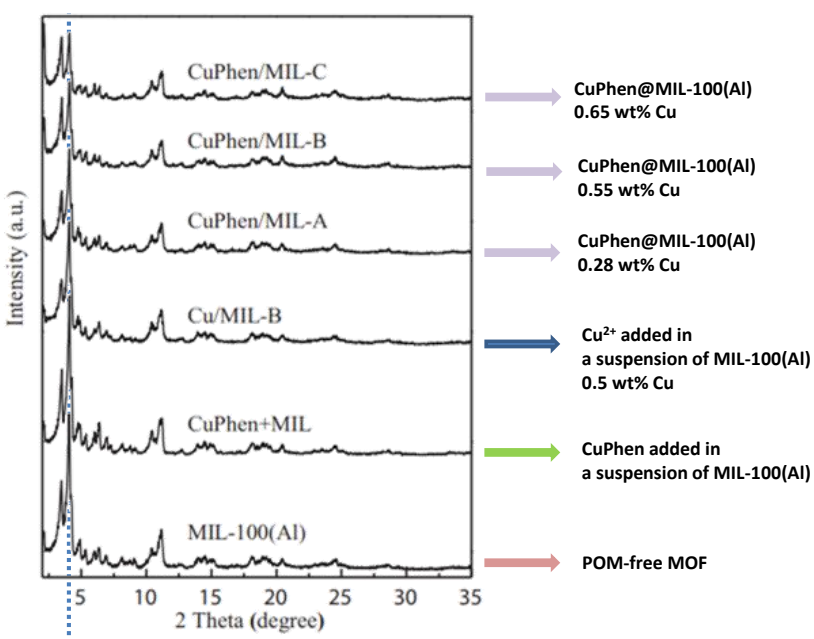

Fig. 15 PXRD patterns for CuPhen@MIL-100(Al) with various CuPhen loading, increasing from CuPhen/MIL-A to CuPhen/MIL-C, compared with the patterns for the pristine MOF and for the material prepared by impregnation of the MOF with a solution of the complex. The dashed line indicates the position of the $2 \theta=4.0^{\circ}$ Bragg peak. Adapted with permission from ref. ${ }^{156}$. Copyright 2015 Elsevier B.V.

These various studies highlight the fact that the localisation of the POMs within the cavities of MOFs may induce great changes in the PXRD patterns of the composites, yet with rare reports of Rietveld refinements. Still the carefull analysis of PXRD patterns allows making hypotheses on the structure of the POM@MOF. Pair Distribution Function (PDF) and Difference envelope density analysis (DED) might be efficient alternatives to go further in their structural characterization, as detailed below. 


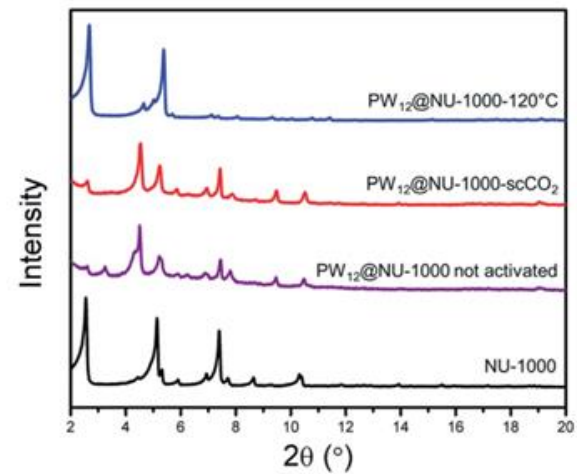

Fig. 16 PXRD patterns for NU-1000 and PW PW $_{12}$ NU-1000 as-synthesised without solvent removal, activated by supercritical $\mathrm{CO}_{2}$, and activated at $120^{\circ} \mathrm{C}$. Reprinted from ref. ${ }^{111}$ with permission from the RSC.

\subsection{Difference envelope density (DED) and pair distribution function (PDF)}

Characterising the structure of a wide variety of Cat@MOF materials is often challenging using conventional diffraction techniques, either due to the lack of single crystals or to the difficulty to perform Rietveld structural refinements from powder data. Although the porous MOF host may have an already known crystal structure that is usually retained upon the immobilization of the hosted molecular catalysts, the resulting Cat@MOF material often lacks long-range order as a result of the disordered placement of the guest. In addition, low Cat loadings resulting from the synthetic steps may further decrease their detectability, prohibiting the use of conventional structure solution methods in order to identify their position within the MOF's pores precisely. In such cases, difference envelope density (DED) analysis was proposed as an efficient alternative in order to locate disordered guest species in porous materials. ${ }^{207}$ The generated envelope separates regions of low and high electron density as extracted from low-order reflections in the X-ray powder diffraction data. In guestfunctionalised MOF, DED may be obtained by subtracting the envelope of the parent MOF from that of the functionalised material, ${ }^{208}$ thus providing the electron density of the guest within the host. Using synchrotron X-ray data, Chapman and coworkers used such DED analysis in order to characterise the PW $12 @ N U-1000-120$ catalyst activated at $120^{\circ} \mathrm{C}$ under vacuum. ${ }^{110}$ Exploiting the small differences between the $\mathrm{NU}$ 1000 and PW $12 @ N U-1000$ PXRD patterns, DED allowed locating the POM guest in the small triangular channels of NU-1000 (Fig. 17). As mentioned above, the same authors further reported a different location of the POM in the PW $12 @ \mathrm{NU}-1000-\mathrm{SCCO}_{2}$ composite prepared under milder conditions (i.e. supercritical $\mathrm{CO}_{2}$ drying) whereby the POM was rather located in the larger c-pores of NU-1000, in line with improved catalytic activities of this composite (Fig. 17). ${ }^{111}$ This structural difference between the two composites was interpreted in terms of the migration of the POM with temperature to more thermodynamically favoured positions within the smaller triangular channels of NU1000. This couple of studies shows the efficacy of DED analysis to detect variants of similar composites and analyse the impact of synthetic conditions.
Another powerful experimental tool not restricted to crystalline materials is the Pair Distribution Function (PDF) method. The PDF signal emanates from both Bragg diffraction and diffuse scattering, providing information about long-range atomic order and short to middle-range structural features, respectively. The PDF signal is defined in real space and reflects the probability of finding a pair of atoms at a distance $r$ in the structure. It may thus be described as a one-dimensional function that exhibits peaks at $r$-values corresponding to characteristic atomic distances within the sample. ${ }^{209}$ Chapman and co-workers proposed an elegant approach, namely the differential PDF (d-PDF) method, ${ }^{210}$ whereby the local structure of the guest, the host-guest interactions and the modification of the host structure are retrieved through the subtraction of the reference PDF of the guest-free host from that of the guest loaded host. PDF and d-PDF have been successfully used for characterising non ideal MOFs, ${ }^{211} \mathrm{MOF}$ materials functionalised with metal oxo-clusters ${ }^{212,213}$ or the adsorption of small molecules. ${ }^{214-216}$
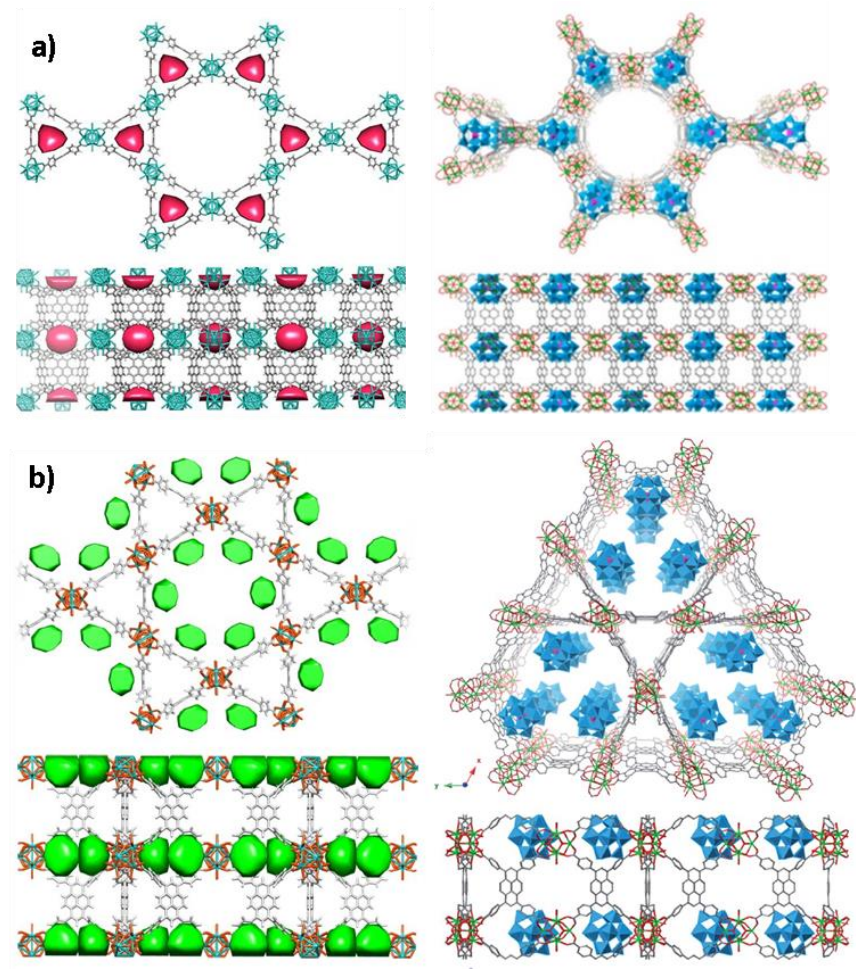

Fig. 17 Left: DED mapping of the PW $12 @ N U-1000-120$ (a) and PW $12 @ N U-1000-\mathrm{scCO}_{2}$ (b) composites where pink or green spheres represent electron density of the POM immobilised into NU-1000. Right: Corresponding proposed location of the POM in the PW $12 @ N U-1000-120$ (small triangular channels) and $\mathrm{PW}_{12} @ \mathrm{NU}-1000-\mathrm{scCO}_{2}$ (hexagonal channels). Adapted with permission from refs. ${ }^{110,111}$ (Copyright 2017 American Chemical Society).

Using a laboratory X-ray source, the use of PDF and d-PDF methods has been recently extended to the characterisation of POM@MOF composites in conjunction with DFT methods (see section 4). ${ }^{103,109}$ The PDF and d-PDF analyses provided an unequivocal signature of the immobilised $\mathrm{PW}_{12}$ polyoxometalate in the PW $12 @ U i O-67$ and (PW $12, C p^{*}$ Rh)@UiO-67 composites (Fig. 18ab). ${ }^{103}$ The d-PDF directly reflected the local structure of the POM through the exhaustive inventory of interatomic distances within the 
$\mathrm{PW}_{12}$ moiety from which a structure refinement of the POM was performed (Fig. 18c). The relatively good quality of the refinement $\left(\mathrm{R}_{\mathrm{w}} \approx 28.2 \%\right)$ and the corresponding structural model indicated that the original structure of the POM was indeed preserved upon its immobilisation into UiO-67. Importantly, the similarity between both experimental d-PDF signals associated to the $\mathrm{PW}_{12}$ immobilised in $\left(\mathrm{PW}_{12}, \mathrm{Cp}\right.$ * Rh)@UiO-67 before and after catalysis provided a direct proof of the integrity of the POM upon photocatalysis (Fig. 18d). A similar approach was reported for characterising composites isolated by in situ immobilisation of $\mathrm{PW}_{12}$ in a porphyrinic MOF. PDF analysis allowed to determine that the MOF phase synthesised by heating preformed $\mathrm{Zr}_{6}$ oxoclusters and Fe-metallated TCPP porphyrins at $25^{\circ} \mathrm{C}$ was a mixture of MOF-525 and PCN-224 phases and that the POM was intact upon its immobilization. ${ }^{109}$
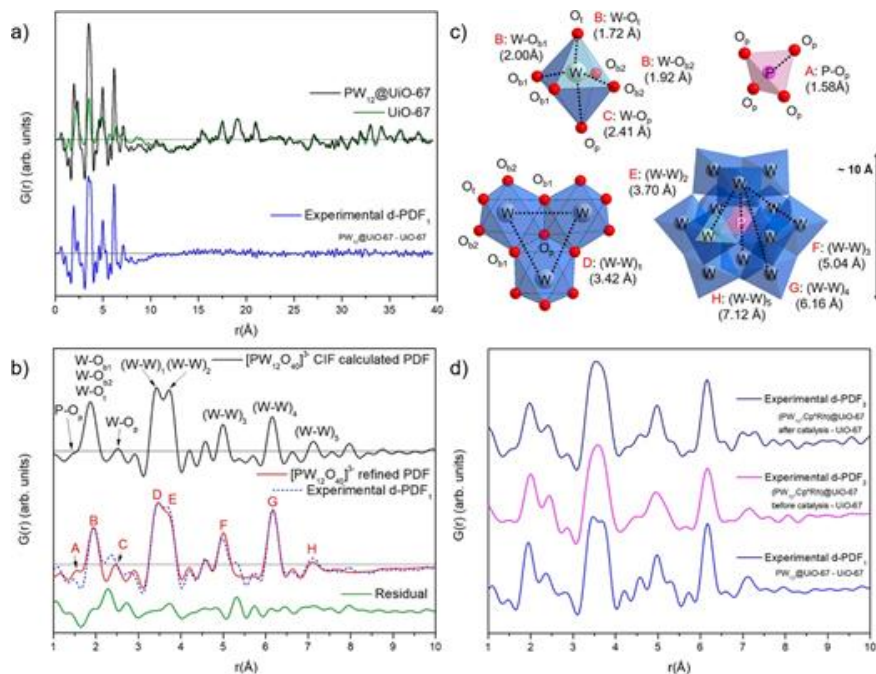

Fig. 18 a) Experimental PDF data of PW $12 @$ UiO-67 (black) and UiO-67 (green) and the corresponding d-PDF associated to the immobilised POM (blue). b) Comparison of the calculated PDF of an isolated PW 12 (black) and the experimental d-PDF of PW $_{12}$ in UiO-67 (blue dotted line), superimposed with the refined d-PDF (red) and its residual profile (green). c) Interatomic distances of the POM composing the d-PDF signal in b). d) Comparison of the d-PDF associated to $\mathrm{PW}_{12}$ in the ( $\left.\mathrm{PW} \mathrm{W}_{12}, \mathrm{Cp} * \mathrm{Rh}\right) @ U i \mathrm{U}-67$ composite before (pink) and after (navy blue) photocatalysis. Adapted with permission from ref. ${ }^{103}$. Copyright 2020 American Chemical Society.

\subsection{XPS, XANES, EXAFS, SAXS spectroscopies}

XPS, XANES, EXAFS and SAXS spectroscopies are techniques more rarely encountered as characterisation methods of Cat@MOFs as they can not be routinely performed in laboratories. Though, they are very powerful. X-ray photoelectron spectroscopy (XPS)

can determine metal oxidation states as well as characterize metal-O(N, C, S ...) bonds and study POM/MOF interactions. For example, the XPS spectra of $\mathrm{N} 1 \mathrm{~s}$ and Mo $3 \mathrm{~d}$ were recorded for $\mathrm{PMo}_{12} @ U i \mathrm{O}-67-b p y$ and $\mathrm{CoPMo}_{12} @ U i \mathrm{U}-67-$ bpy $^{107}$ and compared with the POM-free UiO-67-bpy sample and the POM precursor. The binding energies of $\mathrm{N} 1 \mathrm{~s}$ in the hybrid composite shift positively while the binding energies of Mo $3 \mathrm{~d}$ shift negatively. According to the authors, such shifts suggest some interaction between the POMs and the bipyridine ligands of the UiO-67-bpy host. XPS was also performed to characterise the $\mathrm{P}_{2} \mathrm{~W}_{18} \mathrm{Co}_{4} @ \mathrm{MIL}-101(\mathrm{Cr})$ composite. ${ }^{63}$ The shift observed for the Co $2 \mathrm{p}_{3 / 2}$ peak between the $\mathrm{P}_{2} \mathrm{~W}_{18} \mathrm{Co}_{4}$ precursor (781.1 ev) and the POM immobilised into the MOF (781.6 ev) is attributed to electrostatic POM/MOF interactions.

XPS was also carried out to characterise a $\mathrm{Ni}$ complex immobilised in a functionalised UiO-67 MOF. ${ }^{163}$ The XPS spectrum displays the signature of $\mathrm{C}, \mathrm{O}, \mathrm{N}, \mathrm{S}, \mathrm{Ru}$ and $\mathrm{Ni}$. Furthermore, high resolution XPS S $2 p$ and $\mathrm{Ni} 2 p$ spectra show the peaks corresponding to $\mathrm{Ni}-\mathrm{S}$ bonds and confirm the integrity of the complex within the composite. Similarly, XPS Fe $2 p$ spectra of iron phthalocyanines immobilised in MIL-101(Cr) are close to that of the bulk FePcS precursors. The surface $[\mathrm{Fe}] /[\mathrm{Cr}]$ atomic ratio is also found close to the bulk value determined by ICP-OES which suggests that FePcS may be located on both the external and internal surfaces of MOF particles. ${ }^{145}$

X-ray absorption spectroscopy (XAS) is used to probe the local atomic structure around a targeted atom, as well as its chemical state (oxidation and often spin state). For example, the Co-K edge XANES spectra of $\mathrm{P}_{2} \mathrm{~W}_{18} \mathrm{Co}_{4} @ \mathrm{MIL}-101(\mathrm{Cr})^{63}$ and $\mathrm{P}_{2} \mathrm{~W}_{18} \mathrm{CO}_{4} @ \mathrm{MOF}-545^{108}$ composites were investigated in order to probe the integrity of the POM in the MOF. The comparison with selected standards such as $\mathrm{CO}_{3} \mathrm{O}_{4}, \mathrm{Co}(\mathrm{OH})_{2}$ and $\mathrm{Co}\left(\mathrm{NO}_{3}\right)_{2}$ confirmed that the oxidation state of the Co ions was 2+. EXAFS spectra recorded on $\mathrm{PW}_{12} @ \mathrm{NU}-1000$ were in agreement with the presence of the $\mathrm{WO}_{\mathrm{x}}$ polyhedra constitutive of $\mathrm{PW}_{12}$. This contrasted with the W-SIM material, obtained by impregnation of NU-1000 with a solution of bis(tertbutylimido)bis(dimethylamino)tungsten(VI), which contained isolated $\mathrm{W}$ atoms only. ${ }^{112}$ Identical Ru K-edge XANES and FTEXAFS spectra were obtained for the Ru(bpy) @NH $_{2}-\mathrm{MIL}-$ $125(\mathrm{Ti})$ composite and the $\left[\mathrm{Ru}(\mathrm{bpy})_{3}\right] \mathrm{Cl}_{2}$ precursor, showing the integrity of the Ru complex after its immobilisation in the MOF. ${ }^{161}$ Time-resolved XAS experiments allow going a step further. By determining the chemical state of the active species during the catalytic reaction, these experiments provide information about mechanistic aspects. Such studies have been very rarely described for Cat@MOF composites. Illustratively, Co K-edge XANES spectra were recorded for a freshly suspended cobaloxime@ $\mathrm{NH}_{2}-\mathrm{MIL}-125$ (Ti) composite sample during its in situ incubation in acetonitrile/triethylamine/water (5:1:0.1) mixture and under illumination. ${ }^{217}$ The initial spectrum indicated the presence of $\mathrm{Co}$ (II) cations and clearly differed from those obtained for the pristine $\mathrm{Co}$ (III)-cobaloxime complex. The EXAFS data showed that the Co(II) species exhibited an octahedral first coordination sphere formed by $\mathrm{O}$ and/or $\mathrm{N}$ atoms at $\sim 2 \AA$. Furthermore, a Co-Co atomic distance was detected at $3.4 \AA$ A suggesting the presence of Co dimers. The spectrum evolved during the incubation. Based on these observations, a structural model of the Co centres was proposed where the Co-dimers partially dissociated and got closer to the Ti-oxoclusters. Finally, operando XANES experiments showed a partial reduction of Co centres.

Small-angle X-ray scattering (SAXS) is another analytical technique which is only very rarely applied. SAXS measurements of a $\mathrm{Rh}(\mathrm{I})$ complex immobilised in MIL-101(Cr) and of the parent MOF were performed. ${ }^{218}$ The scattering curves are nearly straight lines in the $q$-range between 0.1 and 1. The slope of log / vs. log $q$ plot is between 3.8 and 4 for both samples. This value is in agreement with a smooth surface of 
the MOF particles. The presence of nanoparticles at the surface of the crystallites would add an additional intensity and give rise to a curve-shape of the plot. Such features were not observed, confirming a high dispersion of the complex within the mesopores of the MOF.

Overall, the chemical and structural characterisations of Cat@MOF composites are essential not only to investigate the assynthesised materials including the effective immobilisation of the hosted molecular complex but also to evaluate their stability and recyclability upon the catalytic events and the integrity of the hosted molecular species. In that respect PDF analysis are deemed to play an increasing role by bringing atomic-scale evidence of the structural integrity of the composite along its catalytic lifetime, although such techniques usually require much larger amounts of powdered samples than those used for performing catalytic tests. Notably, a yet scarcely explored sub-field in Cat@MOFs remains that of defects particularly those formed upon the catalyst's immobilisation - which would deserve a more dedicated attention in the future due to their often critical role in catalysis.

\section{Computational chemistry of Cat@MOFs}

As mentioned above, the catalytic properties of the Cat@MOF solids rely both on the integrity of its multiple components - the MOF host, the guest catalyst or other molecular species co-immobilised into the pores - and on subtle interactions between the immobilised species and the hybrid framework. The understanding of structure-catalytic properties relationships heavily depends on atomic-level structural knowledge. However, the availability of Cat@MOF composites single crystals remains rather rare and is limited to restricted sub-families of compounds (see section 3.6). Rietveld refinements of powder X-ray diffraction patterns - based on the Bragg peaks analysis arising from symmetry in polycrystalline solids - may be used to locate guest species while retrieving the host's crystal structure. However, such techniques may not be suitable for locating large, extra-framework complexes even by using high resolution synchrotron data, when the immobilised guests exhibit a strong positional disorder in the porous host often combined with low loadings. Even though many studies on Cat@MOFs have been published, there has been scarce report of crystal structure determinations from powders, besides those proposed from difference electron density maps $^{110,219}$ (see section 3.7). In this context, computational chemistry approaches of pore-functionalised Cat@MOFs have key roles to play in order to:

i) elucidate the atomic-level positioning of the guest molecular complexes by probing the potential energy surface of the catalyst-MOF interface through statistical methods, and propose reliable possible structures of the Cat@MOF composite. Interestingly, this computational step may take into account the heterogenization method used in the synthesis of the Cat@MOF composite (impregnation vs one-pot synthesis, for instance) by allowing/prohibiting the access to a subset of pores that are accessible/inaccessible to the guest moieties. This first step is an essential one for providing the necessary initial atomic positions for any further computational investigations;

ii) scrutinise the host-guest interactions and identify underlying structure-function relationship relevant to the catalytic reaction of interest;

iii) perform further electronic structure calculations such as band structures or mechanistic studies to investigate reaction pathways. While some Cat@MOF materials maintain their catalytic performances within the same range than the homogeneous counterpart with a stabilising role of the MOF, others exhibit significantly enhanced catalytic activities upon the heterogenization inside the MOF revealing an interesting synergy between the guest and its bearing structure. Such materials call for computations capable of comparing catalytic pathways and understanding the role of the heterogenization step on the reactivity of Cat@MOF composites.

iv) provide rationale grounds to design novel materials with enhanced catalytic performances.

Bearing in mind the complexity of such large-scale MOFbased composites, one of the common challenges to i), ii) and iii) is the affordability and reliability of DFT-level calculations. Cluster models cropped from geometry-optimised periodic models of Cat@MOFs may be necessary or considered as a preferred alternative in terms of computational cost.

The computational chemistry of heterogeneous catalysis in MOFs is an extremely active area. Recent reviews dedicated to single-site catalysis in MOFs have been reported that cover a whole range of situations, whereby the MOF's metal nodes are used as anchoring sites of single-site catalysts, its organic linkers are decorated with covalently anchored functional groups or its pores are used for hosting embedded metal nanoparticles. ${ }^{220-}$ 223 By contrast, turning to non-covalently immobilised molecular complexes within MOF's pores, reports of computational chemistry approaches remain rather scarce, especially using DFT methods, probably limited by the often very large size and disordered nature of the systems to compute. We highlight here a small number of recent studies, pointing out the methodology used for locating the guest and the subsequent computations in terms of reactivity or electronic structures.

The single-step synthesis of an enantioselective catalyst for the epoxidation of dihydronaphtalene, was reported in 2013 by Bogaerts et al. by entrapping a chiral Mn(II)salen into MIL-101 host, leading to Mn-Salen@MIL-101(Al).150 Catalysis experiments showed minor differences in selectivity between the homogeneous ( $82 \%$ conversion, $70 \%$ ee) and heterogeneous conditions (69\% conversion, $70 \%$ ee). In order to gain more insights into this immobilised catalytic system, $a b$ initio calculations were performed using first a simplified model of the non-encapsulated $(S, S)$-variant of the Salen catalytic complex, i.e. neglecting its axial ligand. Optimisations were done with the OPBE functional and $6-31+G(d)$ basis set for $H, C$, $\mathrm{O}, \mathrm{N}$ atoms and 6-311++G(2df,2p) basis set for $\mathrm{Cl}$ and $\mathrm{Mn}$ atoms 
implemented in the Gaussian09 suite of programs. The mechanistic study revealed that the transition state leading to the $(1 R, 2 S)$-epoxydihydronaphthalene enantiomer is disadvantaged when compared to the one leading to the $(1 S, 2 R)$ enantiomer due to local steric hindrance of the latter (see section 5.1.1). A free energy difference of $10 \mathrm{~kJ} \mathrm{~mol}^{-1}$ between the two transition states is calculated. Assessing the impact of the surrounding MOF, further single-point calculations were performed within a single small cage (29 Å diameter) cropped from MIL-101's periodic structure and terminated by formate linkers, with the two transition states successively positioned manually in the centre of the MIL-101 large cage in similar orientations. A similar free energy difference as in homogeneous conditions between the two transition states was found (12 kJ mol-1), thus confirming the experimental findings.

Sharma et al. reported the immobilisation of an ionic porphyrinic complex, $\left[\mathrm{Zn}^{\text {"NMeTPyP }}\right]^{4+}\left[\mathrm{I}^{-}\right]_{4} \quad$ (NMeTPyP = 5,10,15,20-tetrakis(1-methylpyridinium-4'-yl)porphyrin) within the porous porphyrinic PCN-224. The resulting Complex@MOF is an excellent, recyclable catalyst for the cycloaddition of $\mathrm{CO}_{2} .{ }^{167}$ DFT calculations were used in this case to show the proper size match between the 1D channels of PCN-224 and the guest along with the stabilisation of the latter via $\pi-\pi$ interactions with the PCN-224's porphyrin linker. The $\left[\mathrm{Zn}\right.$ "NMeTPyP ${ }^{4+}[]_{4}$ porphyrin complex was manually placed inside the PCN-224 void and further geometry optimised with the DMol software using the GGA-PBE functional with a Double Numeric Polarisation (DNP) basis set and Grimme's DFTdispersion correction scheme to account for short-range interactions. No further electronic structure or mechanistic studies were performed to elucidate the enhanced catalytic activity of the porphyrin@PCN-224 composite toward the cycloaddition of $\mathrm{CO}_{2}$ with epoxides when compared to the homogeneous conditions.

In another context, the non-covalent immobilisation of $\mathrm{C}_{60}$ and quantum dots in the pores of MOFs have recently received attention to address the electrically insulating character of MOFs, which emanates from their poorly conducting organic linkers combined with poor overlap between organic ligands and metal orbitals. The encapsulation of $C_{60}$ is thus envisioned as a strategy for promoting charge transfer from the electrondonating linkers to the $\mathrm{C}_{60}$ acceptor, rendering the MOF electrically conductive.224 Although this is not a catalytic coordination complex, we present here some recent literature on $\mathrm{C}_{60} @$ MOF which provide beautiful examples of the development of computational approaches along the years on rather complex host-guest composites. The concept of enhanced conductivity in $\mathrm{C}_{60} @ \mathrm{MOF}$ composites was initially proposed by Hamel et al. in 2005 on theoretical grounds, with a pioneer DFT study of the encapsulation of $C_{60}$ in the archetypal hybrid zinc-based MOF-5.225 Periodic DFT calculations were performed within the generalised gradient approximation $(\text { GGA })^{226}$ using SIESTA program package 227,228 with a $2 \times 2 \times 2$ kpoint sampling of the Brillouin zone. The calculated band structure of the composite exhibits a high density of conduction states, considerably higher than the one of any of the known $C_{60}$ crystals at the time, with new fullerene-induced bands in the band gap of the host structure, pointing towards the promising electronic properties of such composites. In 2015, we note that Feng et al. compared the relative energies of two selected orientations of fullerene immobilised into MOF-177, namely $\mathrm{Y}_{2} @ C 79 N \subset M O F-177$, at the DFT-level with the Dmol3 package (GGA-PBE functional), however without systematically exploring the energy landscape of the $\mathrm{C}_{60}$-MOF interface or providing electronic structure insights. ${ }^{229}$

Interestingly, Liu et al. recently provided experimental evidence that the photoconductivity of porphyrinic MOF may be boosted by $\mathrm{C}_{60}$ embedded in the nanopores of highly oriented SURMOFs films of the $\mathrm{C}_{60} @ \mathrm{Zn}$ (TPP) (TPP=5,15-bis(3,4,5-trimethoxyphenyl)-10,20-bis-(4-carboxyphenyl)) porphyrinato zinc(II) compound. ${ }^{230}$ In order to understand the mechanism of charge transport of $\mathrm{C}_{60} @ \mathrm{Zn}(\mathrm{TPP})$, the authors performed first-principles DFT calculations using both cluster and periodic models. Placing the $\mathrm{C}_{60}$ manually within the pores, the $\mathrm{C}_{60} @ \mathrm{Zn}($ TPP)-MOF structure was optimised at the periodic level with the PBE exchange-correlation GGA functional with Grimme's D2 dispersion correction, ${ }^{231}$ as implemented in the Vienna $A b$ initio Simulation Package (VASP). ${ }^{232}$ Individual elements calculations (porphyrins, $\mathrm{C}_{60}$ and their complex) were performed using B3LYP hybrid functional with def2-SV(P) basis set and Grimme's D3 dispersion correction ${ }^{233}$ as implemented in the Turbomole package. ${ }^{234}$ The analysis of electronic coupling pointed towards hole transport within the porphyrin linkers while electrons flowed through the fullerenes assisted by the donor-acceptor interactions in the $\mathrm{Zn}(\mathrm{TPP})-\mathrm{C}_{60}$ pairs allowing for a rapid charge separation and limited charge recombination. Fig. 19A illustrates the HOMO-LUMO orbitals of the $\mathrm{Zn}$ (TPP)- $\mathrm{C}_{60}$ complex and the charge separation visible from the electron density difference after the porphyrin photoexcitation. 


\section{ARTICLE}

A

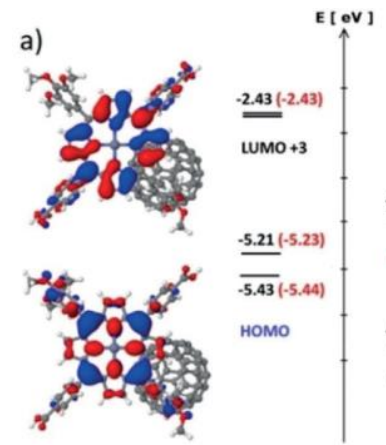

b)

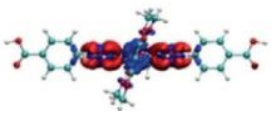

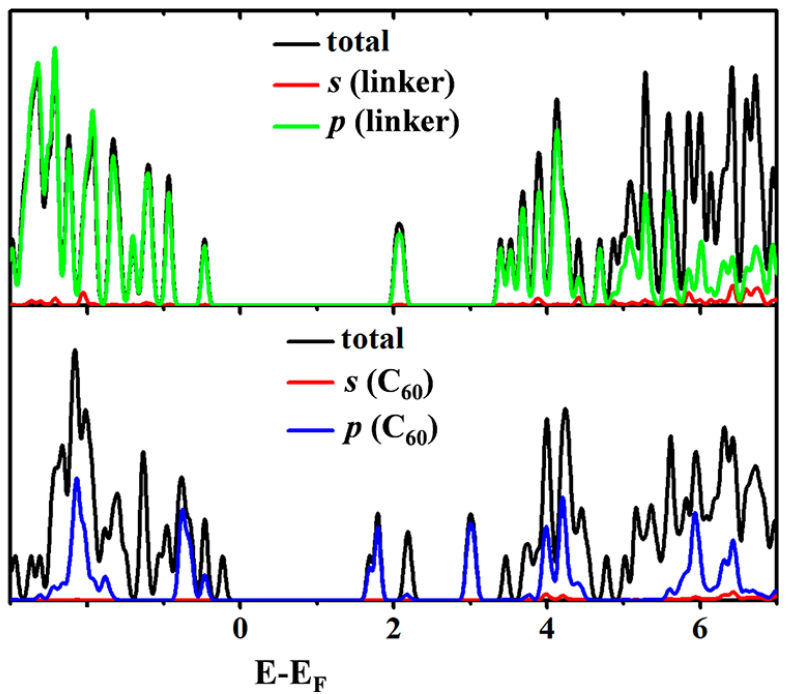

Fig. 19 A) Computational investigation of $\mathrm{C}_{60} @ S U R M O F$ electronic structure: a) Visualised HOMO and LUMO orbitals of the Zn(TPP) linker (left) and $\mathrm{C}_{60}$ (right) with the corresponding orbital energies. While the energies of the $\mathrm{Zn}(\mathrm{TPP})-\mathrm{C}_{60}$ complex are shown in black, the energies of the isolated $\mathrm{Zn}(\mathrm{TPP})$ and $\mathrm{C}_{60}$ are red. The labelling of orbitals, that is, HOMO@-7 and LUMO+3, corresponds to orbitals in the $\mathrm{Zn}(\mathrm{TPP})-\mathrm{C}_{60}$ complex. b), c) Electron density difference upon the singlet-singlet excitation of isolated porphyrin (b) and porphyrin in $\mathrm{Zn}(\mathrm{TPP})-\mathrm{C}_{60}$ complex (c). The electron accepting/donating regions are labelled in red/blue. Adapted with permission from ref ${ }^{230}$. Copyright $2019 \mathrm{Wiley-VCH}$ Verlag GmbH \& Co. KGaA, Weinheim. B) Calculated density of states of F-MOF before (upper panel) and after (lower panel) $\mathrm{C}_{60}$ incorporation. Adapted with permission from ref ${ }^{235}$. Copyright 2020 American Chemical Society.

More recently, Pratik et al. reported an in-depth computational study of $\mathrm{C}_{60}$ guests immobilised in two porphyrinic MOFs (DA-MOF and F-MOF) including their chemical variations at the meso- position of the porphyrin $(\mathrm{H}-$ $\mathrm{F}-, \mathrm{NH}_{2}-$ ). ${ }^{235}$ Geometry optimisation calculations of a series of $\mathrm{C}_{60} @$ MOFs, whereby a handful number of polymorphs were considered by varying the positioning of the $C_{60}$, were performed employing the semilocal PBEsol ${ }^{236}$ functional within the generalised gradient approximation, while single point calculations for band energies and density of states used the HSE06 hybrid functional.237 Time-dependent DFT (TD-DFT) calculations were performed on cluster models of $\mathrm{C}_{60} @ \mathrm{MOFs}$. Overall, these solid-state calculations indeed point towards facilitated electronic transport of $\mathrm{C}_{60}$ encapsulated into porphyrinic MOFs. The HOCO (Highest Occupied Crystal Orbital) mainly comprises p-orbitals of the linkers and the LUCO (Lowest Unoccupied Crystal Orbital) predominantly comprises p-orbitals of $\mathrm{C}_{60}$ (Fig. 19B) indicating that photoelectrons and holes generated on the linker should readily transfer to $C_{60}$ at the interfacial region.

In a similar context of conductivity enhancement of MOFs, Choudhuri et al. investigated in 2018 the electronic transitions and the possibility of charge separation on CdS nanoclusters immobilised in NU-1000 combining periodic calculations, $a b$ initio molecular dynamics calculations and TD-DFT calculations on molecular models derived from the periodic ones. ${ }^{238}$ Various candidate positions of the CdS cluster were installed within the large and small pores of $\mathrm{NU}-1000$, and were geometry optimised, whereby the most favorable site was identified as a 'node' site within the large hexagonal pore (Fig. 20a). The direct charge transfer from the HOCO controlled by the organic linker to the LUCO of the $\mathrm{Cd}_{6} \mathrm{~S}_{6}$ encapsulated cluster lead to charge separation that may increase the life-time of the excitation, thus resulting in the enhanced photocatalytic performances (Fig. 20b). Overall, band edge alignments confirm that the CdS@NU-1000 composite may perform photocatalytic water splitting under visible light which may be further modulated by functionalised pyrene-linkers (Fig. 20c).

In the context of Cat@MOF for photocatalysis, MellotDraznieks and co-workers used a two-step strategy to investigate the structures of Cat@MOF systems. ${ }^{103,108,109,153}$ In a first step, the $\{$ Cat, MOF\} potential energy surface is probed using forcefield-based Monte Carlo simulated annealing (SA) calculations in order to establish a preliminary selection of the most likely positions and orientations of the molecular complex within the pores or channels. In this statistical search, the molecular complex is treated as a rigid body allowed to visit the targeted void space of the MOF, while the framework is treated as a fixed-atom host. Non-covalent interactions between the guest (POM, molecular complex, photosensitiser, ...) and its bearing matrix are described using generic forcefields in which short-range interactions (as Lennard-Jones potentials, for instance) and electrostatic interactions (through partial charges 
on the host and guests using the charge equilibration method) ${ }^{239}$ are explicitly included.

Using the latter selection, subsequent DFT-D3 level periodic or cluster calculations are performed to relax atomic positions and obtain accurate geometry-optimised host-guest systems, using GGA-PBE functional as implemented in the Vienna $A b$ initio Simulation Package VASP. This second step allows ranking in energy the latter selection of candidate positions, identifying the most favored ones while scrutinising the host-guest interactions involved. Further electronic structure calculations may be performed on cluster-like models cropped from the DFT-level optimised periodic ones.

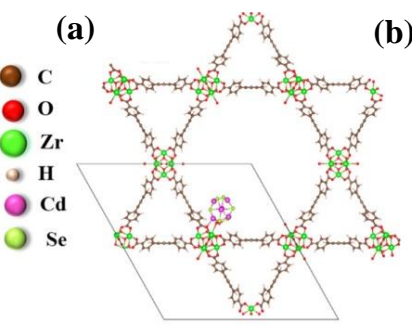

(b)

(c)
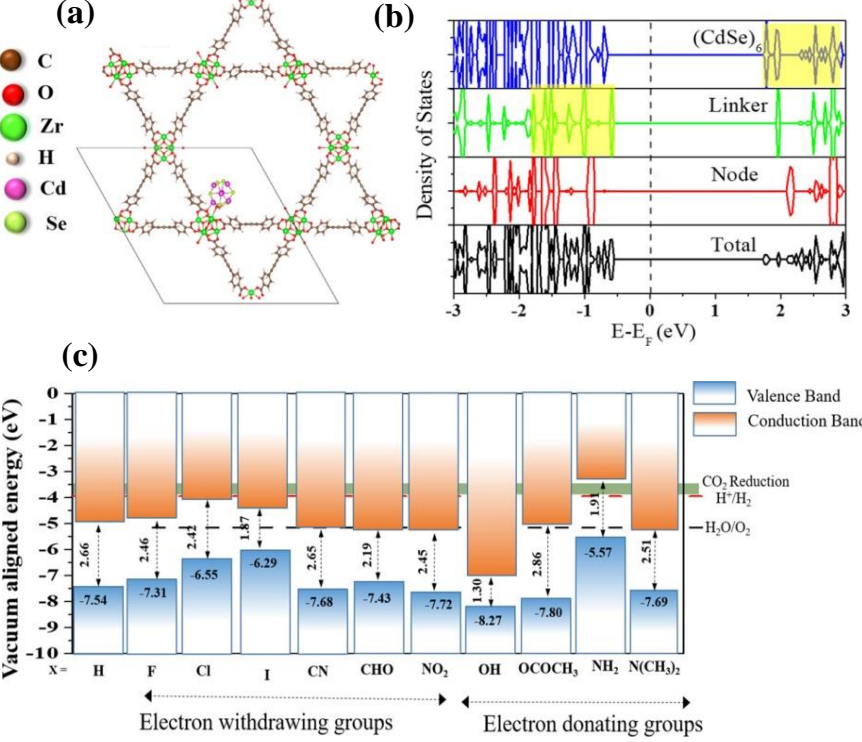

Fig. 20 a) Model structure of the $\mathrm{Cd}_{6} \mathrm{Se}_{6} @ \mathrm{NU}-1000$ composite showing the $\mathrm{Cd}_{6} \mathrm{Se}_{6}$ cluste at a 'node' site. b) Total and partial DOS of the $\mathrm{Cd}_{6} \mathrm{Se}_{6} @ \mathrm{NU}-1000$ composite (Fermi leve is set to zero as a dashed black line) shows the HOCO and LUCO (highlighted in yellow) are controlled by the pyrene linker and by the $\mathrm{Cd}_{6} \mathrm{~S}_{6}$ cluster, respectively. c) Band-edge alignment of $\mathrm{Cd}_{6} \mathrm{~S}_{6} @ \mathrm{NU}-1000$ and its linker-functionalised variants, where the $\mathrm{HOCO}$ is the top of the blue bar (valence band) and the LUCO is the bottom of the orange bar (conduction bar), with standard electrode potential $\left(\varepsilon^{\circ}\right.$, in $\mathrm{V}$ vs SHE) at $\mathrm{pH}=7$ and $\mathrm{T}=298.15 \mathrm{~K}$. Adapted with permission from ref. ${ }^{238}$. Copyright 2020 American Chemical Society.

In 2018, Wang et al. reported the immobilisation of a full photosystem in a MOF for the selective $\mathrm{CO}_{2}$ reduction into formate, whereby the molecular catalyst $\left[\mathrm{Cp}^{*} \mathrm{Rh}\left(4,4^{\prime}-\mathrm{bpydc}\right)\right]^{2+}$ $\left(4,4^{\prime}\right.$-bpydc $=2,2^{\prime}$-Bipyridine-4, $4^{\prime}$-dicarboxylic acid $)$ and photosensitiser $\left[\mathrm{Ru}(\mathrm{bpy})_{2}\left(4,4^{\prime}-\mathrm{bpydc}\right)\right]^{2+}$ are co-immobilised in the highly porous $\mathrm{NH}_{2}-\mathrm{MIL}-101$ (Al) MOF upon post-synthetic impregnation. ${ }^{153}$ The choice of carboxylate guests was initially guided by the intuition that carboxylic acid groups may favor additional host-guest interactions such as hydrogen bonds between the guests and MOF's chemical groups. The combined SA-DFT calculations revealed two favored positions for the Rh- catalyst, whereby the most favorable one is stabilised through a series of hydrogen-bonds between the carboxylic group of the Rh-complex and one amino group of the organic linker and one terminal water molecules of the inorganic Al-subunits. An additional host-guest $\pi-\pi$ interaction provides further stabilisation between the $\mathrm{Cp}^{*}$ moiety of the Rh complex and the phenyl ring of an adjacent MOF's aminated linker. These calculations corroborate the experimental observations whereby the use of carboxylate-functionalised complexes allows enhanced host-guest interactions and prevent them from further leaching during photocatalysis.

The further use of this SA-DFT methodology for probing the structure of a POM@MOF photocatalytic systems was first published in 2018 by Paille et al. ${ }^{108}$ on the immobilisation of the $\left[\left(\mathrm{PW}_{9} \mathrm{O}_{34}\right)_{2} \mathrm{Co}_{4}\left(\mathrm{H}_{2} \mathrm{O}\right)_{2}\right]^{10-}\left(\mathrm{P}_{2} \mathrm{~W}_{18} \mathrm{Co}_{4}\right)$ sandwich POM within the porphyrinic MOF-545's hexagonal channels for water photooxidation purposes. The SA-DFT calculations suggest that the POM is hosted between two $\mathrm{Zr}_{6}$-clusters while surrounded by two adjacent porphyrins, in a position consistent with its oxidation by the oxidised porphyrinic linkers required upon photocatalysis. DFT calculations indicate that a particularly dense network of host-guest hydrogen bonds stabilises the $\mathrm{P}_{2} \mathrm{~W}_{18} \mathrm{Co}_{4} \mathrm{POM}$, whereby the $\mathrm{Co}-\mathrm{OH}_{2}$ catalytic site is exposed to a hydrophilic environment at the POM-MOF interface which may provide ideal shuttling of protons and water molecules from the solvent (Fig. 21A).

Similar computational approaches were used to investigate the positioning of the $\mathrm{PW}_{12}$ Keggin-POM into UiO-67 ${ }^{103}$ and MOF-525109 in conjunction with pair distribution function (PDF) analysis (see section 3.7). Following earlier work on the Cp*Rh@UiO-67 for $\mathrm{CO}_{2}$ reduction under visible light illumination, ${ }^{240}$ Benseghir et al. reported in 2020 the synergetic combination of the $\mathrm{Cp} * \mathrm{Rh}$ (bpydc) $\mathrm{Cl}_{2}$ catalytic linker with an immobilised $\mathrm{PW}_{12}$ Keggin-POM encapsulated inside UiO-67's pores. Besides the high computed affinity of the POM for the Rh-free UiO-67 as a result of its confinement in the rather small size pores of UiO-67, the DFT calculations identified two possible environments for the POM in the $\left(\mathrm{PW}_{12}, \mathrm{Cp} * \mathrm{Rh}\right) @ U i O-$ 67 composite. They were distinguished whereby the $\mathrm{Cp} * \mathrm{Rh}$ catalytic moiety is oriented either toward an empty, i.e. POMfree, neighboring cage (Fig. 21Bb, position 'out') or toward the same cage as the $\mathrm{PW}_{12}$ guest ( $\mathrm{Fig}$. 21Bc, position 'in'), the latter being favored with respect to the former. The presence of the Rh-catalyst displaces the POM off the centre of the cage when the $\mathrm{Cp}^{*}$ moiety points toward the $\mathrm{PW}_{12} \mathrm{POM}$, which results in a new POM environment characterised by a ${ }^{31} \mathrm{P}$ NMR signal at $-14.4 \mathrm{ppm}$ as revealed by the $2 \mathrm{D}{ }^{31} \mathrm{P}-{ }^{1} \mathrm{H}$ correlation experiment (see above section 3.5). The ${ }^{31} \mathrm{P}$ NMR signal at $-15.2 \mathrm{ppm}$ is assigned to the POM centred in the cage with no close interaction with the $\mathrm{Cp}^{*}$ of the $\mathrm{Rh}$-complex. 


\section{ARTICLE}

A

a)

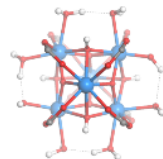

$\left[\mathrm{Zr}_{6}\left(\mu_{3}-\mathrm{O}\right)_{4}\left(\mu_{3}-\mathrm{OH}\right)_{4}(\mathrm{OH})_{4}\left(\mathrm{H}_{2} \mathrm{O}\right)_{6}\right]^{10+}$

b)

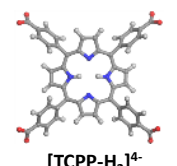

c)

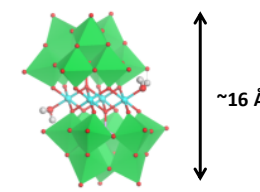

$\left[\left(\mathrm{PW}_{9} \mathrm{O}_{34}\right)_{2} \mathrm{CO}_{4}\left(\mathrm{H}_{2} \mathrm{O}\right)_{2}\right]^{10}$
$\mathrm{P}_{2} \mathrm{~W}_{18} \mathrm{Co}_{4} @ \mathrm{MOF}-545$

d)

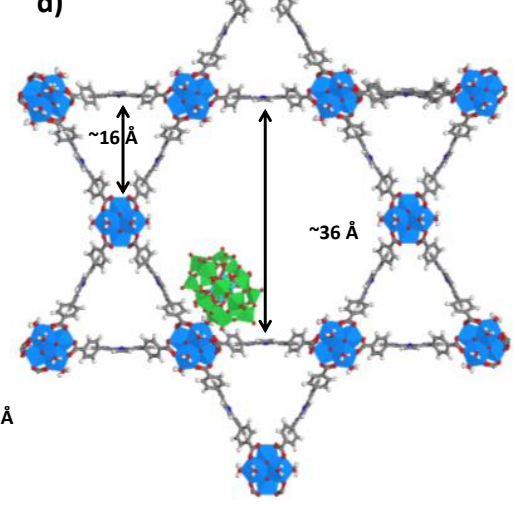

$\mathrm{P}_{2} \mathrm{~W}_{18} \mathrm{Co}_{4} @ M O F-545$
B

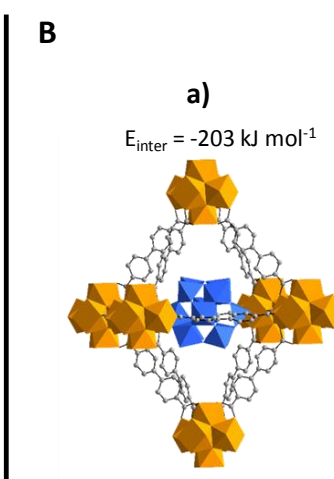

PW12@UiO-67
(PW $12, C p * R h) @ U i O-67$

b)

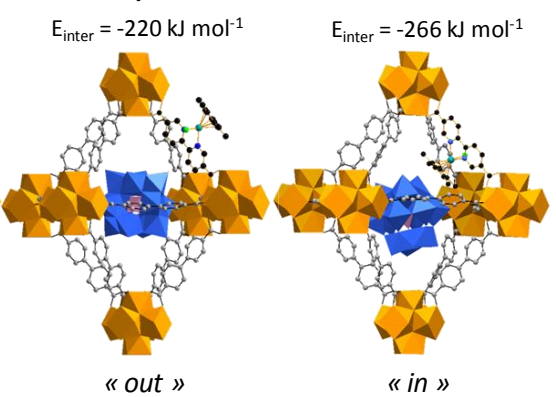

(PW $12, C^{*} *$ Rh)@UiO-67 d)
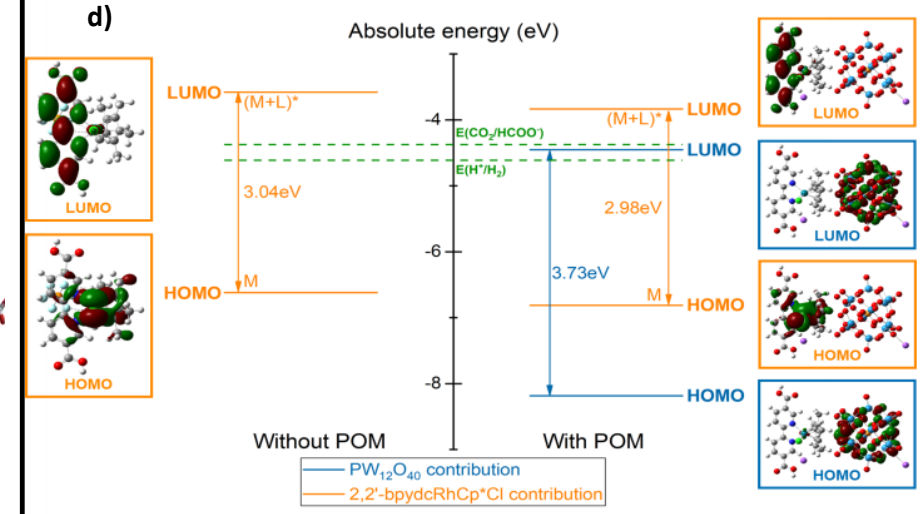

e) Simulated Annealing

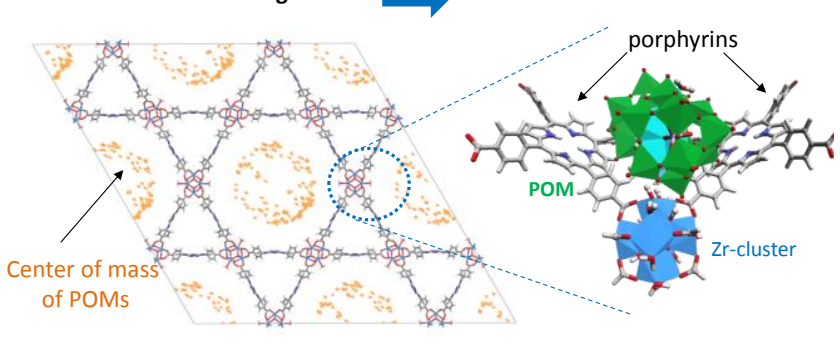

Fig. 21 A) $\mathrm{P}_{2} \mathrm{~W}_{18} \mathrm{CO}_{4} @$ MOF-545 components ( $\mathrm{a}, \mathrm{b}, \mathrm{c}$ ) and the SA-DFT computed position of the $\mathrm{P}_{2} \mathrm{~W}_{18} \mathrm{Co}_{4}$ sandwich-type POM in MOF-545 (d). The computational strategy combining Monte Carlo simulated annealing and DFT-D3 level calculations is illustrated in e). Adapted with permission from ref. ${ }^{108}$. Copyright 2018, American Chemical Society. B) Computed position of the $\mathrm{PW}_{12}$ in $\mathrm{PW}_{12} @$ UiO-67 (a) and ( $\mathrm{PW}_{12}, \mathrm{Cp}^{*} \mathrm{Rh}$ )@UiO-67 (b,c) as obtained from the combination of SA and DFT-D3 level geometry optimisations. Interaction energies

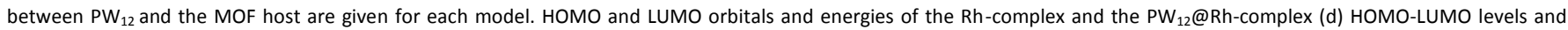
corresponding surfaces for the $\left\{\mathrm{Cp}^{*} \mathrm{Rh}\right.$ (bpydc) Cl-PF $\}$ molecular complex (left); $\mathrm{HOMO}-\mathrm{LUMO}$ levels and corresponding surfaces for the $\left\{\left[\mathrm{Na}_{2} \mathrm{PW}_{12} \mathrm{O}_{40}\right]\right.$; $\left.\left[\mathrm{Cp}^{*} \mathrm{Rh}(\mathrm{bpydc}) \mathrm{Cl}\right]^{+}\right\} \mathrm{cluster}$ (right). All HOMOs energies are aligned with the corresponding ionisation potential. Calculations are done at HSE06/6-311++g(d,p)/LanL2DZ level of theory. The reference redox potentials are those reported in $\mathrm{CH}_{3} \mathrm{CN}$. Adapted with permission from ref. ${ }^{103}$ Copyright 2020, American Chemical Society.

Seeking to elucidate the role of the POM in the boosted photocatalytic performances of the ( $\left.\mathrm{PW}_{12}, \mathrm{Cp} * \mathrm{Rh}\right) @ U i \mathrm{U}-67$ composite in $\mathrm{CO}_{2}$ reduction, further calculations of the relative positioning of the POM'S HOMO-LUMO bands and the Rhcatalyst's were performed. When compared with the POM-free conditions, DFT calculations reveal that the electronic structure of the Rh-catalyst is hardly affected by the POM. Furthermore, the LUMO of the POM is placed, in the absolute scale, at more negative energies than the LUMO of the Rh-complex, thus disfavoring its role as an electron relay. Building on these findings and on the absence of significant catalytic activity of the Rh-free PW $12 @ U i O-67$ solid, the authors rather suggest the POM may assist the $\mathrm{CO}_{2}$ reduction as a proton relay, in line with the known enhanced proton conductivities in PW $12 @ M O F / C O F$ materials. ${ }^{241}$

Duguet et al. used a similar combined DFT-PDF methodology to probe the structure of $\mathrm{PW}_{12}$ encapsulated in MOF-525(Fe) porphyrinic matrix. ${ }^{109}$ SA-DFT simulations reveal a non-centred positioning of the POM within the MOF's cubic cage showing $\mathrm{PW}_{12}$ cornered close to a $\mathrm{Zr}$-oxocluster inorganic node (assorted with a particularly high host-guest interaction energy of $422 \mathrm{~kJ}$ $\left.\mathrm{mol}^{-1}\right)$. They corroborate the $2 \mathrm{D}^{31} \mathrm{P}-1 \mathrm{H}$ correlation CP MAS NMR experiment pointing towards the spatial proximity of the POM with the inorganic subnetwork. Interestingly, these DFT calculations corroborate the experimental finding whereby a structure-directing role of the $\mathrm{PW}_{12}$ polyoxometalate in porphyrinic MOF synthesis is evidenced, with the promotion of the kinetics MOF-525 phase with respect to the thermodynamic MOF-545 phase.

Recently Lan and co-workers used a similar strategy to investigate a series of composites whereby various metallocenes are immobilized in the MOF-545(Co) porphyrinic host, for the electrocatalytic reduction of $\mathrm{CO}_{2} .{ }^{166}$ Monte Carlo simulations in the $(N, V, T)$ ensemble were performed using the 
UFF generic forcefield in order to introduce and locate up to 6 $\mathrm{CoCp}_{2}$ complexes per unit-cell. The calculations show that the $\mathrm{CoCp}_{2}$ species are localised in the triangular channels rather than in the hexagonal ones, near the porphyrin linkers and the $\mathrm{Zr}$-oxoclusters. Finite cluster DFT calculations were also performed on porphyrin-metallocene pairs to evaluate the free energy profile of $\mathrm{CO}_{2}$ reduction to $\mathrm{CO}$, pointing toward the particularly favored adsorption energy of $\mathrm{CO}_{2}$ on the (Co$\left.\mathrm{TCPP} / \mathrm{CoCp}_{2}\right)$ pair when compared to other $\mathrm{MCp}_{2}(\mathrm{M}=\mathrm{Fe}, \mathrm{Ni})$ as a result of a C-Co bond between a carbon atom of the $\mathrm{CoCp}_{2}$ moiety and the Co center of the porphyrin. The electrodonating role of the metallocene is also mentioned.

Overall, computational chemistry approaches have been shown to be particularly efficient in bringing structural insights into the location of molecular guests within the MOF host those being often inaccessible using conventional diffraction techniques - and complement the analysis of PDF experimental data, this at a relatively low computational cost. Still, electronic structures and catalytic pathways remain computationally highly demanding for such host@guest composites, although they are deemed to play an increasing role in the future in order to participate to the design of Cat@MOFs with targeted performances (light capture, conductivity, catalytic selectivity...)

\section{Catalytic applications of Cat@MOF composites}

Owing to their exceptional acidic and redox properties combined to their high thermal stability, the catalytic properties of POMs have been tremendously studied these last decades. Besides fundamental studies, these molecular oxides have found applications in several industrial processes, including hydration of alkenes to alcohols, ${ }^{242}$ esterification of acetic acid to ethyl acetate ${ }^{243}$ or oxidation reactions such as the transformation of ethylene to acetic acid. ${ }^{244}$ This highlights that acid catalysis and oxidative catalysis are two major areas in which these materials can excel. But noticeably, electro- and photocatalysis processes involving POMs have been particularly developed these last years. Among polyoxometalates, Keggintype species - and especially the seminal $\mathrm{H}_{3} \mathrm{PW}_{12} \mathrm{O}_{40}$ saturated highly acidic and robust POM - have been by far the most studied molecular oxide family. This is due to their high stability, but also to their high tunability, vacant Keggin being able to incorporate nearly all the metallic elements of the periodic table. For example, it has been demonstrated that cobaltincorporating Keggin-type POMs are particularly efficient for water oxidation - while saturated Keggin are non-active. But we will see that other POMs, i.e. Ishii-Venturello complexes and several Dawson derivatives, have also been considered with success. MOFs also exhibit a tremendous variety of (photo)(electro)catalytic properties.3,245,246 Though, we will focus in the following on Cat@MOF systems for which the catalytic properties are driven by the encapsulated molecules. In other words, in the composites mentioned below, the MOF is considered as a platform for supporting the incorporated catalytic molecular unit. However, it can act not only as a support for heterogenization but may play many various roles ranging from photocatalyst to Lewis acid, stabilizes the catalyst or improves its selectivity. Nonetheless, we will point out several cases in which both the components are the site of catalytic events. Finally, we have also included in this review MOF materials incorporating non-POM molecular catalysts (coordination complexes incorporating in particular phthalocyanine, porphyrines or bpy ligands, and organometallic complexes). Interestingly, such Cat@MOF composites have been more scarcely reported, in part due to the generally lower stability of these metal-based complexes compared to POMs. Nevertheless, such materials may possess catalytic properties not exhibited so far by POM@MOF compounds, such as the ability to reduce carbon dioxide under photocatalytic conditions, and can therefore be seen as complementary. We will thus give in this section an overview of the catalytic properties of the POM@MOF and Complex@MOF systems reported in Tables 1 and 2, covering the various catalytic, photoand electrocatalytic reactions. In these two tables, the natures of the catalytic reaction and of the reactants as well as the catalytic conditions (solvent, temperature) are indicated. The catalytic properties of Cat@MOFs are usually studied in the liquid phase conditions, Cat@MOF particles being in suspension in the solution but some studies report gas phase reactions (see Tables 1 and 2). Such gas phase reactions represent eco-friendly conditions by avoiding the use of organic solvents and allow easier product separation. Concerning electrocatalytic reactions, the preparation of Cat@MOF-modified electrodes involve two main methods. The first one consists in mixing the Cat@MOF composite with acetylene black carbon and Nafion before coating this mixture ink on a glassy carbon electrode. ${ }^{139,203}$ or on a carbon paper electrode. ${ }^{166}$ In the second method, a small amount of the Cat@MOF composite is directly transferred to a pyrolytic graphite working electrode by rubbing the deposited powder on its surface. ${ }^{37,101}$

\subsection{Oxidation and reduction reactions}

5.1.1 Oxidation of alkenes. Epoxides are intermediates that can participate in a wide range of organic synthetic routes, attracting interest both in academic and industrial research. Among metal-containing catalysts, POMs represent a particularly relevant family of homogeneous catalysts for epoxidation reactions, with mainly $\mathrm{H}_{2} \mathrm{O}_{2}$ as oxidant. ${ }^{2}$ Since the late 2000's, many POM@MOF systems for the catalytic epoxidation of alkenes in heterogeneous conditions have also been synthesised and tested, showing as well their very high efficiency. This will be the main subject of this section, while some other oxidation reactions of alkenes will be also underlined.

MIL-101(Cr) has been widely used for hosting POM species in its pores for performing alkene oxidation reactions, with a large variety of POMs $\left(\mathrm{PW}_{4}, \mathrm{PW}_{9}, \mathrm{PW}_{11}, \mathrm{SiW}_{11}, \mathrm{PW}_{12}, \mathrm{PW}_{11} \mathrm{Co}_{\text {, }}\right.$ $\mathrm{PW}_{11} \mathrm{Ti}, \mathrm{PZnMo}_{2} \mathrm{~W}_{9}, \mathrm{P}_{2} \mathrm{~W}_{18} \mathrm{Co}_{4}$ and $\left.\operatorname{Ln}\left(\mathrm{PW}_{11}\right)_{2}\right)$ (Table 1). Scarce examples of POM@MIL-100(Fe), POM@UiO-66 and POM@HKHUST-1 have also been reported. By contrast, coordination complexes have been much less studied than 
POMs, with a few examples of phthalocyanines@MOFs and porphyrins@MOFs for such reactions (See Table 2).

In 2008, Maksimchuk et al. reported a seminal study on the oxidation in acetonitrile of three alkenes, namely $\alpha$-pinene, caryophyllene and cyclohexene with POM@MIL-101(Cr) materials (Scheme 1). ${ }^{36}$ They showed that PW 11 Ti@MIL-101(Cr) and $\mathrm{PW}_{11} \mathrm{Co} @ \mathrm{MIL}-101(\mathrm{Cr})$ catalyse the oxidation of selected alkenes with $\mathrm{H}_{2} \mathrm{O}_{2}$ and $\mathrm{O}_{2}$, respectively. In all cases, the yields are much higher with the composite than with the POM-free MIL-101(Cr) material. It could be however noticed that the activity of MIL-101(Cr) was significantly higher for the oxidation of caryophyllene, performed at $50^{\circ} \mathrm{C}$, than for the oxidation of $\alpha$-pinene, performed at $30^{\circ} \mathrm{C}$. This is consistent with the chromium MOF activating more efficiently $\mathrm{H}_{2} \mathrm{O}_{2}$ at $50^{\circ} \mathrm{C}$ than at $30^{\circ} \mathrm{C}$. In addition, it underlines that the activity of a given POM@MOF composite must always be compared with that of the related POM-free MOF in exactly the same conditions. The POM-free MIL-101(Cr) matrix does not significantly oxidise cyclohexene in presence of $\mathrm{H}_{2} \mathrm{O}_{2}$ even at $70^{\circ} \mathrm{C}$. Considering $\alpha$ pinene, the substrate mainly converts to the allylic oxidation products, verbenol and verbenone, with both oxidants and with conversion yields and TOF up to $45 \%$ and $80 \mathrm{~h}^{-1}$, respectively, for PW ${ }_{11} \mathrm{Co} @ M I L-101(\mathrm{Cr})\left(2 \mathrm{~h}, \mathrm{O}_{2}\right)$. The selectivity is higher than oxidize of the related mesoporous silica-supported POM systems. ${ }^{247}$ It can be attributed to the MIL-101's zeotype porous structure and the smaller pore diameters which may protect allylic oxidation products from further oxidation. Concerning cyclohexene, its oxidation in the presence of PW 11 Ti@MIL$101(\mathrm{Cr})$ and $\mathrm{H}_{2} \mathrm{O}_{2}$ leads mainly to cyclohexene-2-ol and cyclohexene-2-one, pointing to a homolytic mechanism. Finally, with the same oxidant and catalyst, caryophyllene was successfully oxidised to caryophyllene 4,5-monoepoxide, with a $100 \%$ selectivity. In comparison with homogeneous systems, such a high selectivity was attributed to the deprotonation of $\mathrm{PW}_{11} \mathrm{Ti}$ when immobilised into MIL-101(Cr), further protecting the acid-sensitive epoxide from ring opening. Also, it was shown that the PW 11 Co@MIL-101( $\mathrm{Cr}$ ) composite maintains its activity and selectivity for $\alpha$-pinene oxidation with $\mathrm{O}_{2}$ over at least 5 cycles. However, when $\mathrm{H}_{2} \mathrm{O}_{2}$ is used as the oxidant, relatively mild conditions must be considered for both catalysts in order to maintain the matrix supramolecular network and prevent POM leaching $\left(\mathrm{T} \leq 50^{\circ} \mathrm{C},\left[\mathrm{H}_{2} \mathrm{O}_{2}\right] \leq 0.2 \mathrm{M}\right) .^{36}$

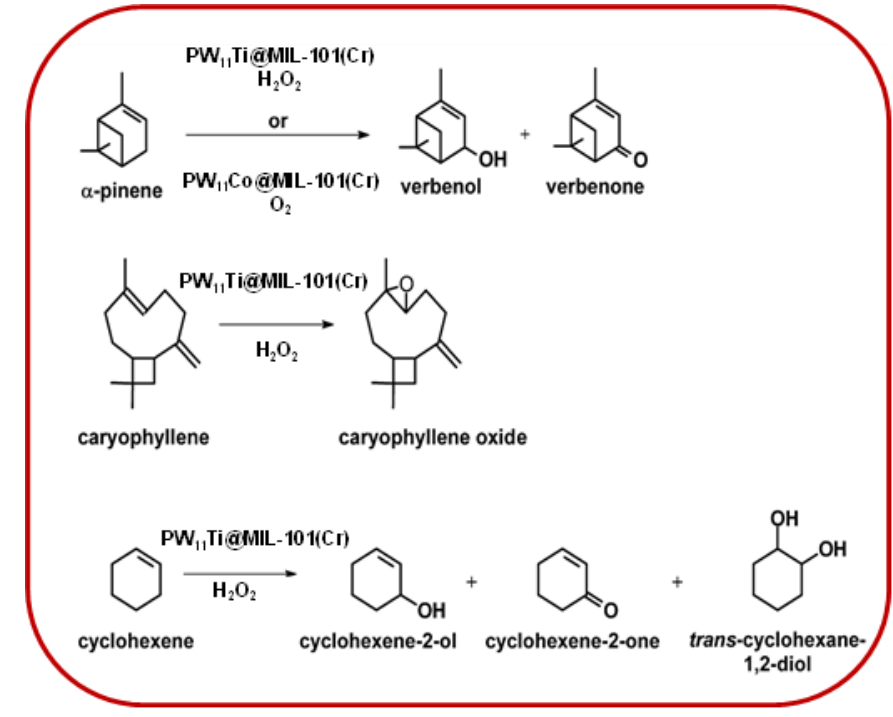

Scheme 1 Selective alkene oxidation over PW 11 Ti@MIL-101(Cr) and PW ${ }_{11}$ Co@MIL$101(\mathrm{Cr})$ materials. Adapted with permission from ref. ${ }^{36}$. Copyright 2008 Elsevier Inc.

Two years later, the same group studied two related materials for the oxidation of various alkenes in the presence of hydrogen peroxide in acetonitrile $\left(\mathrm{T}=50^{\circ} \mathrm{C}\right): \mathrm{PW}_{4} @ \mathrm{MIL}-101(\mathrm{Cr})$, which incorporates the Venturello complex, $\left[\mathrm{PW}_{4} \mathrm{O}_{24}\right]^{3-}$, and PW $12 @ M I L-101(\mathrm{Cr}) .^{30}$ The two composites exhibited similar activities, comparable to those of the polyoxometalates in homogeneous conditions. The 5\%wtPW $12 @ M I L-101(\mathrm{Cr})$ was found to be particularly efficient for the epoxidation of cyclohexene, with a conversion yield of $84 \%$ and a selectivity of $80 \%\left(t=3 \mathrm{~h}\right.$, TOF $\left.=0.40 \mathrm{~min}^{-1}\right)$. Very interestingly, a one-pot procedure combining both the synthesis of the composite and the cyclohexene oxidation showed that the epoxide is obtained with a yield superior to the one obtained when the composite is first prepared and then used as a catalyst. The POM is more resistant to hydrogen peroxide once introduced into the MOF. This allows higher $\mathrm{H}_{2} \mathrm{O}_{2}$ /alkene ratio and thus higher alkene conversion and epoxide selectivity than those observed in homogeneous conditions. The recyclability tests performed on these systems showed that the Venturello-containing $\mathrm{PW}_{4} @ \mathrm{MIL}-101(\mathrm{Cr})$ material is stable over four consecutive runs with only a slight decrease in the epoxide yield after the third run while for PW $12 @ M I L-101(\mathrm{Cr})$ the activity starts to decrease after the fourth run (Fig. 22).

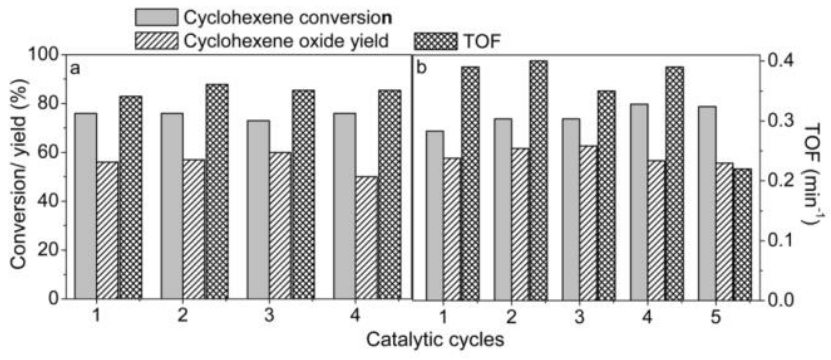

Fig. 22 Catalyst recycling in cyclohexene oxidation with $0.2 \mathrm{M} \mathrm{H}_{2} \mathrm{O}_{2}, 50^{\circ} \mathrm{C}$, acetonitrile: (a) PW $@$ @MIL-101(Cr) and (b) PW 19 MIL-101(Cr). Reprinted with permission from ref. ${ }^{30}$. Copyright 2010 American Chemical Society. 
Bromberg et al. also studied epoxidation reactions using PW $12 @ M I L-101(\mathrm{Cr})$ as the catalyst, but rather under microwave conditions $\left(55^{\circ} \mathrm{C}, 300 \mathrm{~mW}\right.$ power source)..$^{44}$ For caryophyllene, a $93 \%$ yield was reached after only $5 \mathrm{~min}$, with a TOF estimated as ca. 22-fold higher than that measured with the PW 11 Ti@MIL$101(\mathrm{Cr})$ catalyst under conventional heating. Undoubtedly, such an acceleration under otherwise similar conditions and analogous catalysts is assigned to the use of microwaves. Moreover, in the considered catalytic conditions, the excellent recyclability of the catalyst was evidenced, as the kinetics of the degradation of such a composite is minimal in short heating cycles (5 $\mathrm{min}$ ).

In 2013, Granadeiro et al. developed analogous catalytic systems considering the monovacant $\left[\mathrm{PW}_{11} \mathrm{O}_{39}\right]^{7-}$ and $\left[\mathrm{SiW}_{11} \mathrm{O}_{39}\right]^{8-}$ POMs for the epoxidation of cis-cyclooctene, geraniol and $\mathrm{R}-(+)$-limonene (Scheme 2 ), with $\mathrm{H}_{2} \mathrm{O}_{2}$ as oxidant. ${ }^{34}$ $\mathrm{PW}_{11} @ \mathrm{MIL}-101(\mathrm{Cr})$ shows the best activity for the epoxidation of cis-cyclooctene, while SiW $11 @$ MIL-101(Cr) is more active for the epoxidation of geraniol. The activities of PW $11 @ M I L-101(\mathrm{Cr})$ and $\mathrm{SiW}_{11} @ \mathrm{MIL}-101(\mathrm{Cr})$ are similar for the epoxidation of $\mathrm{R}-(+)-$ limonene. This suggests that there is not a "best POM@MOF system" for epoxidation reactions, but that the composite must be tuned in order to optimize the catalytic activity for a given substrate. The reactions were performed in acetonitrile, at room temperature for geraniol and at $75^{\circ} \mathrm{C}$ for the two other alkenes. Cis-cyclooctene was selectively converted into 1,2epoxycyclooctane in the presence of PW $11 @ M I L-101(\mathrm{Cr})$ with high yields (98\%) after $10 \mathrm{~min}\left(\mathrm{TOF}=1922 \mathrm{~mol} \mathrm{~mol}_{\mathrm{POM}^{-1}} \mathrm{~h}^{-1}\right)$. In contrast, using an equivalent amount of $\mathrm{PW}_{11}$ under homogeneous conditions, the conversion of the substrate was inexistent after $10 \mathrm{~min}$, such yields being reached only after $6 \mathrm{~h}$.

Considering a mechanism involving the formation of POM hydroperoxide species followed by an oxygen transfer to the substrate, ${ }^{248}$ the authors proposed that in heterogeneous conditions the porous cage of the MOF - where the catalyst, oxidant and substrate are confined - promotes a faster formation of hydroperoxide species and oxygen transfer than in

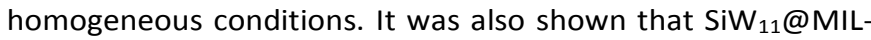
$101(\mathrm{Cr})$ selectively oxidises geraniol into 2,3-epoxygeraniol (yield $=89 \%$, TOF $=875$, selectivity $=100 \%$ ), yet with an activity lower than that determined with $\mathrm{SiW}_{11}$ in homogeneous conditions (yield $=98 \%$, TOF $=1000$, selectivity $=100 \%$ ). In many cases, it remains difficult to rationalise the relative catalytic activities of the heterogeneous POM@MOF vs. the homogeneous POM catalysts, which are obviously substratedependent. Besides, the reported materials also showed a high activity in the oxidation of R-(+)-limonene, leading to limonene1,2-epoxide, limonene-1,2-diol and a small amount of diepoxide (Scheme 2). Finally, $10 \%$ and $17 \%$ POM leaching after three consecutive cycles were observed for SiW $11 @ M I L-101(\mathrm{Cr})$ (oxidation of geraniol) and PW $11 @$ MIL-101(Cr) (oxidation of ciscyclooctene), respectively. ${ }^{34}$

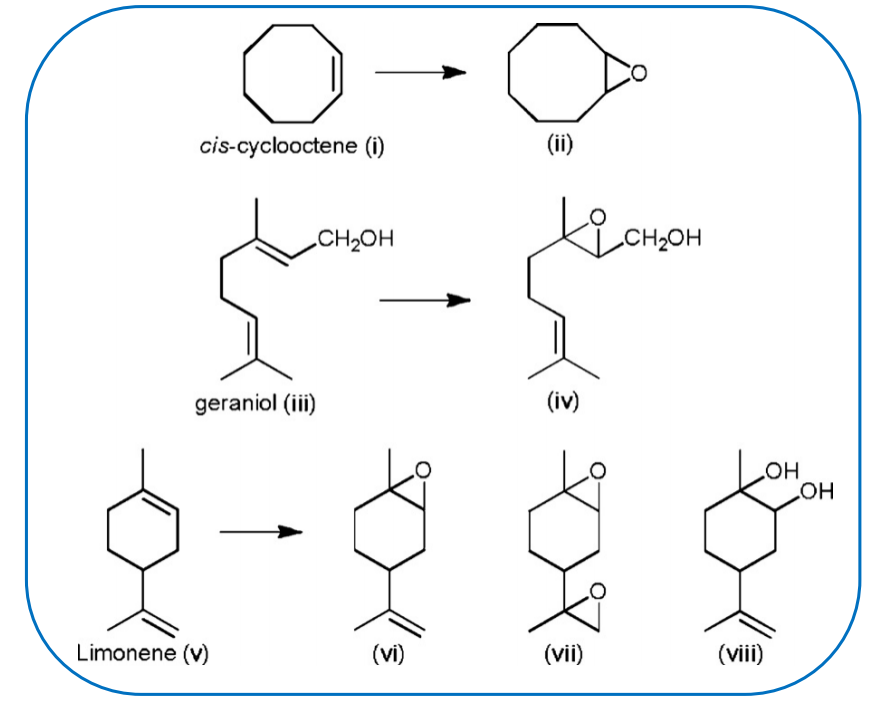

Scheme 2 Oxidation products from cis-cyclooctene, geraniol and limonene using the PW $11 @ M I L-101(C r)$ and SiW $11 @ M I L-101(C r)$ catalysts. Adapted with permission from ref. ${ }^{34}$. Copyright 2013 Elsevier B.V.

The trivacant POM $\left[\mathrm{A}-\mathrm{PW}_{9} \mathrm{O}_{34}\right]^{9-}$ was also considered for the oxidation of geraniol and R-(+)-limonene. ${ }^{32}$ The PW 9 @MIL$101(\mathrm{Cr})$ was particularly active for the epoxidation of geraniol, with an activity superior to that found for PW 11 @MIL-101(Cr) and SiW $11 @ M I L-101(\mathrm{Cr})$. In analogous conditions, complete conversions in $30 \mathrm{~min}$ and $2 \mathrm{~h}$ were found using PW 9 @MIL101(Cr) and SiW $11 @ M I L-101(\mathrm{Cr})$, respectively. As expected, a lower activity of PW9@MIL-101(Cr) was determined for the epoxidation of R-(+)-limonene. However, a conversion of $93 \%$ was obtained after $2 \mathrm{~h}$ of reaction (acetonitrile, $\mathrm{T}=80^{\circ} \mathrm{C}, 1 \mathrm{mmol}$ of substrate, $3 \mu \mathrm{mol}$ of $\mathrm{PW}_{9}, 4.5 \mathrm{mmol}$ of $\mathrm{H}_{2} \mathrm{O}_{2}$ ). As for the studies involving the monovacant species, a mixture of epoxide, diol and diepoxide products was obtained. The recyclability was studied for the geraniol oxidation reaction. The conversion data were nearly the same over three consecutive cycles after $2 \mathrm{~h}$, although the kinetic profile showed a significant loss of activity during the first minutes of reaction starting with the second cycle, suggesting an evolution of the PW @MIL-101(Cr) material. As no $\mathrm{PW}_{9}$ leaching was observed, this was attributed to an evolution of the incorporated trivacant POM under catalytic conditions. ${ }^{32}$ Besides monomeric Keggin-type POMs, the catalytic activity of the sandwich-type $\left[\left(\mathrm{PW}_{9} \mathrm{O}_{34}\right)_{2} \mathrm{CO}_{4}\left(\mathrm{H}_{2} \mathrm{O}\right)_{2}\right]^{10-}$ POM incorporated in MIL-101(Cr) was also investigated and compared to that of the same POM but incorporated into the aptes-functionalized mesoporous silica aptesSBA-15.62 For the geraniol and the R-(+)-limonene substrates, the epoxidation activity is higher with $\mathrm{P}_{2} \mathrm{~W}_{18} \mathrm{Co}_{4} @ \mathrm{MIL}-101(\mathrm{Cr})$ than with $\mathrm{P}_{2} \mathrm{~W}_{18} \mathrm{Co}_{4} @$ aptesSBA-15. This was interpretated in terms of a postulated higher mobility of the POM in the MOF than in aptesSBA-15 - which increases the POM's activity - and to strong interactions between the POM's catalytic centres and the functionalised SBA - which decrease the POM's activity. The activity of $\mathrm{P}_{2} \mathrm{~W}_{18} \mathrm{CO}_{4} @ \mathrm{MIL}-101(\mathrm{Cr})$ was also compared to that of the homogeneous $\mathrm{P}_{2} \mathrm{~W}_{18} \mathrm{Co}_{4}$ catalyst. For both systems, a complete conversion of geraniol into 2,3epoxygeraniol is reached after $4 \mathrm{~h}$ ( $\mathrm{RT}$, acetonitrile), but the 
conversion is almost complete for the homogeneous system after $1 \mathrm{~h}$ only. ${ }^{62}$ The Venturello derivative $\left[\mathrm{BW}_{4} \mathrm{O}_{24}\right]^{5-}$ incorporated in MIL-101(Cr) has been also studied for geraniol oxidation. In presence of the BW 4 @MIL-101(Cr) catalyst, the substrate was fully oxidised after $3 \mathrm{~h}$ (RT, acetonitrile, $\mathrm{H}_{2} \mathrm{O}_{2}$ ), leading to 2,3-epoxygeraniol with a selectivity of $78 \% .{ }^{31}$ However, an important leaching of the POM (47\%) was observed after three cycles.

The oxidation of alkenes into epoxides was also reported for coordination complexes inserted in porous MOFs. The catalytic activity of a copper phthalocyanine complex (CuPc) inserted into MIL-100(Fe) or MIL-101(Cr) was studied by Yeganeh et al. for the oxidation of styrene. They used two oxidative pathways: molecular dioxygen and isobutyraldehyde as co-reductant or TBHP (tert-butyl hydroperoxide). ${ }^{149}$ A poor selectivity was observed with TBHP.CuPc@MIL-101(Cr) allowed a quantitative conversion of styrene but benzaldehyde (47.5\%) and epoxyde (45.6\%) were obtained in similar proportions. With the same catalyst, the selectivity was improved with the $\mathrm{O}_{2}$ /isobutyraldehyde system since $85 \%$ of epoxide were recovered with a $100 \%$ conversion $\left(T=60^{\circ} \mathrm{C}, \mathrm{t}=4 \mathrm{~h}\right)$. With CuPc@MIL-100(Fe), the performances were slightly lower in the same conditions: $82.8 \%$ of conversion and $76.1 \%$ selectivity towards epoxide. This may be explained by the smaller pore windows of MIL-100(Fe) when compared to those in MIL$101(\mathrm{Cr})$, which restrict the diffusion of substrates to the cavities where CuPc-active sites are confined. Importantly, as confirmed by the PXRD patterns of the recycled catalysts, the structural integrity of the catalysts was preserved after three to four consecutive runs. Moreover, despite a very slight decrease of the selectivity towards epoxide, the catalytic activity remains almost unchanged. For the most effective CuPc@MIL-101(Cr) catalyst, $100 \%$ of styrene was still converted after the $4^{\text {th }}$ run and a selectivity of $80.6 \%$ (epoxide) was obtained with $\mathrm{O}_{2}$ /isobutyraldehyde oxidative system. ${ }^{149}$

In 2013, Bogaerts et al. successfully immobilised the chiral Jacobsen's catalyst (Mn-Salen) into the amino functionalised $\mathrm{NH}_{2}$-MIL-101(Al) aiming to achieve enantioselective epoxidation of dihydronaphtalen with metachloroperoxybenzoic acid (MCPBA) and N-methylmorpholine $\mathrm{N}$ oxide (NMO). ${ }^{150}$ Even if the resulting $\mathrm{Mn}$-Salen@ $\mathrm{NH}_{2}-\mathrm{MIL}$ 101(Al) material yielded a lower conversion (69\%) than the pure Mn-Salen complex in a homogeneous medium (82\%), the enantiomeric excess was surprisingly similar in both cases (\%ee 70). $A b$ initio calculations pointed out the essential role of the folded structure of the complex, maintaining its optimal shape in the porous network, which induced selectivity of the substrate (Fig. 23, see section 4 for details). Notably, after 4 runs, the stability of the structure of $\mathrm{Mn}$-Salen@ $\mathrm{NH}_{2}-\mathrm{MIL}-$ 101(Al) was assessed by XRD, with no complex leaching. In addition, TON values remained constant during the 4 runs, demonstrating the reusability of the catalyst.

Metal porphyrins incorporated into porous structures have also been employed for the epoxidation of alkenes. In 2016, Zhang et al. synthesised the sodalite-type ZIF-8 $\left(\mathrm{Zn}(\mathrm{MeIM})_{2}, \mathrm{MeIM}=2\right.$ methylimidazolate) surrounding manganese meso-tetrakis(4aminophenyl)-porphyrins (Mn-TAPP) - both parts interacting through H-bonds. ${ }^{168}$ Oxidations of different alkenes was achieved in acetonitrile at $80{ }^{\circ} \mathrm{C}$ with TBHP as oxidant and the resulting Mn-TAPP@ZIF-8 as catalyst. Interestingly, the catalytic results showed a substrate size selectivity induced by the structure of the composite, the oxidation reaction taking place inside the pores of the framework. As an example, after $24 \mathrm{~h}$ of reaction, the conversions of cyclooctene and cyclohexene reached $62 \%$ and $96 \%$, respectively, although cyclohexene is usually considered as more difficult to oxidize than cyclooctene. Kinetic studies also revealed some limitations in the diffusion of the substrate to attain the active sites within the structure. Still, Mn-TAPP@ZIF-8 exhibited impressive catalytic performances. For the epoxidation of cyclohexene, Mn-TAPP@ZIF-8 presented high conversion, high selectivity (>99\%) and, above all, the highest TON value (7600) when compared to previously reported catalytic systems. Especially, the low catalytic activity of homogeneous Mn-TAPP ( $52 \%$ of conversion, $48 \%$ of epoxide) underlined the key role of the ZIF- 8 framework that prevents the formation of the catalytically inactive $\mu$ oxometalloporphyrin dimers. In addition, the structural integrity and stability of Mn-TAPP@ZIF-8 were checked after 3 cycles, explaining a stable conversion and selectivity over time.

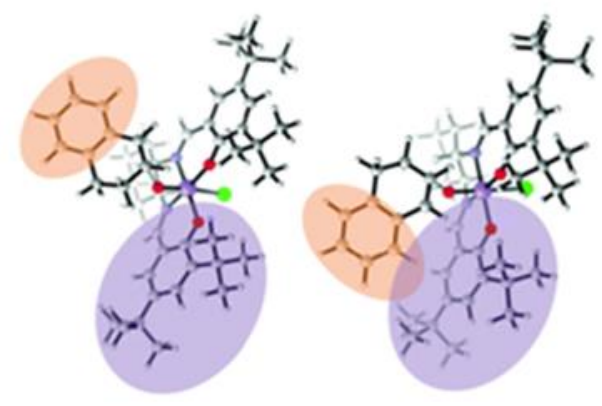

Fig. 23 Transition state for the two possible approaches of dihydronaphthalene to the $\mathrm{Mn}$-Salen complex leading to the $(1 \mathrm{~S}, 2 \mathrm{R})$-enantiomer (left) and $(1 \mathrm{R}, 2 \mathrm{~S})$-enantiomer (right). The second approach suffers from more steric hindrance than the first one. Reprinted from ref. ${ }^{150}$ with permission from the RSC.

Apart from these oxidation reactions leading to epoxide functions, some MOF-based hybrid systems were also reported for the formation of carbonyl derivatives by catalytic oxidation of alkenes. The oxidation of styrene using the $\mathrm{P}_{2} \mathrm{~W}_{18} \mathrm{Co}_{4} @ \mathrm{MIL}-$ $101(\mathrm{Cr})$ catalyst $\left(80^{\circ} \mathrm{C}, \mathrm{H}_{2} \mathrm{O}_{2}\right.$, acetonitrile) showed that the substrate was mainly oxidised into benzaldehyde, with hydroxy ketone and benzoic acid as secondary products (Fig. 24a). ${ }^{62}$ The heterogeneous system was more active than the homogeneous counterparts (Fig. 24b), with yields of 85 and $64 \%$ after $4 \mathrm{~h}$, respectively. This was attributed to a faster degradation of the oxidant in homogeneous conditions. In addition, the oxidation of styrene by the lanthanide sandwich-type $\left[\operatorname{Ln}\left(\mathrm{PW}_{11} \mathrm{O}_{39}\right)_{2}\right]^{11-}$ $(\mathrm{Ln}=\mathrm{Eu}, \mathrm{Sm})$ POMs incorporated in MIL-101(Cr) was investigated in the same experimental conditions. An almost complete conversion was observed after $4 \mathrm{~h}$ for both $\mathrm{Eu}\left(\mathrm{PW} \mathrm{H}_{11}\right)_{2} @ \mathrm{MIL}-101(\mathrm{Cr})$ and Sm(PW 11$)_{2} @ \mathrm{MIL-101}(\mathrm{Cr}) .^{64}$ The conversion was considerably lower in homogeneous conditions (40\% and $57 \%$ for $\mathrm{Eu}\left(\mathrm{PW}_{11}\right)_{2}$ and $\mathrm{Sm}\left(\mathrm{PW}_{11}\right)_{2}$, respectively). 
a)

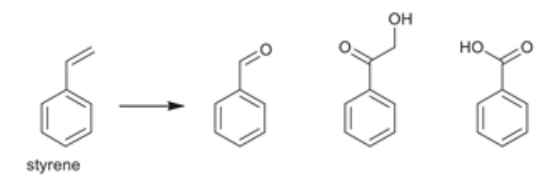

b)

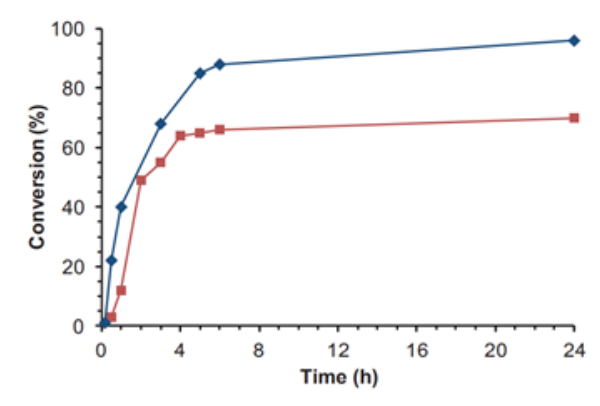

Fig. 24 a) Oxidative products of styrene using $\mathrm{P}_{2} \mathrm{~W}_{18} \mathrm{Co}_{4} @ \mathrm{MIL}-101(\mathrm{Cr})$ as catalyst, b) Kinetic profile for the oxidation of styrene using $\mathrm{P}_{2} \mathrm{~W}_{18} \mathrm{CO}_{4}$ (red) and $\mathrm{P}_{2} \mathrm{~W}_{18} \mathrm{Co}_{4} @$ MIL$101(\mathrm{Cr})$ (blue) as catalysts. Adapted from ref. ${ }^{62}$. Copyright 2013 Elsevier B.V.

The latter results were again interpretated in terms of the beneficial confinement effect promoted by MIL-101's cages acting as nanoreactors. The authors also compared the reactions performed under thermal heating $\left(75^{\circ} \mathrm{C}\right)$ and microwave heating $\left(75^{\circ} \mathrm{C}, 70 \mathrm{~mW}\right)$. In contrast with the study mentioned above ${ }^{44}$ the conversion yields were found to be similar for both heating conditions. However, the selectivity was enhanced under microwaves, with a selectivity for benzaldehyde after $1 \mathrm{~h}$ of $98 \%$ when using Eu(PW $\left.\mathrm{PW}_{11}\right)_{2} @ \mathrm{MIL}-$ $101(\mathrm{Cr})$. Finally, leaching was observed for both materials. In particular, free $\mathrm{Sm}\left(\mathrm{PW}_{11}\right)_{2}$ was detected in solution after three 6 h catalytic cycles with Sm(PW 11$)_{2} @ M I L-101(C r)$ as catalyst, the conversion yield decreasing from $100 \%$ for the first catalytic cycle to ca. $60 \%$ after the third one. Surprisingly, the conversion yield measured using $\mathrm{Eu}\left(\mathrm{PW}_{11}\right)_{2} @ \mathrm{MIL}-101(\mathrm{Cr})$ remained constant over three cycles.

Considering Complex@MOF catalysts, Wu et al. have successfully incorporated copper complexes with bissalicylaldiminato Schiff bases acting as ligands (Cu-Schiff) into MIL-101(Cr). ${ }^{147}$ The resulting composites Cu-Schiff@MIL$101(\mathrm{Cr})(\mathrm{x})$ - where $\mathrm{x}$ refers to the molar ratio $\mathrm{Cu}$-Schiff/MIL$101(\mathrm{Cr})$ - were tested as catalysts for the oxidation of styrene into benzaldehyde with $\mathrm{H}_{2} \mathrm{O}_{2}$ as oxidant in a buffer solution at $30^{\circ} \mathrm{C}$ (Tris. $\mathrm{HCl}, \mathrm{pH}=7.6$ ). The reaction rate constant $\mathrm{k}$ increased from $0.087 \mathrm{~min}^{-1}$ for the bare MIL-101(Cr) to $0.378 \mathrm{~min}^{-1}$ for $\mathrm{Cu}$ Schiff@MIL-101(Cr)(4) which exhibited the greatest styrene conversion (93.5\%). A higher loading of copper complex into the MOF was reported to block the accessibility of the active centres, thus lowering the catalytic activity $\left(\mathrm{k}=0.310 \mathrm{~min}^{-1}\right.$ for Cu-Schiff@MIL-101(Cr)(8)). Despite strong hydrophobic interactions between the complex and the MOF, recyclability tests pointed out a systematic leaching of the complex. Therefore, $k$ decreased in a constant manner after each cycle and reached half of its initial value after 6 runs.

In 2011, Kockrick et al. described the immobilisation of two perfluorinated phthalocyanine derivatives, $\operatorname{MPcF}_{16}(\mathrm{M}=\mathrm{Ru}, \mathrm{Fe})$ and the dimer $\left(\mathrm{FePc}^{\mathrm{t}} \mathrm{Bu}_{4}\right)_{2} \mathrm{~N}$, into $\mathrm{MIL}-101(\mathrm{Cr}) .{ }^{144}$ Taking into account the slight differences in the phthalocyanines' loadings, the catalytic activities of the three new composites were compared in similar conditions for the selective oxidation of tetraline into tetralone, a diesel fuel additive (oxidant: $\mathrm{O}_{2}$ at 8 bars, $90^{\circ} \mathrm{C}$ ). With $\mathrm{FePcF}_{16}$ species, greater selectivity toward tetralone (80\% for $\mathrm{FePcF}_{16} @ \mathrm{MIL}-101(\mathrm{Cr})$ vs 68\% for $\mathrm{FePcF}_{16}$ ) and a higher TON (24200 for FePcF $16 @ M I L-101(C r)$ vs 3400 for FePcF $_{16}$ ) were observed when the metal phthalocyanine is incorporated into the MOF, even if the conversions after $6 \mathrm{~h}$ were quite similar for the composite and the related pure complex (Fig. 25).

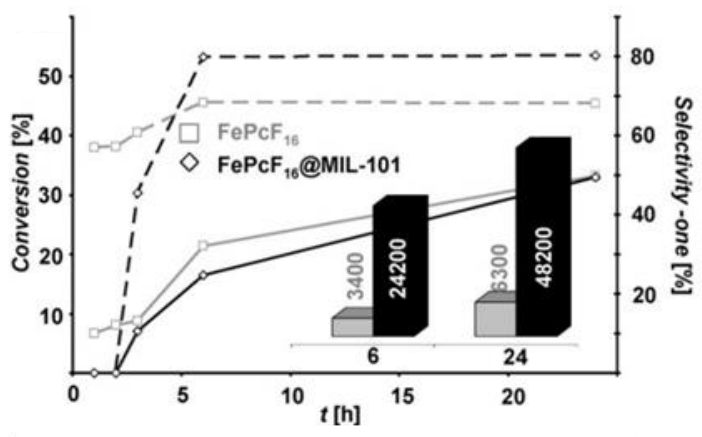

Fig. 25 Tetralin conversion (solid line) and selectivity toward 1-tetralone (dashed line) of the homogeneous FePcF 16 complex (grey) and of the FePcF ${ }_{16} @ M I L-101(C r)$ composite (black) with significantly lower catalyst contents ( $n$ (tetralin) $: n\left(F_{e P c F}\right)=147000: 1$ ) compared to the pure complexes (36 $000: 1$ ) explaining the clear difference in turnover numbers (TONs) after $6 \mathrm{~h}$ and $24 \mathrm{~h}$ (inset), respectively. Reprinted from ref. ${ }^{144}$ with permission from the RSC.

This remarkable enhancement of the catalytic activity in the heterogeneous systems may be explained by the MOF precluding the undesired dimerisation of phthalocyanines, which operates in homogeneous conditions through $\pi$ stacking.

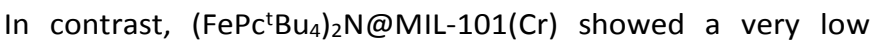
conversion ( $4 \%$ after $6 \mathrm{~h}$ ) and a TON of 5100, close to the value of $\left(\mathrm{FePc}^{\mathrm{t}} \mathrm{Bu}_{4}\right)_{2} \mathrm{~N}(7400)$. Indeed, the size of the dimer prevented its incorporation into the MOF, leading to its placement at the external surface of the crystallites. Consequently, the synergic effect expected from the confinement of the metal complexes was not observed here. It should be noted that an induction period of $3 \mathrm{~h}$ was observed for the MPcF $16 @ \mathrm{MIL}-101(\mathrm{Cr})$ catalyst. This specific behavior was consistent with a free radical mechanism of oxidation. ${ }^{144}$

In 2017, cyclohexene oxidation was also deeply investigated with the incorporation of $\mathrm{PMo}_{12}$ or Keggin phosphomolybdovanadates $\left(\mathrm{PMo}_{11} \mathrm{~V}\right.$ and $\left.\mathrm{PMo}_{10} \mathrm{~V}_{2}\right)$ into $\mathrm{MIL}-$ 100(Fe) using $\mathrm{H}_{2} \mathrm{O}_{2}$ as oxidant. ${ }^{84} \mathrm{~A}$ great enhancement in the conversion of cyclohexene $(72-85 \%)$ was obtained with the $\mathrm{PMo}_{12} @ M I L-100(\mathrm{Fe}), \quad \mathrm{PMo}_{11} \mathrm{~V} @ \mathrm{MIL}-100(\mathrm{Fe}) \quad$ and $\mathrm{PMo}_{10} \mathrm{~V}_{2} @ \mathrm{MIL}-100(\mathrm{Fe})$ catalysts when compared to those obtained with the POMs or MOF alone (31-37\%). These results underline the high accessibility of the active sites of the POM@MOF composites to reagents. While 1,2-cyclohexanediol (54\%) was the major product with $\mathrm{PMo}_{12} @ M I L-100(\mathrm{Fe}), 2-$ cyclohexen-1-one was selectively formed using $\mathrm{PMo}_{11} \mathrm{~V} @ \mathrm{MIL}-$ $100(\mathrm{Fe})$ or $\mathrm{PMo}_{10} \mathrm{~V}_{2} @ \mathrm{MIL}-100(\mathrm{Fe})$. Particularly, PMo ${ }_{11} \mathrm{~V} @ \mathrm{MIL}-$ 
100(Fe) appeared as the best catalyst for cyclohexene conversion (85\%), selectivity in 2-cyclohexen-1-one (91\%) and TOF $\left(715 \mathrm{~h}^{-1}\right)$ in optimised conditions (acetonitrile, $70^{\circ} \mathrm{C}, 9 \mathrm{~h}$ ). Importantly, these values remained almost unchanged after 5 cycles showing the stability and the reusability of the catalyst.

In 2015, Yang et al. considered the UiO-66 MOF as a host material for the design of POM-containing catalytic systems for the oxidation of alkenes. ${ }^{91}$ The $\mathrm{PW}_{12} @ U$ UiO-66 composite was prepared and studied for the oxidation of cyclopentene into glutaraldehyde. While the POM-free MOF was able to oxidise the substrate under the selected catalytic conditions $\left(\mathrm{H}_{2} \mathrm{O}_{2}, t\right.$ $\mathrm{BuOH}, 35^{\circ} \mathrm{C}, 22 \%$ conversion yield after $24 \mathrm{~h}$ ), the incorporation of $\mathrm{PW}_{12}$ into the MOF pores greatly enhanced its catalytic performances. Optimising the amount of immobilised POM, 35 wt\%PW $12 @ U i O-66$ reached the highest conversion (84\%) and selectivity (80\%). This loading was thus considered as a good compromise between the number of active sites and the accessible volume of the material. Moreover, the selectivity for glutaraldehyde was dramatically increased with the POM@MOF when compared to the POM-free MOF $(80 \%$ and $18 \%$, respectively). Although some leaching was found after three consecutive catalytic cycles because of the release of $\mathrm{PW}_{12}$ species adsorbed at the surface of the MOF particles, cycling did not result in any significant decrease in the selectivity. Overall, the optimised material competed well for the oxidation of cyclopentene to glutaraldehyde with other efficient heterogeneous systems such as $20 \mathrm{wt} \% \mathrm{WO}_{3}-\mathrm{MCF}^{249}$

Recently, Song et al. considered a series of polyoxomolybdate@UiO-67 composites. ${ }^{107}$ First, it was found that $\mathrm{CoHPMo}_{12} @ \mathrm{MOF}$ materials were more active than the $\mathrm{PMo}_{12} \mathrm{O}_{40} @ M O F$ ones for the epoxidation of cyclooctene $\left(\mathrm{H}_{2} \mathrm{O}_{2}\right.$, acetonitrile), evidencing the beneficial role of Co ion. Secondly, an UiO-67 functionalised with 2,2'-bipyridine-5,5' dicarboxylates instead of 4,4'-biphenyldicarboxylates linkers, improved the conversion (91\%) and the selectivity $(>99 \%)\left(70^{\circ} \mathrm{C}\right.$, acetonitrile, 6 h) using CoHPMo $12 @ U i O-67$ (bpy), while a conversion of $82 \%$ was found with $\mathrm{CoHPMo}_{12} @ U i \mathrm{O}-67$. In addition, the excellent stability and recyclability of $\mathrm{CoHPMo}_{12} @ U i \mathrm{O}-67$ (bpy) compared to those of the CoHPMo12@UiO-67 composite revealed that the bpy linkers play a critical role (Fig. 26). Further comparison with the catalytic activity of organic polymers incorporating the $\mathrm{CoHPMO}_{12}$ POM suggests that the MOF matrix is a better candidate for the preparation of composites for such epoxidation reactions. CoHPMo ${ }_{12} @ U$ UiO-67(bpy) was also the most efficient phosphomolybdate@UiO-67 material reported in this study for the oxidation of styrene in presence of dioxygen with $t-\mathrm{BuOOH}$ as initiator $\left(80^{\circ} \mathrm{C}\right.$, solvent-free conditions), with a $80 \%$ conversion and a $59 \%$ selectivity to styrene epoxide. Notably, the three other materials studied (CoHPMo ${ }_{12} \mathrm{O}_{40} @ U i \mathrm{O}-67, \quad \mathrm{PMo}_{12} @ U i \mathrm{O}-67$ (bpy) and $\mathrm{PMo}_{12} @$ UiO-67) exhibited selectivities toward benzaldehyde rather than styrene epoxide, as observed for $\operatorname{Ln}\left(\mathrm{PW}_{11}\right)_{2} @ \mathrm{MIL}-$ $101(\mathrm{Cr})$ systems. ${ }^{64}$ Overall, the high performances of $\mathrm{CoHPMo}_{12} @$ UiO-67(bpy) were assigned to the ideal confinement of the POM provided by the cages of UiO67 (bpy). ${ }^{107}$
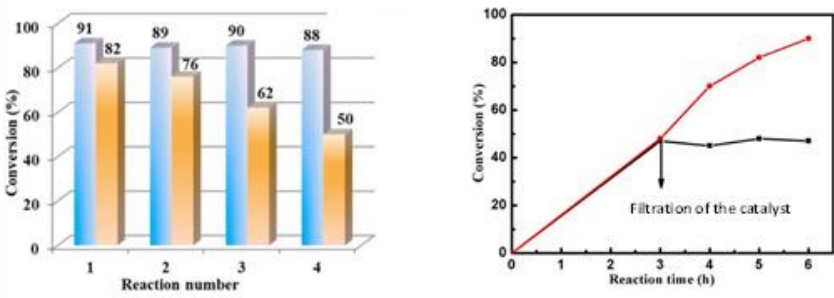

Fig. 26 Left: the recycling experiments of cyclooctene oxidation with $\mathrm{H}_{2} \mathrm{O}_{2}$ as oxidant in $\mathrm{CH}_{3} \mathrm{CN}$ catalysed by $\mathrm{CoHPMo}_{12} @ U i \mathrm{O}-67$ (bpy) (blue) and CoHPMo ${ }_{12} @ U i O-67$ (orange) respectively. Right: comparison of the conversion yield versus time for $\mathrm{CoHPMo}_{12} @ \mathrm{UiO}$ 67 (bpy) with and without filtration of the catalyst after 3h. Adapted with permission from ref. ${ }^{107}$. Copyright 2019 American Chemical Society.

POM@Cu-MOFs were also considered for alkene oxidative

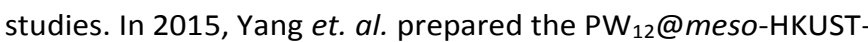
1 material for the selective oxidation of cyclopentene to glutaraldehyde. ${ }^{126}$ Tert-butyl hydroperoxide was chosen as oxidant rather than $\mathrm{H}_{2} \mathrm{O}_{2}$, which rapidly decomposes in the reaction medium upon addition of the catalyst, this being attributed to the action of the copper MOF. Among the various loadings considered, the 30wt\%PW $12 @$ MOF composite was found as the most active one, with a conversion yield of $93 \%$ and a selectivity to glutaraldehyde of $79 \%\left(30^{\circ} \mathrm{C}\right.$, acetonitrile, $36 \mathrm{~h})$. In comparison, the POM-free meso-HKUST-1 in the same conditions presented a conversion yield of $28 \%$, with a selectivity of $80 \%$ to cyclopentenone. Interestingly, the 30wt\%PW $12 @$ HKUST-1 material presented a lower yield (76\%) with a poor selectivity to glutaraldehyde (20\%). This difference was explained considering that the microporous structure of 30wt\%PW $12 @ H K U S T-1$ was not suitable for the formation of the bulky glutaraldehyde but beneficial for that of the smaller cyclopentenone with $80 \%$ selectivity. This highlights the advantage of using the mesoporous HKUST-1 MOF. The role of the solvent is also highlighted. When performed in ethanol instead of acetonitrile, the conversion yields and selectivity dramatically decreased, indicating that aprotic solvents are beneficial to the reaction. In addition, as observed in numerous studies, an excess in oxidant can increase the activity, with here an optimised cyclopentene:tert-butyl hydroperoxide ratio of 1.0:2.5. Finally, only a very small decrease of conversion and selectivity was observed after three consecutive cycles, attributed to a slight POM leaching together with the adsorption of oxidised products on the composite, showing overall the high stability of 30wt\%PW 12 @HKUST-1.

Sun et al. reported one year later a new catalytic POM@CuMOF family. ${ }^{136}$ Three materials were studied, namely $\mathrm{PMo}_{12} @ r h t-M O F-1, \mathrm{SiMo}_{12} @ r h t-M O F-1$ and PW $12 @ r h t-M O F-1$ for reacting alkylbenzenes with tert-butyl hydroperoxide $\left(80^{\circ} \mathrm{C}\right.$, 12-36 h). In all cases, the presence of the POM enhanced the activity of the material, with the POM-free MOF exhibiting also a significant activity. Considering the methylbenzene substrate, a conversion yield of $64 \%$ with a selectivity to benzoic acid of $81 \%$ were observed after $12 \mathrm{~h}$ using the rht-MOF-1 catalyst, while the use of $\mathrm{PMo}_{12} @ r h t-M O F-1$ led to conversion and selectivity yields of $99 \%$. We note that the $\mathrm{PMo}_{12}$ material is more active than the $\mathrm{PW}_{12}$ one, with the $\mathrm{SiW}_{12}$-based composite 
presenting the lowest activity. When ethylbenzene was considered as the substrate, the major product was the corresponding ketone ( $81 \%$ conversion yield, $89 \%$ selectivity with $\mathrm{PMo}_{12} @ r h t-M O F-1$, after 12 h). Also, the conversion yields were strongly dependent on the size of the substrate (Fig. 27). For example, the conversion yield of the large 4-ethylbiphenyl into ketone was the lowest one at $54 \%$. The authors concluded that the $\mathrm{Cu}(\mathrm{II})$ sites in the channel walls and the POMs in the voids were easier to reach for substrates with smaller size, thus allowing higher catalytic activities than with bulky substrates, for which the reaction could only occur at the crystallites' surface.

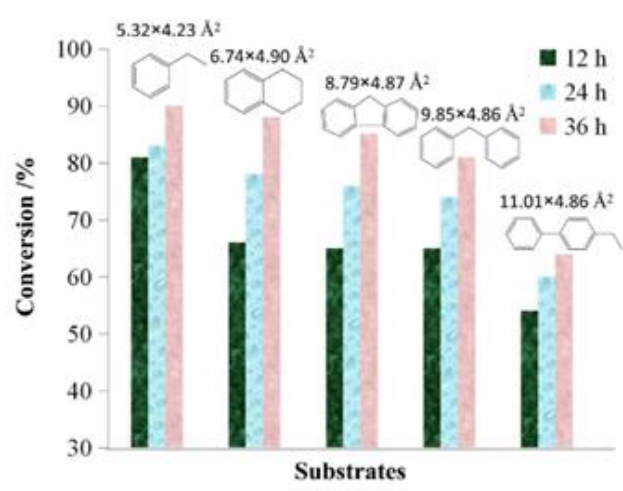

Fig. 27 Conversions yields for the formation of phenylketones from alkylbenzenes of different sizes $\left(T=80^{\circ} \mathrm{C}\right.$, tert-butyl hydroperoxide, for $12 \mathrm{~h}, 24 \mathrm{~h}$ and $\left.36 \mathrm{~h}\right)$ in presence of the $\mathrm{PMo}_{12} @$ rht-MOF-1 catalyst. The molecular size of substrate is indicated at the top of each column. Reprinted with permission from ref. ${ }^{136}$. Copyright 2016 Springer Nature.

In 2016, Choluj et al. reported for the first time the incorporation of ruthenium alkylidene complexes (Fig. 28) into a MOF structure to perform olefin metathesis catalysis. ${ }^{152}$ Due to the large size of the Hoveyda-Grubbs second generation complexes used, $\mathrm{NH}_{2}$-MIL-101(Al) was selected as a large-pore host (Fig. 28). Still, the first attempts in catalysis with the resulting materials were discouraging, as the possible presence of $\mathrm{OH}^{-}$in the MOF host could be poisonous for this kind of catalysis. The possible sequestration of the Ru-bound chloride anions by the Lewis acidic sites (after activation of the MOF) could also contribute to decrease the catalyst's activity. A pretreatment of the MOF by $\mathrm{HCl}$ was shown necessary to overcome these issues giving rise to $\mathrm{NH}_{2}-\mathrm{MIL}-101(\mathrm{Al}) \cdot \mathrm{HCl}$. The excellent yields in ring-closing olefin metathesis (RCM) reactions performed in toluene at room temperature evidenced the recovery of the catalytic activity. Importantly, even a very low content of Ru complexes in the MOF (one molecule every 10 cages), associated with a very low amount of POM@MOF catalyst $(0.01 \%)$ allows a high conversion of the substrate. In addition, this heterogeneous catalyst was successfully tested in continuous flow conditions in a model RCM reaction releasing ethylene. In the optimised conditions $\left(40^{\circ} \mathrm{C}, 9 \mathrm{~h}\right.$, rate of 10 $\mu \mathrm{L} / \mathrm{min}$, retention time $<7 \mathrm{~min}$ ), an average conversion of $57 \%$ was obtained with a high TON of 4700 . Notably, no leaching of Ru complex was observed, highlighting the stability of the composite.
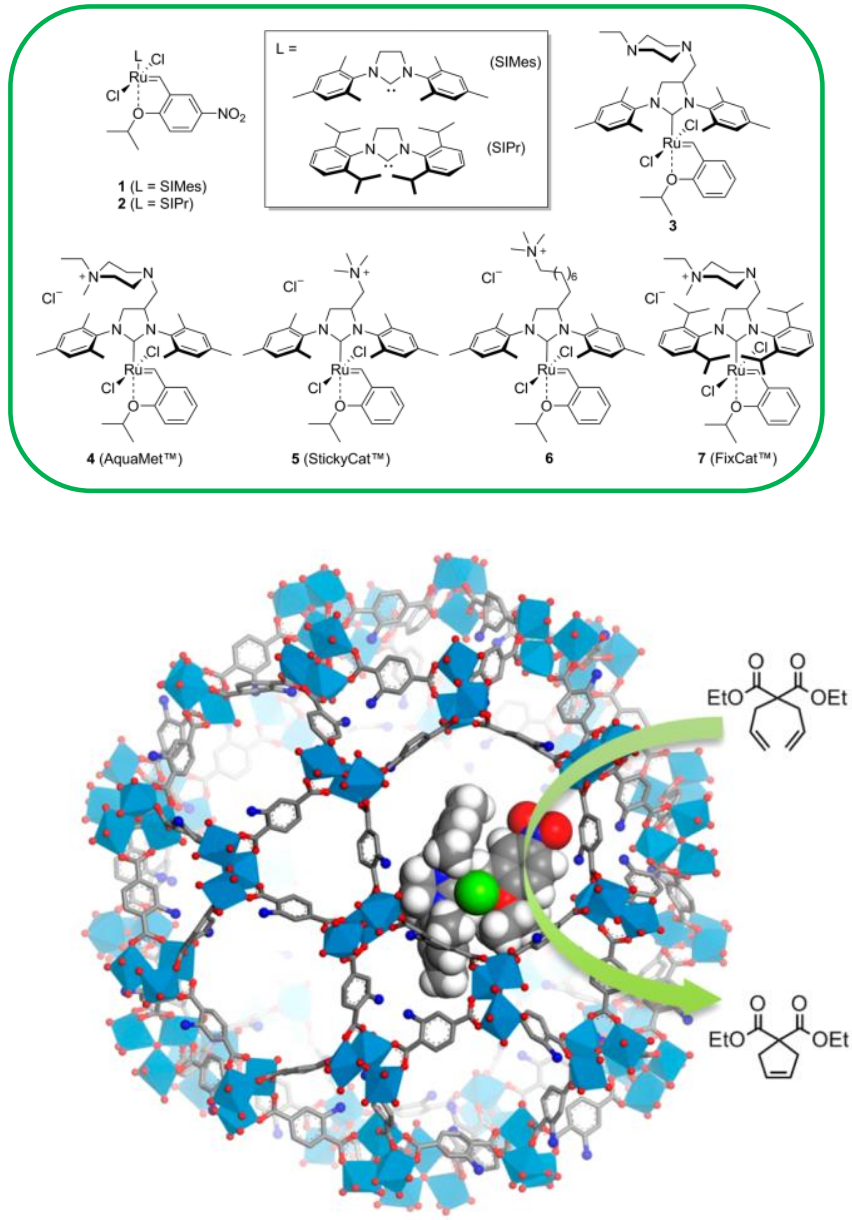

Fig. 28 Structures of Ru complexes investigated for their immobilisation in $\mathrm{NH}_{2}-\mathrm{MIL}-$ 101(Al) and the visualization of an olefin metathesis catalyst inside a cavity of $\mathrm{NH}_{2}-\mathrm{MIL}$ 101(Al). Adapted with permission from ref. ${ }^{152}$. Copyright 2016 American Chemical Society.

At the same time, another example of incorporation of an organometallic catalyst into a MOF was studied by Grigoropoulos et al. ${ }^{172}$ As a proof of concept, they successfully achieved the immobilisation of the cationic Lewis acidic $\left[\mathrm{CpFe}(\mathrm{CO})_{2} \mathrm{~L}\right]^{+}$species (denoted as $[\mathrm{Fp}-\mathrm{L}]^{+}, \mathrm{Cp}=\eta^{5}-\mathrm{C}_{5} \mathrm{H}_{5}, \mathrm{~L}=$ weakly bound solvent) into the anionic $\left[\ln _{3}(B T C)_{4}\right]^{3-}$ porous framework through a controlled cation exchange process. The final $\left[(\mathrm{Fp}-\mathrm{L})_{0.6}\left(\mathrm{Et}_{4} \mathrm{~N}\right)_{2.4}\right]\left[\ln _{3}(\mathrm{BTC})_{4}\right]$ material was tested as a heterogeneous catalyst for Diels-Alder [4+2] cycloaddition reaction between isoprene (Iso) and methyl vinyl ketone (MVK) in dichloromethane. With $10 \mathrm{~mol} \%$ [Fe]/[MVK] loading and a [Iso]/[MVK] ratio of 4 , the yield of the reaction reached $45 \%$ after $96 \mathrm{~h}$ at room temperature. Even if the homogeneous catalysis showed better results in similar conditions $(67 \%$ yield after $48 \mathrm{~h}$ ), the catalytic activity of $\left[(\mathrm{Fp}-\mathrm{L})_{0.6}\left(\mathrm{Et}_{4} \mathrm{~N}\right)_{2.4}\right]\left[\operatorname{In}_{3}(\mathrm{BTC})_{4}\right]$ validated the synthetic cation exchange strategy adopted for the heterogenization of such catalysts. The composite was reused at least 3 times, with however some loss of activity (yield of $27 \%$ in the third cycle). IR spectroscopy revealed a slow, partial decomposition of the complex, as already reported for $[\mathrm{Fp}-\mathrm{L}]^{+}$in homogeneous conditions. 
5.1.2 Oxidation of alcohols. Entrapment of catalytic active metal complexes into a MOF framework constitutes also a strategy to build efficient heterogeneous catalytic systems for the oxidation of alcohols. Zalomaeva et al. successfully incorporated controlled loadings of an iron tetrasulfonatophtalocyanine (FePcS) complex into the highly stable MIL-101(Cr). ${ }^{145}$ They studied the oxidation of benzyl alcohol using TBHP as oxidant $\left(60^{\circ} \mathrm{C}\right.$, acetonitrile). While 15\%wtFePcS@MIL-101(Cr) and homogeneous FePcS showed similar performances (ca. 32\% of conversion after $2 \mathrm{~h}$ ), a faster conversion of $32 \%$ in 15 min was observed for 5\%wtFePcS@MIL-101(Cr). This indicated a better accessibility of active Fe-centres at lower loadings. The efficiency of $5 \%$ wtFePcS@MIL-101(Cr) vs the homogeneous catalyst was confirmed with the oxidation of aromatic alcohols into corresponding quinones. Conversions of 2,3,6-trimethylphenol (TMP) or 8-hydroxyquinoline (8-HQ) were indeed almost complete in only $15 \mathrm{~min}$ whereas conversions of $56 \%$ and $67 \%$ were respectively observed for $\mathrm{FePcS}\left(\mathrm{NBu}_{4}\right)_{4}$ in homogeneous conditions. These striking differences mainly came from the affinity of MIL-101(Cr) to aromatic species making it easily penetrable. Compared to systems with FePcS immobilised into other supports, 5\%wtFePcS@MIL-101(Cr) gave rise to faster reactions kinetics. As an example, comparable yields in the oxidation of 8-HQ into quinoline-5,8-dione were obtained after 2-6 $\mathrm{h}$ for $\mathrm{FePcS} / \mathrm{SiO}_{2}$ (31-66\%) and FePcS/MCM-41 (40-55\%) and after only 15 min for 5\%wtFePcS@MIL-101(Cr) (53\%). Finally, no leaching of iron or chromium was evidenced, proving the stability of this heterogeneous catalyst.

Challenging selective oxidation of alcohols into aldehydes or ketones was also performed by POM@MOF materials. In 2017, Abednatanzi et al. investigated these reactions using a threecomponents MOF-based material. ${ }^{53}$ The catalyst denoted $\mathrm{PW}_{12} /$ DAIL/MIL-101(Cr) (DAIL = dual aminofunctionalized ionic liquid) consisted in the immobilisation of the Keggin-type $\mathrm{PW}_{12}$ into MIL-101(Cr) which was previously modified by an aminofunctionalized ionic liquid. The catalytic activity of this original composite was compared to that of other systems for the oxidation of benzyl alcohol into benzaldehyde using TBHP as oxidant in chloroform $\left(100^{\circ} \mathrm{C}, 6 \mathrm{~h}\right)$. The remaining free amino group of the ionic liquid into the structure allowed a better accessibility of the oxidant through hydrogen bonding thus enhancing the catalytic performance of $\mathrm{PW}_{12} / \mathrm{DAIL} / \mathrm{MIL}-101(\mathrm{Cr})$

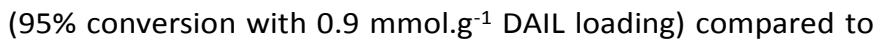
PW $12 @ M I L-101(\mathrm{Cr})$ (70\% of conversion). The efficiency of $\mathrm{PW}_{12} / \mathrm{DAIL} / \mathrm{MIL}-101(\mathrm{Cr})$ was demonstrated not only by its high selectivity towards benzaldehyde ( $>99 \%)$ but also by excellent TON values (1900) with respect to other POM-based catalytic systems. The integrity of the structure was maintained during 5 consecutive runs with no detected leaching, which contributed overall to a constant catalytic activity (Fig. 29).

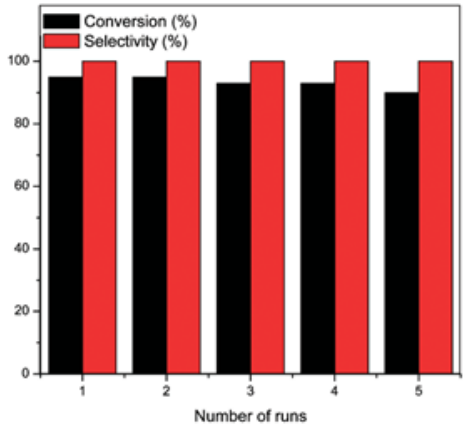

Fig. 29 Recyclability of the PW 12 /DAIL/MIL-101(Cr) catalyst. Reprinted from ref. ${ }^{53}$ with permission from the RSC.

Some of the contributors pursued this strategy by incorporating the $\mathrm{PW}_{4}$ peroxopolyoxotungstate into MIL100 (Fe) previously modified by DAIL. ${ }^{77}$ The resulting $\mathrm{PW}_{4}$ /DAIL/MIL-100(Fe) material was also tested under the same conditions as described for PW 12 /DAIL/MIL-101(Cr). ${ }^{53}$ Even if the catalyst exhibited excellent selectivity (>99\%) and a higher conversion (92\% with 1.2 mmol.g ${ }^{-1}$ DAIL loading) than MIL100 (Fe) (38\%) or $\mathrm{PW}_{12} / \mathrm{MIL}-100(\mathrm{Fe})(65 \%)$, the measured TON (613) was much lower than that of $\mathrm{PW}_{12} / \mathrm{DAIL} / \mathrm{MIL}-101(\mathrm{Cr})$.

In 2014, Zhu et al. chose the copper-based HKUST-1 as a host material for the immobilisation of various $\mathrm{POMs}\left(\mathrm{PW}_{4}\right.$, $\mathrm{PMo}_{12}$ and $\left.\mathrm{PMo}_{10} \mathrm{~V}_{2}\right)^{1}{ }^{116} \mathrm{PW}_{4} @ H K U S T-1$ was used for the green oxidation of benzyl alcohol by $\mathrm{H}_{2} \mathrm{O}_{2}\left(80^{\circ} \mathrm{C}, 3 \mathrm{~h}\right)$ and exhibited a higher efficiency ( $98 \%$ conversion) in CTAB micellar solution than in other media. Micelles, displaying both hydrophobic and hydrophilic parts, allowed the reaction to take place at their surface, overcoming solubility issues of the substrates, oxidant

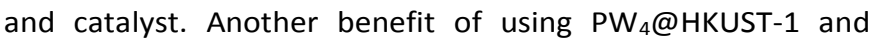
$\mathrm{PMO}_{12} @ H K U S T-1$ was the selectivity whereby benzaldehyde was the only detected product, while benzoic acid was also generated with vanadium-containing POM. The catalytic activity also depends on the substrate's size. With PW 4 @HKUST-1 as a model catalyst, the conversion of 4-tertbutylbenzyl alcohol (65\%) was much lower than that of benzyl alcohol despite the positive electronic substituent effect of the tert-butyl substituent. It is proposed that benzyl alcohol, with smaller size, could diffuse more easily through the pores. It should also be noted that a wide range of aliphatic, allylic and benzylic alcohols were converted specifically to the carbonyl products with good to excellent yields, and the double bonds were not affected by the oxidation process. Finally, considering the oxidation of benzyl alcohol, the recycled catalyst PW 4 @HKUST-1 was used during 5 consecutive runs without a significant loss of activity.

POMs encapsulated into HKUST-1 framework were also employed for the degradation of pollutants, specifically phenol in water. Peculiarly, $\mathrm{PW}_{12}$ was inserted into the MOF via a liquidassisted grinding method, leading to the nanocrystalline NENU$3 \mathrm{~N}$ catalyst formulated $\left[\mathrm{Cu}_{2}(\mathrm{BTC})_{4 / 3}\left(\mathrm{H}_{2} \mathrm{O}\right)_{2}\right]_{6}\left[\mathrm{HPW}_{12} \mathrm{O}_{40}\right] .{ }^{129}$ With particles' size of $85 \mathrm{~nm}, \mathrm{NENU}-3 \mathrm{~N}$ showed a high efficiency for the degradation of phenol ( $97 \%$ elimination after $1 \mathrm{~h}$ ) and total organic compounds (TOC) removal (88\% reduction after $1 \mathrm{~h}$ ) with $\mathrm{H}_{2} \mathrm{O}_{2}$ as oxidant at $35^{\circ} \mathrm{C}$. The oxidation of phenol was then 
achieved in acetonitrile due to the low stability of HKUST-1 in water. Chiefly, the results pointed out the synergy between the POM and the MOF since the removal of phenol in $1 \mathrm{~h}$ was more important with NENU-3N (55\%) than with PW 12 (26\%), HKUST-1 (35\%) or a mixture of $\mathrm{PW}_{12}$ and HKUST-1 (40\%). From a mechanistic point of view, it was proposed that $\mathrm{H}_{2} \mathrm{O}_{2}$ was activated by both the MOF's and POMs' active sites to generate strongly oxidizing hydroxyl radicals and peroxo species which initiated the oxidation of phenol (Fig. 30). Phenol is first oxidised into aromatic intermediates like benzoquinone that are transformed into short-chain carboxylic acids, which are further partially transformed into $\mathrm{CO}_{2}$. Lastly, the observed constant efficiency over 5 cycles and a proven structural stability both confirmed NENU-3N as a promising catalyst with an enhanced activity due to dual catalytic sites (POM and MOF).

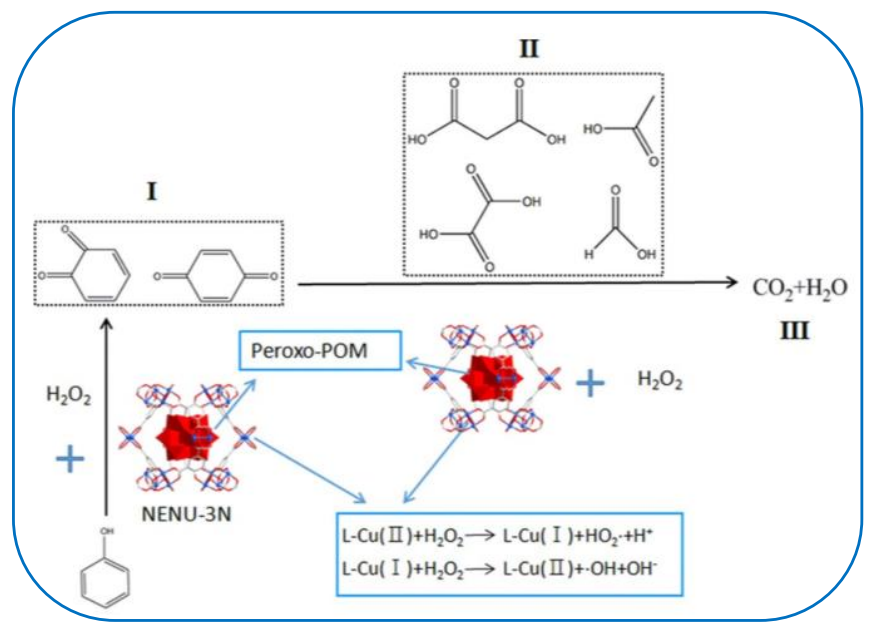

Fig. 30 Proposed mechanism for the catalytic wet peroxide oxidation of phenol with NENU-3N as catalyst. Reprinted with permission from ref. ${ }^{129}$. Copyright Wiley-VCH Verlag GmbH \& Co. KGaA, Weinheim.

While the pores' sizes of MOFs mostly belong to the microporous range, it is possible via various synthetic routes to construct mesoporous and/or macroporous MOF-based materials (hierarchically porous MOFs) which can display improved catalytic properties compared to microporous systems. With this idea in mind, Li et al. synthesised via the gellike/freeze-drying method the hierarchically porous NENU-9HP$1 / 120$ composite (' $H P^{\prime}$ ' means hierarchical pore, ' 1 ' is the concentration of the added copper source in mmol, ' 120 ' is the total volume in $\mathrm{mL}$ of ethanol used for the synthesis), made of $\mathrm{PMo}_{10} \mathrm{~V}_{2}$ species encapsulated in HKUST-1. ${ }^{133}$ The oxidation of 1-phenylethanol into acetophenone with TBHP as oxidant (toluene, $100^{\circ} \mathrm{C}, 7 \mathrm{~h}$ ) was then investigated with a panel of catalysts. As expected, NENU-9HP-1/120 allowed a higher conversion (97\%) than the POM (38\%) or the hierarchically porous HKUST-1 (50\%) alone. Due to its unique structure, NENU-9HP-1/120 exhibits enhanced catalytic activity when compared with that of the microporous nanosized NENU-9N (66\%) and NENU-9HT (39\%). TOF analysis confirmed these results with values of $249 \mathrm{~h}^{-1}$ and $114 \mathrm{~h}^{-1}$ for NENU-9HP-1/120 and NENU-9HT, respectively. Such differences emanate from NENU-9HP-1/120's mesoporous channels that are conducive to the mass transfer of substrates and products as well as a greater number of exposed active sites. Besides, studying linear primary alcohols, the impact of the substrate's length was highlighted. While only a slight decrease in conversion was observed for NENU-9HP-1/120 from $n$-butanol to $n$-octanol (94\% to $87 \%$ ), the conversion dropped for NENU-9HT ( $90 \%$ to $30 \%$ ). Interestingly, the hierarchically porous structure of NENU-9HP-1/120 was maintained after 5 catalytic cycles with intact mesopores and a high catalytic activity ( $80 \%$ conversion for the oxidation of phenylethanol), proving its great stability.

5.1.3. Oxidation of alkanes. Several groups investigated the oxidation of alkanes using metalloporphyrins immobilised into MOFs. In 2008, Alkordi et al. successfully incorporated the cationic 5,10,15,20-tetrakis(1-methyl-4-pyridinio)porphyrin $\left(\left[\mathrm{H}_{2} \mathrm{TMPyP}^{4+}\right)\right.$ into the anionic (indiumimidazoledicarboxylate)-based rho-ZMOF (zeolite-like MOF) taking advantage of highly favourable host-guest electrostatic interactions. ${ }^{174}$ The post-synthetic metalation of the porphyrin using a manganese salt led to the Mn-TMPyP@rho-ZMOF material. The oxidation of cyclohexane was then investigated in neat conditions using a catalyst loading of $3.8 \%$, TBHP as oxidant and with an initial TBHP to cyclohexane molar ratio of $2 / 1$. After $24 \mathrm{~h}$ of reaction at $65^{\circ} \mathrm{C}$, cyclohexanol and cyclohexanone were the only products detected (Fig. 31). The calculated total yield of $91.5 \%$ was significantly higher than that obtained with other heterogeneous catalysts possessing metalloporphyrins immobilized in zeolites or silica matrices. It is worth to note that rho-ZMOF or the free-base porphyrin into rho-ZMOF exhibit no catalytic activity, highlighting the specificity of Mn-TMPyP@rhoZMOF. Moreover, the stability of the catalyst was corroborated by the absence of metalloporphyrin in solution and a constant efficiency under the reaction conditions up to 11 runs at least.

A few years later, the oxidation of cyclohexane with similar types of catalysts was investigated by Chen et al.. ${ }^{156}$ In this case, tris(1,10-phenanthroline) $\mathrm{Cu}(\mathrm{II})$ complex (CuPhen) was encapsulated in two steps into MIL-100(Al). The oxidation of cycloalkane with the resulting CuPhen@MIL-100(Al) catalyst ( 0.55 wt \% $\mathrm{Cu}$ content) was studied in acetonitrile using $\mathrm{H}_{2} \mathrm{O}_{2}$ as oxidant. An increase of temperature leads to higher yield until $70^{\circ} \mathrm{C}$. Above this temperature the decomposition of $\mathrm{H}_{2} \mathrm{O}_{2}$ prevails. Again, cyclohexanol and cyclohexanone were the only observed products with a 1:2 ratio. Interestingly, CuPhen@MIL100(Al) showed a better conversion (21.4\%) than CuPhen (12.3\%) underlining the relative benefit of the encapsulation of the metal complex which prevented its degradation by $\mathrm{H}_{2} \mathrm{O}_{2}$. Encapsulation of CuPhen in zeolite $\mathrm{Y}$ showed a lower catalytic conversion of $11.9 \%$. This highlights the advantageous structural features of MIL-100(Al) whose large supercages (25 and $29 \AA$ ) and windows facilitate the diffusion of the substrate and stabilise active transition-states. However, a loss of catalytic activity probably due to a partial degradation of CuPhen under the reaction conditions was observed after 3 cycles $(18.6 \%$ conversion in the $3^{\text {rd }}$ run). 


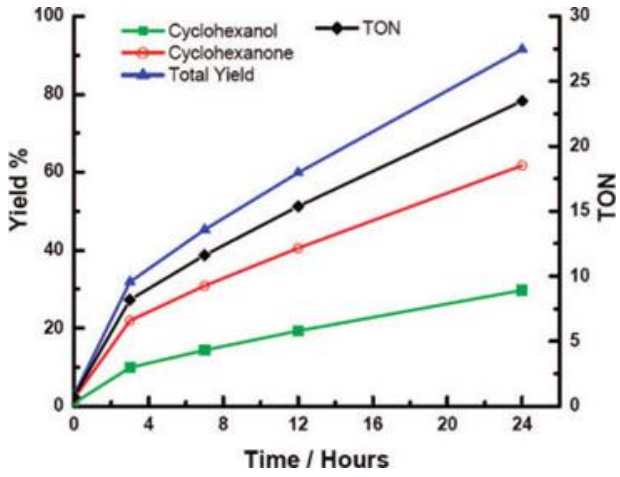

Fig. 31 Cyclohexane catalytic oxidation using Mn-TMPyP@rho-ZMOF as a catalyst at $65^{\circ} \mathrm{C}$. Yield $\%$ based on TBHP, 1 equiv consumed per alcohol produced and 2equiv consumed per ketone produced. Reprinted with permission from ref. ${ }^{174}$. Copyright 2008 American Chemical Society.

5.1.4. Oxidation of carbonyl compounds. In order to obtain the highly demanded adipic acid (AA) without forming toxic byproducts, the oxidation of cyclohexanone by $\mathrm{H}_{2} \mathrm{O}_{2}$ with POM@MOF materials was considered. Feng et al. chose $\mathrm{PW}_{12}$ for its intrinsic catalytic properties and UiO-66 for its remarkable chemical and thermal stability. ${ }^{93}$ The yield in AA using the composite $(80.3 \%)$ was comparable to that of $\mathrm{PW}_{12}$ alone $(88.7 \%)$, proving its efficiency is maintained. The best catalytic performances were observed after $8 \mathrm{~h}$ of reaction at $90^{\circ} \mathrm{C}$ and a molar $\mathrm{H}_{2} \mathrm{O}_{2}$ : cyclohexanone ratio of $4: 5$. Notably, with these conditions, PW $12 @ U i O-66$ appears as one of the best heterogeneous catalysts reported so far for the adipic acid synthesis in terms of yield. The AA yield remained unchanged over 5 consecutive cycles, demonstrating the stability of the composite material, further supported by XRD. In addition, no POM leaching was observed, in contrast with PW $12 @ M I L-$ $101(\mathrm{Cr})$ tested for the same reaction. In the latter case, AA yield fell from $76.0 \%$ for the first cycle to $42.5 \%$ for the third cycle. This result highlights the relevant choice of UiO-66 as a host where the windows' size allows keeping the POM trapped into the pores while the larger windows' size of MIL-101(Cr) cannot prevent the leaching of the POM.

Another key point in organic chemistry is the formation of amide bonds. Indeed, this functional group is observed in numerous chemical compounds of interest (natural products, polymers...). The most studied reaction involves activated carboxylic acid and amine. Recently, Boroujeni et al. proposed for the first time to use a copper phthalocyanine complex incorporated into MIL-101(Cr), CuPc@MIL-101(Cr), for the oxidative amidation of aldehydes. ${ }^{148}$ As a model reaction, the synthesis of $\mathrm{N}$-benzylbenzamide in acetonitrile starting from benzaldehyde and benzylamine hydrochloride in the presence of a base $\left(\mathrm{CaCO}_{3}\right)$ and TBHP as oxidant was investigated (Scheme 3). Amine hydrochloride salts were preferably used than free amine, which could be oxidised in the presence of TBHP. First, the amount of CuPc@MIL-101(Cr) composite was optimized until 92\% yield at room temperature. In these conditions, CuPc@MIL-101(Cr) showed a higher yield than the pristine MIL-101( $\mathrm{Cr})\left(35 \%\right.$ yield at $\left.60^{\circ} \mathrm{C}\right)$, homogeneous CuPc (10\%) or $\mathrm{Cu}^{2+} @ \mathrm{MIL}-101(\mathrm{Cr})(80 \%)$. In the latter composite, the initially good catalytic activity strongly decreased in the next run because of the leaching of the $\mathrm{Cu}^{2+}$ ions. In contrast, CuPc@MIL$101(\mathrm{Cr})$ could be reused after filtration, washing and drying for 6 consecutive runs without loss of activity. Moreover, the authors showed that the reaction with substituted benzaldehyde and benzylamine hydrochloride also took place with high yields (between 80 and 90\%), confirming the efficiency of CuPc@MIL-101(Cr).

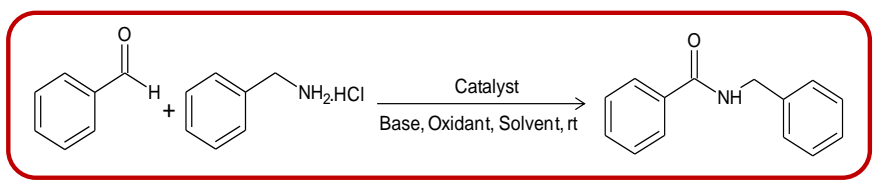

Scheme 3 Synthesis of $\mathrm{N}$-benzylbenzamide. Adapted with permission from ref. ${ }^{148}$ Copyright 2017 John Wiley \& Sons, Ltd.

5.1.5. Peroxidase activity. Thanks to their unique features, MOFs appear as suitable platforms to encapsulate peroxidase mimetics. Notably, this subfield of investigation led to the development of the so-called MOMzyme-1 (Metal Organic Material enzyme) class of materials. This concept was initiated by Larsen et al. in 2011 with the entrapment of metalloporphyrins bearing four sulfonato groups (Fe4SP or Mn4SP) within the well-suited octahedral cages of HKUST-1 $(\mathrm{Cu} / \mathrm{Zn}) .{ }^{170}$ The peroxidase activity of the iron-based MOMzyme-1 materials was assayed through the oxidation of 2,2'-azidodi(3-ethylbenzthiazoline)-6-sulfonate (ABTS) by $\mathrm{H}_{2} \mathrm{O}_{2}$. Still, the initial rate of $\mathrm{ABTS}^{+}$formation was lower with Fe4SP@HKUST-1(Cu) than with a solution of microperoxidase11 (MP-11), horse heart myoglobin (hhMb) and Fe4SP. This was interpretated as a result of the limited diffusion of substrate through the channels of HKUST-1. Nonetheless, the ABTS conversion measured with Fe4SP@HKUST-1(Cu) (50\%) was comparable to those obtained with MP-11 (52\%) and Fe4SP (50\%). These results highlighted the accessibility to the metalloporphyrin for the ABTS substrate and the preserved activity of the catalytic centre when immobilized into the MOF. Importantly, the MOF cavities ensured the stability of the catalytic complex while the homogeneous counterpart became inactive because of intermolecular side-reactions between porphyrin macrocycles. Consistently, no decrease in the ABTS conversion yield was observed for 3 consecutive runs (55\%).

Following the same concept of MOF-based bioinspired materials, Liu et al. achieved the incorporation of hemin (also called iron protoporphyrin IX), which is the active centre of the heme protein family, into $\mathrm{NH}_{2}-\mathrm{MIL}-101(\mathrm{Al}) .{ }^{151}$ In fact, the initial MOF transformed into $\mathrm{NH}_{2}-\mathrm{MIL}-53$ (Al) during the impregnation step in DMF as evidenced by the powder XRD analysis. The peroxidase-like activity of the final Hemin@ $\mathrm{NH}_{2}-\mathrm{MIL}-53$ (Al) composite material was then considered through the oxidation of the chromogenic TMB (3,3,5,5-tetramethylbenzidine) by $\mathrm{H}_{2} \mathrm{O}_{2}$ in a buffer solution $(\mathrm{pH}=5)$. The immobilization of the hemin into the MOF unambiguously improved its catalytic activity. During the reaction, Hemin@ $\mathrm{NH}_{2}-\mathrm{MIL}-53$ (Al) generated a deep blue colour indicating the formation of the oxidised form of TMB (Fig. 32). By contrast, no colour change occurred with $\mathrm{TMB} / \mathrm{H}_{2} \mathrm{O}_{2}$ or $\mathrm{MOF} / \mathrm{TMB} / \mathrm{H}_{2} \mathrm{O}_{2}$ and a negligible coloration was detected with hemin/TMB/ $\mathrm{H}_{2} \mathrm{O}_{2}$. An optimal temperature of 50 
${ }^{\circ} \mathrm{C}$ was established vs $40^{\circ} \mathrm{C}$ for the hemin alone, pointing toward an enhanced thermal stability upon immobilization. Finally, the catalytic activity was maintained after 6 cycles although a small decrease was observed. Importantly, the catalysis was shown to follow typical Michaelis-Menten kinetics while adopting a pingpong mechanism as observed for the native peroxidase. On this basis, Hemin@ $\mathrm{NH}_{2}-\mathrm{MIL}-53(\mathrm{Al})$ found an application for a simple, sensitive and selective detection of glucose and $\mathrm{H}_{2} \mathrm{O}_{2}$ via a colorimetric method.

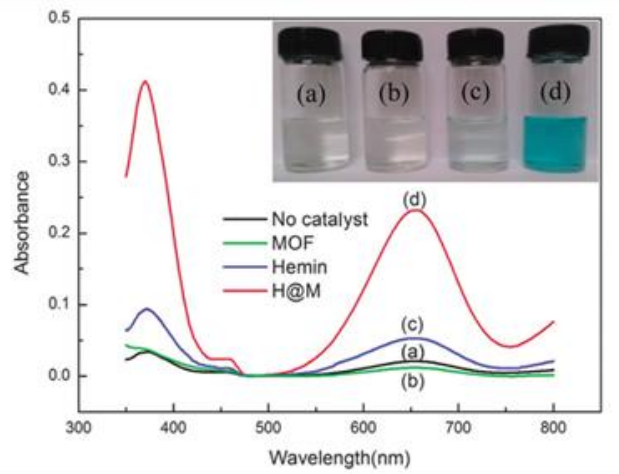

Fig. 32 Typical absorption curves of TMB $(0.8 \mathrm{mM})$ reaction solutions catalytically oxidised by (a) no catalyst; (b) $\mathrm{NH}_{2}-\mathrm{MIL}-101$ (Al) $\left(20 \mu \mathrm{g} \mathrm{mL}^{-1}\right)$; (c) Hemin $\left(20 \mu \mathrm{g} \mathrm{mL}^{-1}\right)$ and (d) Hemin@ $\mathrm{NH}_{2}-\mathrm{MIL}-53(\mathrm{Al})\left(20 \mu \mathrm{gL}^{-1}\right)$ in the presence of $10 \mathrm{mM} \mathrm{H}_{2} \mathrm{O}_{2}$ at room temperature in sodium citrate buffer $(50 \mathrm{mM}, \mathrm{pH} 5)$ after 5 min. Inset: typical photographs of four corresponding samples. Reprinted from ref. ${ }^{151}$ with permission from the RSC.

5.1.6 Water oxidation. Oxidation of water to molecular dioxygen is a key task due to its high importance in the field of energy. In 2013 Nepal and Das immobilised the high-valent di$\mu$-oxo dimanganese water oxidation catalyst [(terpy) $\mathrm{Mn}(\mu-$ O) ${ }_{2} \mathrm{Mn}$ (terpy) $]^{3+}$ (terpy $=2,2^{\prime} ; 6^{\prime}, 2^{\prime \prime}$-terpyridine), denoted as MnTD, into MIL-101(Cr), leading to the MnTD@MIL-101(Cr) heterogeneous catalyst. ${ }^{143}$ Oxygen evolution assays were performed in acetate buffer solution $(\mathrm{pH} 4.5)$ at $25^{\circ} \mathrm{C}$ in presence of the $\mathrm{K}$-oxone $\left(\mathrm{KHSO}_{5}\right)$ electron acceptor. Although high rates of $\mathrm{O}_{2}$ evolution were obtained with molecular MnTD for the first $200 \mathrm{~s}$ (TOF $=0.04 \mathrm{~mol} \mathrm{O}_{2}$ (mol catalyst) $)^{-1} \mathrm{~s}^{-1}$ ), the system slowed down and stopped after $400 \mathrm{~s}$. Even if the rate of catalysis was lower for MnTD@MIL-101(Cr) with a TOF value of $0.02 \mathrm{~mol} \mathrm{O}_{2}$ (mol caged MnTD-species) $)^{-1} \mathrm{~s}^{-1}$, this system appeared much more efficient as oxygen was continuously produced over $7 \mathrm{~h}$ at the same rate (Fig. 33). Control experiments with MIL-101(Cr) only or MnTD adsorbed on the surface of the MOF failed in producing oxygen. The encapsulation of MnTD into the perfectly suited pores of MIL$101(\mathrm{Cr})$ was thus the key in obtaining a performing catalyst for oxygen evolution reactions.

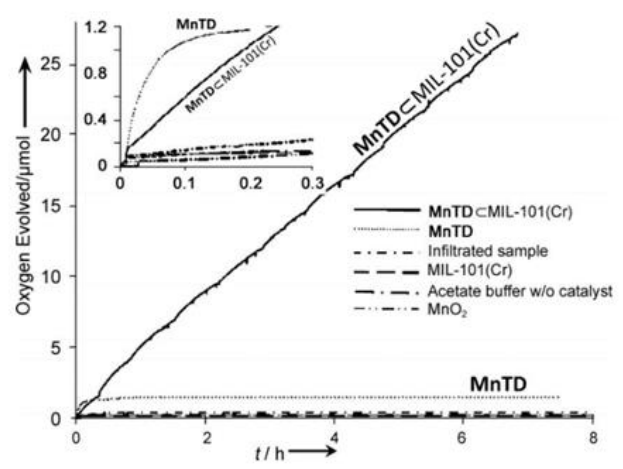

Fig. 33 Oxygen evolution plots for 2 mg of MnTD@MIL-101(Cr), $0.19 \mu$ mole of MnTD, 2 $\mathrm{mg}$ of MIL-101(Cr), $5 \mathrm{mg} \mathrm{MnO}$ and $2 \mathrm{mg}$ of infiltrated sample in $6 \mathrm{~mL}$ acetate buffer $(\mathrm{pH}$ 4.5, $0.23 \mathrm{M}$ ) with $250 \mu \mathrm{L}$ K-oxone $\left(\mathrm{KHSO}_{5}\right)(200 \mathrm{mM})$. In the case of MnTD@MIL-101(Cr), $100 \mu \mathrm{L} \mathrm{K}$-oxone $(200 \mathrm{mM})$ was added once the solution was deoxygenated with $\mathrm{N}_{2}$. Reprinted with permission from ref. ${ }^{143}$. Copyright 2013 Wiley-VCH Verlag GmbH \& Co, KGaA, Weinheim.

5.1.7 Oxidation of sulfur-containing compounds. Fuel combustion leads to the production of $\mathrm{SO}_{x}$ that are extremely damaging to the environment. It is now crucial to limit sulfur levels under $10 \mathrm{ppm}$ in these fuels. ${ }^{250}$ Hydrodesulfurization (HDS) and oxidative desulfurisation (ODS) are the two main techniques considered for desulfurization. HDS is widely used in the petroleum refining industry and is highly efficient for the degradation of sulfides. Unfortunately, HDS generally requires high pressures and temperatures and consumes high amounts of hydrogen. ${ }^{251}$ Moreover, it appears to be less efficient for the removal of sulfur-containing heterocycles. These drawbacks explain the current interest in ODS. In this process, the heterocyclic sulfur compounds are oxidised to the corresponding sulfoxides and sulfones and then removed by extraction. ${ }^{252}$ We are first going to focus on this methodology, before reviewing the oxidation of aliphatic sulfides by Cat@MOF materials. A rapid examination of Table 1 allows to see that a large variety of MOF hosts have been studied for the immobilisation of POMs able to perform oxidation of sulfurcontaining compounds. Among them, $\mathrm{PW}_{12}$ has been the most studied one but $\mathrm{PW}_{9}, \mathrm{PW}_{11} \mathrm{Zn}, \mathrm{PMo}_{12}, \mathrm{PMo}_{10} \mathrm{~V}_{2}, \mathrm{~Tb}\left(\mathrm{PW}_{11}\right)_{2}$ and $\mathrm{Eu}\left(\mathrm{PW}_{11}\right)_{2}$ have been also considered. To the best of our knowledge, no Complex@MOF (Table 2) has been prepared for this kind of reaction.

5.1.7.1 Oxidation of sulfur-containing heterocycles. These last years, the ability of POMs to act as ODS catalysts has been clearly demonstrated.253,254 Furthermore, POM@MOF composites may act as highly active heterogeneous catalytic materials with excellent recyclability. Nevertheless, the experimental conditions for both the oxidation and extraction processes should be optimised in order to obtain performant systems.

For example, Hu et al. carried out a study in 2013 on the oxidation of benzothiophene (BT), dibenzothiophene (DBT) and 4-6 dimethyldibenzothiophene (4,6-DMDBT) (Scheme 4) which are representative of the sulfur-containing heterocyclic compounds found in diesel oil - using PW $12 @ M I L-101(\mathrm{Cr})$ (50 wt $\%$ in POM) with $30 \% \mathrm{H}_{2} \mathrm{O}_{2}$ as oxidant. ${ }^{45}$ Focusing on DBT, the 
conversion yield after $2 \mathrm{~h}$ at $45{ }^{\circ} \mathrm{C}$ was rather modest (27\%). When the cetyltrimethylammonium bromide (CTAB) phase transfer agent was added to the catalytic system, the conversion yield into sulfone reached $91 \%$, showing that the surfactant played a crucial role in this reaction. Also, the $\mathrm{H}_{2} \mathrm{O}_{2}$ /DBT ratio was identified as a key parameter, the DBT removal approaching $95 \%$ for a ratio of 50 while being of only $41 \%$ for a ratio of 12.5 . This was related not only to the beneficial effect of the large excess in oxidant, but also to the formation of an optimised oil-in-water emulsion. We can also note that in the absence of PW $12, \mathrm{MIL}-101(\mathrm{Cr})$ converted DBT modestly (9\%), evidencing that the POM acts as a catalyst. In addition, the recyclability and reusability of PW $12 @ \mathrm{MIL}-101(\mathrm{Cr})$ was demonstrated over four cycles, the DBT conversion dropping only from $91 \%$ to $87 \%$.

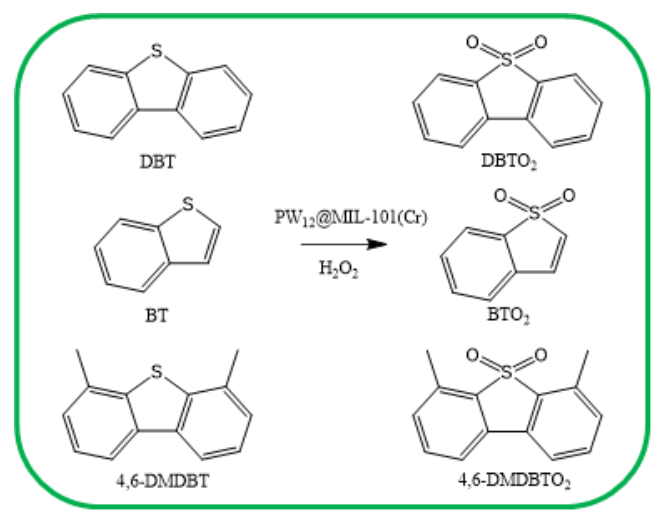

Scheme 4 Representation of benzothiophene (BT), dibenzothiophene (DBT) and 4-6 dimethyldibenzothiophene (4,6-DMDBT) and the related sulfones.

Ribeiro et al. described an analogous catalytic system using the 1-butyl-3-methylimidazolium hexafluorophosphate $\left(\mathrm{BMIPF}_{6}\right)$ ionic liquid (IL) instead of CTAB. ${ }^{46}$ Considering the same substrates and working at $50{ }^{\circ} \mathrm{C}$, the corresponding sulfones were quantitatively extracted (sulfur content $=500 \mathrm{ppm}$ ) into the IL within $1 \mathrm{~h}$ for DBT and $3 \mathrm{~h}$ for BT. The lowest reactivity of BT was attributed to a significantly lower electronic density on the sulfur atom, which decreased in the order DBT>4,6-DMBT>BT. While a similar activity was found for the POM in homogeneous conditions, the advantage of the present system was its recyclability with only a modest POM leaching after three cycles. In 2015, the same group reported the oxidation of the same substrates using the related PW 11 Zn@MIL$101(\mathrm{Cr}) / \mathrm{BMIPF}_{6}$ material, with similar results. ${ }^{39}$ However, a large loss of POM (50\%) was observed after three cycles when the catalyst was used in the oil/BMIPF 6 ODS system. Sun et al. built in 2018 a tricomponent material by dispersing PW $12 @ M I L-101(\mathrm{Cr})$ into the mesoporous diatomite material with in situ synthesis of PW 12 @MIL$101(\mathrm{Cr}) .{ }^{55}$ Comparison of the catalytic properties of PW $12 @ M I L-$ 101(Cr), PW $12 @$ diatomite and PW $12 @ M I L-101(C r)$-diatomite hybrids evidenced that the latter was the most active composite for the oxidation of DTB with a yield up to $98.5 \%$ and only $1.5 \%$ conversion loss after three cycles (Fig. 34a), suggesting that diatomite may limit the leaching of POM.

MIL-101(Cr) incorporating a lanthanide substituted polyoxotungstate has also been considered for ODS. Ribeiro et al. immobilised the $\left[\mathrm{Tb}\left(\mathrm{PW}_{11} \mathrm{O}_{39}\right)_{2}\right]^{11-}$ sandwich-type POM into the MIL-101(Cr) matrix. The resulting composite showed a good activity toward the oxidation of thiophene derivatives $\left(\mathrm{H}_{2} \mathrm{O}_{2}\right.$, $\left.50^{\circ} \mathrm{C}\right) .{ }^{65}$ The influence of the solvent used for extraction was shown whereby its polarity could be correlated with the sulfur extracting efficiency: while DMF showed the highest initial extraction capability, the best catalytic performance was achieved using less polar solvents, i.e. acetonitrile and isopropanol. This material was later compared to the trivacant polyoxotungstate-based PW9@MIL-101(Cr) composite, evidencing a higher activity than Tb(PW $\left.\mathrm{PW}_{11}\right)_{2} @ \mathrm{MIL}-101(\mathrm{Cr})$, with a complete desulfurisation achieved in $2 \mathrm{~h}$ instead of $5 \mathrm{~h}$ in analogous conditions. ${ }^{32}$ However, as suspected in the case of PW9@MIL-101(Cr) for the epoxidation of alkenes (see above), a chemical transformation of the encapsulated POM was not excluded, an evolution of the desulfurisation profile being observed during the first $30 \mathrm{~min}$ from cycle 1 to cycle 3 . Other lanthanide-containing POM@MOF systems were also studied, as exemplified by the investigation of the ODS activity of the closely related Eu(PW 11$)_{2} @ M I L-101(\mathrm{Cr})$ and Eu(PW 11$)_{2} / \mathrm{NH}_{2}-$ MIL-53(Al) materials. ${ }^{66}$ The later composite exhibited even better catalytic performances than Eu(PW $\left(\mathrm{PW}_{11}\right)_{2} @ \mathrm{MIL}-101(\mathrm{Cr})$ for the ODS of a model diesel (initial sulfur content: ca. $2350 \mathrm{ppm}$ ), with $99.9 \%$ and $82.0 \%$ of desulfurisation $\left(t=2 \mathrm{~h}, \mathrm{~T}=70^{\circ} \mathrm{C}\right.$, acetonitrile), respectively. It must be underlined that the two materials presented very different structures. In $\mathrm{Eu}\left(\mathrm{PW} \mathrm{W}_{11}\right)_{2} @ \mathrm{MIL}-101(\mathrm{Cr})$, the POMs were located inside the large cavities of the MOF. In contrast, it was proposed that the $\mathrm{Eu}\left(\mathrm{PW}_{11}\right)_{2}$ molecules (ca. $10 \times 18 \AA$ ) were deposited on the surface of the MOF particles as they are too large for entering $\mathrm{NH}_{2}$-MIL-53(Al)'s channels (ca. $7.5 \AA$ Å). The authors thus attributed the higher activity of the aluminum composite to an easier access of the substrate to the catalyst. We can note that in $\mathrm{Eu}\left(\mathrm{PW}_{11}\right)_{2} / \mathrm{NH}_{2}-\mathrm{MIL}-53(\mathrm{Al})$, the highly negatively charged POMs strongly interacted with the protonated amino groups of the MOF, ensuring a relatively good stability of the POM/MOF composite although the POM are not incorporated into the MOF's pores. However, some decrease of the $\mathrm{Eu}\left(\mathrm{PW}_{11}\right)_{2} / \mathrm{NH}_{2}-$ MIL-53(Al) activity was observed over cycling, which could be attributed to a significant POM leaching (W/Al (wt \%) ratio of 0.57 and 0.41 before and after catalysis, respectively). 


\section{ARTICLE}
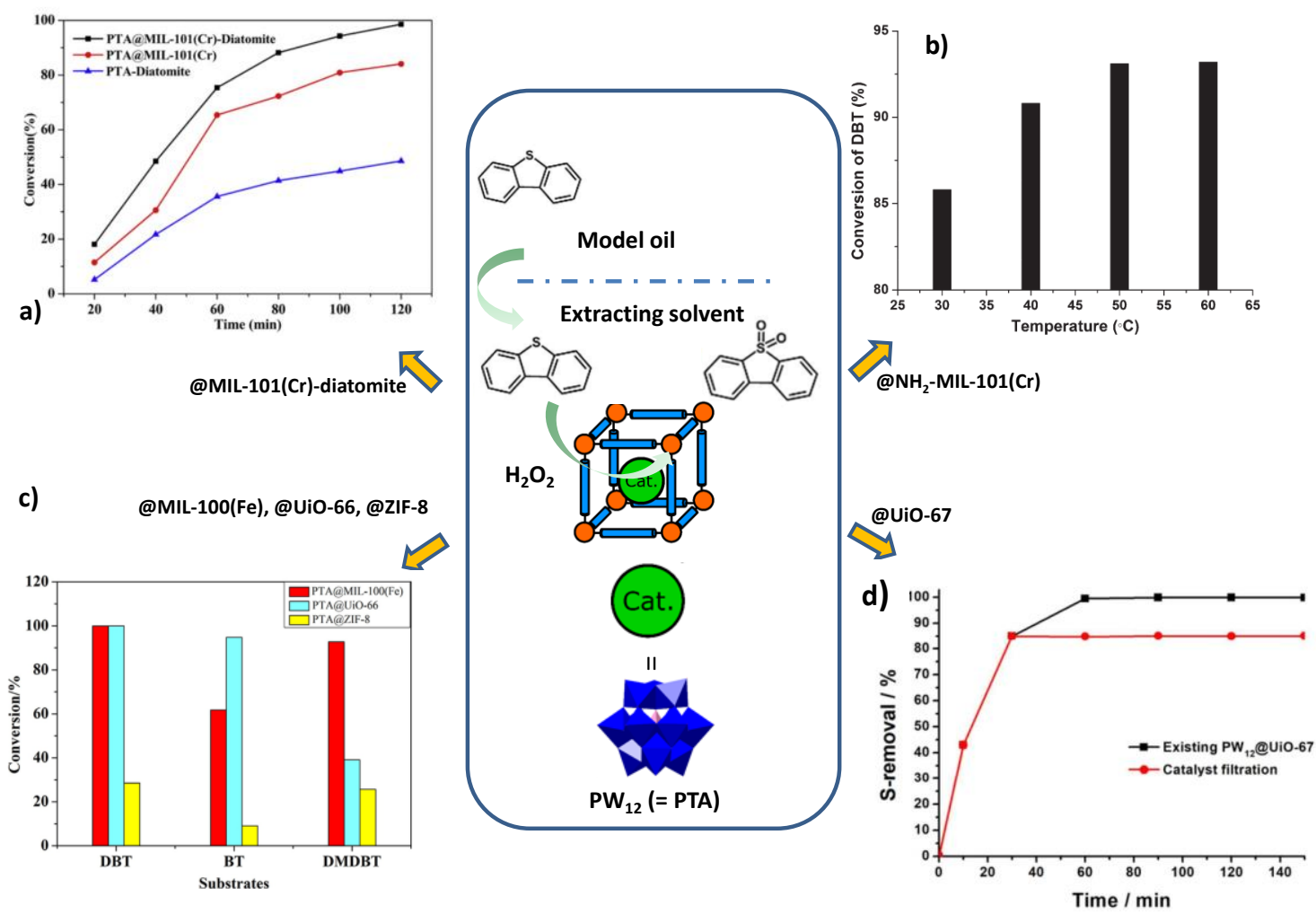

Fig. 34 Representative examples of catalytic results with $\mathrm{PW}_{12} @ M O F$ composites for oxidation of DBT into DBTO $\mathrm{O}_{2}$ : a) The desulfurisation effect as the variation of reaction time for PW 12 -diatomite (blue line), PW $12 @ M I L-101(C r)$ (red line) and PW $12 @ M I L-101(C r)$-diatomite (black line). Adapted with permission from ref. ${ }^{55}$. Copyright 2017 Elsevier B.V. All rights reserved. b) Oxidation activity of DBT under different temperatures with DMF as the extraction and reaction medium with the PW $12 @ M I L-101\left(C_{1}\right)$ composite catalyst. Conditions: time, $4 \mathrm{~h}, \mathrm{O} / \mathrm{S}=50$. Adapted from ref. 70 with the permission from RSC. c) ODS of DBT, BT and DMDBT using PW $12 @ Z$ ZIF-8 (yellow), PW $12 @ U i O-66$ (blue) and PW $12 @ M I L-100(F e)$ (red). Adapted with permission from ref. ${ }^{80}$. Copyright 2017 Wiley-VCH Verlag GmbH \& Co. KGaA, Weinheim. d) Reaction time test (black line) and leaching examination (red line) with the PW $12 @$ UiO- 67 catalyst. Reaction condition: $70^{\circ} \mathrm{C}, 1 \mathrm{~h}$ and $\mathrm{O} / \mathrm{S}=13$. Adapted with permission from ref. 102 from the CCS, PKU and the RSC.

The zinc polyoxometalate $\left[\mathrm{PW}_{11} \mathrm{Zn}\left(\mathrm{H}_{2} \mathrm{O}\right) \mathrm{O}_{39}\right]^{5-}$ was introduced into the cavity of the $\mathrm{NH}_{2}-\mathrm{MIL}-101(\mathrm{Al}) .{ }^{72}$ Again a partial transformation of $\mathrm{NH}_{2}-\mathrm{MIL}-101$ (Al) into $\mathrm{NH}_{2}-\mathrm{MIL}-53$ (Al) was observed, whatever the synthetic method used (impregnation or synthetic encapsulation). The POM-free MOF did not show any significant catalytic activity. Using the material obtained following the one-step synthetic procedure and the [BMIM]PF 6 ionic liquid, a sulfur removal of $83 \%$ was achieved after $6 \mathrm{~h}\left(\mathrm{~T}=50^{\circ} \mathrm{C}\right)$ working on a real diesel. This is a higher yield than that obtained in homogeneous conditions, which is explained by the intrinsic better performance of the composite when compared to that of the POM alone, together with the IL used during the oxidative catalytic stage and an optimised liquid-liquid extraction procedure.

The related chromium $\mathrm{NH}_{2}-\mathrm{MIL}-101(\mathrm{Cr})$ MOF has also been used for POM encapsulation for catalytic ODS reactions. Cao et al. reported in 2014 the incorporation of $\mathrm{PW}_{12}$ via an ion exchange procedure, with a $0.126 \mathrm{mmol} . \mathrm{g}^{-1} \mathrm{POM}$ loading. ${ }^{70}$ The material was tested in model oil for the oxidation of DBT to its corresponding sulfone $\mathrm{DBTO}_{2}$ using $\mathrm{H}_{2} \mathrm{O}_{2}$ as oxidant. Many parameters were explored including the solvent efficiency for the DBT extraction, the oxidant/substrate $(\mathrm{O} / \mathrm{S})$ molar ratio and the temperature. As expected, DMF showed a better extraction efficiency at $10 \mathrm{~min}$ (87\%) when compared to MeCN (57\%) because of its higher polarity. The conversion yield increased from $\mathrm{RT}$ to $50^{\circ} \mathrm{C}$, which was attributed to the increasing formation of metallic peroxide with temperature, while higher temperatures lead to the decomposition of $\mathrm{H}_{2} \mathrm{O}_{2}$ (Fig. 34b). Optimal $\mathrm{O} / \mathrm{S}$ molar ratio is highly linked to the nature of the solvent. The best conversion rate with DMF was reached with an $\mathrm{O} / \mathrm{S}$ ratio of 100 compared to 4 with $\mathrm{MeCN}$. The optimal conditions were thus defined with $\mathrm{MeCN}, 50^{\circ} \mathrm{C}$ and $\mathrm{O} / \mathrm{S}=4$, reaching $99 \%$ DBT oxidation after $1 \mathrm{~h}$. The recyclability of the $\mathrm{PW}_{12} @ \mathrm{NH}_{2}-\mathrm{MIL}-101(\mathrm{Cr})$ composite was checked, the conversion rate being maintained even after 6 runs. Finally, the authors tested the composite with 4,6-DMDBT and BT, leading to $88.2 \%$ and $70.5 \%$ conversion rates, respectively. The reactivity difference was again assigned to the difference in electron density on the sulfur atoms. More recently, Balula et al. studied the $\mathrm{PMo}_{12} @ \mathrm{NH}_{2}-\mathrm{MIL}-101(\mathrm{Cr})$ composite, ${ }^{71}$ whereby experiments were conducted on a multi-component model oil containing BT, DBT, 4-MDBT and 4,6-DMDBT dissolved in $n$ - 
octane (total sulfur concentration: $2000 \mathrm{ppm}$ ). After addition of $\mathrm{H}_{2} \mathrm{O}_{2}, \mathrm{PMo}_{12} @ \mathrm{NH}_{2}-\mathrm{MIL}-101(\mathrm{Cr})$ exhibited a conversion yield of ca. $85 \%$ after $40 \mathrm{~min}$ and $95 \%$ after $2 \mathrm{~h}$. These conversion yields are comparable to those obtained for the PMo $\mathrm{PM}_{12} @ H K U S T-1$ system studied by Rafiee et al., ${ }^{127}$ the copper system requiring however higher temperature and $\mathrm{O} / \mathrm{S}$ ratio than the chromium one. Lastly, the authors worked on real oil desulfurisation with a 2300 sulfur ppm in a 1:1 (v/v) mixture of MeCN:diesel at 50 ${ }^{\circ} \mathrm{C}$, leading to a $69 \%$ conversion rate. ${ }^{71}$

The immobilization of POMs in the iron-based MOF MIL$100(\mathrm{Fe})$ was also considered for similar catalytic purposes. Wang et al. reported in 2017 the use of a PW $12 @$ MIL-100(Fe) composite for ODS. ${ }^{80}$ Optimising the amount of incorporated POMs, the catalytic activity of $16 w t \% \mathrm{PW}_{12} @ \mathrm{MIL}-100(\mathrm{Fe})$ for the oxidation of DBT was found to be twice as good as that of 7wt\%PW $12 @ M I L-100(\mathrm{Fe})$ (70 and 35\%, respectively after $1 \mathrm{~h}$, $80^{\circ} \mathrm{C}, \mathrm{H}_{2} \mathrm{O}_{2} / \mathrm{DBT}=2$ ). This was explained considering that the higher loading of $\mathrm{PW}_{12}$ in the first composite provided more active sites. However, a further increase in the POM loading up to $35 \mathrm{wt} \%$ led to a decrease in the conversion of the substrate down to $28 \%$. This trend was assigned to the partial blocking of the pores when large amounts of POMs are immobilised into the MOF and again, illustrates the required balance between the number of active sites and the diffusion of the substrate. Also, due to decomposition of $\mathrm{H}_{2} \mathrm{O}_{2}$ at high temperatures, it was shown that the ODS conversion increased with the temperature only up to $70^{\circ} \mathrm{C}$. The yield was also dependent on the oxidant/substrate $(\mathrm{O} / \mathrm{S})$ ratio which was also optimized. Hence, a full conversion was obtained with the 16\% $\mathrm{PW}_{12} @ \mathrm{MIL}-100(\mathrm{Fe})$ catalyst, working at $70^{\circ} \mathrm{C}$ and with a $4: 1 \mathrm{O} / \mathrm{S}$ ratio after $1 \mathrm{~h}$ of reaction. The authors also investigated the encapsulation of $\mathrm{PW}_{12}$ in the UiO-66 zirconium MOF and the Zn-based ZIF-8 MOF in the same paper. ${ }^{80}$ While the activity of $\mathrm{PW}_{12} @ \mathrm{MIL}-100(\mathrm{Fe})$ and PW $12 @ U i O-66$ were similar for the oxidation of DBT, PW12@MIL-100(Fe) exhibited much higher activities than PW $12 @ U i O-66$ for the oxidation of 4,6-DMDBT (93 and 39\%, respectively; see Fig. 34c). This was surprising since control experiments showed that the POM-free MIL-100(Fe) was not active for ODS while the POM-free UiO-66 could act as a catalyst due to the formation of active $\mathrm{Zr}^{\mathrm{IV}}$-peroxo species in presence of $\mathrm{H}_{2} \mathrm{O}_{2} .{ }^{255}$ Using DBT as the substrate, UiO-66 was able to perform ODS with a conversion rate of $60 \%$. The above results could be explained considering the larger size of 4,6DMDBT than that of DBT and the larger windows of MIL-100(Fe) when compared to those of UiO-66. In the case of PW $12 @ U i O-$ 66 , only the POMs deposited at the surface of the material acted as molecular catalysts. All of this was also consistent with PW $12 @ M I L-100(F e)$ being less active than PW $12 @ U i O-66$ for the oxidation of the small BT substrate, which may enter the UiO66 's cavities. The low activity of PW $_{12} @$ ZIF-8 was also ascribed to the very narrow windows of the MOF host. Finally, the recyclability of $\mathrm{PW}_{12} @ \mathrm{MIL}-100(\mathrm{Fe})$ was demonstrated over five cycles.

The UiO-67 Zr-MOF was also considered for encapsulating the $\mathrm{PW}_{12}$ polyanion for ODS applications. ${ }^{102}$ In comparable conditions (however with an O/S ratio of 4 for PW $12 @ U i O-66$ and 12 for PW $12 @ U i O-67)$, PW $_{12} @ U i O-67$ was much more efficient for the oxidation of 4,6-DMDBT (80\%) than PW $12 @ U i O-$ 66 (39\%). ${ }^{80}$ Although a larger amount of oxidant was considered with PW12@UiO-67, this trend confirms that the windows size (ca. $6.0 \AA \varnothing$ for UiO-66 and $8.0 \AA \varnothing$ for UiO-67) plays a key role in the oxidation performances of such large size substrates. The size-matched UiO-67 successfully prevents the leaching of POMs while allowing the accessibility of 4,6-DMDBT. (Fig. 34d). ${ }^{102}$

Zhang et al. combined in 2019 the phosphomolybdic acid $\mathrm{H}_{3} \mathrm{PMoVI}_{12} \mathrm{O}_{40}$ and UiO-66, leading to the $\mathrm{PMo}_{12} @ U i \mathrm{U}-66$ composite. ${ }^{96}$ The material was further activated at temperatures ranging from $\mathrm{T}=100$ to $500^{\circ} \mathrm{C}$, affording the $\mathrm{PMo}_{12} @ U i \mathrm{O}-66-\mathrm{T}$ catalysts where the POM was in a Mov/Movi mixed-valent reduced form. The highest $\mathrm{Mov} / \mathrm{Mov}^{\mathrm{VI}}$ ratio was reached after calcination at $200^{\circ} \mathrm{C}$, with the formation of $\left[\mathrm{PMo}_{4} \mathrm{MOVI}_{8} \mathrm{O}_{40}\right]^{7-}$ blue-colored four-electron reduced species. Supported by an XPS analysis, the reduction of the initially fully oxidised $\left[\mathrm{PMOVV}_{12} \mathrm{O}_{40}\right]^{3-}$ was associated to the formation of oxygen vacancies in the MOF with electrons transferred to the POM via the zirconium centres. Catalytic experiments were performed at $80^{\circ} \mathrm{C}$ with the activated composites in a $500 \mathrm{ppm}$ simulated oil obtained by dissolving DBT in decaline (TBHP as oxidant and an $\mathrm{O} / \mathrm{S}$ ratio of 3 ). The best activity was found for the $\mathrm{PMo}_{12} @$ UiO-66-200 compound with a 100\% DBT conversion obtained after $55 \mathrm{~min}$ (Fig. 35). The high ODS performance of this material compared to that of calcined composites in the $300-500^{\circ} \mathrm{C}$ range was attributed to its highest $\mathrm{Mo} / \mathrm{Mo}^{\mathrm{VI}}$ ratio, whereby $\mathrm{Mo}^{\mathrm{V}}$ centres efficiently react with TBHP to form the HO reactive species involved in the proposed ODS mechanism. The collapse of the framework at high temperatures in POM/UiO-66-T composites result in the loss of surface area and pore volume causing the decline of ODS performances. The crucial role of the HO radical in the catalytic cycle was strongly supported by control experiments performed in presence of a radical scavenger, the ODS activity dropping completely when DMSO was added to the reacting medium.

MOF-808X was also considered for the encapsulation of POMs for ODS purposes. This family of Zr-MOFs possesses large cavities, the size of which can be controlled by tuning the nature of the carboxylates $\mathrm{X}(\mathrm{X}=$ propionate, $\mathrm{P}$; acetate, $\mathrm{A}$ formate, $\mathrm{F}$ ) connected to the metal centres in the $\left[\mathrm{Zr}_{6} \mathrm{O}_{4}\left(\mu_{3}-\mathrm{OH}\right)_{4}(\mathrm{X})_{6}(\mathrm{BTC})_{2}\right]$ oxoclusters. First, Lin et al. prepared PW $12 @$ MOF-808X (X: P, A or $\mathrm{F}$ ) materials with the POM loading varying from ca. 5 to $45 \%$ in weight.115 For PW $12 @ M O F-808 \mathrm{~F}$ and PW $12 @ M O F-808 \mathrm{~A}$ that possess large pore windows compared to the size of DBT, the oxidation of DBT was found to continuously increase with the POM loading, the concentration of active POM sites being the decisive factor for these catalytic systems where the pore windows are large enough for mass transfer. For PW $12 @$ MOF$808 \mathrm{P}$ that possesses pore window sizes close to that of DBT, the catalytic activity is reported to first increase and then decrease with the POM loading with a maximal conversion obtained for $21 \% \mathrm{PW}_{12} @ M O F-808 \mathrm{P}$. Hence, a large number of POMs could significantly slow down the mass transfer of DBT and its oxidative products in this framework. Overall, 42\% $\mathrm{PW}_{12} @ \mathrm{MOF}-$ 808A possessed the highest catalytic activity for DBT ODS. Also the PW $12 @ M O F-808 \mathrm{~A}$ material presented a higher crystallinity 
than the PW12@MOF-808F one, which could explain its higher activity. After optimisation of the catalytic parameters $(\mathrm{O} / \mathrm{S}=5$, $\left.\mathrm{T}=60^{\circ} \mathrm{C}\right), 42 \% \mathrm{PW}_{12} @ \mathrm{MOF}-808 \mathrm{~A}$ fully oxidised DBT after only 30 min for an initial sulfur content of $1000 \mathrm{ppm}$. Interestingly, the authors showed that $42 \% \mathrm{PW}_{12} @ M O F-808 \mathrm{~A}$ was more active than PW $12 @ U i O-67, W_{12} @ M I L-101(F e)$ and PW $12 @ N_{2}-M I L-$ 53(Al). Furthermore, control experiments evidenced that the oxidative activity of 42\% $\mathrm{PW}_{12} @ \mathrm{MOF}-808 \mathrm{~A}$ was higher than that of MOF-808A or $\mathrm{PW}_{12}$ alone or that of their physical mixture. This could be assigned to the uniform dispersion of $\mathrm{PW}_{12}$ into the MOF and to the enrichment of the DBT and $\mathrm{H}_{2} \mathrm{O}_{2}$ concentrations into the pores. Alternatively, a synergistic effect of the MOF-808A host and the encapsulated POMs was claimed whereby the activation of both $\mathrm{W}$ and $\mathrm{Zr}$ centres in the presence of oxygen peroxide could also explain these results. The recyclability of this system was demonstrated over five cycles.
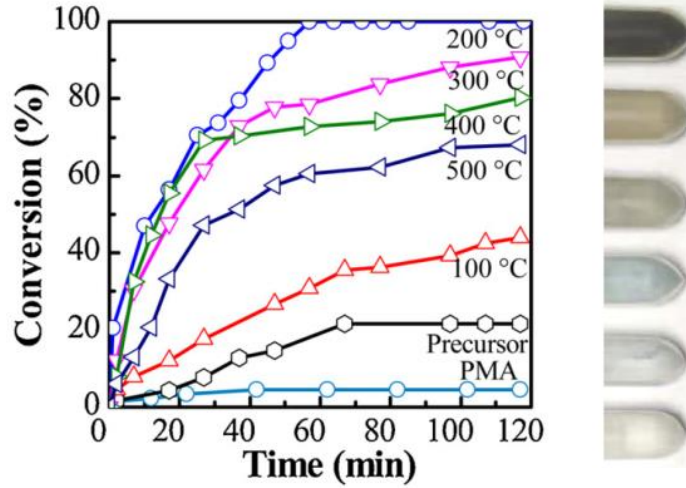

$500^{\circ} \mathrm{C}$

$400^{\circ} \mathrm{C}$

$300^{\circ} \mathrm{C}$

$200^{\circ} \mathrm{C}$

$100^{\circ} \mathrm{C}$

RT

Fig. 35 ODS activities for $\mathrm{PMo}_{12} @ U i O-66$ catalysts calcined at different temperatures $\left(\mathrm{PMA}=\mathrm{PMo}_{12}\right)$ and the photographs of the samples heated at different temperatures. Adapted with permission from ref. ${ }^{96}$. Copyright 2019 Elsevier B.V.

As previously mentioned, Rafiee et al. considered POM@HKUST-1 systems with three different Keggin-type POMs, namely, $\mathrm{H}_{3} \mathrm{PW}_{12} \mathrm{O}_{40}, \mathrm{H}_{3} \mathrm{PMo}_{12} \mathrm{O}_{40}$ and $\mathrm{H}_{3} \mathrm{SiW}_{12} \mathrm{O}_{40}$, for methyl phenyl sulfide (MPS) oxidation. ${ }^{127}$ They showed promising preliminary results with conversion yields after 80 min of ca. 95\% for PMo $12 @ H K U S T-1,90 \%$ for PW $12 @ H K U S T-1$ and SiW $12 @ H K U S T-1 . \mathrm{PMo}_{12} @ H K U S T-1$ was selected to optimise the catalytic conditions, reaching $100 \%$ selectivity for $\mathrm{MPSO}_{2}$ (0.02g POM@MOF, $\mathrm{H}_{2} \mathrm{O}_{2} / \mathrm{MPS}=4,45^{\circ} \mathrm{C}$ ). The oxidation of DBT was also investigated, leading to $100 \%$ selectivity for DBTO $\left(\mathrm{H}_{2} \mathrm{O}_{2} /\right.$ DBT $\left.=4,35^{\circ} \mathrm{C}\right)$. Increasing the $\mathrm{H}_{2} \mathrm{O}_{2} /$ DBT ratio and the temperature led to the formation of $\mathrm{DBTO}_{2}$, with $100 \%$ selectivity for $\mathrm{DBTO}_{2}\left(65^{\circ} \mathrm{C}, \mathrm{H}_{2} \mathrm{O}_{2} / \mathrm{DBT}=6\right)$.

Liu et al. investigated the encapsulation of $\mathrm{PMo}_{10} \mathrm{~V}_{2}$ in the CU-BTC MOF (NENU-9 composite). ${ }^{132}$ Nanocrystals of this material (NENU-9N) were considered, since large size crystals showed limited dispersion in diesel oil together with poor DTB uptakes. The catalytic activities for the oxidation of DBT to $\mathrm{DBTO}_{2}$ of the free POM, NENU-9 composite and NENU-9N nanocomposite were compared $(0.01 \mathrm{mmol}$ catalyst, DBT 0.8 $\mathrm{mmol}$, isobutyraldehyde $8 \mathrm{mmol}$ in decalin $50 \mathrm{~mL}$ at $80^{\circ} \mathrm{C}$ ). The $\mathrm{PMo}_{10} \mathrm{~V}_{2}$ alone showed poor activity with only $2 \%$ conversion after $2 \mathrm{~h}$. The yield increased up to $41 \%$ once it is immobilised in NENU-9 due to improved substrate-catalyst interactions within the porous matrix. Still, NENU-9N achieved $100 \%$ conversion after $2 \mathrm{~h}$ as a result of the shortened diffusion path. Leaching and recyclability tests were conducted showing the system integrity after five catalytic cycles.

In 2020, Wei et al. considered a series of composites based on the Cu-MOF, the rht-MOF-1, also incorporating vanadium substituted phosphomolybdates. ${ }^{137}$ The $\mathrm{PMo}_{11} \mathrm{~V} @ r h t-M O F-1$, $\mathrm{PMo}_{10} \mathrm{~V}_{2} @ r h t-\mathrm{MOF}-1$ and PMog $\mathrm{V}_{3} @ r h t-\mathrm{MOF}-1$ with POM loadings of ca. $27 \mathrm{wt} \%$ were prepared. The catalytic activities of the three materials were compared to the related POMs in homogeneous conditions, showing similar results for BT conversion in the $68-72 \%$ range $\left(T=70^{\circ} \mathrm{C}, \mathrm{O} / \mathrm{S}=12,50 \mathrm{~min}\right)$. Similar results were observed for DBT and 4,6-DMDBT. The authors attributed the slight increase in conversion from $\mathrm{PMo}_{11} \mathrm{~V}$ to $\mathrm{PMo}_{9} \mathrm{~V}_{3}$ species to the increase of reactive oxygen associated with Mo-O-V groups. They also proposed that the substitution of molybdenum with vanadium could turn the acid dominant properties of these species into redox-dominant properties, favouring the oxidation process. In terms of recyclability, the three heterogeneous catalysts displayed a slight decrease in activity after the fourth run which was attributed to the accumulation of sulfone into the pores.

5.1.7.2 Other oxidation reactions of sulfides. The aliphatic sulfides family includes particularly toxic compounds, such as the 1-chloro-2-[(2-chloroethyl)sulfanyl]ethane mustard gas. Fortunately, their activity may decrease upon oxidation to form sulfoxides. Sulfoxides along with sulfones are useful synthetic intermediates for the elaboration of various biologically active molecules such as anti-bacterial, anti-atherosclerotic and antiulcer compounds. While various synthetic methods have been developed for the controlled oxidation of such sulfides, they often use toxic oxidants while leading to toxic wastes. Various systems ranging from metal catalysts to enzymes have been used with $\mathrm{H}_{2} \mathrm{O}_{2}$ as oxidant. ${ }^{256}$ Among them, polyoxometalates have attracted attention for this reaction due to their redox and acidic properties, but also for their low environmental impact ${ }^{257-259}$ with a recent interest for POM@MOF composites as particularly appealing candidates.

In 2011, Song et al. studied the encapsulation of the copperbased Keggin-type $\left[\mathrm{PW}_{11} \mathrm{CuO}_{39}\right]^{5-}$ in the copper-MOF HKUST-1 for mercaptans and hydrogen sulfide oxidation. ${ }^{119}$ $\mathrm{PW}_{11} \mathrm{Cu} @ \mathrm{HKUST}-1$ was found to oxidise $\mathrm{H}_{2} \mathrm{~S}$ into $\mathrm{S}_{8}$, with a TON of 4300 in aqueous solution ( $\mathrm{pH} \mathrm{4.8)}$ after $20 \mathrm{~h}$ under ambient conditions. No formation of $\mathrm{S}_{8}$ was observed in presence of the sole $\left[\mathrm{PW}_{11} \mathrm{CuO}_{39}\right]^{5-}$ or HKUST-1. Strikingly, the immobilization of the POM into the MOF pores was found to greatly stabilise the host, as the POM-free HKUST-1 material dissolved within minutes in the $\mathrm{pH} 4.8$ reaction solution. A synergic effect between the POM and the MOF was also reported in the gas phase. In this case, a low TON of 12 compared to that obtained in aqueous solution was attributed to the clogging of the pores by the oxidation products in such conditions. Control experiments considering the copper-free POM composite, PW $12 @ H K U S T-1$, revealed that the presence of the copper 
centre into the POM was crucial, suggesting that the $3 \mathrm{~d}$ centre was the active site for $\mathrm{H}_{2} \mathrm{~S}$ oxidation. Also, mercaptan oxidative studies performed in chlorobenzene solutions evidenced the high catalytic activity of PW ${ }_{11} \mathrm{Cu} @ H K U S T-1$ for degradation of thiols. A 99\% chemo-selective oxidation was found for all the studied substrates. For instance, propanethiol was oxidised into di- $n$-propyl disulfide selectively, with a TON of $200\left(\mathrm{O}_{2}, 50^{\circ} \mathrm{C}\right.$, chlorobenzene). Again, the synergic effect of the components was demonstrated. Just like ODS studies, steric effects affecting the oxidation process were reported, the conversion yields decreasing with an increase in the number of mercaptan carbon atoms $(95 \%$ and $32 \%$ for 2-hydroxyethanethiol and 1butanethiol, respectively). The integrity of the composite after the catalytic process was checked by FT-IR and PXRD analysis, supporting the robust recyclability of the material.

Farha and co-workers reported the oxidation of 2chloroethyl ethyl sulfide (CEES) - an analogue of the lethal chemical warfare agent mustard gas - to 2-chloroethyl ethyl sulfoxide (CEESO) and 2-chloroethyl ethyl sulfone $\left(\mathrm{CEESO}_{2}\right)$ using the PW $12 @ N U-1000$ catalyst (Fig. 36). ${ }^{110}$ It must be noted that while CEESO is considered as non-toxic, this is not the case for the sulfoxide. Therefore, selectivity is an important issue in this kind of reactions. The composite was activated at $120^{\circ} \mathrm{C}$ prior its characterization. It was shown that the POMs are located in the $12 \AA$ channels, the POM-free 31 A channels being available for substrate diffusion. In this material, both the $\mathrm{PW}_{12}$ and the NU-1000 components acted as catalysts ( $\mathrm{MeCN}, \mathrm{H}_{2} \mathrm{O}_{2}$, $\left.45^{\circ} \mathrm{C}\right)$. Furthermore, the authors evidenced that the $\mathrm{PW}_{12} @ \mathrm{NU}-$ $1000-120^{\circ} \mathrm{C}$ composite possessed a higher activity than that of its individual components, showing a faster initial rate and a higher conversion than the POM or MOF alone (normalising to the sum of the POM and $\mathrm{Zr}_{6}$ nodes; see Fig. 36). ${ }^{111}$ PXRD, DRIFTS and ${ }^{31} \mathrm{P}$ MAS NMR spectroscopy experiments showed the integrity of the material after the catalytic event. Interestingly, when PW $12 @ \mathrm{NU}-1000$ was activated under supercritical $\mathrm{CO}_{2}$ drying, the POMs were located in the $31 \AA$ channels and not in the 12 A ones as observed for $\mathrm{PW}_{12} @ \mathrm{NU}-1000-120^{\circ} \mathrm{C} .{ }^{111}$ It was found that the TOF of PW $12 @ \mathrm{NU}-1000-\mathrm{scCO}_{2}$ was ca. 3 times higher than that of $\mathrm{PW}_{12} @ \mathrm{NU}-1000-120^{\circ} \mathrm{C}$, with a sulfoxide selectivity of $90 \%$ and $59 \%$, respectively. We can note here that while the POM preferentially oxidised the substrate into sulfoxide, the MOF preferentially oxidised it into sulfone. It was thus proposed that the intermediate selectivity of $\mathrm{PW}_{12} @ \mathrm{NU}$ $1000-120^{\circ} \mathrm{C}$ indicated that both the MOF's and POM's active sites were accessible, while the exclusive formation of sulfoxide in $\mathrm{PW}_{12} @ \mathrm{NU}-1000-\mathrm{scCO}_{2}$ indicated that the sulfide readily reacted with $\mathrm{PW}_{12}$ accessible in the mesoporous channels.

Farha and coworkers also investigated the encapsulation of $\mathrm{PW}_{12}$ in the related naphthalene dicarboxylate (NDC) modified NU-1000 MOF (NU-1000-NDC) and in the NU-1008 MOF (NU1008 being a Zr-based MOF with 1,2,4,5-tetrakis(4carboxyphenyl)- 3,6-dibromobenzene linkers) for the same reaction.114 PW $_{12} @ \mathrm{NU}-1000-\mathrm{NDC}$ followed the same catalytic trend than $\mathrm{PW}_{12} @ \mathrm{NU}-1000$, the supercritical $\mathrm{CO}_{2}$ dried sample going to full conversion at the highest rate while the $120^{\circ} \mathrm{C}$ activated sample exhibited a lower activity. Interestingly, the trend was reversed for PW $12 @ \mathrm{NU}-1008, \mathrm{PW}_{12} @ \mathrm{NU}-1008-120^{\circ} \mathrm{C}$ being more active than the $\mathrm{ScCO}_{2}$ analogue. This could be linked to the fact that for this MOF, the POMs remained in the mesopores after heating; in this case, heating the sample to remove water yielded the more active catalyst.

$\mathrm{Li}$ et al. studied in 2018 the incorporation of $\mathrm{H}_{5} \mathrm{PMo}_{10} \mathrm{~V}_{2} \mathrm{O}_{40}$ in MIL-101(Cr) for the oxidation of sulfur mustard. ${ }^{68}$ The catalytic reaction was carried out with the POM-free MIL$101(\mathrm{Cr})(20 \mathrm{mg})$ at ambient temperature with $4 \mu \mathrm{L}$ of sulfur mustard in $40 \mu \mathrm{L}$ of petroleum ether, with ca. $90 \%$ decontamination after $2 \mathrm{~h}$. Materials with different POM loadings were then tested, whereby the higher the POM loading, the better the decontamination yield, with more than 97\% decontamination when using 33.7\%wtPMo ${ }_{10} \mathrm{~V}_{2} @ M I L-$ $101(\mathrm{Cr})$. GC-MS experiments performed with the CEES analogue suggested that the MOF just adsorbed the substrate, while the $\mathrm{PMo}_{10} \mathrm{~V}_{2} @ \mathrm{MIL}-101(\mathrm{Cr})$ material decontaminated CEES by a synergic combination of adsorption by the MOF and oxidation by the POM. Finally, the recyclability of both MIL-101(Cr) and POM@MIL-101(Cr) was assessed, showing a negligible decrease in the activity over four runs.
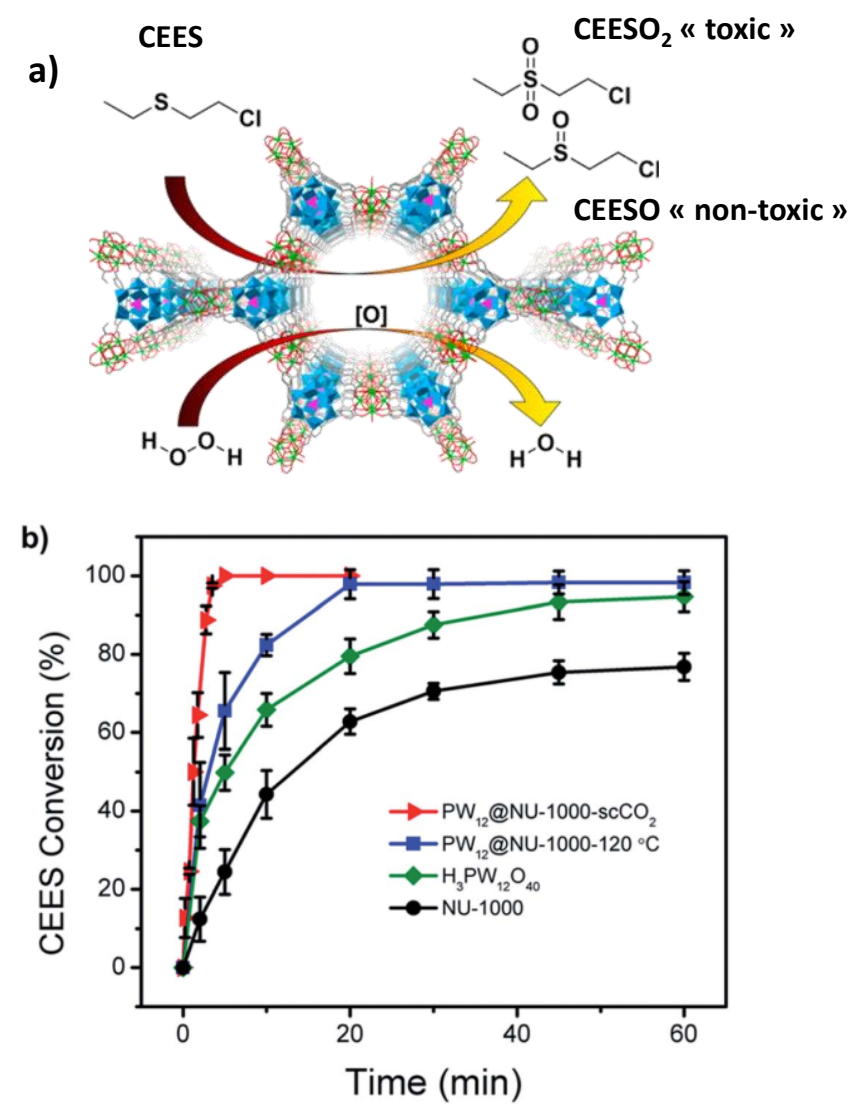

Fig. 36 a) Schematic representation of the reaction pathway for the oxidation of 2 chloroethyl ethyl sulfide (CEES) into 2-chloroethyl ethyl sulfoxide (CEESO) and 2chloroethyl ethyl sulfone $\left(\mathrm{CEESO}_{2}\right)$ with $\mathrm{PW}_{12} @ \mathrm{NU}-1000$ composites. b) Conversion profiles using the catalysts NU-1000 (black), $\mathrm{H}_{3} \mathrm{PW}_{12} \mathrm{O}_{40}$ (green), $\mathrm{PW}_{12} @ \mathrm{NU}-1000-120^{\circ} \mathrm{C}$ (blue) and $\mathrm{PW}_{12} @ \mathrm{NU}-1000-\mathrm{scCO}_{2}$ (red). Adapted with permission from ref. ${ }^{110}$ and ${ }^{111}$. Copyright American Chemical Society. 
Buru et al. compared $\mathrm{PMo}_{12} @ \mathrm{NU}-1000$ and $\mathrm{PMo}_{10} \mathrm{~V}_{2} @ \mathrm{NU}-$ 1000 for CEES oxidation. ${ }^{113}$ As previously observed for PW $12 @ N U-1000$, characterisation of the PMo ${ }_{10} \mathrm{~V}_{2} @ N U-1000$ composite after supercritical $\mathrm{CO}_{2}$ treatment revealed that the POMs are located in the mesopores, while a heating of the material moved the POM from the mesopores to the micropores. CEES oxidation was performed in dark under aerobic condition in cyclohexane at $70^{\circ} \mathrm{C}$ with isobutyraldehyde as the sacrificial reductant. The reaction of $\mathrm{PMoVI}_{10} \mathrm{VV}_{2} \mathrm{O}_{40}$ with dioxygen occurred at the vanadium centres and required its reduction to $\mathrm{PMo} \mathrm{V}_{10} \mathrm{~V}^{\mathrm{IV}} \mathrm{V}^{\mathrm{V}} \mathrm{O}_{40}$. This was supported considering that a full CEES conversion was reached with the $\mathrm{PMo}_{10} \mathrm{~V}_{2} @ \mathrm{NU}$ 1000 catalyst after 30 min while only 5\% CEES conversion was obtained with $\mathrm{PMo}_{12} @ \mathrm{NU}-1000$ in the same conditions. However, the CEES oxidation did not lead to the CEESO sulfoxide but mainly to the toxic $\mathrm{CEESO}_{2}$ sulfone. Importantly, while the $\mathrm{PMo}_{10} \mathrm{~V}_{2} @ \mathrm{NU}-1000$ composite was able to be recycled, achieving full conversion, the pure $\mathrm{PMO}_{10} \mathrm{~V}_{2} \mathrm{POM}$ decomposed in analogous conditions, providing evidence of the superiority of the composite material.

Zhao et al. prepared the $\mathrm{PMo}_{11} \mathrm{~V} @ r h o-Z I F, \mathrm{PMo}_{10} \mathrm{~V}_{2} @ r h o-$ ZIF and PMog${ }_{9} \mathrm{~V}_{3} @ r h o-Z I F$ Zn-based composites for thioether catalytic oxidation. ${ }^{141}$ The catalytic properties and selectivity of the POM and POM@MOF composites were compared for thioanisole oxidation $(0.25 \mathrm{mmol}$ thianisole, $0.45 \mu \mathrm{mol}$ catalyst, $0.3 \mathrm{mmol} \mathrm{H}_{2} \mathrm{O}_{2}$ in $2 \mathrm{~mL}$ of methanol). The POMs displayed great activities (ca. 97\% conversion) but lacked selectivity to sulfoxide $\left(85 \%, 59 \%\right.$ and $51 \%$ for $\mathrm{PMo}_{11} \mathrm{~V}, \mathrm{PMo}_{10} \mathrm{~V}_{2}$ and $\mathrm{PMo}_{9} \mathrm{~V}_{3}$, respectively). The POM@MOF systems exhibited high activities as well, along with higher selectivity, ranging from 93 to $97 \%$. The POM-free rho-ZIF MOF showed only a low conversion yield (22\%). The catalytic conditions were optimised with the $\mathrm{PMo}_{11} \mathrm{~V} @$ rho-ZIF catalyst considering various solvents, oxidant concentrations and reaction times. The nature of the solvent did not affect the conversion yield but greatly impacted the selectivity. Illustratively, $99 \%$ selectivity over sulfoxide $(99 \%$ conversion) was reached in methanol after $12 \mathrm{~h}$ reaction. Various thioethers were studied with $\mathrm{PMo}_{11} \mathrm{~V} @ r$ rho-ZIF as catalyst, with in all cases, good activities and selectivity, even though the bigger the substrate, the lower the activity with only $82.7 \%$ for diphenyl sulfide (Fig. 37). Finally, these systems were recycled at least four times without significant loss of activity, even if a slight decrease in the selectivity was observed after the third run.

Naseri et al. prepared a series of composites by immobilising sandwich-type Keggin anions, namely $\left[\left(\mathrm{HOSn}{ }^{\mathrm{V} O} \mathrm{OH}\right)_{3}\left(\mathrm{XW}_{9} \mathrm{O}_{34}\right)_{2}\right]^{\mathrm{n}-}$ $(\mathrm{X}=\mathrm{P}, \mathrm{n}=12 ; \mathrm{X}=\mathrm{Si}, \mathrm{n}=14),\left[\left(\mathrm{OCe}^{\mathrm{IV}}\right)_{3}\left(\mathrm{PW}_{9} \mathrm{O}_{34}\right)_{2}\right]^{12-}$ and $\left[\mathrm{WM}_{3}\left(\mathrm{H}_{2} \mathrm{O}\right)_{2}\left(\mathrm{MW}_{9} \mathrm{O}_{34}\right)_{2}\right]^{12-}\left(\mathrm{M}=\mathrm{Co}^{\prime \prime}, \mathrm{Zn}^{\prime \prime}\right)$, in $\mathrm{MIL}-101(\mathrm{Cr})$ for the oxidation of diphenylsulfide at room temperature with $\mathrm{H}_{2} \mathrm{O}_{2}$ as oxidant. ${ }^{61}$ While the considered POMs showed almost no activity in homogeneous conditions, the POM-free MIL-101(Cr) displayed some activity, yet far smaller than that of the POM@MIL-101(Cr) materials. Noticeably, $\mathrm{P}_{2} \mathrm{~W}_{18} \mathrm{Sn}_{3} @ \mathrm{MIL}-$ 101(Cr) and $\mathrm{P}_{2} \mathrm{~W}_{18} \mathrm{Ce}_{3} @ \mathrm{MIL}-101(\mathrm{Cr})$ exhibited the highest oxidising activity for the substrate, with a $98 \%$ yield in sulfone (acetonitrile) in 120 and $35 \mathrm{~min}$, respectively. The reaction could be performed in water, however with longer reaction times
(210 min for $\mathrm{P}_{2} \mathrm{~W}_{18} \mathrm{Sn}_{3} @ \mathrm{MIL}-101(\mathrm{Cr}), 98 \%$ in sulfone). In addition, the reaction was sped up by heating at $60^{\circ} \mathrm{C}$. As mentioned above, further heating slowed the reaction due to the decomposition of hydrogen peroxide. For both $\mathrm{P}_{2} \mathrm{~W}_{18} \mathrm{Sn}_{3} @ \mathrm{MIL}-101(\mathrm{Cr})$ and $\mathrm{P}_{2} \mathrm{~W}_{18} \mathrm{Ce}_{3} @ \mathrm{MIL}-101(\mathrm{Cr})$, the study was extended to a whole series of organosulfides, providing in each case high conversions and selectivities. Finally, the reusability of the systems was studied, showing only a slight decrease of the yield after 6 cycles $\left(90 \%\right.$ for $\mathrm{P}_{2} \mathrm{~W}_{18} \mathrm{Ce}_{3} @ \mathrm{MIL}-$ 101(Cr) and 80\% for $\mathrm{P}_{2} \mathrm{~W}_{18} \mathrm{Sn}_{3} @ \mathrm{MIL}-101(\mathrm{Cr})$ ).

\begin{tabular}{|c|c|c|c|}
\hline Entry & Substrate & Conversion (\%) & $\begin{array}{l}\text { Selection for } \\
\text { sulfoxides (\%) }\end{array}$ \\
\hline 1 & & 97.0 & 95.5 \\
\hline 2 & & 92.8 & 84.2 \\
\hline 3 & & 90.4 & 89.5 \\
\hline 4 & & 94.4 & 91.3 \\
\hline 5 & & 82.7 & 89.0 \\
\hline 6 & & 97.1 & 92.0 \\
\hline 7 & & $>99$ & 91.3 \\
\hline
\end{tabular}

Fig. 37 Conversion and selectivity yields for the catalytic oxidation of various thioethers using the $\mathrm{PMo}_{11} \mathrm{~V} @$ rho-ZIF catalyst. Reprinted with permission from ref. ${ }^{141}$. Copyright 2017 American Chemical Society.

5.1.8 Reduction reactions. Very few studies have been dedicated to reduction reactions catalysed by POM@MOF materials, and most of them are performed under photocatalytic conditions (see below). We can however note that Shah et al. encapsulated the $\left[\mathrm{PMo}_{11} \mathrm{Mnn}^{\prime \prime}\left(\mathrm{H}_{2} \mathrm{O}\right) \mathrm{O}_{39}\right]^{5-}$ manganophosphomolybdate in $\mathrm{MIL}-100(\mathrm{Fe})$ for the reduction of p-nitrophenol into p-aminophenol in presence of $\mathrm{NaBH}_{4} .^{86}$ The reaction was followed by UV-Vis spectroscopy, showing that $96 \%$ of p-nitrophenol was reduced after $25 \mathrm{~min}$ in presence of the PMo ${ }_{11} \mathrm{Mn} @ \mathrm{MIL}-101(\mathrm{Fe})$ composite (water, $20^{\circ} \mathrm{C}$ ). No conversion was observed without the addition of catalyst after a period of 2 h. Also, both the POM and the MOF taken separately were found inactive. On a mechanistic point of view, it was proposed that the electron transfer took place from $\mathrm{BH}_{4}$ to the POM, followed by an electron transfer to the $\mathrm{Fe}^{3+}$ Lewis acidic centres of the MOF and the reduction of the substrate in a final step. Still, improvements are needed in order to have POM@MOF composites that compete with the best catalysts reported so far such as the noble-metal incorporating Pd@MIL100 or Pt/MoS 2 NSs materials. ${ }^{86}$

\subsection{Acid and base catalysis}

5.2.1 Acid catalysis. Polyoxometalates in their protonated forms possess a superacidic behavior. ${ }^{260}$ Their molar catalytic activity in organic media can be 100-1000 times higher than that of $\mathrm{H}_{2} \mathrm{SO}_{4}$. Furthermore, they resist to oxidative degradation. They can exhibit both Brønsted and/or Lewis acidic catalytic properties, depending on their chemical composition. ${ }^{261}$ These 
features explain why a very large number of POM@MOF systems have been designed for heterogeneous acid catalysis applications. Above all, materials based on the incorporation of $\mathrm{H}_{3} \mathrm{PW}_{12}$ POMs into MOFs have been widely considered. Polyoxotungstates - and especially the phosphotungstic acid represent indeed candidates of choice for acid catalysis because of their strong acidity and high stability when compared to polyoxomolybdates. ${ }^{262}$

In 2010, Juan-Alcañiz et al. studied the esterification of $n$ butanol with acetic acid in presence of such POM@MIL-101(Cr) catalysts. ${ }^{41}$ TON (3000) and TOF $\left(11 \mathrm{~h}^{-1}\right)$ values were calculated at $\mathrm{T}=110^{\circ} \mathrm{C}$ for the $20 \mathrm{wt} \% \mathrm{PW}_{12},\left\{\mathrm{PW}_{11} \mathrm{Cr}\right\} @ \mathrm{MIL}-101(\mathrm{Cr})$ catalyst prepared by synthetic encapsulation. These values were higher than those previously reported in the literature for POMs immobilised on mesoporous supports under similar reaction conditions. ${ }^{263}$ Interestingly, no significant activity was found when using the related composite prepared by impregnation. The latter case was interpreted considering stronger POM-MOF interactions, whereby the acidity of the POM is reduced. Alternatively, this could be attributed to the different nature of the POMs in the composite (i.e. different $\mathrm{PW}_{12} / \mathrm{PW}{ }_{11} \mathrm{Cr}$ ratios, this last species being formed in larger amount when the composite is prepared in one-step). The acid catalysis activity of the material prepared in one-step was also evidenced via the study of the dehydration of methanol to dimethyl ether in the gas phase.

The dehydration of carbohydrates was also considered. Zhang et al. showed that the one-step prepared 33.8wt\%PW $12 @ M I L-101(\mathrm{Cr})$ catalyst allowed forming 5hydroxymethylfurfural (HMF) from fructose with a $63 \%$ yield and a $77 \%$ selectivity $\left(130^{\circ} \mathrm{C}, 30 \mathrm{~min}\right.$, DMSO) (Fig. 38$) .42$ By contrast, the POM-free MIL-101(Cr) framework did not show any significant activity despite the presence of chromium Lewis acid centres, corroborating that the catalytic activity of the composite was due to the Brønsted acidity of the encapsulated phosphotungstic acid. ICP measurements indicated that only few tungsten $(0.2 \%)$ and chromium (0.4\%) leached out from the 33.8wt\%PW $12 @ M I L-101(\mathrm{Cr})$ catalyst upon the first reaction cycle. The 5-hydroxymethylfurfural yield and selectivity decreased somewhat in the consecutive runs $(47 \%$ yield and $58 \%$ selectivity after the third run).

Bromberg et al. proposed the use of PW $12 @ M I L-101(\mathrm{Cr})$ for the Baeyer condensation of volatile aldehydes. ${ }^{43}$ The targeted reactions are the acetaldehyde phenol and benzaldehyde methanol condensations known to be catalysed by strong acids in homogeneous conditions. Materials were synthesised via two methods, i.e. encapsulation synthesis and post-synthetic impregnation. Both methods led to similar 31wt\%PW $12 @ M I L-$ 101(Cr) materials. In an acetaldehyde vapour-saturated desiccator, uptake of acetaldehyde by the $\mathrm{PW}_{12}$-doped materials was more than 4 times higher than that with the POM-free MOF. After two days at room temperature $97 \%$ of the acetaldehyde was converted. With the same catalysts, the exothermic acetaldehyde phenol condensation was conducted at room temperature and studied by ${ }^{1} \mathrm{H}$ NMR. Deuterated tetrahydrofuran was used both as solvent and NMR lock. A conversion of $50 \%$ of the initial acetaldehyde was reached after
$30 \mathrm{~min}$, a complete conversion within 5 days. Finally, benzaldehyde acetalisation was studied showing a $95 \%$ conversion within $24 \mathrm{~h}$ with the POM@MOF composite, while the POM-free MIL-101(Cr) lead to $80 \%$ conversion within the same span of time. In both studied reactions, the PW $12 @ \mathrm{MIL}-$ $101(\mathrm{Cr})$ composite was shown to be more efficient than the POM-free material. Elemental analysis evidenced a leaching of 3-5 wt\% of $\mathrm{PW}_{12}$ after 4 catalytic cycles for the acetaldehyde phenol condensation.
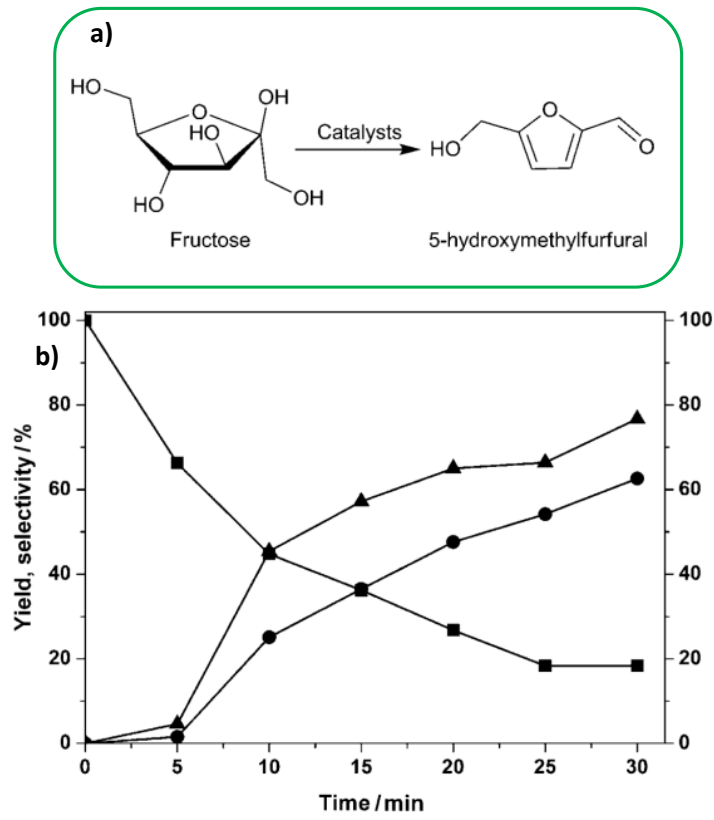

Fig. 38 a) Production of 5-hydroxymethylfurfural through dehydration of fructose. b) Yields and selectivities over time for fructose dehydration using 33.8wt\%PW $12 @$ MIL$101(\mathrm{Cr})$ in DMSO at $130^{\circ} \mathrm{C}$; - fructose retention, - HMF yield, $\Delta$ HMF selectivity. Adapted with permission from ref. ${ }^{42}$. Copyright 2013 Wiley-VCH Verlag GmbH \& Co, KGaA, Weinheim.

Khder et al. synthesised PW 12 @MIL-101(Cr) materials with high POM loadings (50-70-90 wt \%) via post-synthetic impregnation. ${ }^{47}$ The surface acidity sampled by potentiometric titration increased with the POM loading in 50wt\% and 70wt\%PW $12 @ M I L-101(\mathrm{Cr})$ samples, however decreased in 90wt\%PW $12 @ M I L-101(\mathrm{Cr})$, allegedly due to the aggregation of $\mathrm{PW}_{12}$ crystals on the MIL-101(Cr) surface in this last case. Also, in contrast with 90wt\%PW $12 @ M I L-101(\mathrm{Cr}), 50 w t \% \mathrm{PW}_{12} @ \mathrm{MIL}-$ 101(Cr) and 70wt\%PW12@MIL-101(Cr) composites remained highly porous, with a good dispersion of the POM into the MOF. These materials were studied as catalysts for three targeted solvent-free reactions, i.e. Pechmann reaction, esterification reaction and Friedel-Crafts acylation reaction. In the three cases, the reactants were magnetically stirred and heated at $120^{\circ} \mathrm{C}$ before addition of $0.05 \mathrm{~g}$ of catalyst. The reactions were conducted for $1 \mathrm{~h}$ before filtration and analysis of the products by GC-MS. While the POM-free MOF showed little catalytic activity, 70wt\%PW $12 @ M I L-101(\mathrm{Cr})$ possessed the best POM loading for the three reactions. The authors evidenced that even at such high loading the POMs are well dispersed in the MOF. In the case of the Pechmann and Friedel-Crafts reactions, no significant decrease in the activity for the selected 
70wt\%PW $12 @ M I L-101(\mathrm{Cr})$ was observed after four consecutive runs. For esterification, the yield decreased from $92.3 \%$ to 80.1\% after four runs.

To overcome selectivity issues in the self-condensation of

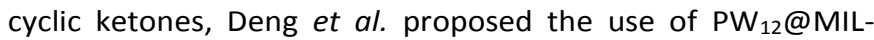
101(Cr) and PW $12 @ M I L-100(M)(M=C r, F e)$ as catalysts with variable amount of $\mathrm{PW}_{12} .{ }^{48}$ The authors showed that the optimal amount of $\mathrm{PW}_{12}$ (ranging from $0 \mathrm{wt} \%$ to $42.7 \mathrm{wt} \%$ inside MIL-101(Cr)) decreased as the size of the reactants increased, showing a correlation between the size of the pores and the selectivity. For the self-condensation of cyclopentanone, the targeted 2-cyclopentylidenecyclopentanone product was obtained with a selectivity $>98 \%$ when using 42.7wt\%PW $12 @ M I L-101(\mathrm{Cr})\left(130^{\circ} \mathrm{C}, 48 \mathrm{~h}\right.$, no solvent, $\mathrm{N}_{2}$ atmosphere) (Fig. 39). For comparison, the POM-free MIL$101(\mathrm{Cr})$ exhibited a selectivity of $20 \%$. In addition, the authors showed that the POM-free MIL-100(M) and PW $12 @ M I L-100(M)$ synthesized using $\mathrm{Fe}$ and $\mathrm{Cr}$ ions show very similar conversions and selectivities, indicating that the catalytic activity is driven by the MOF cages size and the acidity of POM rather than by the nature of the $M$ centres. Upon recovery of the catalyst, there was a negligible amount of POM leaching $\left(7.4 \times 10^{-4} \mathrm{~g}\right.$ per gram of catalyst). Five consecutive runs for the cyclopentanone selfcondensation did not affect the performances of the 42.7wt\%PW $12 @ M I L-101(\mathrm{Cr})$ catalyst, keeping its selectivity above $98 \%$.

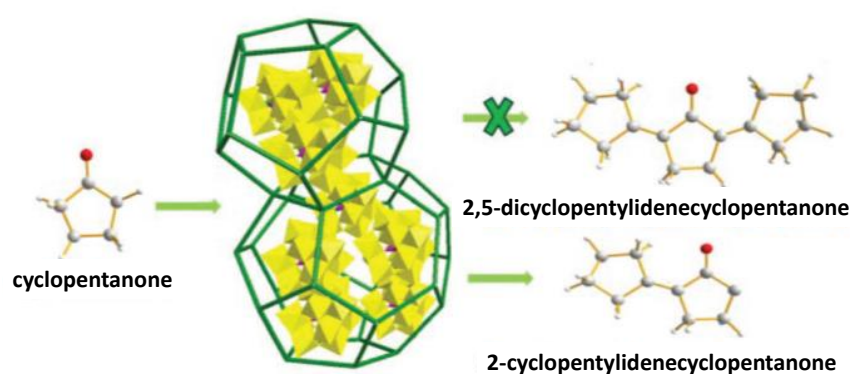

Fig. 39 Selective synthesis of 2-cyclopentylidenecyclopentanone via shape-selectivity in a MOF cage. Adapted from ref. ${ }^{48}$ with the permission from the RSC.

The hydroxyalkylation of phenol with formaldehyde into bisphenol F by PW $12 @ M I L$ materials was investigated.49 First, it was shown that the POM-free MIL-100(M) and MIL-101(M) (M $=\mathrm{Cr}, \mathrm{Fe}$ ) did not have any significant activity for such a reaction. The POM@MIL materials were then prepared, and the amount of incorporated $\mathrm{PW}_{12}$ optimised for the catalytic purpose. 18wt\%PW $12 @ M I L-100(\mathrm{Fe})$ was found to be the most active composite, with a yield in bisphenol $\mathrm{F}$ (BPF) of $71 \%$ after $1 \mathrm{~h}$ (95\% selectivity) and an isomer distribution of 18,51 and 31 for the $4,4^{\prime}-, 2,4^{\prime}-$ and $2,2^{\prime}-$ isomers, respectively $\left(80^{\circ} \mathrm{C}\right.$, phenol:formaldehyde molar ratio 30:1). The yield was further increased after $8 \mathrm{~h}$ (92\%), with only a slight decrease in the selectivity (93\%). A mechanistic pathway was proposed (Fig. 40). First, a hydroxymethyl carbocation is formed by protonation of the formaldehyde by the POM, with the release of a water molecule. Second, the carbocation attacks a carbon of the phenol to form a new resonance-stabilised carbocation.
Third, the p-hydroxybenzyl alcohol is formed after a proton transfer to the catalyst. Fourth, the hydroxymethyl abstracts a proton from the POM to form the hydroxybenzyl carbocation. Finally, this carbocation attacks a carbon of a second phenol, forming the bisphenol $\mathrm{F}$ product, with a regeneration of the catalyst. ${ }^{49}$ Interestingly, the nature of the metal structuring the framework was shown to play here a crucial role on the distribution of isomers, the $\mathrm{Fe}$ - and $\mathrm{Cr}$-based MOFs favouring the formation of the $2,4^{\prime}$ - and $4,4^{\prime}$-isomers, respectively. The recyclability was tested over six runs, showing a decrease of the yield from 71 to $53 \%$ ( $1 \mathrm{~h}$ reaction).

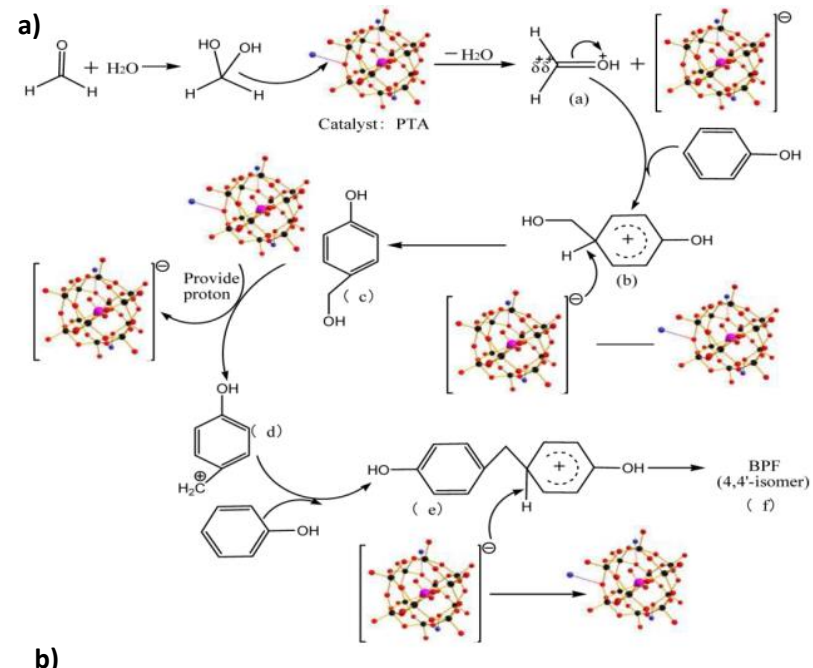

b)

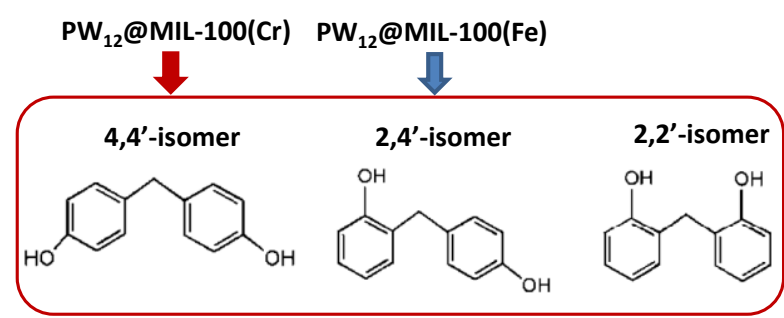

Fig. 40 a) Proposed mechanism for the hydroxyalkylation of phenol and formaldehyde into bisphenol F (based on the 4,4'-isomer) for the PW $12 @ \mathrm{MIL}-100$ (M) ( $\mathrm{M}=\mathrm{Cr}, \mathrm{Fe}$ ) catalysts. b) a) Formula of the three bisphenol $\mathrm{F}$ isomers. Reprinted with permission from ref. ${ }^{49}$. Copyright 2015 American Chemical Society.

The Biginelli condensation reaction (Scheme 5$)$ between benzaldehyde $(1 \mathrm{mmol})$, ethylacetoacetate $(1 \mathrm{mmol})$ and urea (1.5 mmol) was carried out using PW $12 @ M I L-101(\mathrm{Cr})$ materials prepared via the impregnation method. ${ }^{50}$ Under solvent free conditions at $100^{\circ} \mathrm{C}$, the $10 \mathrm{wt} \% \mathrm{PW}_{12} @ \mathrm{MIL}-101(\mathrm{Cr})$ catalyst afforded the desired product with a yield based on benzaldehyde of $90 \%$ after $1 \mathrm{~h}$. The study was extended to fourteen different substituted aromatic aldehydes with electron withdrawing or releasing substituents on the phenyl ring, showing that the catalyst was efficient for the whole series with yields ranging from 75 to $85 \%(t=1-3 \mathrm{~h})$. It was proposed that the reaction first proceeded by the formation of the imine from aldehyde and urea, followed by the addition of the enol tautomer of the 1,3-dicarbonyl compound to the imine. In the final step, the cyclodehydration of the ureide affords the corresponding dihydropyrimidin-2(1H)-one. The PW $12 @ M I L-$ $101(\mathrm{Cr})$ catalyst acted as a proton source, allowing the 
enolization of the 1,3-dicarbonyl compound and dehydrating the ureide.

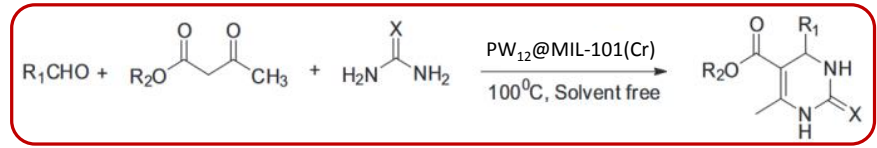

Scheme 5 The Biginelli condensation reaction catalysed by PW $12 @ M I L-101(\mathrm{Cr})$. Adapted with permission from ref. ${ }^{50}$. Copyright 2015 Elsevier B.V.

The 32wt\%PW $12 @ \mathrm{NH}_{2}-\mathrm{MIL}-101(\mathrm{Al})$ and 29wt\%PW $12 @ \mathrm{NH}_{2}-$ MIL-53(Al) materials prepared by impregnation of the aminoMOFs were considered for acid catalysis. ${ }^{76}$ Interestingly, it was shown that the equilibrium uptake of acetaldehyde from its saturated vapour phase was much higher for the POM-based composites than for the POM-free ones, with 600 and 50 wt\% uptakes at $25^{\circ} \mathrm{C}$, respectively. Such exceptional acetaldehyde vapour uptake was correlated to vapour condensation and pore-filling. It was associated to the simultaneous conversion of acetaldehyde to much less volatile polymeric compounds resulting from repeated aldol condensation (Scheme 6), the heteropolyacid acting as a catalyst. The activity of 32wt\%PW $12 @ \mathrm{NH}_{2}-\mathrm{MIL}-101(\mathrm{Al})$ in liquid phase was also investigated. The composite catalysed the conversion of acetaldehyde into crotonaldehyde $\left(25^{\circ} \mathrm{C}\right.$, water/acetonitrile 30:70) through the Mannich pathway or via aldol condensation, with a fast kinetic $\left(\mathrm{t}_{1 / 2}=3.2 \mathrm{~h}\right.$, i.e. $5-10$ fold shorter than those obtained in water catalysed by amino-acids or $80 \mathrm{wt} \%$ sulfuric acid). No significant loss of activity was observed after three runs.

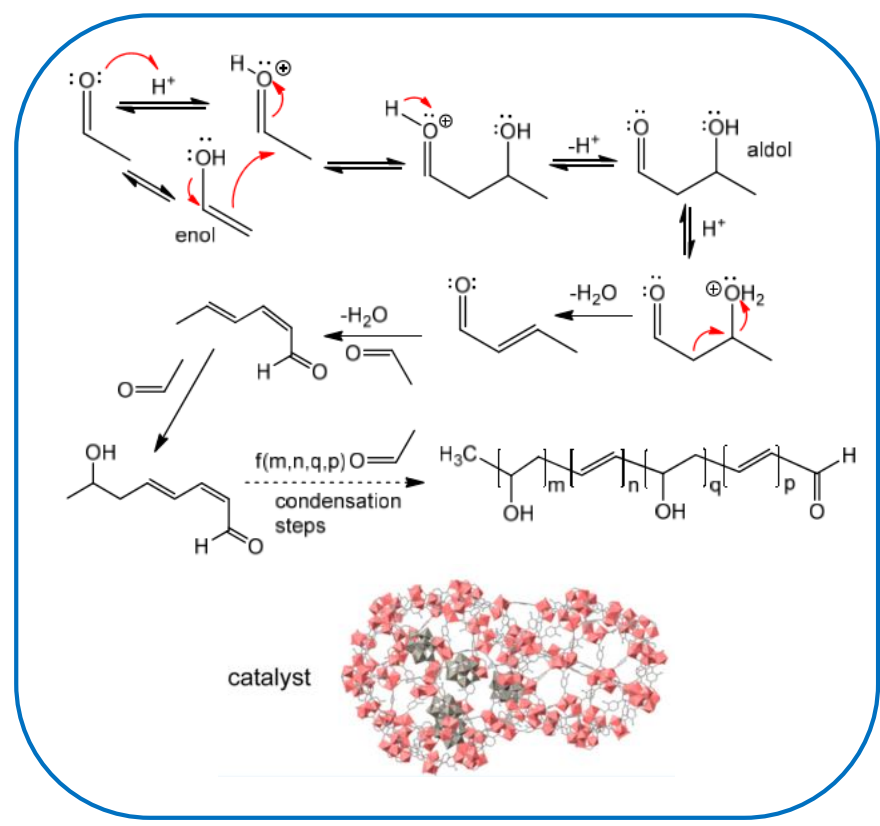

Scheme 6 Mechanism of repeated acid-catalysed aldol condensation of acetaldehyde with the $\mathrm{PW}_{12} @ \mathrm{NH}_{2}-\mathrm{MIL}-101$ (Al) catalyst. Adapted with permission from ref. ${ }^{76}$ Copyright 2013 American Chemical Society.

The conversion of ethanol into ethylene and/or diethyl ether was investigated using PW $12 @$ Basolite $^{\mathrm{TM}} \mathrm{F}-300$ as catalyst. The Basolite ${ }^{\mathrm{TM}} \mathrm{F}-300$ commercial MOF studied by Micek-Ilnicka et al. possessed a structure analogous to MIL-100(Fe). ${ }^{78}$ The conversion yield increased with the temperature and the $\mathrm{PW}_{12}$ loading. Concerning the selectivity, diethyl ether was selectively formed in the $90-130^{\circ} \mathrm{C}$ temperature range, while, the selectivity to ethylene increased from 130 to $200^{\circ} \mathrm{C}$, reaching $90 \%$ at the highest temperature for 80wt\%PW $12 @$ Basolite ${ }^{\mathrm{TM}} \mathrm{F}-300$ (Fig. 41). Interestingly, two maxima were found for the diethyl ether yield vs temperature curves for 50wt\%PW $12 @$ Basolite $^{\mathrm{TM}} \mathrm{F}-300$, at ca. 130 and $170^{\circ} \mathrm{C}$ (Fig. 41). The location of the POM on the external or internal surfaces of the MOF may be responsible for the occurrence of these low and high temperature maxima, respectively. For the 80wt\%PW12@Basolite ${ }^{\mathrm{TM}} \mathrm{F}-300$ sample, only one maximum was observed at ca. $130^{\circ} \mathrm{C}$ suggesting that - for this high POMloading composite - mainly the POM located on the external surface of the MOF acted as catalyst. This is consistent with the fact that the catalytic properties for 80wt\%PW $12 @$ Basolite ${ }^{\mathrm{TM}} \mathrm{F}$ 300 and the pure $\mathrm{PW}_{12}$ POM were comparable. No POM leaching experiment was however reported.

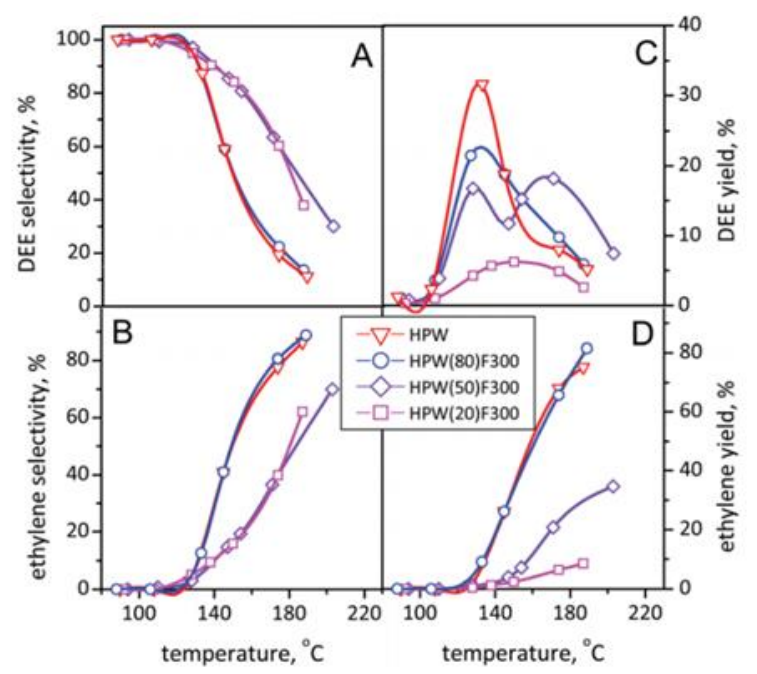

Fig. 41 Diethylether and ethylene formation from ethanol using 20wt\%PW $12 @$ Basolite ${ }^{\mathrm{TM}} \mathrm{F}-300 \quad$ (HPW(20)F300), 50wt\%PW $12 @$ Basolite $^{\mathrm{TM} F-300}$ (HPW(50)F300), 80wt\%PW $12 @$ Basolite TMF-300 (HPW(80)F300) and PW 12 (HPW). (A, B) Selectivities to diethylether and ethylene, (C, D) diethylether and ethylene yields. Reprinted from ref. ${ }^{78}$ with permission from the RSC.

The one-pot prepared PW $12 @ M I L-100(\mathrm{Fe})$ system was studied by Zhang et al. as acid catalyst for esterification and acetalisation reactions in liquid solution. ${ }^{79}$ Esterification of $n$ hexanol with acetic acid afforded only $n$-hexyl acetate, with conversion yields of 96\% (23wt\%PW $12 @ M I L-100(\mathrm{Fe})), 78 \%$ (MIL-100(Fe)), 88\% $\left(\mathrm{PW}_{12}\right)$ and $89 \%$ (for a mixture of $\mathrm{PW}_{12}$ and MIL-100(Fe) $\left(110^{\circ} \mathrm{C}, 12 \mathrm{~h}\right)$. The higher activity of 23wt\%PW12@MIL-100(Fe) was assigned to the accumulation of the reactants inside the MOF pores. The temperature was a crucial parameter: the conversion yield was only of $50 \%$ at $70^{\circ} \mathrm{C}$ considering 23wt\%PW $12 @ M I L-100(F e)$ as the catalyst. The reusability of the catalyst was demonstrated as the conversion yield remained constant after five cycles. The study was extended to other monohydric alcohols with different chain lengths. The yield in formed ester decreased when the chain 
length increased, in agreement with an esterification reaction occurring within the MOF's pores. Benzaldehyde glycol acetal was obtained with conversion yields of 98\% (23wt\%PW $12 @ M I L-$ 100(Fe)), 85\% (MIL-100(Fe)), 92\% (PW $\mathrm{PW}_{12}$ ) and 94\% (for a mixture of $\mathrm{PW}_{12}$ and $\mathrm{MIL}-100(\mathrm{Fe})\left(80{ }^{\circ} \mathrm{C}, 120 \mathrm{~min}\right)$, showing a slight beneficial effect of combining POM and MOF.

After electing MIL-100(Fe) over HKUST-1 as the best material for immobilising the porcine pancreatic lipase, Nobakht et al. explored the use of PW12@MIL-100(Fe) as a support composite. ${ }^{81}$ The enzyme was post-synthetically immobilised on both MIL-100(Fe) and PW $12 @ M I L-100(F e)$ for comparison. The authors showed not only that the immobilization of the lipase improved its thermal, $\mathrm{pH}$ and operational stabilities but also that the addition of the POM increased its catalytic activity for the synthesis of benzyl cinnamate. After 5 successive catalytic cycles, the enzyme kept $90.4 \%$ of its initial activity.

Wan et al. explored the combination of PW 12, MIL-100(Fe) and Ionic Liquids (IL) for the esterification of oleic acid. ${ }^{82}$ The synthesis of PW12@MIL-100(Fe) was performed by synthetic encapsulation and was then followed by the addition of sulfonic acid groupfunctionalised IL via the anion-exchange method, the final composite exhibiting both Lewis and Brönsted acid sites. For the esterification of oleic acid with ethanol, these features allowed an excellent conversion yield (94.6\%). The conversion yields determined with MIL-100(Fe) (15.5\%), PW $12 @ M I L-100(F e) ~(40.3 \%)$ and IL@MIL$100(\mathrm{Fe})(90.2 \%)$ catalysts provided evidence for the synergic effect of the three-party POM-MOF-IL combination. Reusability of the catalyst was assessed, whereby it was still stable after 6 runs showing no observable leaching of the encapsulated species, contrasting with the IL@MOF material which degraded. These results highlighted the stabilizing role of the POM, a feature we will encounter also later in this section.

Considering $\mathrm{Zr}$-based MOFs, we can note that the acidolysis of soybean oil for the production of low-calorie structured lipids has been studied employing a material mixing the $\mathrm{Cs}_{2.5} \mathrm{H}_{0.5} \mathrm{PW}_{12}$ POM and the UiO-66 MOF. ${ }^{92}$ In presence of this catalyst $\left(150^{\circ} \mathrm{C}, 10 \mathrm{~h}\right)$, the medium chain fatty acids content increased significantly in the acidolysis products whereas the unsaturated fatty acids were greatly reduced. The reusability of the catalyst was relatively good, with a slight decrease of the catalytic activity after five runs.

Zhang et al. encapsulated another Keggin POM, SiW 12 , inside UiO-66. ${ }^{94}$ This material was used as a solid acidic catalyst for lauric acid esterification with methanol. The first conversion results were $80.5 \%\left(160^{\circ} \mathrm{C}, 1: 20\right.$ lauric acid:methanol molar ratio, $7 w t \%$ catalyst, $4 \mathrm{~h}$ ). After optimisation using Response Surface Methodology, the conversion rate reached a maximum of $92.8 \%\left(170^{\circ} \mathrm{C}, 1: 20\right.$ lauric acid:methanol molar ratio, $11 \mathrm{wt} \%$ catalyst, $5 \mathrm{~h})$, competing with previously published heterogeneous catalysts. ${ }^{94}$ The importance of the polyanion was also demonstrated in the recyclability experiments. Indeed, after 6 runs the SiW $12 @$ UiO-66 composite material showed only a slight decrease of catalytic activity while the POM-free MOF activity drastically dropped. The same authors explored another esterification reaction using a slightly modified catalyst. Instead of using $\mathrm{SiW}_{12}$, they studied the $\mathrm{Zr}$-doped version of the polysilicotungstic acid encapsulated in UiO-66 or in Fe-BTC for comparison. ${ }^{95}$ After in situ synthesis of the related ZrSiW@UiO66 and ZrSiW@Fe-BTC nanomaterials, esterification of oleic acid with methanol was tested considering various parameters (oleic acid:methanol molar ratio, temperature, synthesis time, catalyst loading). They concluded about the superiority of ZrSiW@UiO-66 over the Fe-BTC counterpart, with optimised conditions for $1: 20$ oleic acid:methanol molar ratio, $\mathrm{T}=150^{\circ} \mathrm{C}, 4$ $\mathrm{h}$ and $0.24 \mathrm{~g}$ of catalyst, reaching an optimal conversion rate of $98 \%$. After 3 catalytic cycles, the conversion rate started to drop to reach $89 \%$ after 6 runs. Xie et al. went one step further by introducing additional sulfonic acid group-functionalised IL by post-synthetic anion exchange after the in situ synthesis of POM@UiO-66-2COOH $\left(\mathrm{POM}=\mathrm{PW}_{12}, \quad \mathrm{SiW}_{12}, \mathrm{PMo}_{12}\right) .{ }^{99}$ As mentioned above, the combination of the three POM-MOF-IL components allowed excellent conversion rate for the targeted esterification and transesterification reactions. The conversion rates for soya bean oil esterification ranged from $92.8 \%$ to $95.2 \%$ for the POM@UiO-66-2COOH/IL $\left(110^{\circ} \mathrm{C}, 1: 35\right.$ oil:methanol ratio, $6 \mathrm{~h}, 10 \mathrm{wt} \%$ catalyst), much above the POM@UiO-66-2COOH (23.6-30.1\% conversion) or the POMfree MOF (8.4\% conversion). Also, the authors correlate the increase in conversion with the increase of the POM acidity, notwithstanding the presence of IL. Finally, the stabilising role of POM was once again critical since the recyclability of the POM-free material dropped drastically after 5 runs (Fig. 42).

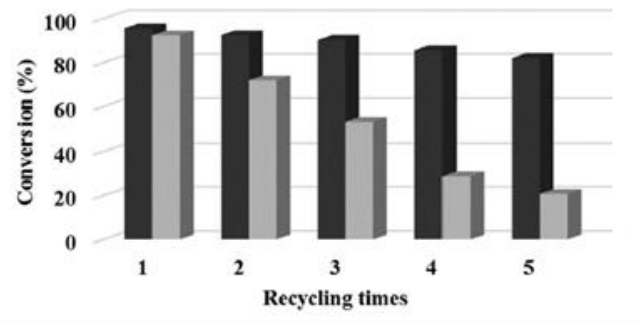

Fig. 42 Recycling tests for PW $12 @ U i O-66-2 \mathrm{COOH} / \mathrm{IL}$ (black) and UiO-66-2COOH/IL (grey), highlighting the stabilising effect of the POM. Reprinted with permission from ref. ${ }^{99}$. Copyright 2019 Elsevier B.V.

The Zr-based PW $12 @ N U-1000$ composite was prepared and used as catalyst for the isomerisation/disproportionation of $o$ xylene (Scheme 7)..$^{112}$ Interestingly, the stability of the composite - which is of primarily importance for its use in harsh conditions such as those considered for C-C skeletal rearrangement reactions - was highly dependent on the amount of POM incorporated into the MOF framework. A high $\mathrm{PW}_{12}$ loading (ca. one POM by unit cell of NU-1000, corresponding to $45 \mathrm{wt} \%$ ) was required, as materials with a lower loading lost their structural integrity under the catalytic conditions $\left(250^{\circ} \mathrm{C}\right)$. The highly stable 45wt\%PW $12 @ N U-1000$ catalyst was found to be active toward the transmethylation pathway, which requires two adjacent active sites in a confined pore, as created when POMs are confined in NU-1000 at such a high loading. Selectivities of $17 \%$ for the isomerisation process ( $\mathrm{m}$ - and $\mathrm{p}$-xylene) and $83 \%$ for the disproportionation process (toluene and trimethylbenzene) were determined ( $t=240 \mathrm{~min}$ ). In comparison, the $\mathrm{WO}_{\mathrm{x}}-\mathrm{ZrO}_{2}(16.5 \mathrm{wt} \% \mathrm{~W})$ material exhibited a 
$100 \%$ selectivity toward the isomerisation pathway under the same experimental conditions.

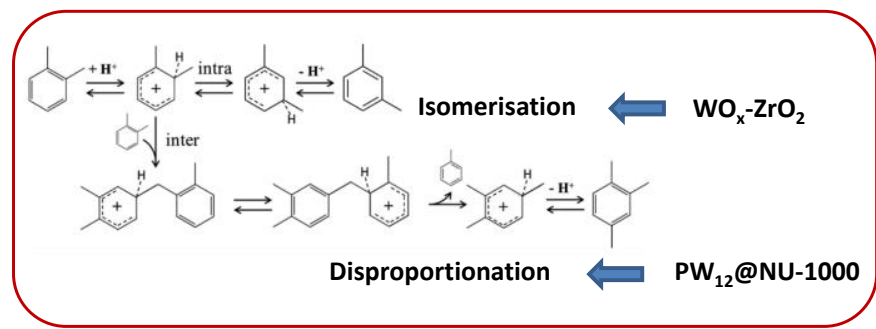

Scheme 7 o-xylene reaction pathways: intramolecular isomerisation, observed with the $\mathrm{WO}_{\mathrm{x}}-\mathrm{ZrO}_{2}$ reference compound and intermolecular disproportionation, favored with the $\mathrm{PW}_{12} @ \mathrm{NU}-1000$ composite catalyst. Adapted with permission from ref. ${ }^{112}$. Copyright 2018 American Chemical Society.

Concerning copper-containing matrices, Zhu et al. used POMs immobilised in HKUST-1 to selectively synthesise ester from glycerol $\left(40^{\circ} \mathrm{C}, \mathrm{H}_{2} \mathrm{O}_{2}, \mathrm{H}_{2} \mathrm{O}\right) .117$ Varying the nature of the $\mathrm{POM}$, they encapsulated via in situ process $\mathrm{H}_{3} \mathrm{PW}_{12} \mathrm{O}_{40}$, $\mathrm{H}_{3} \mathrm{PMO}_{12} \mathrm{O}_{40}, \mathrm{H}_{4} \mathrm{PVMo}_{11} \mathrm{O}_{40}, \mathrm{H}_{5} \mathrm{PV}_{2} \mathrm{Mo}_{10} \mathrm{O}_{40}$ and $\mathrm{H}_{6} \mathrm{PV}_{3} \mathrm{Mo}_{9} \mathrm{O}_{40}$ inside HKUST-1. The best selectivity toward ester formation was obtained with the PW $12 @ H K U S T-1$ catalyst (35\%). The authors further elected this material to test its reusability, however showing a significant decrease in selectivity and conversion after 5 cycles. Sun et al. characterised the 47wt\%PW 12 @HKUST1 material (NENU-3) and used it in ester hydrolysis reactions. ${ }^{121}$ This compound contained water molecules and tetramethyl ammonium cations which could be evacuated by a thermal treatment at $200^{\circ} \mathrm{C}$. This afforded the NENU-3a composite with three acidic protons per POM compared to one for NENU-3. The hydrolysis of ethyl acetate in an excess of water was performed at $60^{\circ} \mathrm{C}$. A conversion yield of $95 \%$ was observed for NENU-3a after $7 \mathrm{~h}$, i.e. approximately four-times the yield observed for NENU-3. It was also shown that the catalytic activity of NENU3a after $2 \mathrm{~h}$ was 3 to 7 times higher than those of $\mathrm{H}_{2} \mathrm{SO}_{4}$, $\mathrm{H}_{3} \mathrm{PW}_{12} \mathrm{O}_{40}, \mathrm{SO}_{4}{ }^{2-} / \mathrm{ZrO}_{2}$, Nafion- $\mathrm{H}$, and Amberlyst-15. Substrates with increasing dimensions were also tested. In brief, while similar conversion of methyl acetate and ethyl acetate molecules were found with NENU-3a (ca. 64\% after $5 \mathrm{~h}$ ), the conversion of the bulky, aromatic ethyl benzoate ( $17 \%$ after $5 \mathrm{~h}$ ) was much lower (Fig. 43). It was thus again proposed that the reactants with small sizes and high hydrophilicity quickly diffused through the pores, where the reaction took place, while substrates with larger sizes and higher hydrophobicity could adsorb onto the surface of the pores, slowing the conversion. The recyclability is shown over 15 cycles, the solution being completely inactive upon removal of the catalyst, evidencing that the process was genuinely heterogeneous.

Liu et al. proposed using the same catalyst, NENU-3a, for the esterification of acetic acid with various alcohols. ${ }^{128}$ Their final goal was biodiesel production with large fatty acid (lauric acid, myristic acid, palmitic acid and stearic acid). NENU-3a was synthesised with two different crystal topologies: octahedral (oNENU-3a) and cubic (c-NENU-3a). This feature changed drastically the catalytic performances. Indeed, c-NENU-3a displayed excellent conversion rates for the 14 studied reactions ( $83 \leq$ yield $<99 \%$ ) while the octahedral version was much less efficient ( $17 \leq$ yield $\leq 90 \%$ ). This behaviour was explained through the study of the surface topologies of the catalysts. Carefully examining the porous environment of the POM, the authors highlighted key differences between the cubic and octahedral morphology: in the case of the octahedral shape, the distribution of the polyanion in the pores limited the contact between the reactants and the catalyst while it was maximised in the case of the cubic particles.

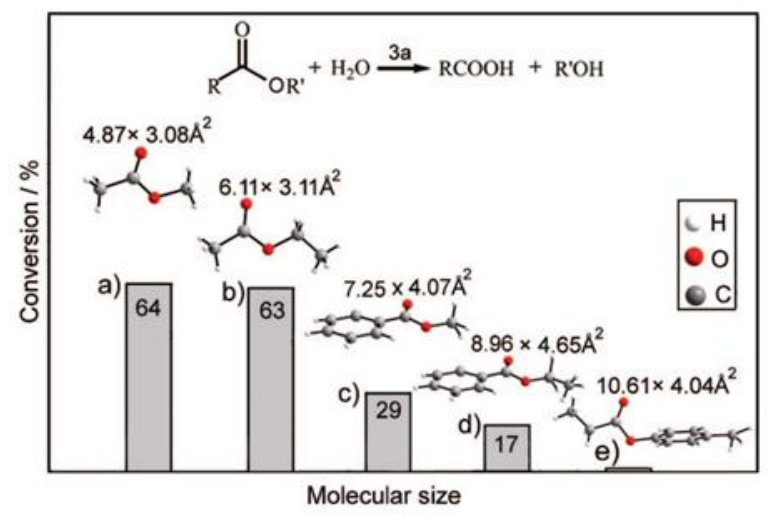

Fig. 43 Hydrolysis of ester in the presence of NENU-3a: a) methyl acetate; b) ethyl acetate; c) methyl benzoate; d) ethyl benzoate and e) 4-methyl-phenyl propionate. The reactions were performed with $5 \mathrm{wt} \% 30 \mathrm{~mL}$ aqueous solutions for a) and b) at $60^{\circ} \mathrm{C}$ and 2 wt $\% 30 \mathrm{~mL}$ aqueous solutions for c)-e) at $80^{\circ} \mathrm{C}$, respectively; reaction time $5 \mathrm{~h}$. Reprinted with permission from ref. ${ }^{121}$. Copyright 2009 American Chemical Society.

In 2010 and 2011, Wee et al. published two joint studies concerning the catalytic activity of PW $12 @ H K U S T-1$ nanocrystals for the esterification of acetic acid with 1-propanol. ${ }^{124,125}$ The authors showed not only that the POM@MOF material performed better than the classical $Y$ zeolite for the same reaction, but also that the particle size was an important parameter. The major drawback observed was the lack of stability of the catalyst, which could even dissolve in certain reaction conditions (high acetic acid concentration). To address this problem, they optimised the reaction parameters to diminish the concentration of acetic acid. They finally showed an increase in the conversion rate between micron-sized composite particles ( $17 \%$ conversion after $7 \mathrm{~h}$ ), $65 \mathrm{~nm}$-sized particles ( $28 \%$ conversion after $7 \mathrm{~h}$ ) and $50 \mathrm{~nm}$-sized particles ( $30 \%$ conversion after $7 \mathrm{~h}$ ) under the optimised conditions $\left(60^{\circ} \mathrm{C}, 1: 40\right.$ acetic acid: 1 -propanol molar ratio, $2.3 \mathrm{wt} \%$ catalyst).

The related 54wt\%SiW $12 @$ HKUST-1 (NENU-1) with different particle sizes was also synthesised. Its activated form NENU-1a was studied for the dehydration of methanol to dimethyl ether in gas phase. ${ }^{130}$ Methanol conversions with NENU-1a particles with average diameters of 23,105 , and $450 \mu \mathrm{m}$ were of $60 \%$, $58 \%$, and $46 \%$, respectively, with selectivities up to $100 \%$ $\left(240^{\circ} \mathrm{C}, \mathrm{P}=6 \mathrm{bar}\right)$. These values were much higher than for the POM-free HKUST-1 MOF (ca. 9\%), evidencing the crucial role of the Brønsted acidic molecular catalyst. The material with the largest particle size exhibited the lowest catalytic activity, possibly due to internal diffusion limitations. We could however see that particles of 23 and $105 \mu \mathrm{m}$ possessed similar activities, showing that even relatively large particles were highly active. 
This was related to the small size of the substrate considered. Compared to $\gamma-\mathrm{Al}_{2} \mathrm{O}_{3}$-supported $\mathrm{H}_{4} \mathrm{SiW}_{12} \mathrm{O}_{40}$ catalysts, the studied POM@MOFs exhibited higher activity due to a higher accessibility of the active sites and to much higher POM loading than the reported optimal loading of $\gamma-\mathrm{Al}_{2} \mathrm{O}_{3}$ (15 wt\%). The PW $12 @$ HKUST-1 material was less active and selective than SiW12@HKUST-1, which could be attributed to a lower stabilisation of the framework and to the higher acidity of the $\mathrm{PW}_{12}$ POM. It was indeed underlined that, as dimethylether was an intermediate of methanol dehydration, in presence of highly acidic catalysts the methanol tended to further dehydrate to form olefins or coke.

The same group described a related compound, NENU-11, a $\mathrm{PW}_{12}$-incorporating copper $\mathrm{MOF}$, together with its thermally activated form, NENU-11a. The materials were tested for the decomposition of dimethyl methylphosphonate (DMMP), which is commonly used as a simulant for type- $G$ and type- $X$ toxic nerve agents. ${ }^{123}$ Firstly, it was shown that NENU-11a adsorbed a considerable amount of DMMP (up to $24 \mathrm{wt} \%$ after $100 \mathrm{~min}$ at room temperature and under $1 \mathrm{~atm})$. The POM probably played a role in the uptake capacity of the material via the formation of hydrogen bonds with the substrate. Secondly, when NENU-11a with adsorbed DMMP was put in water, the methanol, methyl methylphosphonic acid and methylphosphonic acid products were formed (Scheme 8), with a conversion yield of DMMP of $34 \%$ at room temperature and $93 \%$ at $50^{\circ} \mathrm{C}(8 \mathrm{~h})$. The stability of the material was checked over more than 10 cycles.

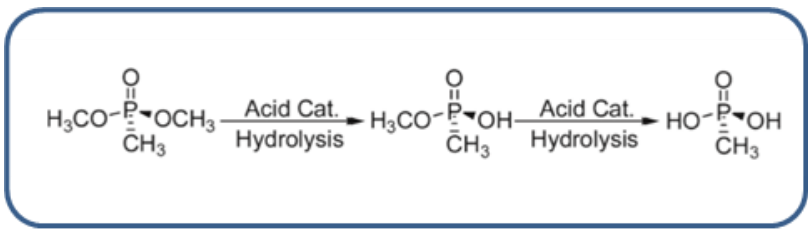

Scheme 8 Hydrolysis of DMMP in methyl methylphosphonic acid and methylphosphonic acid. Adapted with permission from ref. ${ }^{123}$. Copyright 2011 American Chemical Society.

The PMo ${ }_{12} @ H K U S T-1$ (NENU-5) composite was studied by Wang et al. in 2016 for converting 5-hydroxymethylfurfural (HMF) into 5-ethoxymethylfurfural (EMF) and ethyl levulinate (EL). ${ }^{135}$ Catalytic performances unambiguously evidenced the activity of the POM with $100 \%$ conversion of HMF ( $43.7 \%$ yield for EMF; $7.6 \%$ for $\mathrm{EL}$ ) while the POM-free material did not allow any conversion. In homogeneous conditions, the POM exhibited similar catalytic performances than in heterogeneous ones ( $100 \%$ conversion, $44.6 \%$ yield for EMF, $8.9 \%$ for EL). This material was thus a perfect example of the heterogenization of a molecular catalyst with no significant loss in activity. Finally, the recyclability tests showed that the total yield was maintained over 5 cycles (ca. $50 \%$ in each run). Still, the yield in EMF decreased by $6.5 \%$ between the first and the fifth runs while the yield in EL increased by $4.4 \%$.

It can be concluded from this section devoted to acid catalysis that Keggin-type polyoxometalates are almost exclusively used for acid catalysis application in MOFs. $\mathrm{H}_{3} \mathrm{PW}_{12} \mathrm{O}_{40}$ has been encapsulated in the major MOFs: MIL-101, UiO, HKUST, NU-1000. The resulting hybrid was used for a variety of reactions often exhibiting better catalytic activity compared to the POM in homogeneous conditions or the POMfree MOF.

5.2.2. Base catalysis. Compared to acid catalysis, base catalysis involving polyoxometalates has been scarcely investigated even if several POM systems were recently reported to act as catalysts for base-catalysed reactions such as the cyanosilylation of carbonyl compounds or $\mathrm{C}-\mathrm{C}$ bond formation reactions. ${ }^{264}$ We can mention here one study devoted to POM@MOF systems for such reactions. The very efficient Knoevenagel condensation of benzaldehyde with ethyl cyanoacetate with POM@MOF catalysts was investigated by Juan-Alcañiz et al.. ${ }^{41}$ Considering the $10 w t \% \mathrm{PW}_{12},\left\{\mathrm{PW}_{11} \mathrm{Cr}\right\} @ \mathrm{MIL}-101(\mathrm{Cr})$ composite prepared in one-step (see above), a TON of 216 after $20 \mathrm{~min}$ was reached (DMF, $40^{\circ} \mathrm{C}$ ), corresponding to a TOF $>656 \mathrm{~h}^{-1}$, highlighting the outstanding performance of this material. The catalyst was shown to be highly active either in polar or apolar solvents (TON $=195$ and TOF $>591 \mathrm{~h}^{-1}$ in toluene). It was proposed that the catalytic mechanism (Fig. 44) is similar to that occurring with metallic complexes. ${ }^{265}$ Finally, the catalyst was proved reusable in the absence of leaching even after eight cycles.

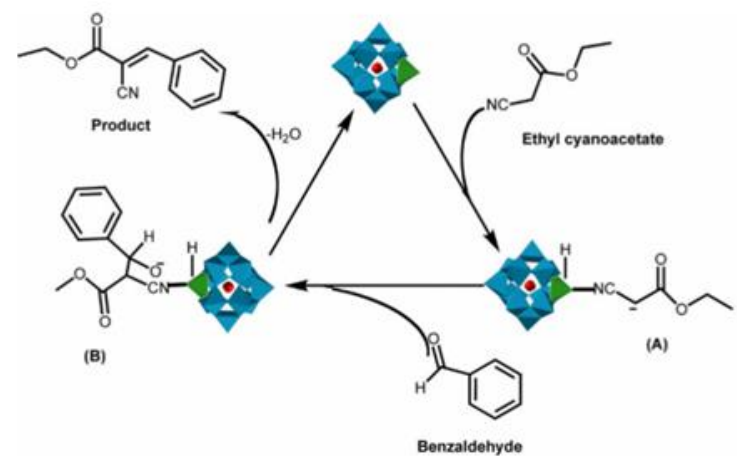

Fig. 44 Proposed reaction mechanism for the Knoevenagel condensation using the $10 w t \% \mathrm{PW}_{12},\left\{\mathrm{PW}_{11} \mathrm{Cr}\right\} @ \mathrm{MIL}-101(\mathrm{Cr})$ catalyst. Reprinted with permission from ref. ${ }^{41}$. Copyright 2009 Elsevier B.V.

\subsection{Photo- and electrocatalytic reactions}

5.3.1 Oxygen Evolution Reaction (OER). The generation of molecular oxygen driven by photocatalysis or electrolysis via the oxygen evolution reaction (OER) is a fundamental reaction for energy storage and conversion applications such as solar fuel production and metal-air batteries. ${ }^{266,267}$ Over these last ten years, POMs have shown to be effective molecular catalysts for water oxidation. A remarkable discovery in this field was made by Yin et al., who reported in 2010 the visible light driven OER using the noble metal-free catalyst $\left[\mathrm{CO}_{4}\left(\mathrm{H}_{2} \mathrm{O}\right)_{2}\left(\mathrm{PW}_{9} \mathrm{O}_{34}\right)_{2}\right]^{10-}$ $\left(\mathrm{P}_{2} \mathrm{~W}_{18} \mathrm{Co}_{4}\right)$ which exhibited at $\mathrm{pH} 8$ a TON of 75 using $\left[\mathrm{Ru}(\mathrm{bpy})_{3}\right]^{2+}$ as photosensitizer. ${ }^{268}$ The immobilization of $\mathrm{P}_{2} \mathrm{~W}_{18} \mathrm{CO}_{4}$ into a MOF was shown not only to allow a heterogenous POM system but also optimise its catalytic activity. In 2016, Han et al. indeed studied photochemical and electrochemical water oxidation by $\mathrm{P}_{2} \mathrm{~W}_{18} \mathrm{Co}_{4} @ \mathrm{MIL}-101(\mathrm{Cr}) .63$ The photocatalytic activity under visible light irradiation of the 
POM@MOF material for water oxidation was performed at $\mathrm{pH}$ 8 using $\left[\mathrm{Ru}(\mathrm{bpy})_{3}\right]^{2+}$ as a photosensitiser and $\mathrm{Na}_{2} \mathrm{~S}_{2} \mathrm{O}_{8}$ as sacrificial electron acceptor (Fig. 45a). A TOF in the first $20 \mathrm{~min}$ of the reaction of $7.1 \times 10^{-3} \mathrm{~s}^{-1}$ per cobalt atom of $\mathrm{P}_{2} \mathrm{~W}_{18} \mathrm{Co}_{4} @ \mathrm{MIL}-101(\mathrm{Cr})$ and an oxygen yield of $66 \%$ were determined. Under the same experimental conditions, a TOF of $4.0 \times 10^{-3} \mathrm{~s}^{-1}$ per cobalt atom and an $\mathrm{O}_{2}$ yield of $49 \%$ were observed with an equivalent amount of free POM. Under electrocatalytic conditions, the $\mathrm{P}_{2} \mathrm{~W}_{18} \mathrm{Co}_{4} @ \mathrm{MIL}-101(\mathrm{Cr})$ material showed lower overpotential and higher current density than $\mathrm{P}_{2} \mathrm{~W}_{18} \mathrm{CO}_{4}$ (Fig. 45b). ${ }^{63}$ However, the composite suffered from POM leaching during catalysis. This issue could be addressed by using a MOF with lower pore windows than MIL101(Cr). Two years later, Shah et al. thus reported on the incorporation of [Co"l $\left.\mathrm{Co}^{\prime \prime \prime} \mathrm{W}_{11} \mathrm{O}_{39}\left(\mathrm{H}_{2} \mathrm{O}\right)\right]^{7-}\left(\mathrm{Co}_{2} \mathrm{~W}_{11}\right)$ and $\mathrm{P}_{2} \mathrm{~W}_{18} \mathrm{CO}_{4}$ into MIL-100(Fe), which possesses smaller windows than MIL101(Cr). ${ }^{83}$ The photocatalytic experiments were performed in experimental conditions analogous to those considered by Han et al. ${ }^{63}$
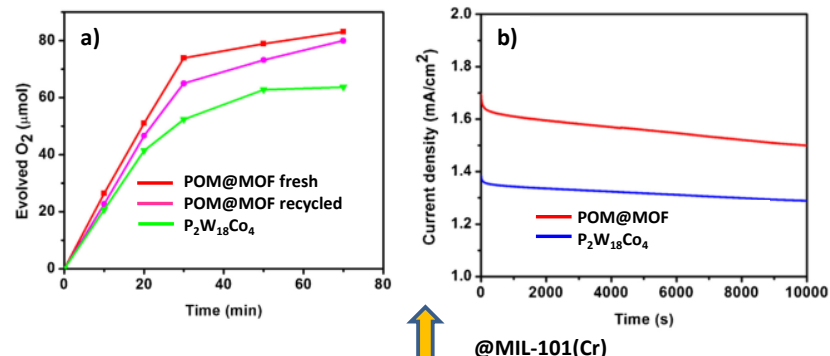

Ð @MIL-101(Cr)
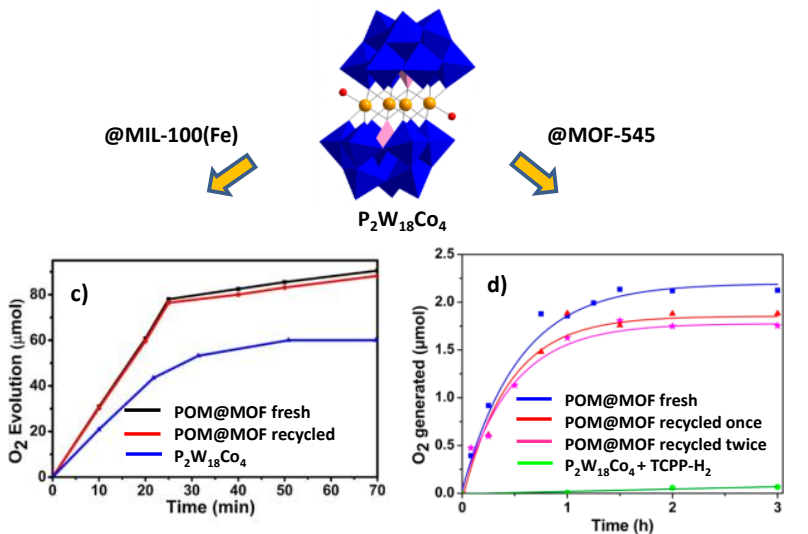

Fig. 45 Three examples of $\mathrm{P}_{2} \mathrm{~W}_{18} \mathrm{Co}_{4} @ \mathrm{MOF}$ composites for water oxidation: a) Kinetics of $\mathrm{O}_{2}$ evolution by $12.5 \mathrm{mg}$ of $\mathrm{P}_{2} \mathrm{~W}_{18} \mathrm{Co}_{4} @ \mathrm{MIL}-101(\mathrm{Cr})$ and $30 \mu \mathrm{M} \mathrm{P} \mathrm{P}_{18} \mathrm{Co}_{4}, 50 \mathrm{~mL}$ of 40.0 $\mathrm{mM} \mathrm{pH} 8$ borate buffer, $5.0 \mathrm{mM} \mathrm{Na} \mathrm{S}_{2} \mathrm{O}_{8}, 1.0 \mathrm{mM}\left[\mathrm{Ru}(\mathrm{bpy})_{3}\right] \mathrm{Cl}_{2}$. b) $i-t$ plots of $\mathrm{P}_{2} \mathrm{~W}_{18} \mathrm{Co}_{4} @ \mathrm{MIL}-101(\mathrm{Cr})$ and $\mathrm{P}_{2} \mathrm{~W}_{18} \mathrm{Co}_{4}, \mathrm{O}_{2}$-saturated electrolyte ( $\mathrm{pH} 9$ borate buffer), rotation rate of $1600 \mathrm{rpm}$. c) kinetics of $\mathrm{O}_{2}$ evolution reaction by $12 \mathrm{mg}$ of $\mathrm{P}_{2} \mathrm{~W}_{18} \mathrm{Co}_{4} @ \mathrm{MIL}-100(\mathrm{Fe})$ and $\mathrm{P}_{2} \mathrm{~W}_{18} \mathrm{Co}_{4}$ catalyst, $\mathrm{pH} 8$ borate buffer solution $(50 \mathrm{~mL}, 10$ $\mathrm{mM}$ ), $1.0 \mathrm{mM}\left[\mathrm{Ru}(\mathrm{bpy})_{3}\right] \mathrm{Cl}_{2}$ and $5 \mathrm{mM} \mathrm{Na}_{2} \mathrm{~S}_{2} \mathrm{O}_{8}$. d) kinetics of $\mathrm{O}_{2}$ evolution of $0.5 \mathrm{mg}$ of $\mathrm{P}_{2} \mathrm{~W}_{18} \mathrm{Co}_{4} @ \mathrm{MOF}-545$ and $131 \mu \mathrm{M}$ TCPP- $\mathrm{H}_{2}$ and $13 \mu \mathrm{M} \mathrm{P} \mathrm{W}_{18} \mathrm{Co}_{4}, 5 \mathrm{mM} \mathrm{Na} \mathrm{S}_{2} \mathrm{O}_{8}$ in $2 \mathrm{~mL}$ of $80 \mathrm{mM}$ borate buffer solution, $\mathrm{pH} 8$; for all photocatalytic experiments $300 \mathrm{~W}$ Xenon lamp with $\lambda>420 \mathrm{~nm}$. Adapted with permission from refs. 63,83,108. Copyright 2015 Elsevier B.V. Copyright 2018 Elsevier B.V. Copyright 2018, American Chemical Society.

On the one hand, the yield in $\mathrm{O}_{2}$ of $\mathrm{Co}_{2} \mathrm{~W}_{11} @ \mathrm{MIL}-100$ (Fe) was higher than that of the bare POM (41\% vs 30\%) in the first 10 min of illumination, and the TOF in the first two minutes increased from $0.48 \mathrm{~s}^{-1}$ for the bare POM up to $0.53 \mathrm{~s}^{-1}$ for the
POM@MOF with a plateau reached after 7-8 min of illumination. On the other hand, the $\mathrm{P}_{2} \mathrm{~W}_{18} \mathrm{Co}_{4} @ \mathrm{MIL}-100(\mathrm{Fe})$ system (Fig. 45c) displayed an $\mathrm{O}_{2}$ yield and TOF of $72 \%$ and $9.2 \times 10^{-3} \mathrm{~s}^{-1}$, respectively. These values were higher than the TOF and $\mathrm{O}_{2}$ yield of the bare POM and slightly higher than the values reported for $\mathrm{P}_{2} \mathrm{~W}_{18} \mathrm{Co}_{4} @ \mathrm{MIL}-101(\mathrm{Cr}) .63$ This enhanced activity of POM@MOF composite was attributed to the proximity between the Lewis acidic $\mathrm{Fe}_{3}$ units of MIL-100 and the anionic POMs. The latter is claimed to facilitate electron transfer between the two components in which the LUMO of the POM accepted the photoinduced electrons from the conduction band of MIL-100(Fe). Furthermore, $\mathrm{Co}_{2} \mathrm{~W}_{11} @ \mathrm{MIL}-$ 100(Fe) and $\mathrm{Co}_{4} \mathrm{P}_{2} \mathrm{~W}_{18} @ \mathrm{MIL}-100(\mathrm{Fe})$ composites also displayed a better electrochemical water oxidation activity than the bare POM, with a lower onset potential and a higher current density. Importantly, no leaching was observed during the catalytic reactions.

Obviously, the design of highly active fully noble metal-free photocatalytic systems is of prime importance in the field of photocatalysis. Besides the use of ruthenium-based photosensitisers, photosensitivity may be introduced into MOFs thanks to the light absorbing properties of organic linkers such as porphyrins. Paille et al. reported in 2018 the immobilisation of the $\mathrm{P}_{2} \mathrm{~W}_{18} \mathrm{CO}_{4} \mathrm{POM}$ into the cavities of the $\mathrm{Zr}(\mathrm{IV})$ porphyrinic MOF-545. ${ }^{108}$ The photocatalytic OER activity of $\mathrm{P}_{2} \mathrm{~W}_{18} \mathrm{Co}_{4} @ M O F-545$ was studied under visible light irradiation in $\mathrm{pH} 8$ borate buffer, using $\mathrm{Na}_{2} \mathrm{~S}_{2} \mathrm{O}_{8}$ as electron acceptor and in absence of any external photosensitiser. The POM@MOF composite was shown to be an excellent catalyst to oxidise water into $\mathrm{O}_{2}$ (TOF $=40 \times 10^{-3} \mathrm{~s}^{-1}$ calculated for the first $15 \mathrm{~min}$, TON $=70$ after 1 h) (Fig. 45d). Notably, the free porphyrin was not able to photosensitise the free $\mathrm{P}_{2} \mathrm{~W}_{18} \mathrm{Co}_{4} \mathrm{POM}$. This was interpreted by a shift of the valence band (HOMO) of the porphyrin in the MOF, which increases the driving force for water oxidation. Although the TONs were slightly lower for the second and third cycles, addition of a fresh solution of the sacrificial acceptor resulted in a $\mathrm{O}_{2}$ production with the same initial TOF. Moreover, TGA, XRD, and EDS analysis supported that the POM@MOF composite remained intact after catalysis. It was proposed that the photocatalytic mechanism could be decomposed in four steps, with the visible light capture by the porphyrin, the one-electron oxidation of the excited porphyrin by the sacrificial electron acceptor, the one-electron oxidation of the POM, and finally, after accumulation of 4 oxidising equivalents on the POM, the oxidation of water into $\mathrm{O}_{2}$ (Fig. 46).

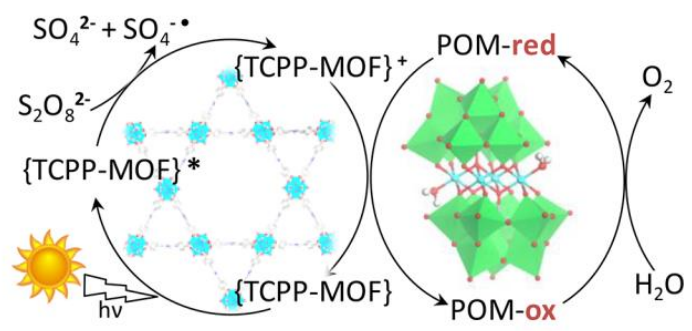

Fig. 46 Schematic representation of the proposed mechanism for the light-driven OER by $\mathrm{P}_{2} \mathrm{~W}_{18} \mathrm{Co}_{4} @ \mathrm{MOF}-545$. Reprinted with permission from ref. ${ }^{108}$. Copyright 2018 Americal Chemical Society. 
Mukhopadhyay et al. presented in 2018 a robust catalyst for the electrochemical oxidation of water consisting of the Keggin anion $\left[\mathrm{CoW}_{12} \mathrm{O}_{40}\right]^{6-}\left(\mathrm{CoW}_{12}\right)$ inserted into ZIF-8. ${ }^{203}$ The immobilised POMs underwent partial electronic redistribution and increment of electron density from the MOF host, making it favourable for reversible electron transfer. Electrocatalytic water oxidation investigations showed promising performances with sustained oxygen evolution, while the POM alone was not able to perform the water oxidation under these conditions (Fig. 47a). The TOF calculated from the quantitative oxygen evolution was $10.8 \mathrm{~mol} \mathrm{O}_{2}\left(\mathrm{~mol} \mathrm{Co}^{-1} \mathrm{~s}^{-1}\right.$. $\mathrm{CoW}_{12} @ \mathrm{ZIF}-8$ retained its initial activity even after 1000 catalytic cycles and chronoamperometric measurements showed very small drop in catalytic current (Fig. 47b), while the physical POM and MOF mixture could not sustain 10 catalytic cycles due to the degradation of the POM.
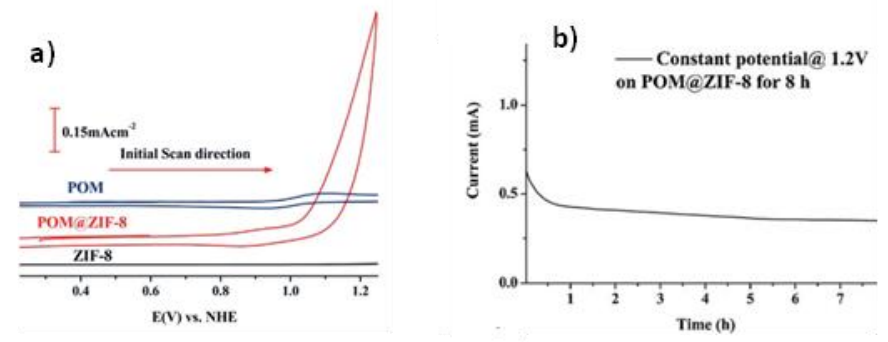

Fig. 47 a) Cyclic voltammograms of ZIF-8, CoW $12 @ Z I F-8$ and $\mathrm{CoW}_{12}\left(\mathrm{pH} 70.1 \mathrm{M} \mathrm{Na}_{2} \mathrm{SO}_{4}\right.$ aqueous solution). b) chronoamperometric measurements at $1.2 \mathrm{~V}$ of POM@ZIF-8 for 8 $\mathrm{h}$ in $0.1 \mathrm{M} \mathrm{Na}_{2} \mathrm{SO}_{4}$. Adapted with permission from ref. ${ }^{203}$. Copyright 2018 Wiley-VCH Verlag GmbH \& Co. KGaA, Weinheim.

In 2020 Abdelkader-Fernández et al. prepared an efficient OER electrocatalyst by encapsulating the cobalt trisubstituted silicotungstic Keggin $\mathrm{POM} \mathrm{SiW}_{9} \mathrm{CO}_{3}$ into the cages of the Cobased ZIF-67 and the Zn-based ZIF-8 MOFs. ${ }^{140}$ A 24 times higher OER activity of the $\mathrm{SiW}_{9} \mathrm{Co}_{3} @ \mathrm{ZIF}-67$ composite compared to that of the $\mathrm{SiW}_{9} \mathrm{CO}_{3} \mathrm{POM}$ was observed. Also, in comparison with the pristine ZIF-67, the $\mathrm{SiW}_{9} \mathrm{Co}_{3} @ \mathrm{ZIF}-67$ composite exhibited a remarkable OER performance by increasing the current density values by two, reducing overpotential by 110 $\mathrm{mV}$ and decreasing the Tafel slope by $21 \%$. The high activity of the $\mathrm{SiW}_{9} \mathrm{CO}_{3} @ \mathrm{ZIF}-67$ composite was attributed to the activation of the $\mathrm{Co}^{2+}$ centres of the POM via electron transfer with the surrounding ZIF-67 - promoted by the significant conductivity of ZIF-67 along with good host-guest orbitals overlapping - and to the possible generation of two/three coordinated Co sites in ZIF-67 induced by the encapsulation of the POM. In comparison, $\mathrm{SiW}_{9} \mathrm{Co}_{3} @ \mathrm{ZIF}-8$ exhibited no such prominent OER activity even though the amount and distribution of incorporated $\mathrm{SiW}_{9} \mathrm{CO}_{3}$ units were independent of the ZIF type (ZIF-8 or ZIF-67), evidencing the decisive role of $\mathrm{Co}^{2+}$ nodes in the ZIF-67 skeleton. Finally, the POM@MOF composite preserved its $100 \%$ initial activity for at least $12 \mathrm{~h}$ of chronoamperometry test.

Following their work on $\mathrm{CoW}_{12} @ Z$ ZIF-8, 203 Mukhopadhyay et al. reported in 2020 an efficient and robust composite for electrocatalytic OER constructed by the co-encapsulation of the $\mathrm{Fe}$ (salen) catalyst and the $\mathrm{SiW}_{12}$ POM into the cavities of ZIF-8 via in situ synthesis. ${ }^{139}$ This material exhibited high TOF $\left(\approx 5 \mathrm{~s}^{-1}\right)$ and high Faradic efficiency ( $\approx 94 \%)$. The superior activity of the (Fe(salen),SiW 12 )@ZIF-8 composite compared to that of the POM-free Fe(salen)@ZiF-8 was attributed to both the increase in charge transfer in the material, lowering the overall electrical resistance, and a higher loading of Fe-salen. Unlike the free [Fe(salen) Cl] complex which showed a rapid decrease in onset current after 10 cyclic voltammetry scans, the (Fe(salen),SiW 12 )@ZIF-8 composite underwent only a slight loss of catalytic current after 500 cyclic voltammetry cycles. Furthermore, no leaching of $\mathrm{Fe}$ (II) or Fe(III) species together with the intact crystallinity of the composite after the catalytic event, with no formation of iron oxides, corroborated the genuine catalytic behaviour and robustness of Fe(salen)@ZiF-8 toward electrochemical OER.

Besides acting as supports for the preparation of POM@MOF materials, MOFs have also been reported to act as porous templates allowing accessing POM@transition metal oxide materials after calcination. In this way, Lan et al. reported in 2016 the synthesis of PW $12 @ Z I F-67$ materials prepared by the direct incorporation of various amount of phosphotungstic acid into the ZIF-67 cobalt MOF, affording the $\left[\mathrm{Co}\left(\mathrm{C}_{4} \mathrm{H}_{5} \mathrm{~N}_{2}\right)_{2}\right]_{159} \mathrm{H}_{3} \mathrm{PW}_{12} \mathrm{O}_{40}(\mathrm{ZW}-1), \quad\left[\mathrm{Co}\left(\mathrm{C}_{4} \mathrm{H}_{5} \mathrm{~N}_{2}\right)_{2}\right]_{96} \mathrm{H}_{3} \mathrm{PW}_{12} \mathrm{O}_{40}$ $(\mathrm{ZW}-2)$ and $\left[\mathrm{Co}\left(\mathrm{C}_{4} \mathrm{H}_{5} \mathrm{~N}_{2}\right)_{2}\right]_{36} \mathrm{H}_{3} \mathrm{PW}_{12} \mathrm{O}_{40}(\mathrm{ZW}-3)$ compounds. ${ }^{142}$ After thermal treatment at $350^{\circ} \mathrm{C}$, a series of porous hollow spinel-type $\mathrm{PW}_{12} @ \mathrm{Co}_{3} \mathrm{O}_{4}$ compounds were obtained. The photocatalytic water oxidation performed under visible-light illumination in $\mathrm{Na}_{2} \mathrm{SiF}_{6} / \mathrm{NaHCO}_{3}$ buffer solution ( $\mathrm{pH} 6.0$ ), using $\left[\mathrm{Ru}(\mathrm{bpy})_{3}\right]^{2+}$ as photosensitiser and $\mathrm{Na}_{2} \mathrm{~S}_{2} \mathrm{O}_{8}$ as the sacrificial electron acceptor, showed that an increase in POM concentration resulted in materials with higher activities, with a highest TOF of $1.11 \times 10^{-3} \mathrm{~s}^{-1}$ (Fig. 48a). The composite materials had an enhanced reproducible photocurrent response under visible-light irradiation (Fig. 48b) and the photocurrent density of the composite materials increased when the POM concentration increased. The prepared materials were more active than pure $\mathrm{Co}_{3} \mathrm{O}_{4}$ and their photocatalytic performances were close to the most active $\mathrm{Co}_{3} \mathrm{O}_{4}$-based materials. ${ }^{142}$ Besides, the authors found that related materials annealed at temperatures higher than $400{ }^{\circ} \mathrm{C}$ were less catalytically active. Finally, it was demonstrated that the $350^{\circ} \mathrm{C}$-calcinated materials retained their crystallinity and catalytic activity after three recycling experiments.
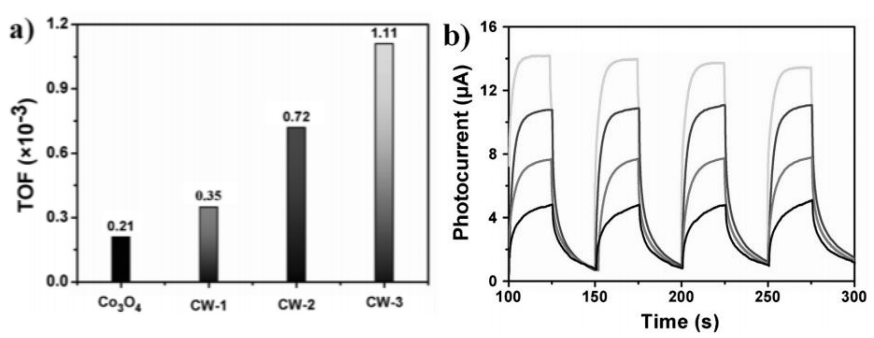

Fig. 48 (a) TOF of $\mathrm{CO}_{3} \mathrm{O}_{4}, \mathrm{CW}-1$ (calcined ZW-1), CW-2 (calcined ZW-2), and CW-3 (calcined $\mathrm{ZW}-3$ ); (b) transient photocurrent response in $0.1 \mathrm{M} \mathrm{Na}_{2} \mathrm{SO}_{4}$ aqueous solution under visible-light irradiation at $0 \mathrm{~V}$ vs. $\mathrm{Ag} / \mathrm{AgCl}$. Reprinted with permission from ref. ${ }^{142}$. Copyright 2016 Wiley-VCH GmbH \& Co. KGaA, Weinheim. 
5.3.2 Hydrogen Evolution Reaction (HER). Development of efficient catalysts for the photo or electrocatalytic hydrogen evolution reaction (HER) is crucial to establish future carbonfree energy systems, and in this respect, MOFs as matrices to support HER catalysts have attracted specific research efforts. In 2018, Li et al. described the immobilisation of the Wells-Dawson-type POMs, $\mathrm{P}_{2} \mathrm{~W}_{15} \mathrm{~V}_{3}, \mathrm{P}_{2} \mathrm{~W}_{17} \mathrm{Ni}$, and $\mathrm{P}_{2} \mathrm{~W}_{17} \mathrm{Co}$ into the cavities of MIL-101(Cr) for visible light-driven hydrogen production. ${ }^{59}$ The negative charge of the POMs immobilised in the POM@MOF composites allowed them to efficiently adsorb the dicationic photosensitiser $\left[\mathrm{Ru}(\mathrm{bpy})_{3}\right]^{2+}$ present in the solution. The catalytic tests were performed in $\mathrm{DMF} / \mathrm{CH}_{3} \mathrm{CN}$ (7/3) using triethanolamine (TEOA) as a sacrificial electron donor (Fig. 49). After $8 \mathrm{~h}$ of visible light irradiation, TONs of 56, 50, and 49 were determined for $\mathrm{P}_{2} \mathrm{~W}_{15} \mathrm{~V}_{3} @ \mathrm{MIL}-101(\mathrm{Cr})$, $\mathrm{P}_{2} \mathrm{~W}_{17} \mathrm{Ni} @ \mathrm{MIL}-101(\mathrm{Cr})$ and $\mathrm{P}_{2} \mathrm{~W}_{17} \mathrm{Co} @ \mathrm{MIL}-101(\mathrm{Cr})$, respectively. These POM@MIL-101(Cr) materials were more active than their related POM-containing homogeneous catalytic counterpart under the same reaction conditions. This was rationalized considering that the MIL-101(Cr) host not only allows the uniform distribution of POMs in its 3D matrix but also enhances the concentration in $\left[\mathrm{Ru}(\mathrm{bpy})_{3}\right]^{2+}$ around the confined POMs. Still, the similar reactivities of the three POM@MOF composites suggested that hydrogen evolution rate could be controlled by diffusive processes related to the MOF structure. The recyclability experiments of $\mathrm{P}_{2} \mathrm{~W}_{15} \mathrm{~V}_{3} @ \mathrm{MIL}-101(\mathrm{Cr})$ showed unchanged reactivity over three catalytic cycles, the structural integrity of the composite being maintained after photocatalysis. The same immobilisation strategy was further used for the adsorption of smaller anionic $\mathrm{Mo}_{2} \mathrm{~S}_{12}{ }^{2-}$ units that could easily enter the cages of MOFs. The $\mathrm{Mo}_{2} \mathrm{~S}_{12} @ \mathrm{MIL}-101(\mathrm{Cr})$ material demonstrated an excellent photocatalytic HER activity with $\mathrm{H}_{2}$ evolution rate of up to $25578 \mu \mathrm{molh}^{-1} \mathrm{~g}^{-1}(\mathrm{TON}=237)$ in $8 \mathrm{~h}$ under visible light irradiation, again higher than the related homogenous system.
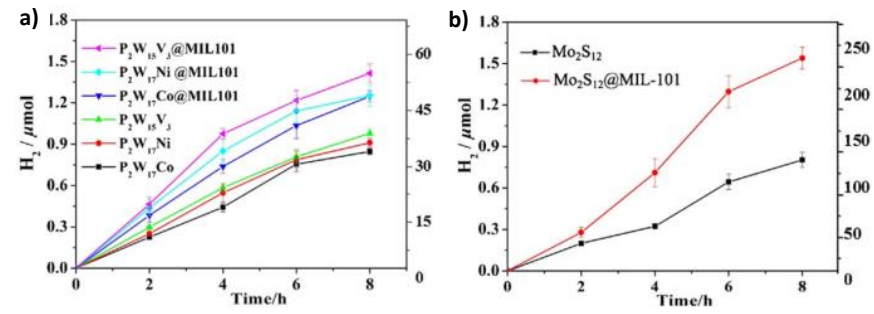

Fig. 49 Kinetics of $\mathrm{H}_{2}$ production for a) $\mathrm{P}_{2} \mathrm{~W}_{15} \mathrm{~V}_{3} @ \mathrm{MIL}-101(\mathrm{Cr}), \mathrm{P}_{2} \mathrm{~W}_{17} \mathrm{Ni} @ \mathrm{MIL}-101(\mathrm{Cr})$ and $\mathrm{P}_{2} \mathrm{~W}_{17} \mathrm{Co} @ \mathrm{MIL}-101(\mathrm{Cr})$ and b) $\mathrm{Mo}_{2} \mathrm{~S}_{12}$, together with their related POMs in solution. 16 $\mathrm{mL} \mathrm{DMF} / \mathrm{CH}_{3} \mathrm{CN}(7 / 3)$, catalyst concentration $3.1 \mu \mathrm{M}, 48 \mu \mathrm{M}\left[\mathrm{Ru}(\mathrm{bpy})_{3}\right]^{2+} ; 94 \mathrm{mM}$ TEOA, and $200 \mu \mathrm{L} \mathrm{pH} 2.0$ water, $300 \mathrm{~W}$ Xe-lamp with a $420 \mathrm{~nm}$ filter. Adapted from ref. ${ }^{59}$. Copyright 2017 Elsevier B.V.

In 2015 Nasalevich et al. prepared a noble metal free HER catalyst by the encapsulation of cobaloxime catalytic complexes (Coox) into the pores of the Ti-based photoactive $\mathrm{NH}_{2}-\mathrm{MIL}-$ 125(Ti) MOF. ${ }^{159}$ Under visible-light irradiation, in $\mathrm{CH}_{3} \mathrm{CN} / \mathrm{H}_{2} \mathrm{O}$ (50/1), with triethylamine (TEA) as electron donor, the Coox@ $\mathrm{NH}_{2}$-MIL-125(Ti) maintained a constant $\mathrm{H}_{2}$ TOF of $0.8 \mathrm{~h}^{-1}$ even after $65 \mathrm{~h}$. The composite showed remarkable photocatalytic performances compared to the pristine $\mathrm{NH}_{2}-$ MIL-125(Ti). The authors proposed that photon-absorption by the MOF linker resulted in charge separation to generate reduced $\mathrm{Ti}^{3+}$ centers and a hole at the organic linker. The hole then reacted with the electron donor, while the electron was
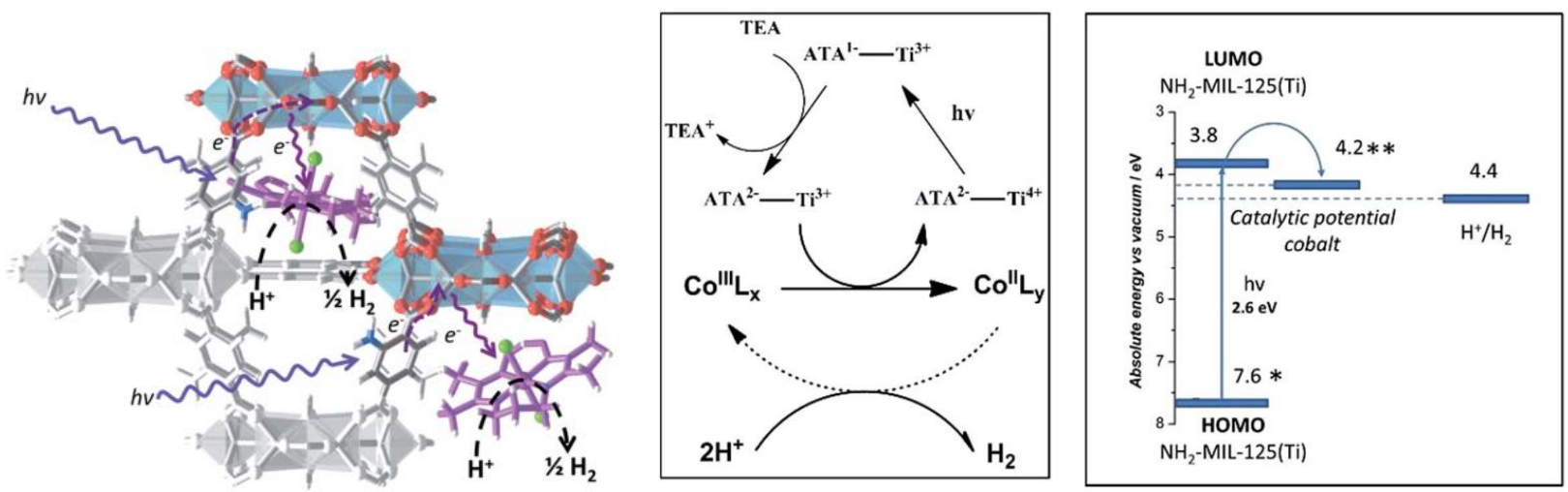

Fig. 50 Proposed hydrogen evolution mechanism for Coox@ $\mathrm{NH}_{2}-\mathrm{MIL}-125$ (Ti) (ATA = 2-aminoterephthalic acid) (left), and schematic diagram of redox potentials of components of Coox@NH 2 -MIL-125(Ti) (right). $\left({ }^{*}\right)$ : Calculated values. $\left({ }^{* *}\right)$ : Experimental data. Reprinted from ref. ${ }^{159}$ with permission from the RSC.

rapidly injected into the Co species within the pores to reduce $\mathrm{Co}(\mathrm{III})$ to $\mathrm{Co}(\mathrm{II})$, finally resulting in the hydrogen evolution reaction (Fig. 50). The Coox@MOF catalyst was recycled at least three times without loss of activity. In addition, no activity of the filtrate obtained after isolation of the catalyst was observed, confirming that the catalysis was heterogeneous exclusively.

In 2016, Li et al. immobilised via a ship-in-the-bottle strategy the HER photocatalyst $[\mathrm{Co}(\mathrm{TPA}) \mathrm{Cl}] \mathrm{Cl}$ (TPA = tris(2pyridylmethyl)-amine) in the same $\mathrm{NH}_{2}-\mathrm{MIL}-125$ (Ti) MOF. Due to the congestion of the precursors around the pore windows of the MOF, only a limited amount of Co(II) complexes could be incorporated into the pores, with Co contents comprised between 0.97 and $1.93 \mathrm{wt} \%$. Nevertheless, under illumination with visible light in a $\mathrm{CH}_{3} \mathrm{CN} / \mathrm{TEOA} / \mathrm{H}_{2} \mathrm{O}$ medium, the 1.93wt\%Co(TPA)Cl@ $\mathrm{NH}_{2}$-MIL-125(Ti) composite exhibited a $\mathrm{H}_{2}$ production rate of $553 \mu \mathrm{mol} \mathrm{g}^{-1} \mathrm{~h}^{-1}$, higher than any component of the catalyst or their physical mixture. Based on the results of ESR analysis, the authors proposed that the photoelectrons produced by $\mathrm{NH}_{2}-\mathrm{BDC}$ during irradiation directly transferred to the $\mathrm{Co}(\mathrm{II})$ complex, reducing $\mathrm{Co}^{2+}$ to $\mathrm{Co}^{+}$, followed by the 
reduction of $\mathrm{H}^{+}$to $\mathrm{H}_{2}$ and the re-oxidation of the cobalt centre. This mechanism was thus close to the one proposed by Nasalevich (Fig. 50). ${ }^{159}$ Also, it was shown that Co(TPA)Cl@ $\mathrm{NH}_{2-}$ MIL-125(Ti) displayed almost unchanged activity during the recycling experiments up to three runs, maintaining its structural integrity throughout the catalytic events.
In 2016, Bu et al. used the SiW12@UiO-67 material as a support for $\mathrm{CdS}$ nanoparticles and the $\mathrm{MoS}_{2} /$ reduced graphene oxide (M/G) co-catalyst. ${ }^{104}$ The resulting SiW $12 @ U i O-67 / M / G-$ CdS composite showed an optimal $\mathrm{H}_{2}$ production of $1.27 \mathrm{mmol}$ $\mathrm{h}^{-1}$ with 30 wt\%SiW $12 @ U i O-67$ in the presence of 5\% M/G (Fig. $51 \mathrm{a}-\mathrm{b})$. This amount of $\mathrm{H}_{2}$ produced was almost twice as high than that of the related MOF-free POM@M/G-CdS material. a)

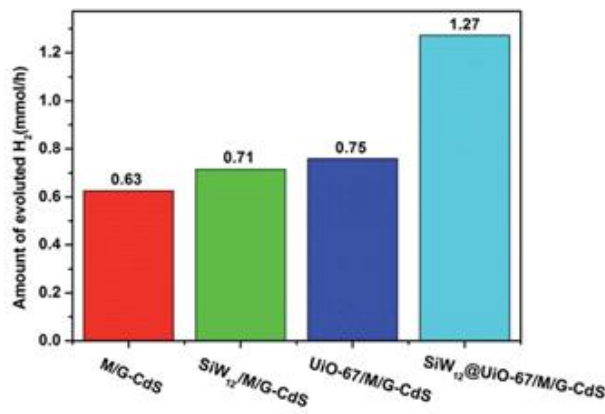

b)

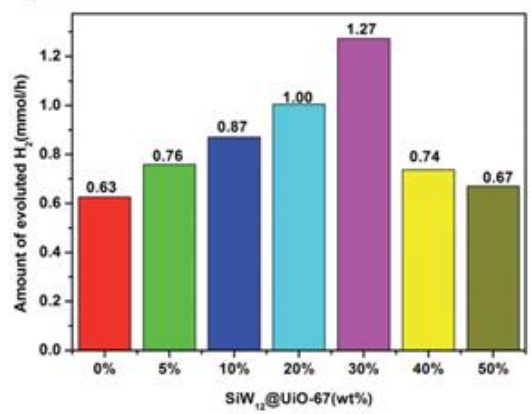

c)

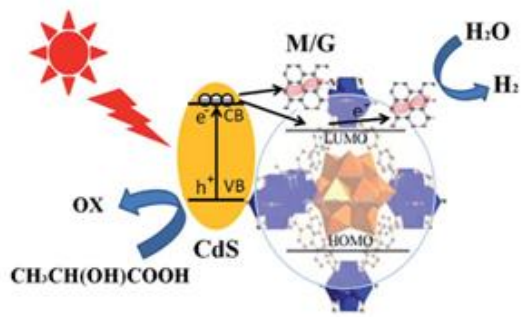

$\mathrm{SiW}_{12} @ \mathrm{UiO}-67$

Fig. $51 \mathrm{H}_{2}$ evolution under visible light irradiation of SiW $12 @ U i O-67 / M / G-C d S$ photocatalysts : a) compared to related materials and b) with different amounts of SiW $12 @$ UiO-67. c) Proposed mechanism. Reaction conditions: $0.1 \mathrm{~g}$ catalyst; $5 \mathrm{wt} \% \mathrm{MoS}_{2}-\mathrm{RGO}$ loaded; $160 \mathrm{~mL}$ aqueous solution containing 30 vol\% lactic acid; light source: $300 \mathrm{~W}$ Xe lamp ( $\lambda>400$ $\mathrm{nm})$. Reprinted from ref. ${ }^{104}$ with permission from the RSC.

The superior performance of SiW $12 @ U i O-67 / M / G-C d S$ was ascribed to the large specific surface area of SiW $12 @ U i O-67$ and the effective heterostructure between SiW $12 @ U i O-67$ and CdS. This allowed photogenerated electron transfer from the conduction band of CdS to the LUMO of SiW $12 @ U i O-67$ and thus to $M / G$, or by direct transfer from the CdS conduction band to M/G (Fig. 51 c). In addition, the SiW $12 @ U i O-67 / M / G-C d S$ composite showed an enhanced durability compared to CdS.

Recently, a photochemical HER system fabricated by the sole encapsulation of $\mathrm{PW}_{12}$ within the pores of $\mathrm{NH}_{2}-\mathrm{UiO}-66$ in a one-step solvothermal method was reported by Tian et al..98 The higher catalytic performance of $\mathrm{PW}_{12} @ \mathrm{NH}_{2}$-UiO-66 $\left(\mathrm{H}_{2}\right.$ production multiplied by 6.2) compared to pristine $\mathrm{NH}_{2}-\mathrm{UiO}-66$ was explained by the fact that the photo-generated electrons from $\pi$-conjugated electrons in $\mathrm{NH}_{2}$ - $\mathrm{BDC}$ were transferred to $\mathrm{PW}_{12}$. This could hinder the recombination of electrons-holes pairs and create surface redox-reaction sites. Note that these photocatalytic studies were performed with a Xe lamp with no cut-off for UV light.

Photoexcitation in the visible range often requires the use of Ru- or Ir- based photosensitisers. In 2015, Zhang et al. reported the encapsulation of $\mathrm{P}_{2} \mathrm{~W}_{18}$ into the cavities of an UiO derivative containing $\left[\mathrm{Ru}(\mathrm{bpy})_{3}\right]^{2+}$-functionalised dicarboxylate ligands through a one-pot self-assembly method. ${ }^{105}$ Under irradiation with visible light and using methanol as sacrificial electron donor in aqueous medium ( $\mathrm{pH}$ 1.8), the POM@UiO photosystem yielded an $\mathrm{H}_{2}$ evolution TON of 79 over $14 \mathrm{~h}$, while no activity was observed in the homogenous reference system. According to the authors, this superior activity of the POM@UiO system was ascribed to the facile multielectron injection from the six and twelve $\left[\mathrm{Ru}(\mathrm{bpy})_{3}\right]^{2+}$-based ligands located in the tetrahedral and octahedral cages, respectively, into the encapsulated POM. The POM@UiO composite was re-used for three catalytic cycles with only slight losses in activity and crystallinity. One year later, the same group immobilised the $\mathrm{Ni}$ based POM $\left[\mathrm{Ni}_{4}\left(\mathrm{H}_{2} \mathrm{O}\right)_{2}\left(\mathrm{PW}_{9} \mathrm{O}_{34}\right)_{2}\right]^{10-}\left(\mathrm{P}_{2} \mathrm{~W}_{18} \mathrm{Ni}_{4}\right)$ into the pores of the $\left[\operatorname{Ir}(\mathrm{ppy})_{2}(\mathrm{bpy})\right]^{+}$-derived UiO-MOF to perform photochemical and electrochemical hydrogen evolution. ${ }^{106}$ Visible-light driven $\mathrm{H}_{2}$ evolution experiment carried out in aqueous solution at $\mathrm{pH} 1.2$ with methanol as sacrificial electron donor showed that the TON associated to the POM@MOF reached 1476 after $72 \mathrm{~h}$ of reaction, while homogeneous counterparts showed only traces of $\mathrm{H}_{2}$. Again, the close proximity between the $\left[\operatorname{Ir}(\mathrm{ppy})_{2}(\mathrm{bpy})\right]^{+} \mathrm{PSs}$ and POMs allowed the facile electron transfer from the former to the latter. The material retained its activity over three catalytic cycles.

In 2014, the biomimetic heterogeneous photocatalyst [FeFe]@MOF-545(Zn) was synthesised incorporating the [(i$\left.\left.\mathrm{SCH}_{2}\right)_{2} \mathrm{NC}(\mathrm{O}) \mathrm{C}_{5} \mathrm{H}_{4} \mathrm{~N}\right]-\left[\mathrm{Fe}_{2}(\mathrm{CO})_{6}\right]$ molecular catalyst into the highly robust $\mathrm{Zn}$ (TCPP)-based material, MOF-545(Zn), where $\mathrm{Zn}$ (TCPP) acts as the PS. ${ }^{165}$ Upon irradiation with visible light and using ascorbic acid as a sacrificial electron donor, the [FeFe]@MOF-545(Zn) composite showed a linear increase in $\mathrm{H}_{2}$ production for the first $50 \mathrm{~min}$, reaching a plateau in $120 \mathrm{~min}$ and producing $\sim 3.5 \mu \mathrm{mol} \mathrm{H}_{2}$. The homogenous counterpart of the composite showed a lower activity and a dramatic decrease in the activity after $40 \mathrm{~min}$. The higher activity of [FeFe]@MOF$545(\mathrm{Zn})$ was probably due to enhanced stability of the incorporated [FeFe] complex. No recycling experiments was reported in this case.

5.3.3. $\mathrm{CO}_{2}$ reduction Reaction. The transformation of $\mathrm{CO}_{2}$ into hydrocarbons is of vital importance as the hydrocarbons produced ( $\mathrm{CO}, \mathrm{HCOOH}, \mathrm{CH}_{4}, \mathrm{CH}_{3} \mathrm{OH}, \ldots$ ) represent important energy carriers. Inspired by the photosynthesis, the development of systems made of photosensitiser, catalyst, and 
sacrificial reducing agent is appealing to generate hydrocarbon fuels from $\mathrm{CO}_{2}$. However, due to the high kinetic and thermal stability of $\mathrm{CO}_{2}$, its reduction is an energy intensive process. Although several molecular catalysts incorporating second and third row transition metals have been developed so far, their limited stability and reusability remain major issue. Their incorporation into MOF matrices represents interesting alternatives.

In 2018, a heterogeneous catalyst for $\mathrm{CO}_{2}$ reduction was designed by the co-immobilisation of the molecular [Cp*Rh(4,4'-bpydc) Cl] ${ }^{+}$rhodium catalyst and the $\left[\mathrm{Ru}(\mathrm{bpy})_{2}\left(4,4^{\prime}\right.\right.$ bpydc) $]^{2+}$ photosensitizer into the large pore $\mathrm{NH}_{2}-\mathrm{MIL}-101(\mathrm{Al})$, affording the Rh-Ru@NH 2 -MIL-101(Al) photosystem. ${ }^{153}$ The carboxylic groups of both the catalyst and the PS contributed to enhance host-guest hydrogen-bond interactions and prevent their leaching. Interestingly, the photocatalytic activity of the photosystem made of $\mathrm{Rh} @ \mathrm{NH}_{2}-\mathrm{MIL}-101$ (Al) and free PS accounts to only $50 \%$ of that of Rh-Ru@ $\mathrm{NH}_{2}-\mathrm{MIL}-101(\mathrm{Al})$ emphasizing the benefit of co-immobilising the two components into the MOF. Rh-Ru@NH $\mathrm{N}_{2}-\mathrm{MIL}-101$ (Al) showed a remarkable selectivity for formate formation. This contrasted with the $\left[\mathrm{Cp}^{*} \mathrm{Rh}\left(4,4^{\prime}-\mathrm{bpydc}\right) \mathrm{Cl}\right]^{+} / \mathrm{PS}$ homogeneous system, which led to $\mathrm{H}_{2}$ as the major product, clearly evidencing the role of the MOF which acted as an inhibitor for the proton reduction reaction. Finally, recyclability experiments evidenced some decrease in the catalytic activity due to the well-known photobleaching/photodegradation of the ruthenium-based PS.

In 2019, the encapsulation of [ $\mathrm{Ni}^{\prime \prime}$ (bpet) $\left(\mathrm{H}_{2} \mathrm{O}\right)_{2}$ ] (bpet $=1,2-$ bis((pyridin-2-ylmethyl)thio)ethane) into the cages of the photoactive Ru-UiO-67 through a "ship-in-a-bottle" synthetic approach was reported by Yan et al.. ${ }^{163}$ An almost linear increase in the generation of $\mathrm{CO}$ was observed over the first 10 h upon irradiation with a LED lamp ( $82 \mathrm{~W}, \lambda=450 \mathrm{~nm}$ ) with 1,3dimethyl-2-phenyl-2,3-dihydro-1H-benzoimidazole $(\mathrm{BIH})$ as a sacrificial electron donor and TEOA. The Ni@Ru-UiO-67 composite loaded with $0.31 \mathrm{wt} \%$ of $\mathrm{Ni}$ complex exhibited a $\mathrm{CO}$ evolution rate of $426.0 \mu \mathrm{mol} \mathrm{g} \mathrm{g}^{-1} \mathrm{~h}^{-1}$ (yield: $85.2 \mathrm{mmol}$ ) with a TON of 510, while those with 0.15 wt\% and 0.23 wt\% loadings showed lower $\mathrm{CO}$ evolution rates of $55.2 \mu \mathrm{mol} \mathrm{g} \mathrm{g}^{-1} \mathrm{~h}^{-1}$ (yield: $11.0 \mu \mathrm{mol}$, TON: 136 ) and $196.8 \mu \mathrm{mol} \mathrm{g}^{-1} \mathrm{~h}^{-1}$ (yield: $39.3 \mu \mathrm{mol}$, TON: 317), respectively. These results highlighted the influence of the $\mathrm{Ni}$ loading on the performances of the material. At higher irradiation times $(20$ h) using 0.31wt\%Ni@UiO-67, CO production reaches a plateau with a TON of 581 and a CO selectivity $>99 \%$. From a mechanistic point of view, the combination of electrochemical experiments, advanced ultrafast absorption spectroscopy and theoretical calculations suggested that photoelectrons produced by the Ru-ligand fragments are directly transferred to the $\mathrm{Ni}(\mathrm{II})$ catalyst to form $\mathrm{Ni}^{0}$ species which reduce $\mathrm{CO}_{2}$ to $\mathrm{CO}$. Finally, a good stability and recyclability of the $0.31 \% w t N i @ M O F$ composite were found (Fig. 52). The heterogeneous system exhibited a better durability than the related homogeneous ones by limiting selfaggregation and oxidative self-degradation processes.
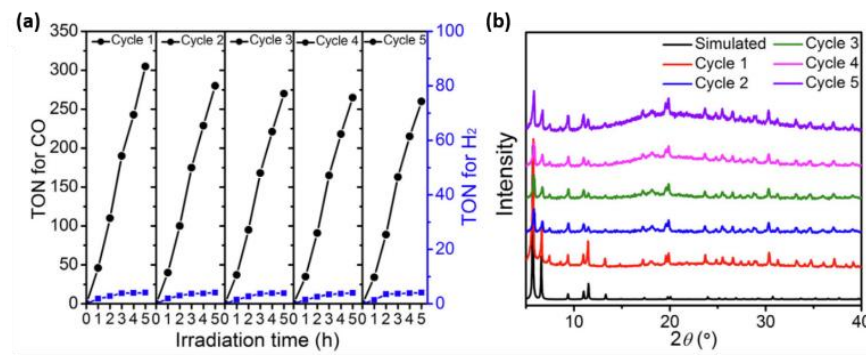

Fig. 52 a) Reusability test of 0.31\%Ni@Ru-UiO-67 in five consecutive runs and b) Powder XRD patterns for 0.31\%Ni@Ru-UiO-67 before and after successive catalytic runs. Reproduced from ref. ${ }^{163}$ Copyright 2019 Science China Press. Publishes by Elsevier B.V. and Science China Press.

Liu et al. reported in 2018 the encapsulation of $\left[\mathrm{PW}_{10} \mathrm{Ti}_{2} \mathrm{O}_{40}\right]^{7-}$ into HKUST-1 (NENU-10) where the POM acts as both an electron/proton reservoir and reactive centers for $\mathrm{CO}_{2}$ reduction and the deposition of $\mathrm{Au}$ nanoparticles for lightharvesting, affording the Au@PTi $2 \mathrm{~W}_{10} @ H K U S T-1$ (also named Au@NENU-10) composite. ${ }^{118}$ Under visible light irradiation, the composite showed $\mathrm{CO}$ and $\mathrm{H}_{2}$ yields of 12.8 and $2.6 \mu \mathrm{mol} \mathrm{g}^{-1} \mathrm{~h}^{-1}$, respectively (in addition to the production of methane), i.e. 85fold and 5-fold higher than those reported for the $\mathrm{PW}_{12-}$ containing analogue composite. The difference between crystal shapes of Au@NENU-10 and Au@NENU-3 was mentioned for explaining the improved catalytic performance of the Ti-POM system. Finally, the Au@NENU-10 composite exhibited an excellent structural stability over three catalytic cycles (Fig. 53).

The immobilization of $\mathrm{MCp}_{2}(\mathrm{M}=\mathrm{Fe}, \mathrm{Co}, \mathrm{Ni})$ metallocenes in the cavities of the porphyrinic MOF-545(Co) host was reported in 2020 by Chen, Lan and coworkers. ${ }^{166}$ The MCp ${ }_{2} @ M O F-545(\mathrm{Co})$ composites exhibit excellent catalysis performances in the electrocatalytic reduction of $\mathrm{CO}_{2}$ into CO.CoCp $\mathrm{C}_{2} @ \mathrm{MOF}-545$ (Co) was reported as the most efficient composite with a high Faradic efficiency $\mathrm{FE}_{\mathrm{CO}}$ of $97 \%$ at $-0.7 \mathrm{~V}$ when compared to that of the reference materials, MOF-545(Co) (54.6\%) and CoCp $\mathrm{p}_{2} @ \mathrm{MOF}-545$ (19.8\%). Relying on experimental evidences and DFT calculations (see above), the authors proposed that $\mathrm{CoCp}_{2}$ both enriches the electron density of the MOF structure and favors the adsorption of $\mathrm{CO}_{2}$ on the metallophorphyrin, supporting the better performances of the CoCp $p_{2} @ M O F-545(\mathrm{Co})$ composite over other materials for $\mathrm{CO}_{2}$ electrocatalytic reduction.
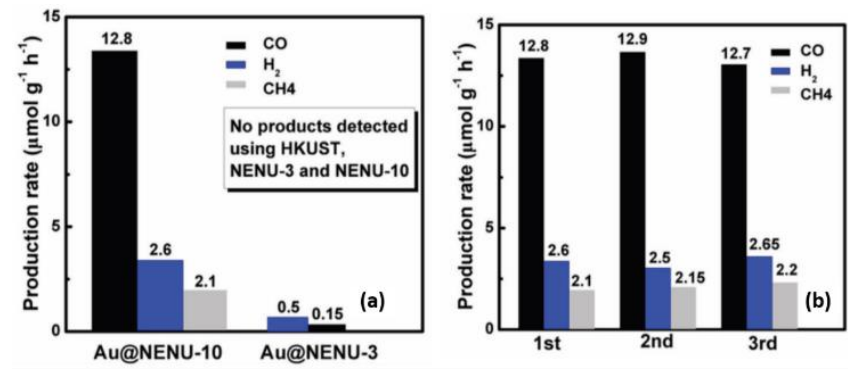

Fig. 53 a) Yields of $\mathrm{CO}, \mathrm{H}_{2}$, and $\mathrm{CH}_{4}$ from $\mathrm{CO}_{2}$ using Au@NENU-10 (Au@PW $10 \mathrm{Ti}_{2} @ H K U S T$ 1) and Au@NENU-3 (Au@PW $12 @ H K U S T-1)$ as photocatalysts under visible light irradiation for $5 \mathrm{~h}$, and b) Reusability tests with Au@NENU-10 photocatalyst. Reprinted from ref. ${ }^{118}$. Copyright 2018 Wiley. 
Finally, the co-immobilisation of the $\mathrm{PW}_{12} \mathrm{POM}$ and $\mathrm{Cp} * \mathrm{Rh}$ catalyst was reported with the $\left(\mathrm{PW}_{12}, \mathrm{Cp} \mathrm{P}^{*} \mathrm{Rh}\right) @ \mathrm{UiO}-67$ composite as catalytic composite for $\mathrm{CO}_{2}$ reduction. ${ }^{103}$ Although the $\mathrm{PW}_{12}$ guest is not catalytically active here, the POM can play for this reaction the role of proton or electron relay. The production of formate and $\mathrm{H}_{2}$ under visible-light irradiation (acetonitrile, TEOA as electron and proton donor, $\mathrm{Ru}(\mathrm{bpy})_{3} \mathrm{Cl}_{2}$ as PS) were indeed significantly enhanced with the (PW $\left.12, C p^{*} \mathrm{Rh}\right) @ U i \mathrm{U}-67$ composite when compared to those of the POM-free Cp*Rh@UiO-67. The (PW $12, C p * R h) @ U i O-67$ composite was also deposited as films on ITO plates, providing enhanced formate TONs when compared to the suspension (175 compared to 14.6 , at $3 \mathrm{~h}$ ), as well as evidence for the stability and the recyclability of the system. The former was attributed to the better illumination of the crystallites deposited on the ITO plate when compared to usual photocatalytic experiments performed on a suspension.

\subsubsection{Other photo/electro-catalytic reactions}

5.3.4.1 Oxidation reactions. In 2015, Liang et al. reported a photocatalyst resulting from the encapsulation of $\mathrm{PMo}_{12}$ in the pores of MIL-100(Fe) for the oxidation of benzyl alcohols. ${ }^{88}$ Under visible-light irradiation and $\mathrm{O}_{2}$ atmosphere, the higher photocatalytic activity of $\mathrm{PMo}_{12} @ \mathrm{MIL}-100(\mathrm{Fe})$ (with 30 wt\% $\mathrm{PMO}_{12}$ ) when compared to that of MIL-100(Fe) was assigned to enhanced light absorption and more efficient separation of the charge-carriers in the presence of the POM. The PMo ${ }_{12} @ M I L-$ 100 (Fe) material showed an excellent reusability over four catalytic cycles, the composite retaining its integrity during the catalysis process. The absence of Fe and Mo leaching during the course of reaction was indicative of the heterogenous nature of the catalytic event.
In 2019, the incorporation of $\left[\mathrm{Ru}(\mathrm{bpy})_{3}\right]^{2+}$ into the cavities of $\mathrm{NH}_{2}-\mathrm{MIL}-125$ (Ti) to catalyse the oxidation of benzyl alcohol was reported by Isaka et al.. ${ }^{161}$ While no significant amount of oxidised product was observed in homogeneous conditions with $\left[\mathrm{Ru}(\mathrm{bpy})_{3}\right]^{2+}$ as a catalyst (visible light, $\mathrm{O}_{2}$ saturated acetonitrile solution), Ru(bpy) ${ }_{3} @ \mathrm{NH}_{2}-\mathrm{MIL}-125$ (Ti) presented a high activity for the oxidation of benzyl alcohol into benzaldehyde (Fig. 54a). This was attributed to a synergic catalytic activity of the Ru complex (for reducing of $\mathrm{O}_{2}$ ) and $\mathrm{NH}_{2}-$ MIL-125(Ti) (for reducing benzaldehyde) which resulted in the rapid formation of $\mathrm{O}_{2}{ }^{\bullet-}$ and ${ }^{\circ} \mathrm{OH}$ species which were further involved in the substrate oxidation mechanism. It was checked that much lower amounts of benzaldehyde were formed when using the Ru complex-free MOF or a physical mixture of the Ru complex and of the MOF. No leaching of the Ru complex was observed after $8 \mathrm{~h}$ of reaction, and the catalytic activity of the $\mathrm{Ru}(\mathrm{bpy})_{3} @ \mathrm{NH}_{2}-\mathrm{MIL}-125$ (Ti) composite was maintained for at least three catalytic cycles.

Wang et al. reported in 2016 the encapsulation of the same $\left[\mathrm{Ru}(\mathrm{bpy})_{3}\right]^{2+}$ complex within the cavities of the anionic PCN-99 MOF in order to catalyse the aerobic hydroxylation of arylboronic acids. ${ }^{173}$ Yet, a reduced catalytic activity was observed for Ru(bpy) $@$ @PCN-99 when compared to that of $\left[\mathrm{Ru}(\mathrm{bpy})_{3}\right] \mathrm{Cl}_{2}$ in homogenous solution (Fig. 54b) which was attributed to the fact that the framework structure partially impedes the access of substrates. It was noted that the Ru(bpy) ${ }_{3} @ P C N-99$ composite maintained a similar activity in the second catalytic cycle while a slight leaching of $\left[\mathrm{Ru}(\mathrm{bpy})_{3}\right]^{2+}$ from the MOF was observed, possibly due to partial decomposition of the metal-organic framework under basic catalytic conditions. 


\section{ARTICLE}

a)

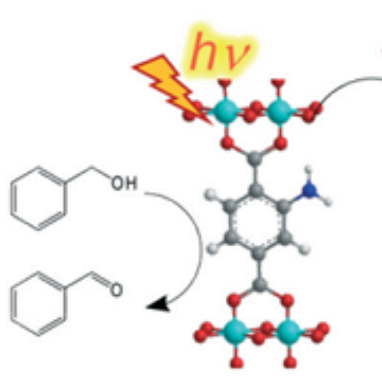

\section{hy}

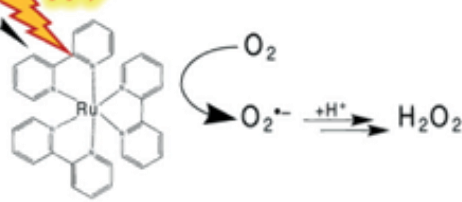

@PCN-99

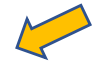

b)

\begin{tabular}{llll}
\hline Entry & $\mathrm{R}-$ & Catalyst & Conversion (\%) \\
\hline 1 & $\mathrm{COOMe}$ & {$\left[\mathrm{Ru}(\mathrm{bpy})_{3}\right] \mathrm{Cl}_{2}$} & 71.9 \\
2 & $\mathrm{COOMe}$ & $\mathrm{Ru}(\mathrm{bpy})_{3} @ \mathrm{PCN}-99$ & 59.0 \\
3 & $\mathrm{Me}$ & {$\left[\mathrm{Ru}(\mathrm{bpy})_{3}\right] \mathrm{Cl}_{2}$} & 89.4 \\
4 & $\mathrm{Me}$ & $\mathrm{Ru}(\mathrm{bpy})_{3} @ \mathrm{PCN}-99$ & 65.4 \\
5 & $\mathrm{CHO}$ & {$\left[\mathrm{Ru}(\mathrm{bpy})_{3}\right] \mathrm{Cl}_{2}$} & 70.8 \\
6 & $\mathrm{CHO}$ & $\mathrm{Ru}(\mathrm{bpy})_{3} @ \mathrm{PCN}_{3}-99$ & 45.9
\end{tabular}

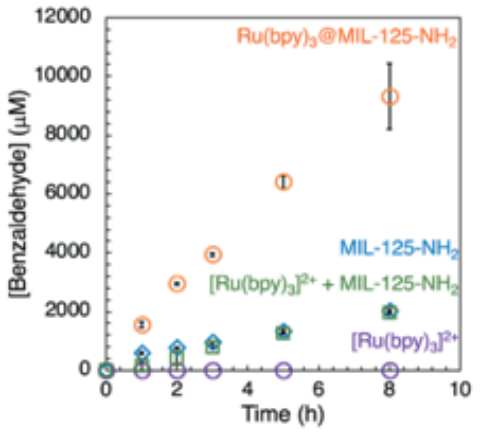

@NH $2-M I L-125(T i)$
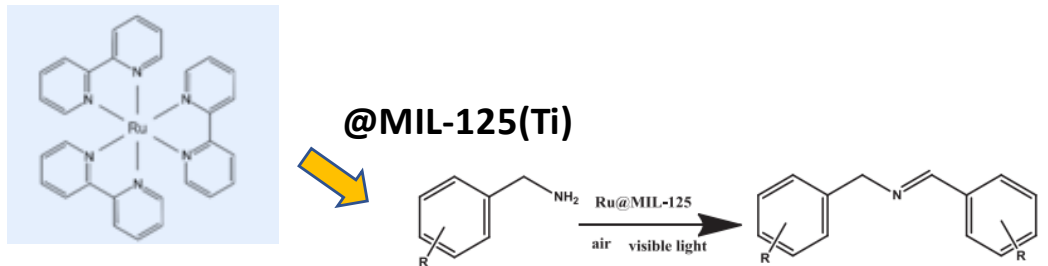

c)

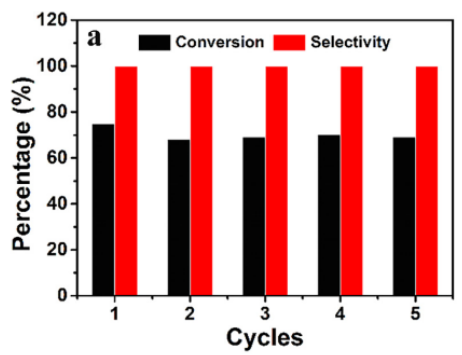

Fig. 54 Three examples of Ru(bpy) $)_{3} @$ MOF composites for photocatalytic oxidation reactions: (a) Benzaldehyde production from benzyl alcohol as a function of time using the $\mathrm{Ru}(\mathrm{bpy})_{3} @ \mathrm{NH}_{2}-\mathrm{MIL}-125$ catalytic composite (orange circle), $\left[\mathrm{Ru}(\mathrm{bpy})_{3}\right] \mathrm{Cl}_{2}$ (purple circle), $\mathrm{NH}_{2}-\mathrm{MIL}-125$ (blue diamond), and a physical mixture of $\left[\mathrm{Ru}(\mathrm{bpy})_{3}\right] \mathrm{Cl} \mathrm{L}_{2}$ and $\mathrm{NH} \mathrm{H}_{2}-\mathrm{MIL}-125$ (green rectangle) under visible-light irradiation $\left(\lambda>450 \mathrm{~nm}\right.$ ). Adapted from ref. ${ }^{161}$ with permission from the RSC (b) Visible-light-induced aerobic oxidative hydroxylation of arylboronic acid using Ru(bpy) ${ }_{3} @ P C N-99$ as catalyst. Adapted from ref. ${ }^{173}$ with permission from the RSC (d) Reusability tests on Ru(bpy) ${ }_{3} @ M I L-125$ for the aerobic coupling oxidation of benzylamine under visible-light illumination for 3 h. Adapted with permission from ref. ${ }^{158}$. Copyright 2019 Elsevier Inc.

In 2019, the incorporation of the Ru complex $\left[\mathrm{Ru}(\mathrm{bpy})_{3}\right]^{2+}$ into MIL-125(Ti) was also studied.158 The Ru(bpy) ${ }_{3} @ M I L-125(T i)$ composite with $0.58 \% \mathrm{Ru}$ content is an excellent catalyst to perform photooxidative coupling of amines to imines (Fig. 54c), with $75 \%$ conversion yield and a full selectivity within $3 \mathrm{~h}$ of reaction under visible-light irradiation and oxygen atmosphere. The crystalline structure of the MOF provided for the charge carriers short migration path to the surface for reacting with substrates. Ru@MIL-125(Ti) maintained its structural integrity after the reaction as well as its catalytic activity after five catalytic cycles (Fig. 54c).

5.3.4.2. Reduction reactions. The reduction of $\mathrm{Cr}(\mathrm{VI})$ by $\mathrm{PMo}_{12} @ \mathrm{MIL}-100$ (Fe) was reported in 2015 by Liang et al..88 With 5 wt\% of encapsulated $\mathrm{PMo}_{12}$ within the MOF-100(Fe) cavities, almost $100 \%$ reduction of $\mathrm{Cr}$ (IV) was observed after 8 min of visible-light illumination. The activity of the catalyst remained constant even after four catalytic cycles. Also, Fernandes et al. reported in 2014 an electroactive catalyst,
$\mathrm{SiW}_{11} \mathrm{Fe} @ \mathrm{MIL}-101(\mathrm{Cr})$, to carry out electrochemical nitrite and iodate reduction as well as ascorbic acid oxidation. ${ }^{37}$ The SiW11Fe@MIL-101(Cr) composite immobilised on a pyrolytic graphite electrode exhibited an excellent activity towards nitrite reduction with a limit of detection (LOD) of $3.2 \times 10^{-5} \mathrm{~mol}$ $\mathrm{dm}^{-3}$. This was somehow lower than that of SiW ${ }_{11} \mathrm{Fe}$ (LOD: $4.2 \times 10^{-5} \mathrm{~mol} \mathrm{dm}^{-3}$ ) but also lower than the LOD observed for $\mathrm{SiW}_{11} \mathrm{Fe}$ immobilised on other electrodes modified by other methodologies $\left(\approx 7.2 \times 10^{-5} \mathrm{~mol} \mathrm{dm}^{-3}\right)$. The higher sensitivity of $\mathrm{SiW}_{11} \mathrm{Fe} @ \mathrm{MIL}-101(\mathrm{Cr})$ was attributed to the higher concentration of $\mathrm{SiW}_{11} \mathrm{Fe}$ in porous MIL-101 than on a bare electrode surface. Similarly, the iodate electroreduction catalysed with SiW 11 Fe@MIL-101(Cr) showed a lower LOD $\left(3.0 \times 10^{-5} \mathrm{~mol} \mathrm{dm}^{-3}\right)$ than with $\mathrm{SiW}_{11} \mathrm{Fe}\left(5.9 \times 10^{-5} \mathrm{~mol} \mathrm{dm}^{-3}\right)$. Electrochemical characterisations revealed that only the POM moiety in SiW11 Fe@MIL-101(Cr) acts as catalyst in the electroreduction of these substrates. In contrast, the ascorbic acid electro-oxidation catalysed by $\mathrm{SiW}_{11} \mathrm{Fe} @ \mathrm{MIL}-101(\mathrm{Cr})$ was 
attributed to a synergic effect of the chromium centres of MIL$101(\mathrm{Cr})$ and the encapsulated $\mathrm{SiW}_{11} \mathrm{Fe}$ species.

\section{Conclusion}

While Cat@MOF composites involving the covalent grafting of the catalyst to the MOF have been widely explored, we have herein focused on a related and emerging sub-class of composites whereby the catalytic guest interacts with its MOF host via short-range host-guest interactions, electrostatic interactions or hydrogen bonding. Focusing on this kind of functionalised materials, this review shows that the field of these Cat@MOF materials has exploded over the last ten years, with a tremendous diversity of catalytic applications. Although seminal catalysts such as $\mathrm{PW}_{12}$ or metallated porphyrin or phthalocyanines have been privileged, an ever-growing variety of catalysts are incorporated into MOFs, leading to increasingly complex composites with excellent catalytic performances, stability and reusability. Such developments are allowed considering that three synthetic strategies - encapsulation, impregnation and "ship in a bottle" - are available, allowing synthetic chemists to adopt the most appropriate method to successfully immobilise molecular compounds known to be unstable under the MOF's synthetic conditions and/or of dimensions significantly larger than the dimensions of the MOF windows. Moreover, these rather simple synthetic approaches when compared to those required for the covalent grafting of the catalyst to the MOF can afford systems with strong and specific Cat/MOF interactions. This is highlighted in particular with the use of emerging characterization techniques such as PDF combined with theoretical calculations or solid-state NMR, which proved to be key in providing accurate structural descriptions of increasingly complex composites. Altogether, the numerous studies reported so far tend to confirm that such Cat@MOF composites offer specific advantages in view of their use in catalytic applications. Above all, the synthesis of Cat@MOF is an accessible route for turning molecular homogenous catalysts into heterogenous systems, whereby their stability may be increased due to their immobilisation into the MOF's pores or channels. In particular, this immobilization usually prevents the deactivation process, which generally occurs via the catalyst's aggregation in homogenous conditions, while ensuring the recyclability of the Cat@MOF as observed in most cases. It must be underlined also that in some composites, the MOF not only acts as a support for the molecular catalysts but can also play the role of co-catalyst leading sometimes to synergic effects. Still, one major drawback of these materials is that mass transfer processes can be hindered in MOF crystals with large sizes, preventing the diffusion of the reactants towards the catalytic sites. Another possible issue which may occur with Cat@MOF prepared by impregnation of the molecular catalyst is the resulting non-homogeneity in the catalyst's distribution. In that respect, the synthesis of nanocrystals of MOFs (the so-called nanoMOFs) is one very important way to improve both the homogeneity of the catalyst's distribution within the porous network and limit mass transfer issues. A further step is to deposit the particles of MOFs on solid supports as thin films to allow a better processability and improve their catalytic performances, as exemplified in recent photocatalytic studies. ${ }^{103,269}$ Another promising aspect of Cat@MOF is that the rational design of multi-component and thus multi-functional chemical systems is indeed possible, although still scarcely explored. Illustratively, we note that among the many Complex@MOFs and POM@MOFs considered in this review, less than a handful number of composites result from the co-immobilisation of two guests, whereby each guest has a specific role. We can cite the three composites, $\left(\mathrm{RhH}(\mathrm{CO})\left(\mathrm{PPh}_{3}\right)_{3}, \mathrm{PW}_{12} \mathrm{O}_{40}\right) @ \mathrm{MIL}-101(\mathrm{Cr}),{ }^{51}$

([Fe(salen) $\left.(\mathrm{OH})], \mathrm{SiW}_{12} \mathrm{O}_{40}\right) @ \mathrm{ZIF}-8^{139}$ and $\left(\mathrm{Cp}^{*} \mathrm{Rh}\left(4,4^{\prime}-\mathrm{bpydc}\right) \mathrm{Cl}\right.$, $\mathrm{Ru}(\mathrm{bpy})_{2}\left(4,4^{\prime}\right.$-bpydc))@NH $\mathrm{H}_{2}-\mathrm{MIL}-101$ (Al). ${ }^{153}$ In the first material, the catalyst is the Rh complex, while the POM helps the Rh complex immobilisation. Similarly, in the second one, the Fesalen is the active catalyst while the POM improves the loading of Fe-salen by facilitating electrical charge conduction and lowering the overall electrical resistance of the composite. In the third material, both the Rh catalytic complex and the Ru photosensitiser are co-confined into the MOF pores, which play the role of nanoreactors. These complementarities indicate that such multi-component approaches must lead to important future developments in this sub-class of materials for catalytic applications. We can finally underline that, importantly, efforts should be made for considering green routes for MOFs synthesis ${ }^{270}$ and selecting noble metal-free catalysts. Also, the limited conductivity of MOF-based materials remains a problem for electro(photo)catalytic applications. In this respect, the encapsulation of selected species (quantum dots, 271 complexes $\left.^{166} \quad \ldots\right)$ allow to boost the performance of the composites. Besides, thermal treatments up to the carbonisation of MOFs is a recent strategy to obtain new conductive carbonaceous materials with anchored single-atom catalysts (SACs) ${ }^{272}$. In such process, the use of Cat@MOFs is one way to obtain multi-metallic active sites (via the MOF and the Cat), especially interesting in view of electrochemical catalytic applications. As they represent a particularly appealing emerging family of catalysts, Cat@MOF may thus be also seen as precursors for the preparation of a new generation of highly active catalytic materials.

\section{Conflicts of interest}

There are no conflicts to declare.

\section{Acknowledgements}

This work was supported by CNRS, UVSQ, the Ministère de I'Enseignement Supérieur, de la Recherche et de l'Innovation, the French National Research Agency (ANR) as part of the 'Investissements d'Avenir' program No. ANR-11-IDEX-0003-02 and CHARMMMAT ANR-11-LABX-0039. We also acknowledge financial support from the Paris lle-de-France Region DIM 'Respore'. AD, PM, OO and CMD gratefully acknowledge all the students and colleagues who have worked with them on this 
subject and whose contribution is cited in this review. Alex Lemarchand is acknowledged for his help in the PDF section.

\section{Abbreviations}

AA

ABTS

B3LYP

bdpc

$B D C$

BET

BIH

$\mathrm{BMIPF}_{6}$

bpet

bpy

BT

BTC

$\mathrm{CB}$

CEES

CEESO

$\mathrm{CEESO}_{2}$

$\mathrm{COF}$

Adipic Acid

\section{2,2'-azidodi(3(ethylbenzthiazoline)}

Becke 3-parameters, Lee-Yang-Parr

4,4'-diphenyldicarboxylic acid

Benzenedicarboxylate

Brunauer-Emmett-Teller

1,3-dimethyl-2-phenyl-2,3-dihydro-1H-benzoimidazole

Resonnance

CTAB Cetyltrimethylammonium bromide

Cat Catalyst

$\mathrm{Cp}\left({ }^{*}\right) \quad$ (Pentamethyl)Cyclopentadiene

DAIL Dual Aminofunctionalized Ionic Liquid

DBT Dibenzothiophene

DED Difference Envelope Density

DMDBT Dimethyl Dibenzothiophene

DMF Dimethylformamide

DMMP Dimethyl methyl phosphonate

DMSO Dimethylsulfoxide

DNP

(d-)PDF

DRIFTS

Analysis

EDS

Double Numeric Polarisation

(a)

(differential-)Pair Distribution Function

Diffuse Reflectance Infrared Fourier Transform SpectroscopPS

Energy Dispersive X-Ray Spectroscopy

Ethyl Luminate

EMF 5-ethoxymethylfurfural

ESR Electron Spin Resonance

EXAFS Extended X-ray Absorption Fine Structure

FT-IR Fourier Transform - Infrared

GC-MS Gaz Chromatography - Mass Spectroscopy

GGA-PBE Generalised Gradient Approximation - Perdew-BurkeErnzerhof

$\mathrm{H}_{2}$ TMPyP $\quad$ 5,10,15,20-tetrakis(1-methyl-4-pyridinio)porphyrin

$\mathrm{H}_{4}$ TBAPy $\quad$ 1,3,6,8-tetrakis(p-benzoic-acid)

HD Sulfur Mustard

HDS Hydrodesulfuration

HER Hydrogen Evolution Reaction

HETCOR Heteronuclear Correlation

hhMb Horse heart hemoglobin

HKUST Hong Kong University of Science and Technology

HMF 5-hydroxymethylfurfural

HOCO Highest Occupied Crystal Orbital
HOMO Highest Occupied Molecular Orbital

HP Hierarchical Pore

HPW $\quad \mathrm{PW}_{12}$

HRTEM High Resolution Transmission Electron Microscopy

HSE06 Heyd-Scuseria-Ernzerhof 06

HT High-Throughput

ICP(-OES) Inductive Coupled Plasma(- Optic Emission Spectroscopy)

IL Ionic Liquid

Imp Impregnation

Iso Isoprene

LOD Limit Of Detection

LUCO Lowest Unoccupied Crystal Orbital

LUMO Lowest Unoccupied Molecular Orbital

M/G $\quad \mathrm{MoS}_{2} /$ reduced graphene oxide

MCM Mobil Composition of Matter

MCPBA meta-chloroperoxybenzoic acid

MIL Materials of Institut Lavoisier

MOF Metal-Organic Framework

MOMzyme Metal Organic Material enzyme

MP-11 Microperoxydase-11

MPS Methyl Phenyl Sulfide

MVK Methyl Vinyl Ketone

2-methylimidazolate

Mn-TAPP meso-tetrakis(2,3-dihydroxyphenyl)

porphyrinatomanganese(III)

MnTD [(terpy)Mn( $\mu-0) 2 \mathrm{Mn}$ (terpy) $]^{3+}$

NDC Naphtalene Dicarboxylate Modified

NENU North-east Normal University

NMO N-methylmorpholine $\mathrm{N}$-oxide

NU North-western University

ODS Oxydative Desulfuration

OER Oxygen Evolution Reaction

OPBE Optimised Perdew-Burke-Ernzerhof

PCN Porous Coordination Network

PG Pyrolytic graphite

POM Polyoxometalate

Photosensitiser

PSM Post-Synthetic Modification

Pc Phthalocyanine

(P)XRD (Powder)X-Ray Diffracition

RCM Ring-Closing olefin Metathesis

RT Room Temperature

SA Simulated Annealing

Salen $\quad \mathrm{N}, \mathrm{N}^{\prime}$-bis(salicylidene)ethylenediamine

SAXS Small-Angle $X$-ray Scattering

SB Ship in a bottle

SE Synthetic encapsulation

SEM Scanning Electron Microscopy

ST SuperTetrahedron

STEM-HAADF Scanning Transmission Electron Microscopy - High-angle annular dark-field imaging

SURMOF Surface-Anchored Metal-Organic-Framework

$T$ Thiophene

TBA Tetrabutylammonium

TBHP Tert-butyl hydroperoxide

tbupNP 2,6-bis((di-tert-butyl-phosphino)methyl)

TCPP Tetrakis(4-carboxyphenyl)porphyrin 
(TD-)DFT (Time Dependant-)Density Functional Theory

TEA

TEOA

terpy

TGA

THF

TMA

TMB

TOF

TON

TPA

UIO

VASP

XANES

XAS

XPS

ZIF

ZJU

ZMOF

Triethylamine

Triethanolamine

2,2',6',2"-terpyridine

Thermogravimetric Analysis

Tetrahydofuran

Trimethylammonium

3,3,5,5-tetramethylbenzidine

Turn-Over Frequency

Turn-Over Number

tris(2-pyridylmethy)-amine)

Universitetet i Oslo

Vienna Ab-Initio Simulation Package

$X$-ray Absorption Near Edge Structure

$X$-ray Absorption Spectroscopy

$\mathrm{X}$-ray Photoelectron Spectroscopy

Zeolitic Imidazolate Framework

Zhejiang University

Zeolite-like MOF

\section{Notes and references}

1 A. Dolbecq, E. Dumas, C. R. Mayer and P. Mialane, Chem. Rev., 2010, 110, 6009-6048.

2 S.-S. Wang and G.-Y. Yang, Chem. Rev., 2015, 115, 4893-4962.

3 A. Dhakshinamoorthy, Z. Li and H. Garcia, Chem. Soc. Rev., 2018, 47, 8134-8172.

4 J. D. Evans, C. J. Sumby and C. J. Doonan, Chem. Soc. Rev., 2014, 43, 5933-5951.

5 R. J. Marshall and R. S. Forgan, Eur. J. Inorg. Chem., 2016, 2016, 4310-4331.

6 S. M. Cohen, Chem. Rev., 2012, 112, 970-1000.

7 S. M. Cohen, J. Am. Chem. Soc., 2017, 139, 2855-2863.

8 J. Juan-Alcañiz, J. Gascon and F. Kapteijn, J. Mater. Chem., 2012, 22, 10102-10118.

9 C. T. Buru and O. K. Farha, ACS Appl. Mater. Interfaces, 2020, 12, 5345-5360.

10 M. Samaniyan, M. Mirzaei, R. Khajavian, H. Eshtiagh-Hosseini and C. Streb, ACS Catal., 2019, 9, 10174-10191.

11 C. Freire, D. M. Fernandes, M. Nunes and V. K. Abdelkader, ChemCatChem, 2018, 10, 1703-1730.

12 D.-Y. Du, J.-S. Qin, S.-L. Li, Z.-M. Su and Y.-Q. Lan, Chem Soc Rev, 2014, 43, 4615-4632.

13 J.-X. Liu, X.-B. Zhang, Y.-L. Li, S.-L. Huang and G.-Y. Yang, Coord. Chem. Rev., 2020, 414, 213260.

14 A. Bavykina, N. Kolobov, I. S. Khan, J. A. Bau, A. Ramirez and J. Gascon, Chem. Rev., 2020, 120, 8468-8535.

15 Z. Liang, C. Qu, D. Xia, R. Zou and Q. Xu, Angew. Chem. Int. Ed., 2018, 57, 9604-9633.

16 L. Chen, R. Luque and Y. Li, Chem. Soc. Rev., 2017, 46, 46144630.

17 G. Ferey, C. Mellot-Draznieks, C. Serre, F. Millange, J. Dutour, S. Surblé and I. Margiolaki, Science, 2005, 309, 2040-2042.

18 P. B. S. Rallapalli, M. C. Raj, S. Senthilkumar, R. S. Somani and H. C. Bajaj, Environ. Prog. Sustain. Energy, 2016, 35, 461-468.

19 C. Mellot-Draznieks, J. Mater. Chem., 2007, 17, 4348-4358.

20 C. Mellot-Draznieks and G. Férey, Prog. Solid State Chem., 2005, 33, 187-197.

21 M. Lammert, S. Bernt, F. Vermoortele, D. E. De Vos and N. Stock, Inorg. Chem., 2013, 52, 8521-8528.
22 S. Bhattacharjee, C. Chen and W.-S. Ahn, RSC Adv., 2014, 4, 52500-52525.

23 T. Wittmann, R. Siegel, N. Reimer, W. Milius, N. Stock and J. Senker, Chem. - Eur. J., 2015, 21, 314-323.

24 J. H. Cavka, S. Jakobsen, U. Olsbye, N. Guillou, C. Lamberti, S. Bordiga and K. P. Lillerud, J. Am. Chem. Soc., 2008, 130, 13850-13851.

25 G. Férey, C. Serre, C. Mellot-Draznieks, F. Millange, S. Surblé, J. Dutour and I. Margiolaki, Angew. Chem. Int. Ed., 2004, 116, 6456-6461.

26 G. Akiyama, R. Matsuda and S. Kitagawa, Chem. Lett., 2010, 39, 360-361.

27 P. Küsgens, M. Rose, I. Senkovska, H. Fröde, A. Henschel, S. Siegle and S. Kaskel, Microporous Mesoporous Mater., 2009, 120, 325-330.

28 M. Haouas, C. Volkringer, T. Loiseau, G. Férey and F. Taulelle, J. Phys. Chem. C, 2011, 115, 17934-17944.

29 I. Bezverkhyy, G. Weber and J.-P. Bellat, Microporous Mesoporous Mater., 2016, 219, 117-124.

30 N. V. Maksimchuk, K. A. Kovalenko, S. S. Arzumanov, Y. A. Chesalov, M. S. Melgunov, A. G. Stepanov, V. P. Fedin and O. A. Kholdeeva, Inorg. Chem., 2010, 49, 2920-2930.

31 I. C. M. S. Santos, S. S. Balula, M. M. Q. Simões, L. Cunha-Silva, M. G. P. M. S. Neves, B. de Castro, A. M. V. Cavaleiro and J. A. S. Cavaleiro, Catal. Today, 2013, 203, 87-94.

32 C. M. Granadeiro, A. D. S. Barbosa, S. Ribeiro, I. C. M. S. Santos, B. de Castro, L. Cunha-Silva and S. S. Balula, Catal. Sci. Technol., 2014, 4, 1416-1425.

33 Z. Saedi, S. Tangestaninejad, M. Moghadam, V. Mirkhani and I. Mohammadpoor-Baltork, J. Coord. Chem., 2012, 65, 463-473.

34 C. M. Granadeiro, A. D. S. Barbosa, P. Silva, F. A. A. Paz, V. K. Saini, J. Pires, B. de Castro, S. S. Balula and L. Cunha-Silva, Appl. Catal. Gen., 2013, 453, 316-326.

35 P. M. P. de Sousa, R. Grazina, A. D. S. Barbosa, B. de Castro, J. J. G. Moura, L. Cunha-Silva and S. S. Balula, Electrochimica Acta, 2013, 87, 853-859.

36 N. Maksimchuk, M. Timofeeva, M. Melgunov, A. Shmakov, Y. Chesalov, D. Dybtsev, V. Fedin and O. Kholdeeva, J. Catal., 2008, 257, 315-323.

37 D. M. Fernandes, C. M. Granadeiro, P. M. Paes de Sousa, R. Grazina, J. J. G. Moura, P. Silva, F. A. Almeida Paz, L. CunhaSilva, S. S. Balula and C. Freire, ChemElectroChem, 2014, 1, 1293-1300.

38 W. Salomon, F.-J. Yazigi, C. Roch-Marchal, P. Mialane, P. Horcajada, C. Serre, M. Haouas, F. Taulelle and A. Dolbecq, Dalton Trans, 2014, 43, 12698-12705.

39 D. Julião, A. C. Gomes, M. Pillinger, L. Cunha-Silva, B. de Castro, I. S. Gonçalves and S. S. Balula, Fuel Process. Technol., 2015, 131, 78-86.

40 A.-X. Yan, S. Yao, Y.-G. Li, Z.-M. Zhang, Y. Lu, W.-L. Chen and E.B. Wang, Chem. - Eur. J., 2014, 20, 6927-6933.

41 J. Juan-Alcañiz, E. V. Ramos-Fernandez, U. Lafont, J. Gascon and F. Kapteijn, J. Catal., 2010, 269, 229-241.

42 Y. Zhang, V. Degirmenci, C. Li and E. J. M. Hensen, ChemSusChem, 2011, 4, 59-64.

43 L. Bromberg and T. A. Hatton, ACS Appl. Mater. Interfaces, 2011, 3, 4756-4764.

44 L. Bromberg, Y. Diao, H. Wu, S. A. Speakman and T. A. Hatton, Chem. Mater., 2012, 24, 1664-1675.

45 X. Hu, Y. Lu, F. Dai, C. Liu and Y. Liu, Microporous Mesoporous Mater., 2013, 170, 36-44. 
46 S. Ribeiro, A. D. S. Barbosa, A. C. Gomes, M. Pillinger, I. S. Gonçalves, L. Cunha-Silva and S. S. Balula, Fuel Process. Technol., 2013, 116, 350-357.

47 A. E. R. S. Khder, H. M. A. Hassan and M. S. El-Shall, Appl. Catal. Gen., 2014, 487, 110-118.

48 Q. Deng, G. Nie, L. Pan, J.-J. Zou, X. Zhang and L. Wang, Green Chem., 2015, 17, 4473-4481.

49 M. Chen, J. Yan, Y. Tan, Y. Li, Z. Wu, L. Pan and Y. Liu, Ind. Eng. Chem. Res., 2015, 54, 11804-11813.

50 M. Saikia, D. Bhuyan and L. Saikia, Appl. Catal. Gen., 2015, 505, 501-506.

51 S. Sartipi, M. J. Valero Romero, E. Rozhko, Z. Que, H. A. Stil, J. de With, F. Kapteijn and J. Gascon, ChemCatChem, 2015, 7, 3243-3247.

52 X. Lai, Y. Liu, G. Yang, S. Liu, Z. Shi, Y. Lu, F. Luo and S. Liu, J. Mater. Chem. A, 2017, 5, 9611-9617.

53 S. Abednatanzi, K. Leus, P. G. Derakhshandeh, F. Nahra, K. De Keukeleere, K. Van Hecke, I. Van Driessche, A. Abbasi, S. P. Nolan and P. V. Der Voort, Catal. Sci. Technol., 2017, 7, 1478-1487.

54 M. Taherimehr, B. Van de Voorde, L. H. Wee, J. A. Martens, D. E. De Vos and P. P. Pescarmona, ChemSusChem, 2017, 10, 1283-1291.

55 M. Sun, W.-C. Chen, L. Zhao, X.-L. Wang and Z.-M. Su, Inorg. Chem. Commun., 2018, 87, 30-35.

56 J.-S. Li, X.-J. Sang, W.-L. Chen, L.-C. Zhang, Z.-M. Zhu, Y.-G. Li, Z.-M. Su and E.-B. Wang, J. Mater. Chem. A, 2015, 3, 1457314577.

57 A. Marandi, S. Tangestaninejad, M. Moghadam, V. Mirkhani, A. Mechler, I. Mohammadpoor-Baltork and F. Zadehahmadi, Appl. Organomet. Chem., 2018, 32, e4065.

58 A. Marandi, M. Bahadori, S. Tangestaninejad, M. Moghadam, V. Mirkhani, I. Mohammadpoor-Baltork, R. Frohnhoven, S. Mathur, A. Sandleben and A. Klein, New J. Chem., 2019, 43, 15585-15595.

59 H. Li, S. Yao, H.-L. Wu, J.-Y. Qu, Z.-M. Zhang, T.-B. Lu, W. Lin and E.-B. Wang, Appl. Catal. B Environ., 2018, 224, 46-52.

60 A. Jarrah and S. Farhadi, RSC Adv., 2018, 8, 37976-37992.

61 E. Naseri and R. Khoshnavazi, RSC Adv., 2018, 8, 28249-28260.

62 S. S. Balula, C. M. Granadeiro, A. D. S. Barbosa, I. C. M. S. Santos and L. Cunha-Silva, Catal. Today, 2013, 210, 142148.

63 J. Han, D. Wang, Y. Du, S. Xi, Z. Chen, S. Yin, T. Zhou and R. Xu, Appl. Catal. Gen., 2016, 521, 83-89.

64 C. M. Granadeiro, P. Silva, V. K. Saini, F. A. A. Paz, J. Pires, L. Cunha-Silva and S. S. Balula, Catal. Today, 2013, 218, 35-42.

65 S. Ribeiro, C. M. Granadeiro, P. Silva, F. A. Almeida Paz, F. F. de Biani, L. Cunha-Silva and S. S. Balula, Catal. Sci. Technol., 2013, 3, 2404-2414.

66 C. M. Granadeiro, L. S. Nogueira, D. Julião, F. Mirante, D. Ananias, S. S. Balula and L. Cunha-Silva, Catal. Sci. Technol., 2016, 6, 1515-1522.

67 D. M. Fernandes, A. D. S. Barbosa, J. Pires, S. S. Balula, L. Cunha-Silva and C. Freire, ACS Appl. Mater. Interfaces, 2013, 5, 13382-13390.

68 Y. Li, Q. Gao, L. Zhang, Y. Zhou, Y. Zhong, Y. Ying, M. Zhang, C. Huang and Y. Wang, Dalton Trans., 2018, 47, 6394-6403.

69 C. Roch-Marchal, T. Hidalgo, H. Banh, R. A. Fischer and P. Horcajada, Eur. J. Inorg. Chem., 2016, 2016, 4387-4394.

70 X.-S. Wang, Y.-B. Huang, Z.-J. Lin and R. Cao, Dalton Trans, 2014, 43, 11950-11958.
71 C. Granadeiro, P. Ferreira, D. Julião, L. Ribeiro, R. Valença, J. Ribeiro, I. Gonçalves, B. de Castro, M. Pillinger, L. Cunha-Silva and S. Balula, Energies, 2018, 11, 1696.

72 D. Julião, A. C. Gomes, M. Pillinger, R. Valença, J. C. Ribeiro, B. de Castro, I. S. Gonçalves, L. Cunha Silva and S. S. Balula, Eur. J. Inorg. Chem., 2016, 2016, 5114-5122.

73 J. Yan, W.-Z. Zhou, H. Tan, X.-J. Feng, Y.-H. Wang and Y.-G. Li, CrystEngComm, 2016, 18, 8762-8768.

74 E. V. Ramos-Fernandez, C. Pieters, B. van der Linden, J. JuanAlcañiz, P. Serra-Crespo, M. W. G. M. Verhoeven, H. Niemantsverdriet, J. Gascon and F. Kapteijn, J. Catal., 2012, 289, 42-52.

75 J. Juan-Alcañiz, M. Goesten, A. Martinez-Joaristi, E. Stavitski, A. V. Petukhov, J. Gascon and F. Kapteijn, Chem. Commun., 2011, 47, 8578-8580.

76 L. Bromberg, X. Su and T. A. Hatton, ACS Appl. Mater. Interfaces, 2013, 5, 5468-5477.

77 S. Abednatanzi, A. Abbasi and M. Masteri-Farahani, Catal. Commun., 2017, 96, 6-10.

78 A. Micek-IInicka and B. Gil, Dalton Trans., 2012, 41, 1262412629.

79 F. Zhang, Y. Jin, J. Shi, Y. Zhong, W. Zhu and M. S. El-Shall, Chem. Eng. J., 2015, 269, 236-244.

80 X.-S. Wang, L. Li, J. Liang, Y.-B. Huang and R. Cao, ChemCatChem, 2017, 9, 971-979.

81 N. Nobakht, M. A. Faramarzi, A. Shafiee, M. Khoobi and E. Rafiee, Int. J. Biol. Macromol., 2018, 113, 8-19.

82 H. Wan, C. Chen, Z. Wu, Y. Que, Y. Feng, W. Wang, L. Wang, G. Guan and X. Liu, ChemCatChem, 2015, 7, 441-449.

83 W. A. Shah, A. Waseem, M. A. Nadeem and P. Kögerler, Appl. Catal. Gen., 2018, 567, 132-138.

84 J. Tong, W. Wang, L. Su, Q. Li, F. Liu, W. Ma, Z. Lei and L. Bo, Catal. Sci. Technol., 2017, 7, 222-230.

85 M. Zhang, A.-M. Zhang, X.-X. Wang, Q. Huang, X. Zhu, X.-L. Wang, L.-Z. Dong, S.-L. Li and Y.-Q. Lan, J. Mater. Chem. A, 2018, 6, 8735-8741.

86 W. A. Shah, L. Noureen, M. A. Nadeem and P. Kögerler, J. Solid State Chem., 2018, 268, 75-82.

87 R. Canioni, C. Roch-Marchal, F. Sécheresse, P. Horcajada, C. Serre, M. Hardi-Dan, G. Férey, J.-M. Grenèche, F. Lefebvre, J.S. Chang, Y.-K. Hwang, O. Lebedev, S. Turner and G. Van Tendeloo, J Mater Chem, 2011, 21, 1226-1233.

88 R. Liang, R. Chen, F. Jing, N. Qin and L. Wu, Dalton Trans., 2015, 44, 18227-18236.

89 J. Juan-Alcañiz, M. G. Goesten, E. V. Ramos-Fernandez, J. Gascon and F. Kapteijn, New J. Chem., 2012, 36, 977-987.

90 J. Chen, S. Wang, J. Huang, L. Chen, L. Ma and X. Huang, ChemSusChem, 2013, 6, 1545-1555.

91 X.-L. Yang, L.-M. Qiao and W.-L. Dai, Microporous Mesoporous Mater., 2015, 211, 73-81.

92 W. Xie, X. Yang and P. Hu, Catal. Lett., 2017, 147, 2772-2782.

93 J. Feng, M. Li and X. Meng, Catal. Lett., 2019, 149, 1504-1512.

94 Q. Zhang, T. Yang, X. Liu, C. Yue, L. Ao, T. Deng and Y. Zhang, RSC Adv., 2019, 9, 16357-16365.

95 Q. Zhang, D. Lei, Q. Luo, J. Wang, T. Deng, Y. Zhang and P. Ma, RSC Adv., 2020, 10, 8766-8772.

96 X. Zhang, Z. Zhang, B. Zhang, X. Yang, X. Chang, Z. Zhou, D.-H. Wang, M.-H. Zhang and X.-H. Bu, Appl. Catal. B Environ., 2019, 256, 117804

97 X. Chang, X. Yang, Y. Qiao, S. Wang, M. Zhang, J. Xu, D. Wang and X. Bu, Small, 2020, 16, 1906432. 
98 P. Tian, X. He, W. Li, L. Zhao, W. Fang, H. Chen, F. Zhang, W. Zhang and W. Wang, J. Mater. Sci., 2018, 53, 12016-12029.

99 W. Xie and F. Wan, Chem. Eng. J., 2019, 365, 40-50.

100 W. Salomon, A. Dolbecq, C. Roch-Marchal, G. Paille, R. Dessapt, P. Mialane and H. Serier-Brault, Front. Chem., 2019, 6, 188-193.

101 W. Salomon, C. Roch-Marchal, P. Mialane, P. Rouschmeyer, C. Serre, M. Haouas, F. Taulelle, S. Yang, L. Ruhlmann and A. Dolbecq, Chem. Commun., 2015, 51, 2972-2975.

102 Y.-L. Peng, J. Liu, H.-F. Zhang, D. Luo and D. Li, Inorg. Chem. Front., 2018, 5, 1563-1569.

103 Y. Benseghir, A. Lemarchand, M. Duguet, P. Mialane, M. Gomez-Mingot, C. Roch-Marchal, T. Pino, M.-H. Ha-Thi, M. Haouas, M. Fontecave, A. Dolbecq, C. Sassoye and C. Mellot-Draznieks, J. Am. Chem. Soc., 2020, 142, 9428-9438.

104 Y. Bu, F. Li, Y. Zhang, R. Liu, X. Luo and L. Xu, RSC Adv., 2016, 6, 40560-40566.

105 Z.-M. Zhang, T. Zhang, C. Wang, Z. Lin, L.-S. Long and W. Lin, J. Am. Chem. Soc., 2015, 137, 3197-3200.

106 X.-J. Kong, Z. Lin, Z.-M. Zhang, T. Zhang and W. Lin, Angew. Chem. Int. Ed., 2016, 55, 6411-6416.

107 X. Song, D. Hu, X. Yang, H. Zhang, W. Zhang, J. Li, M. Jia and J. Yu, ACS Sustain. Chem. Eng., 2019, 7, 3624-3631.

108 G. Paille, M. Gomez-Mingot, C. Roch-Marchal, B. LassalleKaiser, P. Mialane, M. Fontecave, C. Mellot-Draznieks and A. Dolbecq, J. Am. Chem. Soc., 2018, 140, 3613-3618.

109 M. Duguet, A. Lemarchand, Y. Benseghir, P. Mialane, M. Gomez-Mingot, C. Roch-Marchal, M. Haouas, M. Fontecave, C. Mellot-Draznieks, C. Sassoye and A. Dolbecq, Chem. Commun., 2020, 56, 10143-10146.

110 C. T. Buru, P. Li, B. L. Mehdi, A. Dohnalkova, A. E. Platero-Prats, N. D. Browning, K. W. Chapman, J. T. Hupp and O. K. Farha, Chem. Mater., 2017, 29, 5174-5181.

111 C. T. Buru, Ana. E. Platero-Prats, D. G. Chica, M. G. Kanatzidis, K. W. Chapman and O. K. Farha, J. Mater. Chem. A, 2018, 6, 7389-7394.

112 S. Ahn, S. L. Nauert, C. T. Buru, M. Rimoldi, H. Choi, N. M. Schweitzer, J. T. Hupp, O. K. Farha and J. M. Notestein, J. Am. Chem. Soc., 2018, 140, 8535-8543.

113 C. T. Buru, M. C. Wasson and O. K. Farha, ACS Appl. Nano Mater., 2020, 3, 658-664.

114 C. T. Buru, J. Lyu, J. Liu and O. K. Farha, Front. Mater., 2019, 6, 152.

115 Z.-J. Lin, H.-Q. Zheng, J. Chen, W.-E. Zhuang, Y.-X. Lin, J.-W. Su, Y.-B. Huang and R. Cao, Inorg. Chem., 2018, 57, 13009-13019.

116 J. Zhu, M. Shen, X. Zhao, P. Wang and M. Lu, ChemPlusChem, 2014, 79, 872-878.

117 J. Zhu, P. Wang and M. Lu, Catal. Sci. Technol., 2015, 5, 33833393.

118 S.-M. Liu, Z. Zhang, X. Li, H. Jia, M. Ren and S. Liu, Adv. Mater. Interfaces, 2018, 5, 1801062.

119 J. Song, Z. Luo, D. K. Britt, H. Furukawa, O. M. Yaghi, K. I. Hardcastle and C. L. Hill, J. Am. Chem. Soc., 2011, 133, 1683916846.

120 C. Li, M. Sun, L. Xu, Y. Wang and J. Huang, CrystEngComm, 2016, 18, 596-600.

121 C.-Y. Sun, S.-X. Liu, D.-D. Liang, K.-Z. Shao, Y.-H. Ren and Z.-M. Su, J. Am. Chem. Soc., 2009, 131, 1883-1888.

122 L. Yang, H. Naruke and T. Yamase, Inorg. Chem. Commun., 2003, 6, 1020-1024.
123 F.-J. Ma, S.-X. Liu, C.-Y. Sun, D.-D. Liang, G.-J. Ren, F. Wei, Y.G. Chen and Z.-M. Su, J. Am. Chem. Soc., 2011, 133, 41784181.

124 L. H. Wee, S. R. Bajpe, N. Janssens, I. Hermans, K. Houthoofd, C. E. A. Kirschhock and J. A. Martens, Chem. Commun., 2010, 46, 8186-8188.

125 L. H. Wee, N. Janssens, S. R. Bajpe, C. E. A. Kirschhock and J. A. Martens, Catal. Today, 2011, 171, 275-280.

126 X. Yang, L. Qiao and W. Dai, Chin. J. Catal., 2015, 36, 18751885.

127 E. Rafiee and N. Nobakht, J. Mol. Catal. Chem., 2015, 398, 1725.

128 Y. Liu, S. Liu, D. He, N. Li, Y. Ji, Z. Zheng, F. Luo, S. Liu, Z. Shi and C. Hu, J. Am. Chem. Soc., 2015, 137, 12697-12703.

129 X. Zhong, Y. Lu, F. Luo, Y. Liu, X. Li and S. Liu, Chem. - Eur. J., 2018, 24, 3045-3051.

130 D.-D. Liang, S.-X. Liu, F.-J. Ma, F. Wei and Y.-G. Chen, Adv. Synth. Catal., 2011, 353, 733-742.

131 F.-J. Ma, S.-X. Liu, G.-J. Ren, D.-D. Liang and S. Sha, Inorg. Chem. Commun., 2012, 22, 174-177.

132 Y. Liu, S. Liu, S. Liu, D. Liang, S. Li, Q. Tang, X. Wang, J. Miao, Z. Shi and Z. Zheng, ChemCatChem, 2013, 5, 3086-3091.

133 X.-H. Li, Y.-W. Liu, S.-M. Liu, S. Wang, L. Xu, Z. Zhang, F. Luo, Y. Lu and S.-X. Liu, J. Mater. Chem. A, 2018, 6, 4678-4685.

134 X.-H. Li, Y.-W. Liu, Y. Lu, Z. Zhang, H.-R. Tian, S.-M. Liu and S.-X. Liu, Chem. Commun., 2020, 56, 1641-1644.

135 Z. Wang and Q. Chen, Green Chem., 2016, 18, 5884-5889.

136 J.-W. Sun, P.-F. Yan, G.-H. An, J.-Q. Sha, G.-M. Li and G.-Y. Yang, Sci. Rep., 2016, 6, 25595.

137 P. Wei, Y. Yang, W. Li and G. Li, Fuel, 2020, 274, 117834

138 R. Li, X. Ren, J. Zhao, X. Feng, X. Jiang, X. Fan, Z. Lin, X. Li, C. Hu and B. Wang, J Mater Chem A, 2014, 2, 2168-2173.

139 S. Mukhopadhyay, O. Basu, A. Kar and S. K. Das, Inorg. Chem., 2020, 59, 472-483.

140 V. K. Abdelkader-Fernández, D. M. Fernandes, S. S. Balula, L. Cunha-Silva and C. Freire, ACS Appl. Energy Mater., 2020, 3, 2925-2934.

141 X. Zhao, Y. Duan, F. Yang, W. Wei, Y. Xu and C. Hu, Inorg. Chem., 2017, 56, 14506-14512.

142 Q. Lan, Z.-M. Zhang, C. Qin, X.-L. Wang, Y.-G. Li, H.-Q. Tan and E.-B. Wang, Chem. - Eur. J., 2016, 22, 15513-15520.

143 B. Nepal and S. Das, Angew. Chem. Int. Ed., 2013, 52, 72247227

144 E. Kockrick, T. Lescouet, E. V. Kudrik, A. B. Sorokin and D. Farrusseng, Chem Commun, 2011, 47, 1562-1564.

145 O. V. Zalomaeva, K. A. Kovalenko, Y. A. Chesalov, M. S. Mel'gunov, V. I. Zaikovskii, V. V. Kaichev, A. B. Sorokin, O. A. Kholdeeva and V. P. Fedin, Dalton Trans., 2011, 40, 14411444.

146 H. D. Park, M. Dincă and Y. Román-Leshkov, ACS Cent. Sci., 2017, 3, 444-448.

147 Y. Wu, W. Wang, L. Liu, S. Zhu, X. Wang, E. Hu and K. Hu, ChemistryOpen, 2019, 8, 333-338.

148 M. B. Boroujeni, A. Hashemzadeh, A. Shaabani and M. M. Amini, Appl. Organomet. Chem., 2017, 31, e3715.

149 A. D. Yeganeh, M. M. Amini and N. Safari, J. Porphyr. Phthalocyanines, 2019, 23, 1118-1131.

150 T. Bogaerts, A. Van Yperen-De Deyne, Y.-Y. Liu, F. Lynen, V. Van Speybroeck and P. Van Der Voort, Chem. Commun., 2013, 49, 8021-8023.

151 F.-X. Qin, S.-Y. Jia, F.-F. Wang, S.-H. Wu, J. Song and Y. Liu, Catal. Sci. Technol., 2013, 3, 2761-2768. 
152 A. Chołuj, A. Zieliński, K. Grela and M. J. Chmielewski, ACS Catal., 2016, 6, 6343-6349.

153 X. Wang, F. M. Wisser, J. Canivet, M. Fontecave and C. MellotDraznieks, ChemSusChem, 2018, 11, 3315-3322.

154 D. T. Genna, L. Y. Pfund, D. C. Samblanet, A. G. Wong-Foy, A. J. Matzger and M. S. Sanford, ACS Catal., 2016, 6, 3569-3574.

155 A. Grigoropoulos, A. I. McKay, A. P. Katsoulidis, R. P. Davies, A. Haynes, L. Brammer, J. Xiao, A. S. Weller and M. J. Rosseinsky, Angew. Chem. Int. Ed., 2018, 57, 4532-4537.

156 Y. Chen, B. Fan, N. Lu and R. Li, Catal. Commun., 2015, 64, 9195.

157 P. Miao, G. Li, G. Zhang and H. Lu, J. Energy Chem., 2014, 23, 507-512.

158 X. Yang, T. Huang, S. Gao and R. Cao, J. Catal., 2019, 378, 248255.

159 M. A. Nasalevich, R. Becker, E. V. Ramos-Fernandez, S. Castellanos, S. L. Veber, M. V. Fedin, F. Kapteijn, J. N. H. Reek, J. I. van der Vlugt and J. Gascon, Energy Environ. Sci., 2015, 8, 364-375.

160 Z. Li, J.-D. Xiao and H.-L. Jiang, ACS Catal., 2016, 6, 5359-5365.

161 Y. Isaka, Y. Kondo, Y. Kuwahara, K. Mori and H. Yamashita, Catal. Sci. Technol., 2019, 9, 1511-1517.

162 R. W. Larsen and L. Wojtas, J. Solid State Chem., 2017, 247, 77-82.

163 Z.-H. Yan, B. Ma, S.-R. Li, J. Liu, R. Chen, M.-H. Du, S. Jin, G.-L. Zhuang, L.-S. Long, X.-J. Kong and L.-S. Zheng, Sci. Bull., 2019, 64, 976-985.

164 R. Chen, J. Zhang, J. Chelora, Y. Xiong, S. V. Kershaw, K. F. Li, P.K. Lo, K. W. Cheah, A. L. Rogach, J. A. Zapien and C.-S. Lee, ACS Appl. Mater. Interfaces, 2017, 9, 5699-5708.

165 K. Sasan, Q. Lin, C. Mao and P. Feng, Chem. Commun., 2014, 50, 10390-10393.

166 Z. Xin, Y.-R. Wang, Y. Chen, W.-L. Li, L.-Z. Dong and Y.-Q. Lan, Nano Energy, 2020, 67, 104233.

167 N. Sharma, S. S. Dhankhar and C. M. Nagaraja, Sustain. Energy Fuels, 2019, 3, 2977-2982.

168 W. Zhang, Y. Wang, Y. Leng, P. Zhang, J. Zhang and P. Jiang, Catal. Sci. Technol., 2016, 6, 5848-5855.

169 D. Chen, R. Luo, M. Li, M. Wen, Y. Li, C. Chen and N. Zhang, Chem. Commun., 2017, 53, 10930-10933.

170 R. W. Larsen, L. Wojtas, J. Perman, R. L. Musselman, M. J. Zaworotko and C. M. Vetromile, J. Am. Chem. Soc., 2011, 133, 10356-10359.

171 D. T. Genna, A. G. Wong-Foy, A. J. Matzger and M. S. Sanford, J. Am. Chem. Soc., 2013, 135, 10586-10589.

172 A. Grigoropoulos, G. F. S. Whitehead, N. Perret, A. P. Katsoulidis, F. M. Chadwick, R. P. Davies, A. Haynes, L. Brammer, A. S. Weller, J. Xiao and M. J. Rosseinsky, Chem. Sci., 2016, 7, 2037-2050.

173 X. Wang, W. Lu, Z.-Y. Gu, Z. Wei and H.-C. Zhou, Chem. Commun., 2016, 52, 1926-1929.

174 M. H. Alkordi, Y. Liu, R. W. Larsen, J. F. Eubank and M. Eddaoudi, J. Am. Chem. Soc., 2008, 130, 12639-12641.

175 D. Masih, V. Chernikova, O. Shekhah, M. Eddaoudi and O. F. Mohammed, ACS Appl. Mater. Interfaces, 2018, 10, 1139911405

176 H. Wu, Y. S. Chua, V. Krungleviciute, M. Tyagi, P. Chen, T. Yildirim and W. Zhou, J. Am. Chem. Soc., 2013, 135, 1052510532.

177 K. Leus, T. Bogaerts, J. De Decker, H. Depauw, K. Hendrickx, H. Vrielinck, V. Van Speybroeck and P. Van Der Voort, Microporous Mesoporous Mater., 2016, 226, 110-116.
178 W. Morris, B. Volosskiy, S. Demir, F. Gándara, P. L. McGrier, H. Furukawa, D. Cascio, J. F. Stoddart and O. M. Yaghi, Inorg. Chem., 2012, 51, 6443-6445.

179 D. Feng, Z.-Y. Gu, J.-R. Li, H.-L. Jiang, Z. Wei and H.-C. Zhou, Angew. Chem. Int. Ed., 2012, 51, 10307-10310.

180 H.-Q. Xu, J. Hu, D. Wang, Z. Li, Q. Zhang, Y. Luo, S.-H. Yu and H.-L. Jiang, J. Am. Chem. Soc., 2015, 137, 13440-13443.

181 J. E. Mondloch, W. Bury, D. Fairen-Jimenez, S. Kwon, E. J. DeMarco, M. H. Weston, A. A. Sarjeant, S. T. Nguyen, P. C. Stair, R. Q. Snurr, O. K. Farha and J. T. Hupp, J. Am. Chem. Soc., 2013, 135, 10294-10297.

182 J. E. Mondloch, M. J. Katz, N. Planas, D. Semrouni, L. Gagliardi, J. T. Hupp and O. K. Farha, Chem. Commun., 2014, 50, 89448946.

183 S. S.-Y. Chui, S. M.-F. Lo, J. P. H. Charmant, A. G. Orpen and I. D. Williams, Science, 1999, 283, 1148-1150.

184 K. S. Park, Z. Ni, A. P. Côté, J. Y. Choi, R. Huang, F. J. UribeRomo, H. K. Chae, M. O'Keeffe and O. M. Yaghi, Proc. Natl. Acad. Sci., 2006, 103, 10186-10191.

185 J. F. Keggin, Nature, 1933, 131, 908-909.

186 A. Téazéa, G. Hervéa, R. G. Finke and D. K. Lyon, in Inorganic Syntheses, ed. A. P. Ginsberg, John Wiley \& Sons, Inc., Hoboken, NJ, USA, 2007, pp. 85-96.

187 T. J. R. Weakley, H. T. Evans, J. S. Showell, G. F. Tourné and C. M. Tourné, J. Chem. Soc. Chem. Commun., 1973, 139-140.

188 K. Sakamoto and E. Ohno-Okumura, Materials, 2009, 2, 11271179.

189 H. Rao, C.-H. Lim, J. Bonin, G. M. Miyake and M. Robert, J. Am. Chem. Soc., 2018, 140, 17830-17834.

190 W. Zhang, W. Lai and R. Cao, Chem. Rev., 2017, 117, 37173797.

191 M. Costas, Coord. Chem. Rev., 2011, 255, 2912-2932.

192 E. Rose, B. Andrioletti, S. Zrig and M. Quelquejeu-Ethève, Chem. Soc. Rev., 2005, 34, 573-583.

193 C. Costentin, M. Robert and J.-M. Savéant, Acc. Chem. Res., 2015, 48, 2996-3006.

194 I. Azcarate, C. Costentin, M. Robert and J.-M. Savéant, J. Phys. Chem. C, 2016, 120, 28951-28960.

195 V. Balzani, A. Juris, M. Venturi, S. Campagna and S. Serroni, Chem. Rev., 1996, 96, 759-834.

196 H. Takeda, K. Koike, H. Inoue and O. Ishitani, J. Am. Chem. Soc., 2008, 130, 2023-2031.

197 M. Tokunaga, J. F. Larrow, F. Kakiuchi and E. N. Jacobsen, Science, 1997, 277, 936-938.

198 D. J. Darensbourg, Chem. Rev., 2007, 107, 2388-2410.

199 S. L. James, C. J. Adams, C. Bolm, D. Braga, P. Collier, T. Friščić, F. Grepioni, K. D. M. Harris, G. Hyett, W. Jones, A. Krebs, J. Mack, L. Maini, A. G. Orpen, I. P. Parkin, W. C. Shearouse, J. W. Steed and D. C. Waddell, Chem Soc Rev, 2012, 41, 413447.

200 B. Szczęśniak, S. Borysiuk, J. Choma and M. Jaroniec, Mater. Horiz., 2020, 7, 1457-1473.

201 Z. Li, T. M. Rayder, L. Luo, J. A. Byers and C.-K. Tsung, J. Am. Chem. Soc., 2018, 140, 8082-8085.

202 F.-J. Ma, S.-X. Liu, D.-D. Liang, G.-J. Ren, F. Wei, Y.-G. Chen and Z.-M. Su, J. Solid State Chem., 2011, 184, 3034-3039.

203 S. Mukhopadhyay, J. Debgupta, C. Singh, A. Kar and S. K. Das, Angew. Chem. Int. Ed., 2018, 130, 1936-1941.

204 E. Gkaniatsou, C. Sicard, R. Ricoux, L. Benahmed, F. Bourdreux, Q. Zhang, C. Serre, J. Mahy and N. Steunou, Angew. Chem. Int. Ed., 2018, 130, 16373-16378. 
205 Q. Y. Li, L. Zhang, Y. X. Xu, Q. Li, H. Xue and H. Pang, ACS Sustain. Chem. Eng., 2019, 7, 5027-5033.

206 S. R. Bajpe, C. E. A. Kirschhock, A. Aerts, E. Breynaert, G. Absillis, T. N. Parac-Vogt, L. Giebeler and J. A. Martens, Chem. Eur. J., 2010, 16, 3926-3932.

207 A. A. Yakovenko, Z. Wei, M. Wriedt, J.-R. Li, G. J. Halder and H.C. Zhou, Cryst. Growth Des., 2014, 14, 5397-5407.

208 L. C. Gallington, I. S. Kim, W.-G. Liu, A. A. Yakovenko, A. E. Platero-Prats, Z. Li, T. C. Wang, J. T. Hupp, O. K. Farha, D. G. Truhlar, A. B. F. Martinson and K. W. Chapman, J. Am. Chem. Soc., 2016, 138, 13513-13516.

209 T. Egami and S. J. L. Billinge, Underneath the Bragg Peaks: Structural Analysis of Complex Materials, Elsevier, 2003.

210 K. W. Chapman, P. J. Chupas and C. J. Kepert, J. Am. Chem. Soc., 2005, 127, 11232-11233.

211 C. Castillo-Blas, J. M. Moreno, I. Romero-Muñiz and A. E. Platero-Prats, Nanoscale, 2020, 12, 15577-15587.

212 A. E. Platero-Prats, A. B. League, V. Bernales, J. Ye, L. C. Gallington, A. Vjunov, N. M. Schweitzer, Z. Li, J. Zheng, B. L. Mehdi, A. J. Stevens, A. Dohnalkova, M. Balasubramanian, O. K. Farha, J. T. Hupp, N. D. Browning, J. L. Fulton, D. M. Camaioni, J. A. Lercher, D. G. Truhlar, L. Gagliardi, C. J. Cramer and K. W. Chapman, J. Am. Chem. Soc., 2017, 139, 1041010418.

213 A. E. Platero-Prats, Z. Li, L. C. Gallington, A. W. Peters, J. T. Hupp, O. K. Farha and K. W. Chapman, Faraday Discuss., 2017, 201, 337-350.

214 D. F. Sava Gallis, K. W. Chapman, M. A. Rodriguez, J. A. Greathouse, M. V. Parkes and T. M. Nenoff, Chem. Mater., 2016, 28, 3327-3336.

215 S. Rangwani, A. J. Howarth, M. R. DeStefano, C. D. Malliakas, A. E. Platero-Prats, K. W. Chapman and O. K. Farha, Polyhedron, 2018, 151, 338-343.

216 D. F. Sava, M. A. Rodriguez, K. W. Chapman, P. J. Chupas, J. A. Greathouse, P. S. Crozier and T. M. Nenoff, J. Am. Chem. Soc., 2011, 133, 12398-12401.

217 A. Iglesias-Juez, S. Castellanos, M. Monte, G. Agostini, D. Osadchii, M. A. Nasalevich, J. G. Santaclara, A. I. Olivos Suarez, S. L. Veber, M. V. Fedin and J. Gascón, J. Mater. Chem. A, 2018, 6, 17318-17322.

218 T. Van Vu, H. Kosslick, A. Schulz, J. Harloff, E. Paetzold, M. Schneider, J. Radnik, N. Steinfeldt, G. Fulda and U. Kragl, Appl. Catal. Gen., 2013, 468, 410-417.

219 C. T. Buru, A. E. Platero-Prats, D. G. Chica, M. G. Kanatzidis, K. W. Chapman and O. K. Farha, J. Mater. Chem. A, 2018, 6, 7389-7394.

220 S. M. J. Rogge, A. Bavykina, J. Hajek, H. Garcia, A. I. OlivosSuarez, A. Sepúlveda-Escribano, A. Vimont, G. Clet, P. Bazin, F. Kapteijn, M. Daturi, E. V. Ramos-Fernandez, F. X. L. i Xamena, V. V. Speybroeck and J. Gascon, Chem. Soc. Rev., 2017, 46, 3134-3184.

221 W. Tu, Y. Xu, S. Yin and R. Xu, Adv. Mater., 2018, 30, 1707582.

222 V. Bernales, M. A. Ortuño, D. G. Truhlar, C. J. Cramer and L. Gagliardi, ACS Cent. Sci., 2018, 4, 5-19.

223 O. V. Kharissova, B. I. Kharisov and L. T. González, J. Mater. Res., 2020, 35, 1424-1438.

224 S. Goswami, D. Ray, K. Otake, C.-W. Kung, S. J. Garibay, T. Islamoglu, A. Atilgan, Y. Cui, C. J. Cramer, O. K. Farha and J. T. Hupp, Chem. Sci., 2018, 9, 4477-4482.

225 S. Hamel, V. Timoshevskii and M. Côté, Phys. Rev. Lett., 2005, 95, 146403 .
226 J. P. Perdew, K. Burke and M. Ernzerhof, Phys. Rev. Lett., 1996, 77, 3865-3868.

227 P. Ordejón, E. Artacho and J. M. Soler, Phys. Rev. B, 1996, 53, R10441-R10444

228 J. M. Soler, E. Artacho, J. D. Gale, A. García, J. Junquera, P. Ordejón and D. Sánchez-Portal, J. Phys. Condens. Matter, 2002, 14, 2745-2779.

229 Y. Feng, T. Wang, Y. Li, J. Li, J. Wu, B. Wu, L. Jiang and C. Wang, J. Am. Chem. Soc., 2015, 137, 15055-15060.

230 X. Liu, M. Kozlowska, T. Okkali, D. Wagner, T. Higashino, G. Brenner-Weiß, S. M. Marschner, Z. Fu, Q. Zhang, H. Imahori, S. Bräse, W. Wenzel, C. Wöll and L. Heinke, Angew. Chem. Int. Ed., 2019, 58, 9590-9595.

231 S. Grimme, J. Comput. Chem., 2006, 27, 1787-1799.

232 G. Kresse and J. Furthmüller, Phys. Rev. B, 1996, 54, 11169.

233 S. Grimme, J. Antony, S. Ehrlich and H. Krieg, J. Chem. Phys., 2010, 132, 154104.

234 R. Ahlrichs, M. Bär, M. Häser, H. Horn and C. Kölmel, Chem. Phys. Lett., 1989, 162, 165-169.

235 S. M. Pratik, L. Gagliardi and C. J. Cramer, J. Phys. Chem. C 2020, 124, 1878-1887.

236 J. P. Perdew, A. Ruzsinszky, G. I. Csonka, O. A. Vydrov, G. E. Scuseria, L. A. Constantin, X. Zhou and K. Burke, Phys. Rev. Lett., 2008, 100, 136406.

237 A. V. Krukau, O. A. Vydrov, A. F. Izmaylov and G. E. Scuseria, J. Chem. Phys., 2006, 125, 224106.

238 I. Choudhuri and D. G. Truhlar, J. Phys. Chem. C, 2020, 124, 8504-8513.

239 A. K. Rappe and W. A. Goddard, J. Phys. Chem., 1991, 95, 3358-3363.

240 M. B. Chambers, X. Wang, N. Elgrishi, C. H. Hendon, A. Walsh, J. Bonnefoy, J. Canivet, E. A. Quadrelli, D. Farrusseng, C. Mellot-Draznieks and M. Fontecave, ChemSusChem, 2015, 8, 603-608.

241 X. Meng, H.-N. Wang, S.-Y. Song and H.-J. Zhang, Chem. Soc. Rev., 2017, 46, 464-480.

242 I. Kozhevnikov, Catalysts for fine chemical synthesis, catalysis by polyoxometalates, Wiley, 2002, vol. 2.

243 M. J. Howard, G. J. Sunley, A. D. Poole, R. J. Watt and B. K. Sharma, in Studies in Surface Science and Catalysis, eds. $\mathrm{H}$. Hattori and K. Otsuka, Elsevier, 1999, vol. 121, pp. 61-68.

244 K. Sano, H. Uchida and S. Wakabayashi, Catal. Surv. Asia, 1999, 3, 55-60.

245 V. Pascanu, G. González Miera, A. K. Inge and B. MartínMatute, J. Am. Chem. Soc., 2019, 141, 7223-7234.

246 H. B. Aiyappa, J. Masa, C. Andronescu, M. Muhler, R. A. Fischer and W. Schuhmann, Small Methods, 2019, 3, 1800415.

247 N. Maksimchuk, M. Melgunov, J. Mrowiecbialon, A. Jarzebski and O. Kholdeeva, J. Catal., 2005, 235, 175-183.

248 R. Prabhakar, K. Morokuma, C. L. Hill and D. G. Musaev, Inorg Chem., 2006, 45, 5703-5709.

249 X. L. Yang, A. Y. Yin, W. L. Dai and K. N. Fan, Acta Phys.-Chim. Sin., 2011, 27, 177-185.

250 E. B. Fox, Z.-W. Liu and Z.-T. Liu, Energy Fuels, 2013, 27, 63356338.

251 V. Chandra Srivastava, RSC Adv, 2012, 2, 759-783.

252 Z. Ismagilov, S. Yashnik, M. Kerzhentsev, V. Parmon, A Bourane, F. M. Al-Shahrani, A. A. Hajji and O. R. Koseoglu, Catal. Rev., 2011, 53, 199-255.

253 R. Wang, G. Zhang and H. Zhao, Catal. Today, 2010, 149, 117121. 
254 W. Trakarnpruk and K. Rujiraworawut, Fuel Process. Technol., 2009, 90, 411-414.

255 C. M. Granadeiro, S. O. Ribeiro, M. Karmaoui, R. Valença, J. C. Ribeiro, B. de Castro, L. Cunha-Silva and S. S. Balula, Chem. Commun., 2015, 51, 13818-13821.

256 J.-E. Bäckvall, Modern Oxidation Methods, John Wiley \& Sons, 2011.

257 P. Tundo, G. P. Romanelli, P. G. Vázquez and F. Aricò, Catal. Commun., 2010, 11, 1181-1184.

258 G. P. Romanelli, P. I. Villabrille, C. V. Cáceres, P. G. Vázquez and P. Tundo, Catal. Commun., 2011, 12, 726-730.

259 C. Yang, Q. Jin, H. Zhang, J. Liao, J. Zhu, B. Yu and J. Deng, Green Chem., 2009, 11, 1401.

260 P. Gouzerh and A. Proust, Chem. Rev., 1998, 98, 77-112.

261 C. Boglio, G. Lemière, B. Hasenknopf, S. Thorimbert, E. Lacôte and M. Malacria, Angew. Chem. Int. Ed., 2006, 118, 34023405.

262 I. V. Kozhevnikov, Russ. Chem. Rev., 1987, 56, 811-825.

263 S. Wu, J. Wang, W. Zhang and X. Ren, Catal. Lett., 2008, 125, 308-314.

264 K. Kamata and K. Sugahara, Catalysts, 2017, 7, 345.

265 R. A. Sheldon and H. Van Bekkum, Fine Chemicals through Heterogeneous Catalysis, John Wiley \& Sons, 2008, pp. i-xxv.

266 Y. Li, M. Gong, Y. Liang, J. Feng, J.-E. Kim, H. Wang, G. Hong, B. Zhang and H. Dai, Nat. Commun., 2013, 4, 1-7.

267 J. Duan, S. Chen, A. Vasileff and S. Z. Qiao, ACS Nano, 2016, 10, 8738-8745.

268 Q. Yin, J. M. Tan, C. Besson, Y. V. Geletii, D. G. Musaev, A. E. Kuznetsov, Z. Luo, K. I. Hardcastle and C. L. Hill, Science, 2010, 328, 342-345.

269 G. Paille, M. Gomez-Mingot, C. Roch-Marchal, M. Haouas, Y. Benseghir, T. Pino, M.-H. Ha-Thi, G. Landrot, P. Mialane, M. Fontecave, A. Dolbecq and C. Mellot-Draznieks, ACS Appl. Mater. Interfaces, 2019, 11, 47837-47845.

270 S. Wang and C. Serre, ACS Sustain. Chem. Eng., 2019, 7, 11911-11927.

271 Y.-C. Chen, W.-H. Chiang, D. Kurniawan, P.-C. Yeh, K. Otake and C.-W. Kung, ACS Appl. Mater. Interfaces, 2019, 11, 3531935326.

272 Z. Song, L. Zhang, K. Doyle-Davis, X. Fu, J.-L. Luo and X. Sun, Adv. Energy Mater., 2020, 10, 2001561. 